TESORO ELENA DEL CARPIO HUAYLLAS

\title{
ANÁLISE COMPARATIVA DE MODELOS PARA FIXAÇÃO DE TARIFAS DE TRANSMISSÃO E DE PREVISÃO DE MERCADO DE ENERGIA DE ALGUNS PAISES SUL AMERICANOS
}

\footnotetext{
Dissertação apresentada à Escola Politécnica da Universidade de São Paulo para obtenção do título de Mestre em Engenharia.
} 
Área de Concentração:

Sistemas de Potência

Orientador:

Prof. Dr. Dorel Soares Ramos 


\section{Este exemplar foi revisado e alterado em relação à versão original, sob}

responsabilidade única do autor e com a anuência de seu orientador.

São Paulo, 16 de Dezembro de 2008.

Assinatura do autor

Assinatura do orientador

FICHA CATALOGRÁFICA

Huayllas, Tesoro Elena Del Carpio

Análise comparativa de modelos para fixação de tarifas de transmissão e de previsão de mercado de energia de alguns paises sul americanos / T.E.D.C. Huayllas. - ed. rev.-- São Paulo, 2008. $136 \mathrm{p}$.

Dissertação (Mestrado) - Escola Politécnica da Universidade de São Paulo. Departamento de Engenharia de Energia e Automação Elétricas.

1.Tarifas públicas 2.Transmissão de energia elétrica I.Universidade de São Paulo. Escola Politécnica. Departamento de Engenharia de Energia e Automação Elétricas II. t. 


\section{AGRADECIMENTOS}

Ao Professor Dorel Soares Ramos, não só pela orientação, apoio e sugestões feitas durante o desenvolvimento do trabalho, mas principalmente pela oportunidade que me foi concedida para com esta pesquisa.

Aos Profs. C.M.V. Tahan, Marco A. Saidel e Ericson de Paula pelas sugestões e comentários feitos para a conclusão do trabalho.

À CAPES, pelo apoio financeiro que tornou possível a realização do presente trabalho.

Aos todos os meus colegas do GEPEA (Grupo de Energia) do Departamento de Engenharia de Energia e Automação Elétricas, pela amizade e o ameno convívio. 


\section{Resumo}

O setor elétrico é um setor de natureza estratégica para qualquer nação, na medida em que na era moderna a eletricidade é um insumo fundamental para a qualidade de vida das pessoas e para o desenvolvimento e a produção da indústria, sendo mesmo considerado como uma "mola mestra" da economia do país. Em função dessa importância, crescente ao longo do tempo e aguçada em decorrência de restrições de disponibilidade e de cunho ambiental para a utilização massiva do petróleo, o setor elétrico deve ser planejado com extrema atenção e de forma muito criteriosa, posto que sua expansão necessite estar garantida e se trata de um setor intensivo em capital e com empreendimentos de longo prazo de maturação, particularmente no caso dos grandes aproveitamentos hidrelétricos e as plantas nucleares. Dentro desse contexto, o presente trabalho buscou endereçar a temática de planejamento de sistemas elétricos, aproveitando a experiência profissional pregressa da autora, especialmente no que tange às vertentes de estudos tarifários e de mercado, como também pelo fato de conhecer em algum detalhe os marcos regulatórios e o funcionamento dos setores elétricos no âmbito do Mercosul.

Nesse sentido, o presente trabalho apresenta uma análise crítica comparativa de modelos tarifários, dos sistemas de transmissão, atualmente vigentes em alguns países da América do Sul. As recentes tendências políticas e energéticas dos países considerados constituem-se em importantes sinais para o estabelecimento de futuras negociações na área elétrica. Isso propicia a realização de um estudo referente às condições tarifarias e regulatórias destes mercados. Questões técnicas em projetos deste tipo poderiam ser superadas, porém, eventuais divergências regulatórias e tarifarias entre os mercados elétricos poderiam adiar ou até mesmo inviabilizar os referidos projetos. Por outro lado, levando em conta o nexo existente entre o estudo dos modelos tarifários, os sinais de possíveis negociações de energia e a expansão do sistema, apresentam-se também uma análise comparativa entre as metodologias de previsão utilizadas no cálculo da demanda de energia elétrica nos países considerados. As referidas metodologias de previsão, sobre as quais foram utilizados o histórico de consumo do Brasil (1996-2006) e as variáveis explicativas inerentes a cada modelo, correspondem às classes de consumo Residencial, Industrial, Comercial e Rural; responsáveis por aproximadamente 90\% do consumo nacional. Foram encontradas certas semelhanças principalmente no relacionado às variáveis econométricas utilizadas por estes modelos, os quais se refletiram nos resultados obtidos.

Palavras chave - Metodologias de tarifação, Alocação de preços, Sistema de Transmissão, Previsão de energia, Sul América. 


\begin{abstract}
The electric power sector is an area of strategic nature for any country as electricity is an essential product for both the quality of life and the development of the industry. This reason led to consider it as a sound foundation for the economy development and GNP growing. Because of its role, which grows along time even due to the restrictions of availability and environmental issues for the massive use of oil, the electric sector must be carefully planned as its expansion needs to be guaranteed. This sector embraces large capital and long-term investments, particularly those related to hydroelectric projects and nuclear plants. Within that framework, this work aims at to address the electric power planning subject using the author's past knowledge related to electric tariffs as well as on the regulatory framework and market operation of the Mercosul.

A critical comparative analysis of transmission tariff models currently applied in some South American countries is particularly addressed. The recent political and energy policy trends of the considered countries appear as important signals for the establishment of future negotiations of electricity. This situation demands the realization of new studies related to both tariff and regulatory conditions in these markets. Technical issues in projects of this kind may well be overcome; however, some regulatory differences and even tariff model differences among marketers could delay or even turn unfeasible the referred projects. On the other hand, considering issues like the link existing among the transmission pricing models adopted and the likely electricity trading as well as the system expansion, a comparative analysis of the methodologies used to forecast the energy demand in the South American countries previously considered, is also presented. Such forecast methodologies, upon which were applied the annual electricity consumption in Brazil in the period 1996 through 2006 as well as the explanatory variables inherent to each model, correspond to the Residential, Industrial, Commercial and Rural consumptions, responsible for nearly $90 \%$ of the national consumption. From this analysis, some similarities mainly those related to the econometric variables used by each methodology were found. Such similarities and related findings are reflected in the results presented.
\end{abstract}

Keywords - Pricing methodologies, Cost allocation, Transmission system, Electrical power forecast, South America. 


\section{Sumário}

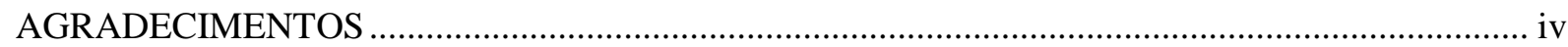

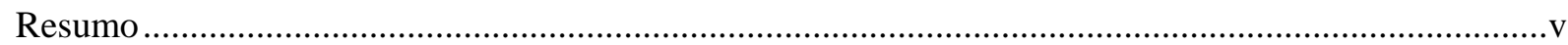

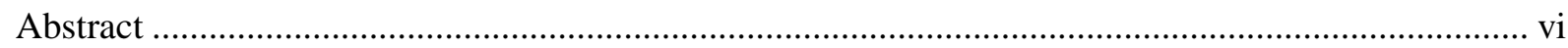

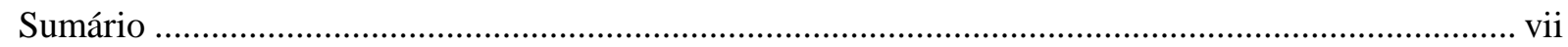

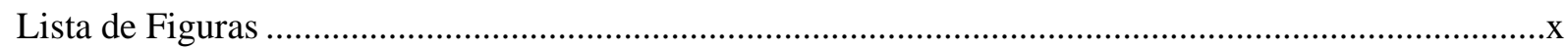

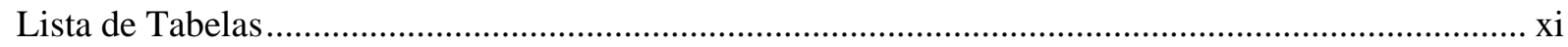

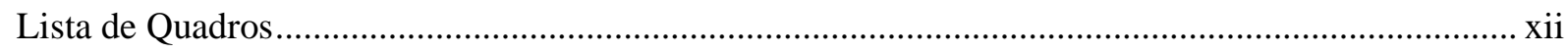

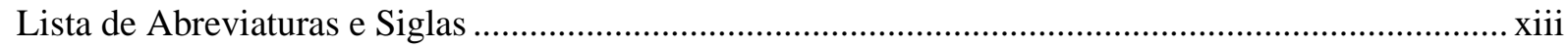

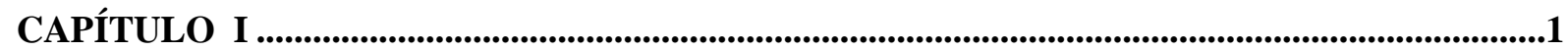

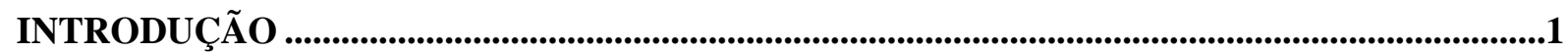

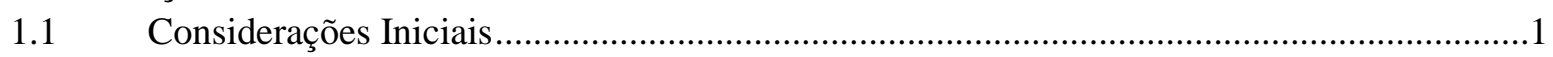

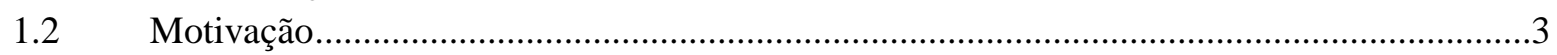

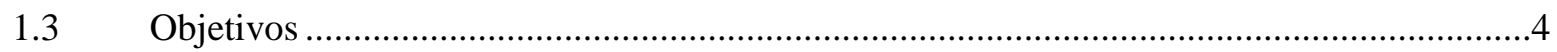

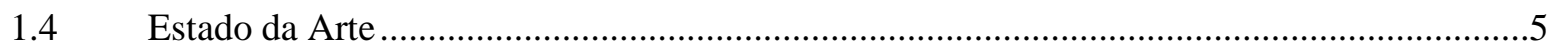

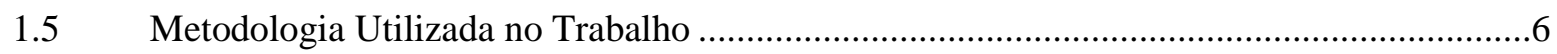

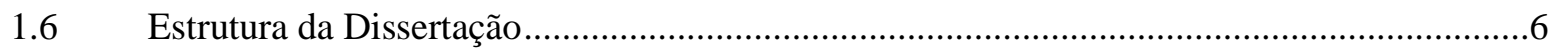

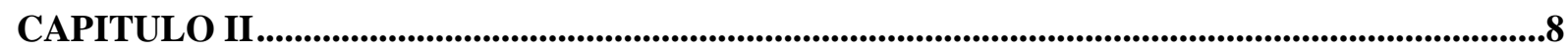

CONCEITOS BÁSICOS DE TARIFAÇÃO DOS SISTEMAS DE TRANSMISSÃO......................8

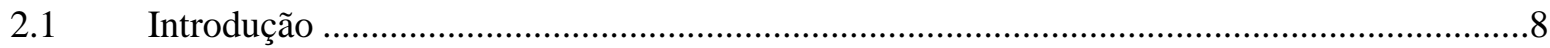

2.2 Principais Requisitos de um Método de Tarifação...............................................................

2.3 Definição de um Esquema de Tarifação na Transmissão......................................................10

2.4 Metodologias de Cálculo das Tarifas de Uso da Transmissão ............................................10

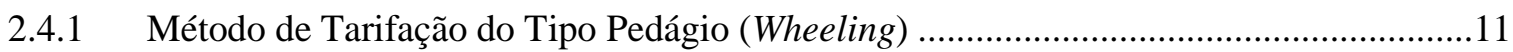

2.4.1.1 Alocação do Tipo Preços Globais (Rolled in Allocation) ............................................11

2.4.1.2 Alocação do Tipo Rota ou Trajetória Contratual (Contract Path Allocation) ...........13

2.4.1.3 Alocação do Tipo MW-Milha (MW-Mile Allocation) ..............................................14

2.4.1.3.1 MW-Milha Estendido ou Método do Módulo ........................................................16

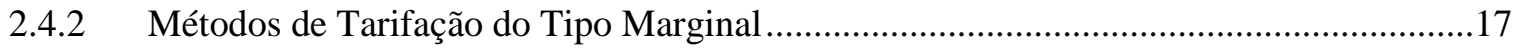

2.4.2.1 Custos Marginais de Curto Prazo (CMCP) ................................................................... 17

2.4.2.2.1 Vantagens e Desvantagens do CMCP …….........................................................19

2.4.2.2 Custos Marginais de Longo Prazo (CMLP) ..........................................................

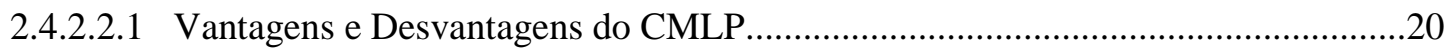

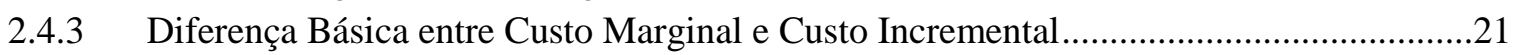

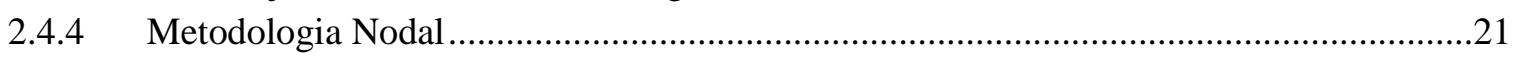

2.4.5 Metodologias para o Cálculo da Parcela Complementar (Pedágio) ...................................22

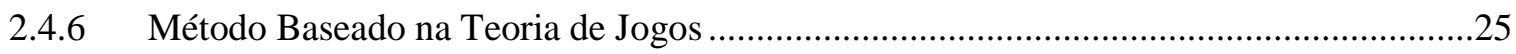

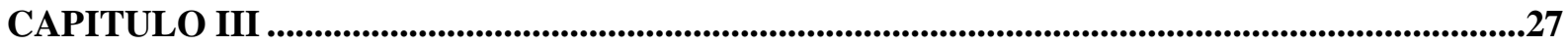

CARACTERÍSTICAS E ESQUEMAS TARIFÁRIOS UTILIZADOS NO SEGMENTO DA

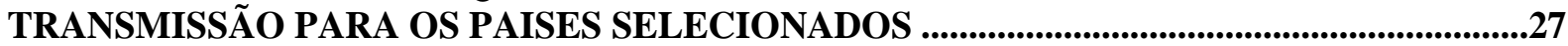

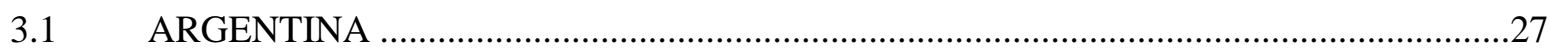

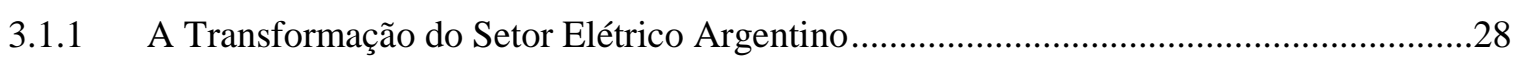

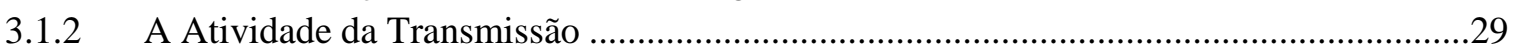

3.1.3 Regulamentação dos Preços da Transmissão .................................................................... 


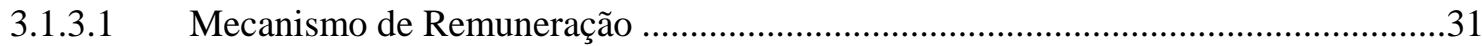

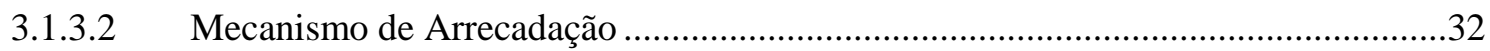

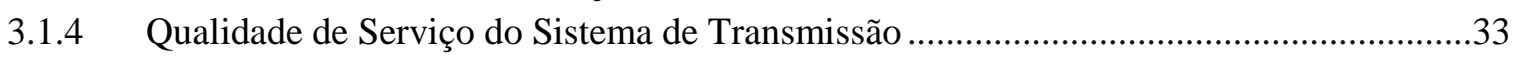

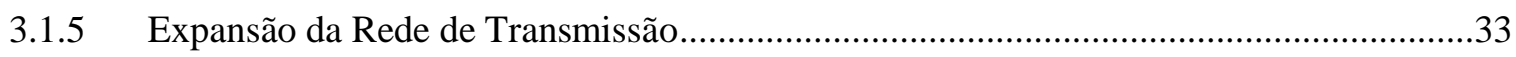

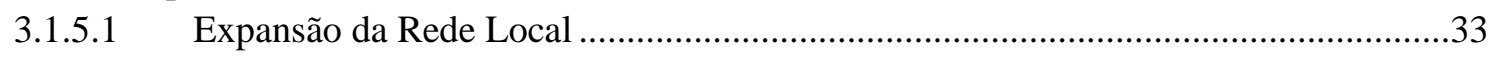

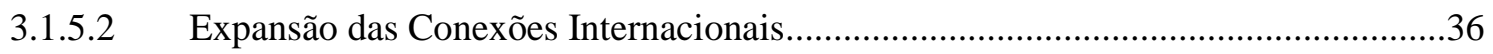

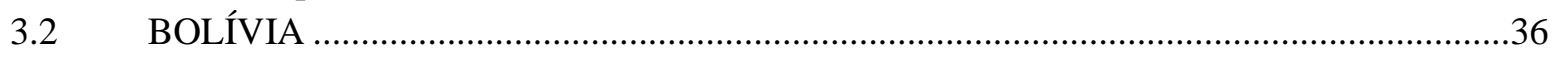

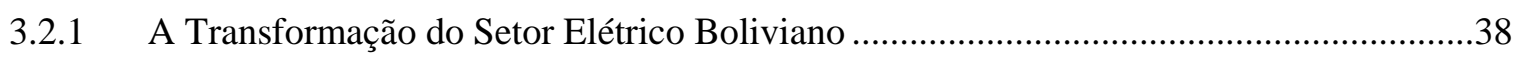

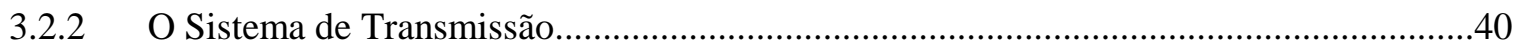

3.2.3 Regulamentação dos Preços da Transmissão .................................................................

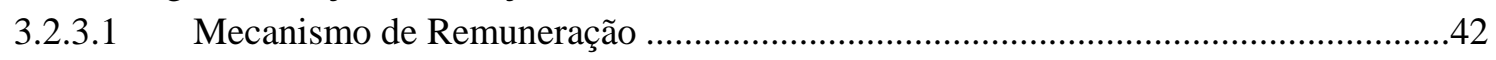

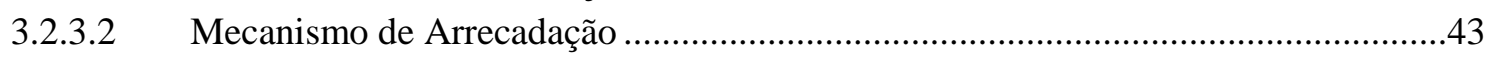

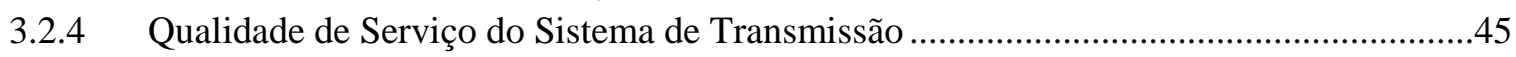

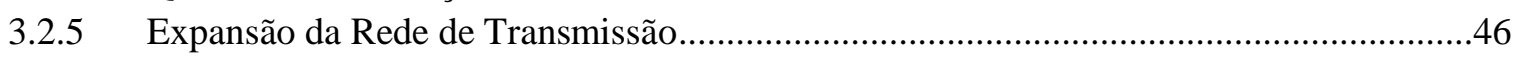

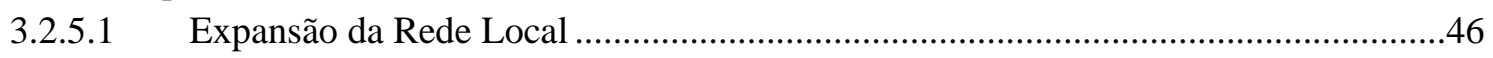

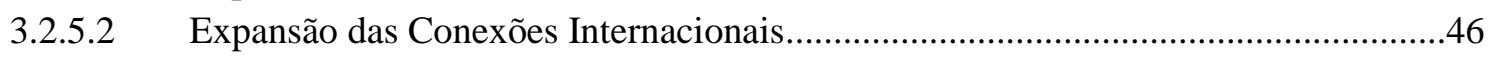

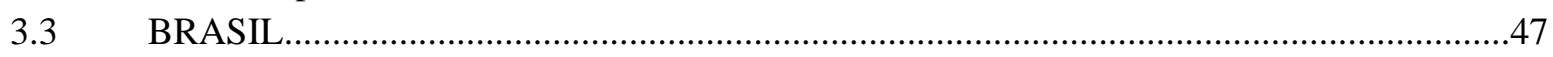

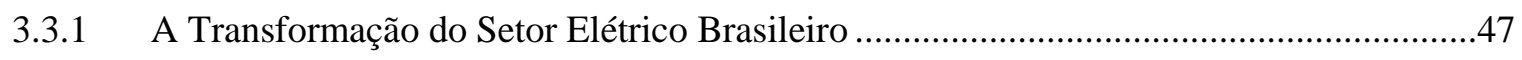

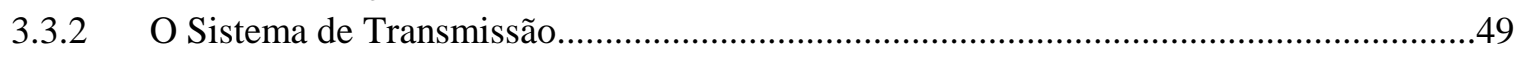

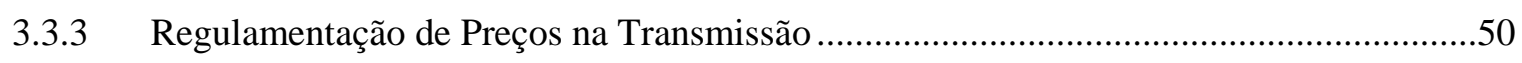

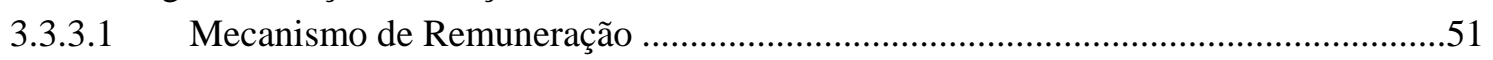

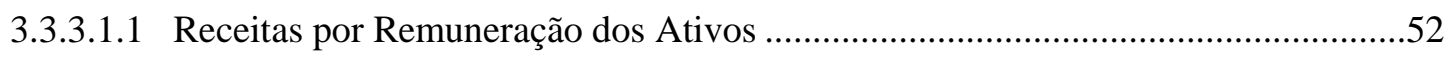

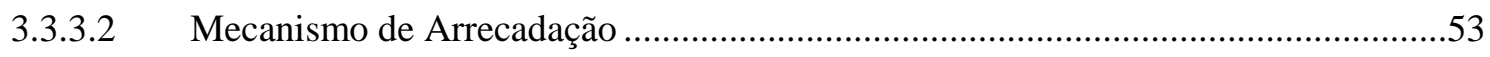

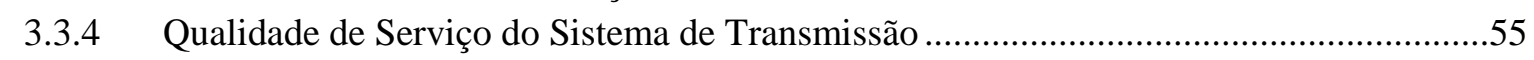

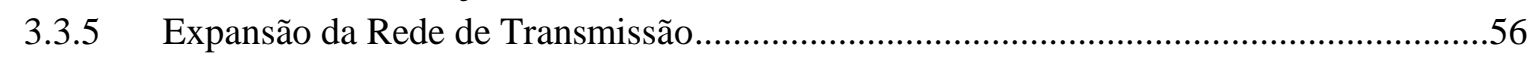

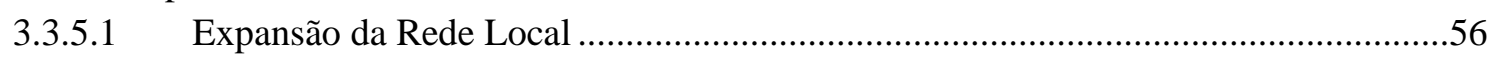

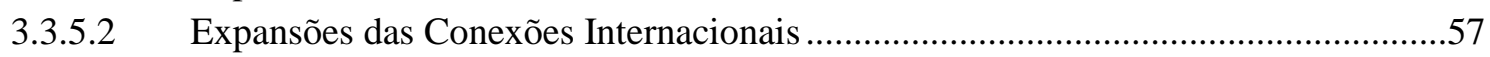

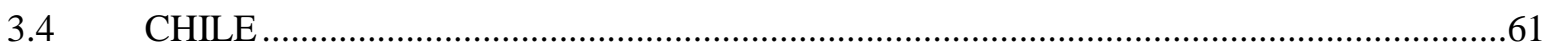

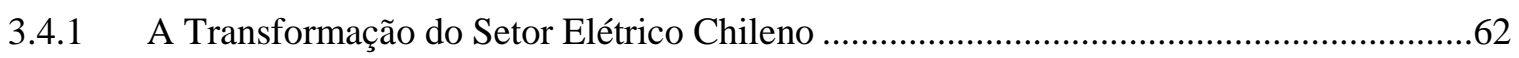

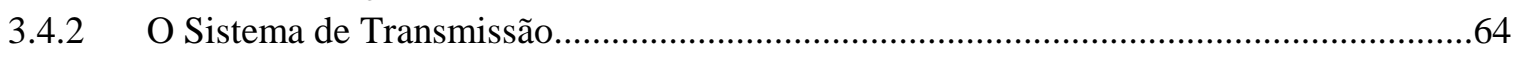

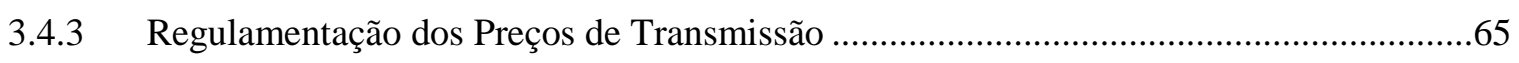

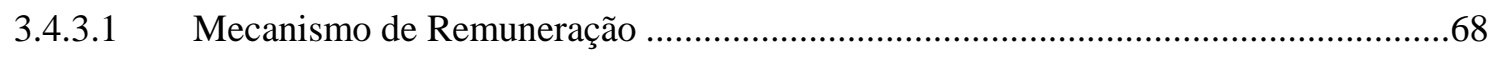

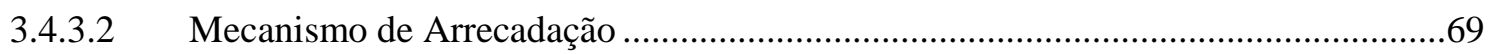

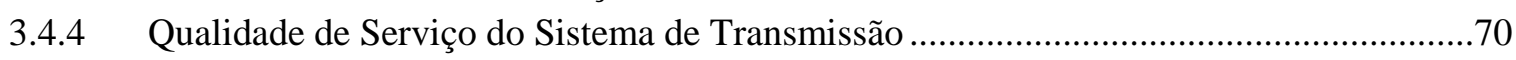

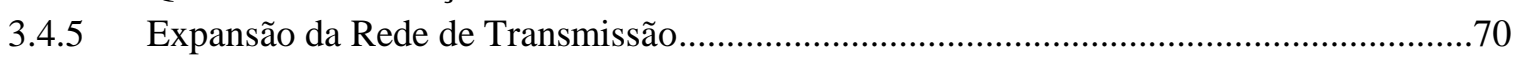

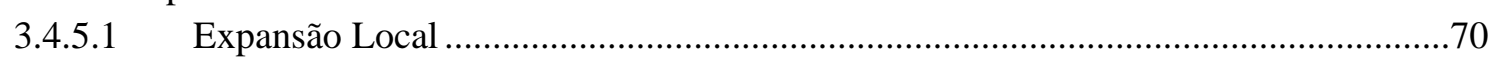

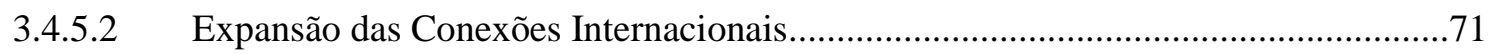

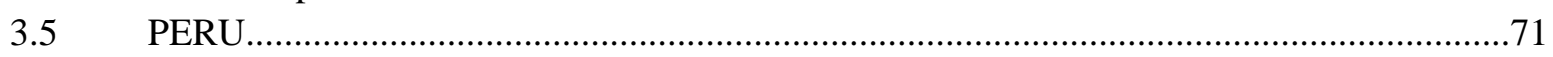

3.5.1 A Transformação do Setor Elétrico Peruano.................................................................... 72

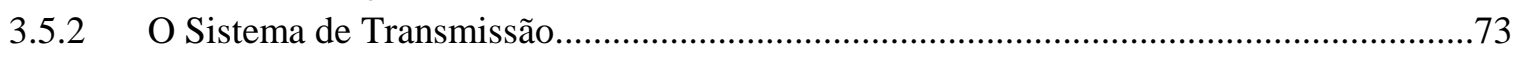

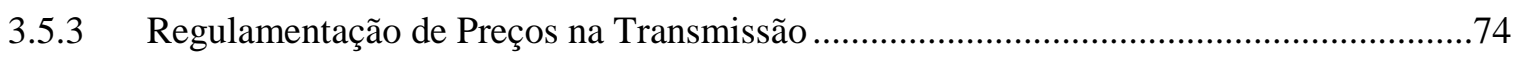

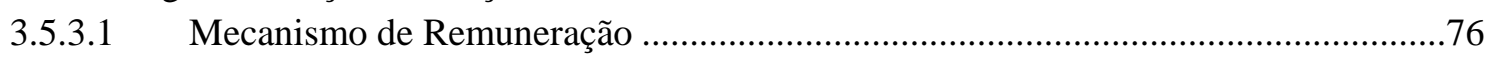

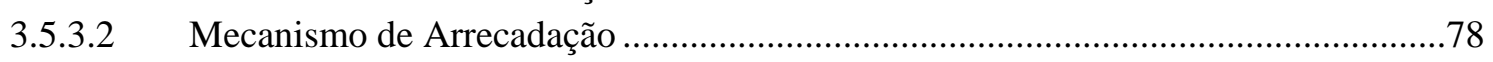

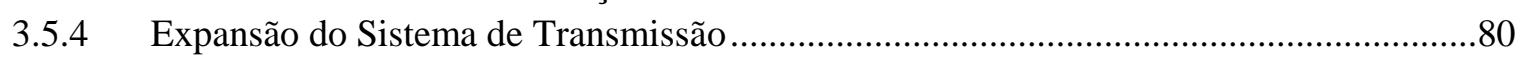

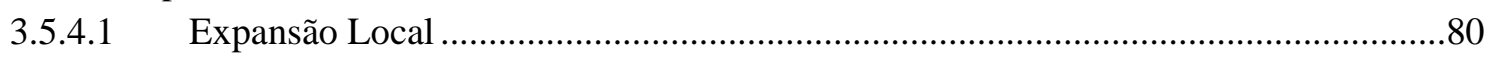

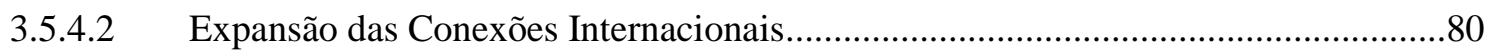

3.6 Comparações de Modelos Tarifários dos Países Analisados ..............................................82 


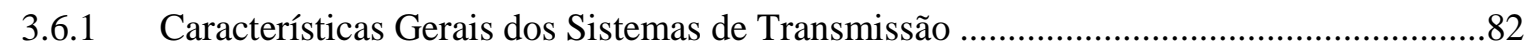

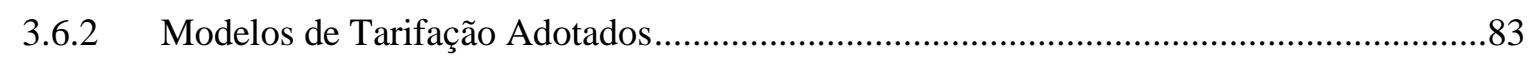

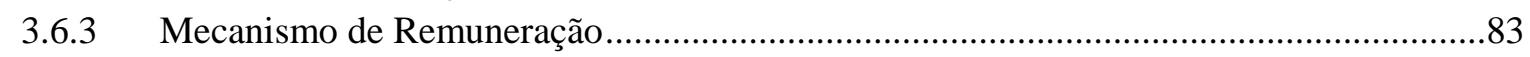

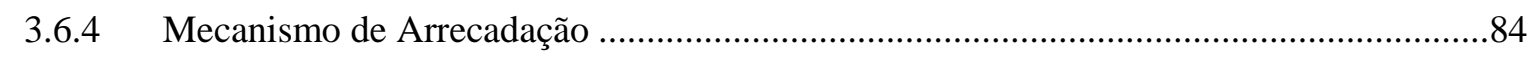

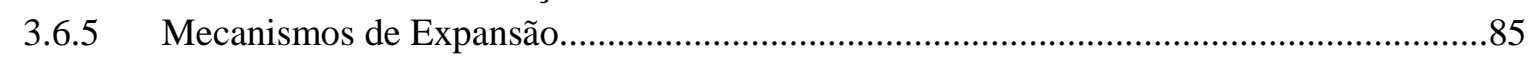

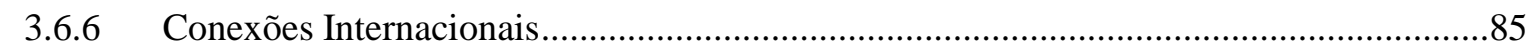

3.6.7 Contribuição do Usuário Final aos Diferentes Segmentos do Sistema Elétrico.................86

3.6.8 Grau de Aproximação do Modelo de Tarifação aos Requisitos do Grupo Standford .......86

3.7 Relação entre a Previsão de Mercado e a Expansão do Sistema de Transmissão .................88

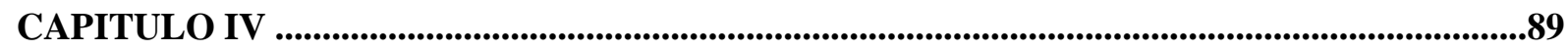

ANÁLISE COMPARATIVA DE MÉTODOS DE PREVISÃO DE ENERGIA ............................89

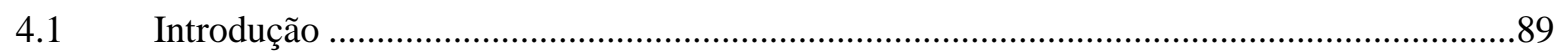

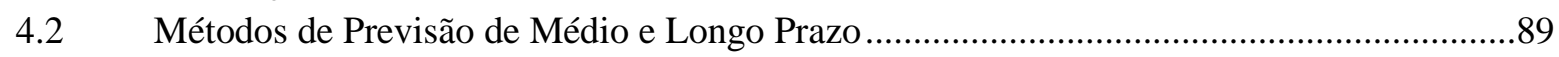

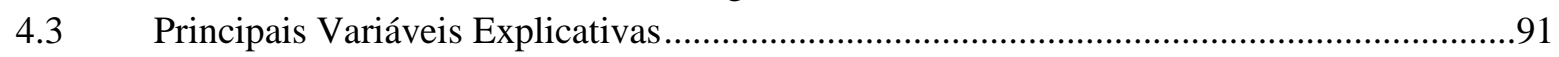

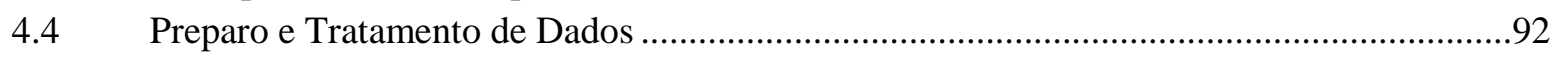

4.4.1 Outros Métodos de Regressão Comumente Utilizados dentro do SAS .............................93

4.5 Metodologias de Previsão de Longo Prazo dos Países Analisados ........................................94

4.5.1 Metodologia de Previsão Utilizada no Brasil ....................................................................94

4.5.1.1 Previsão Utilizando a Metodologia do Brasil.............................................................98

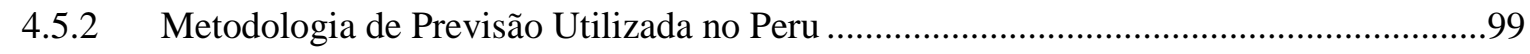

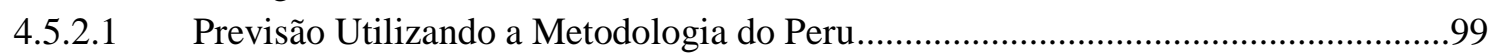

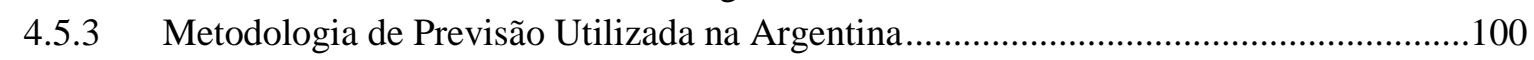

4.5.3.1 Previsão Utilizando a Metodologia da Argentina .................................................... 101

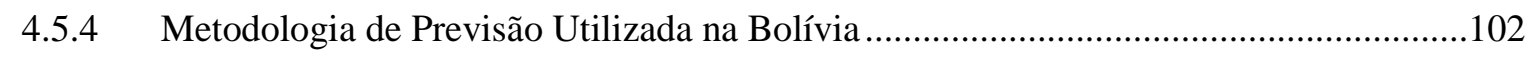

4.5.4.1 Previsão Utilizando a Metodologia da Bolívia........................................................103

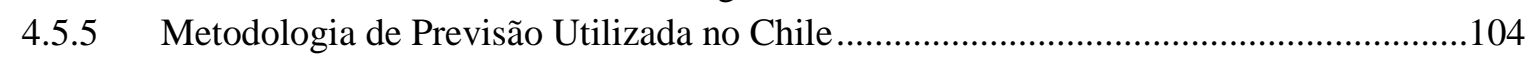

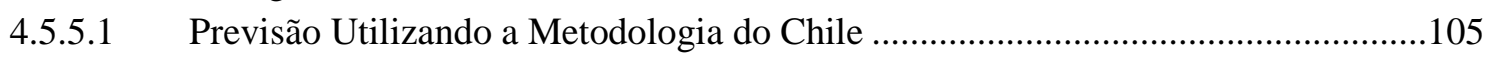

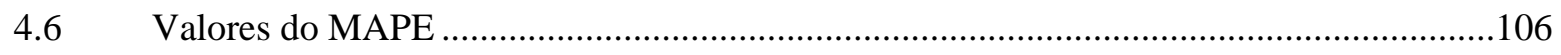

4.7 Comparação e Análise dos Resultados de Previsão Obtidos ..............................................106

4.7.1 Diferenças Relativas entre as Metodologias dos Países Analisados com a do Brasil ....109

4.7.2 Análise de Sensibilidade das Metodologias Utilizadas ..................................................110

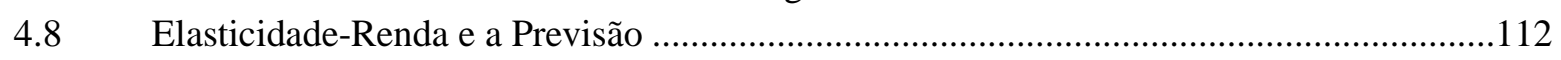

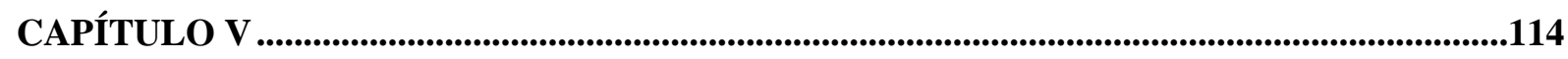

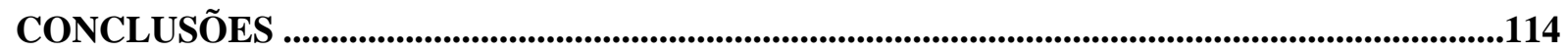

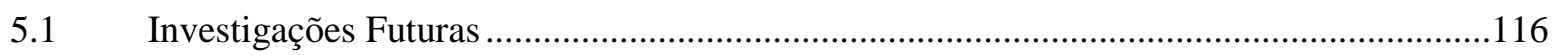

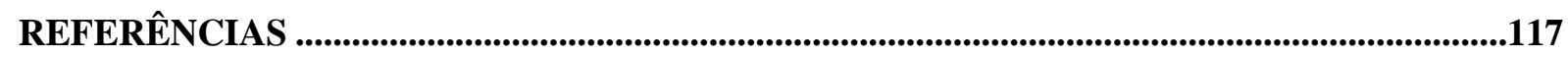

ANEXO A: Outros Métodos de Previsão de Mercado de Energia Elétrica Comumente Utilizados .122

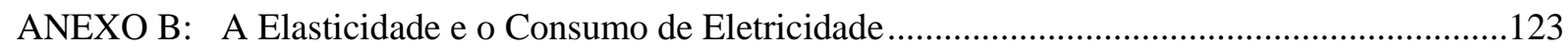

ANEXO C: Históricos de Dados Utilizados nas Simulações...........................................................125

ANEXO D: Diferenças Relativas Individuas entre a Metodologia do Brasil e os Outros Países .......127

ANEXO E: Decisión 536 para la Interconexión Subregional de Sistemas Eléctricos ........................133 


\section{Lista de Figuras}

Figura 2.1

Figura 2.2

Figura 2.3

Figura 2.4

Figura 3.1

Figura 3.2

Figura 3.3

Figura 3.4

Figura 3.5

Figura 3.6

Figura 3.7

Figura 3.8

Figura 3.9

Figura 3.10

Figura 3.11

Figura 3.12

Figura 3.13

Figura 3.14

Figura 3.15

Figura 3.16

Figura 3.17

Figura 3.18

Figura 3.19

Figura 3.20

Figura 3.21

Figura 3.22

Figura 3.23

Figura 3.24

Figura 3.25

Figura 3.26

Figura 3.27

Figura 4.1

Figura 4.2

Figura 4.3

Figura 4.4

Figura 4.5

Figura 4.6

Figura 4.7

Figura 4.8

Figura 4.9

Figura 4.10

Figura 4.11

Figura 4.12

Figura 4.13

Figura 4.14

Figura 4.15

Figura 4.16
Sistema mostrando a metodologia de rota contratual

14

Sistema exemplo para a metodologia MW - Milha.

Fluxos em dois circuitos diferentes para uma determinada transação

Exemplo do uso da área de influência.

Organização institucional do sistema elétrico Argentino

Empresas de transmissão na Argentina

Resumo da forma de remuneração da transmissão na Argentina

Procedimento de expansão através de concurso público

Procedimento de expansão através de contrato entre partes

Procedimento para ampliações menores

Participação dos subsistemas na capacidade instalada no mercado Boliviano

Participação das empresas de geração e distribuidoras no SIN

Marco institucional do setor elétrico Boliviano

Sistema Interconectado Nacional Boliviano

Esquema físico e comercial do sistema elétrico Brasileiro

Linhas em alta tensão que compõem o SIN

Fator de ponderação

Determinação dos encargos de uso-TUST

Sistema de transmissão, rede básica, conexões e rede local

Encargos correspondentes a: (a) injeções, (b) retiradas

Tarifas nodais: encargos na transmissão segundo zonas de geração ou cargas

Tarifas de transmissão estabelecidas e pagas por plantas térmicas

Principais sistemas elétricos no Chile

Área de influência comum

(a) Potência instalada por tipo de geração, (b) Potência instalada no SEIN e nos SSAA

Cronologia atual do marco elétrico Peruano

Mapa mostrando o Sistema Elétrico Interconectado Peruano (SEIN)

Classificação dos sistemas de transmissão

Sistema Economicamente Adaptado

Sistemas de preços segundo o SEA Peruano

Seqüência e vínculo entre previsão e expansão do sistema

Ajuste do consumo total devido ao período de racionamento

Modelo econométrico de previsão que representa ao sistema Brasileiro

Previsão do PIB per cápita Brasileiro

Evolução das tarifas médias por classe de consumo

Resultados da previsão, metodologia do Brasil (previsão em GWh)

Modelos econométricos de previsão utilizados no Peru

Resultados da previsão, metodologia do Peru (previsão em GWh)

Modelo econométrico de previsão que representa ao sistema Argentino

Resultados da previsão, metodologia da Argentina (previsão em GWh)

Modelo econométrico de previsão que representa ao sistema Boliviano

Resultados da previsão, metodologia da Bolívia (previsão em GWh)

Modelo econométrico de previsão que representa ao sistema Chileno

Resultados da previsão, metodologia do Chile (previsão em GWh)

Resultados da previsão de energia, classes: (a) Residencial, (b) Industrial,

(c) Comercial e (d) Rural 


\section{Lista de Tabelas}

Tabela 3.1 Evolução do número de Agentes participantes no MEM Argentino

Potência instalada segundo o tipo de geração no Chile

Avaliação econômica da interconexão Peru-Bolívia 


\section{Lista de Quadros}

Quadro 3.1 Principais normas e regulamentos no setor elétrico Argentino 28

Quadro 3.2 Principais normas e regulamentos no setor elétrico Boliviano 39

Quadro 3.3 Principais normas e regulamentos no setor elétrico Brasileiro 48

Quadro 3.4 Principais concessionárias de transmissão no SIN $\quad 51$

Quadro 3.5 Leis, Decretos e principais modificações à regulação Chilena $\quad 62$

Quadro 3.6 Principais normas e regulamentos no setor elétrico Peruano $\quad 72$

Quadro 3.7 Principais Características e empresas de transmissão dos países analisados 82

Quadro 3.8 Método base de tarifação, custos e remuneração ao transmissor $\quad 83$

Quadro 3.9 Expansão do Sistema de Transmissão 285

Quadro 3.10 Conexões Internacionais $\quad 86$

Quadro 3.11 Grau de aproximação do modelo de tarifação aos princípios do Standford Energy 


\section{Lista de Abreviaturas e Siglas}

\begin{tabular}{|c|c|}
\hline CMCP & Custo Marginal de Curto Prazo \\
\hline CMLP & Custo Marginal de Longo Prazo \\
\hline MW-Mile & MW-Milha \\
\hline MICP & Método incremental de curto prazo \\
\hline MILP & Método Incremental de longo prazo \\
\hline DCLCFP & DC Flow Pricing \\
\hline ICRP & Investment Cost Relating Pricing \\
\hline Pdg & Pedágio \\
\hline GLDF & Generalized Generation Distribution Factor \\
\hline GSDF & Generation Shift Distribution Factors \\
\hline GGDF & Generalized Generation Distribution Factor \\
\hline SADI & Sistema Argentino de Interconexión \\
\hline MEMSP & Mercado Eléctrico Mayorista del Sistema de la Patagónica \\
\hline ENRE & Ente Regulador de Eletricidade \\
\hline MEM & Mercado Eléctrico Mayorista (Argentina) \\
\hline CAMMESA & Compañia Administradora de Electricidad (Argentina) \\
\hline DNDC & Despacho Nacional de Carga (Argentina) \\
\hline TRANSENER & Compañia de Transmisión de Energia Eléctrica en Alta Tensión (Argentina) \\
\hline TRANSBA & Empresa de Distribución Troncal de la Provincia de Buenos Aires \\
\hline TRANSNOA & Empresa de Distribución Troncal del Noroeste Argentino \\
\hline DISTROCUYO & Empresa de Distribución Troncal de Cuyo (Argentina) \\
\hline TRANSNEA & Empresa de Distribución Troncal del Nordeste Argentino \\
\hline TRANSPA & Empresa de Distribución Troncal de la Región de la Patagónia \\
\hline SIN & Sistema Interconectado Nacional (Bolívia) \\
\hline ENDE & Empresa Nacional de Electricidad \\
\hline COBEE- BPCo & Compañia Boliviana de Energia Eléctrica - Bolivian Power \& Company \\
\hline CNDC & Comité Nacional de Despacho de Carga (Bolívia) \\
\hline TDE & Transmisora de Electricidad (Bolívia) \\
\hline MERELEC & Mercados Eléctricos (Bolivia) \\
\hline STI & Sistema Troncal de Interconexión (Bolívia) \\
\hline CRE & Cooperativa Rural de Electrificación (Bolívia) \\
\hline CNPE & Conselho Nacional de Política Energética (Brasil) \\
\hline MME & Ministério de Minas e Energia \\
\hline ANEEL & Agência Nacional de Energia Elétrica \\
\hline EPE & Empresa de Pesquisas Energéticas \\
\hline ONS & Operador Nacional do Sistema \\
\hline CCEE & Câmara de Comercialização de Energia Elétrica \\
\hline CMSE & Comitê de Monitoramento do Setor Elétrico \\
\hline MW & Mega Watt \\
\hline MWh & Mega Watt hora \\
\hline RT & Receita Tarifária \\
\hline VNR & Valor Novo e Reposição \\
\hline AVNR & Anualidade do Valor Novo de Reposição \\
\hline COEM & Custo de Operação e Manutenção \\
\hline REET & Remuneración por Energía Eléctrica Transportada (Argentina) \\
\hline $\mathrm{RCT}$ & Remuneración por Capacidad de Transporte (Argentina) \\
\hline $\mathrm{RC}$ & Remuneración por Conexión (Argentina) \\
\hline RVT & $\begin{array}{l}\text { Recaudación (Arrecadação) Variable por Energía Eléctrica Transportada } \\
\text { (Argentina) }\end{array}$ \\
\hline RVTE & Recaudación Variable Total por Transporte de Energía (Argentina) \\
\hline RVTP & Recaudación Variable por Potencia Vinculada (Argentina) \\
\hline CAI & Costo Anual de Inversión (Bolívia) \\
\hline CAT & Costo Anual de Transmisión (Bolívia) \\
\hline
\end{tabular}




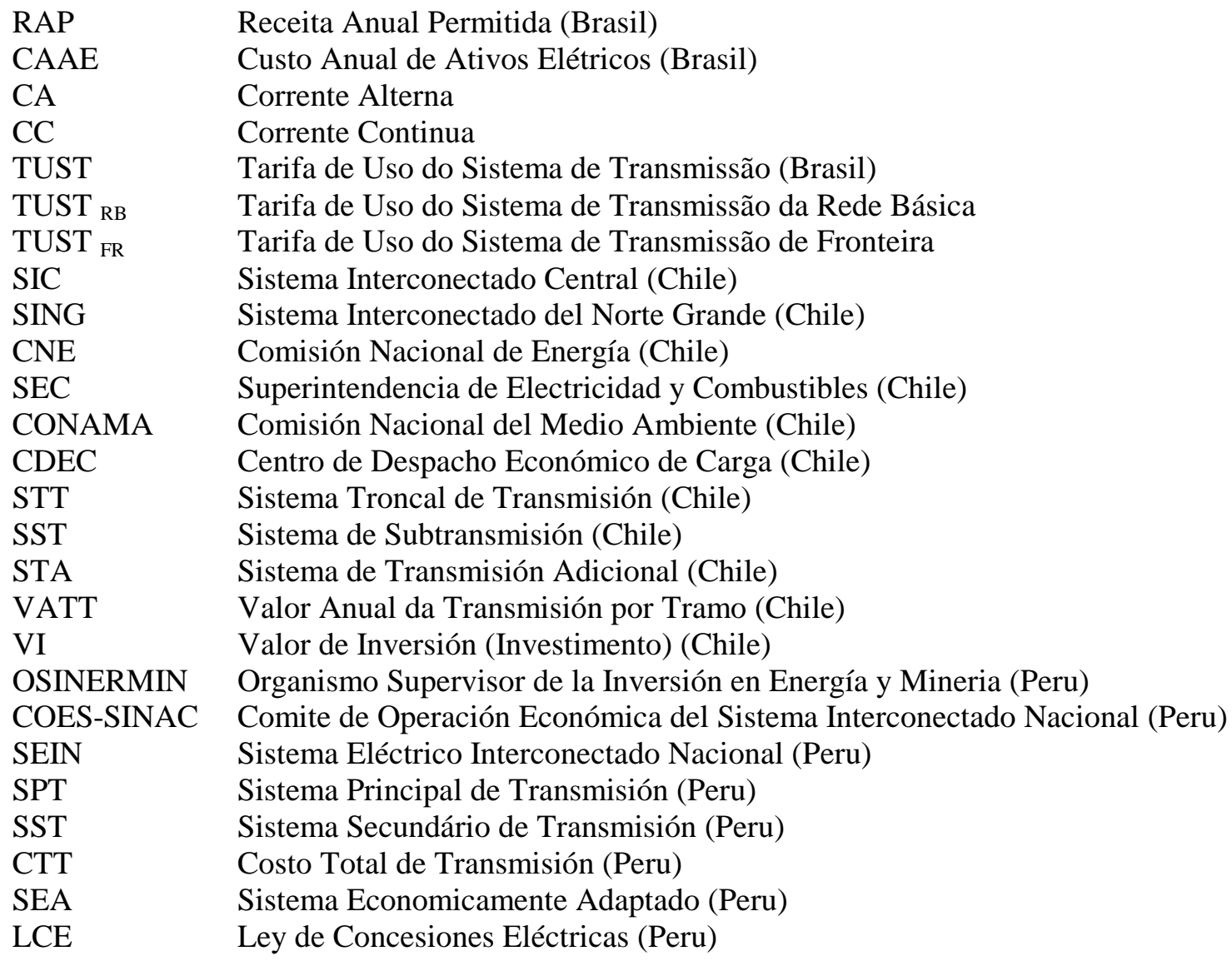




\section{CAPÍTULO I}

\section{INTRODUÇÃO}

\subsection{Considerações Iniciais}

A indústria elétrica na maioria dos países Sul Americanos foi afetada, durante os anos 1970 e 1980, por uma crise financeira, técnica e de gestão que determinou a substituição do monopólio estatal, integrado de forma vertical, por um sistema de mercado baseado na competição e livre acesso à rede. Assim, foram separadas as atividades de geração, transmissão e distribuição em negócios diferentes. Na maioria dos países da América do Sul, nos quais foi implantado o processo de reestruturação, que substituiu ao modelo institucional vertical ${ }^{1}$, ocorreram diversas mudanças. Por outro lado, em alguns outros como no caso do Paraguai, da Venezuela e Uruguai, o setor elétrico ainda está administrado pelo Estado. No caso de Uruguai, o setor elétrico atualmente está em processo de transformação visando principalmente a concorrência no setor da geração.

Os sistemas de transmissão constituem-se no meio físico necessário para a existência do mercado caracterizado pelas transações de compra e venda de energia entre geradores e consumidores. Em conseqüência, a competitividade deste mercado depende das políticas adotadas no setor de transmissão. De acordo com os princípios estabelecidos no processo de desregulamentação, o acesso não discriminado à rede de transmissão seria um aspecto fundamental para a criação da concorrência no setor da geração.

Comumente, os sistemas de transmissão, encarregados de transportar a energia elétrica produzida nos centros de geração, são construídos considerando aspectos tecnológicos, econômicos, geográficos, de confiabilidade, e outros. Questões de confiabilidade e crescimento da demanda, por exemplo, promoveram a interconexão das redes de transmissão inclusive a nível internacional, como aconteceu nos sistemas de transmissão da Europa, América do Norte e outros países. Na América do Sul, a interconexão das redes entre os países poderá trazer benefícios significativos ${ }^{2}$. Até agora, e com o intuito de melhorar a sua eficiência, os sistemas elétricos da América Latina tem implementado reformas institucionais e regulatórias. O Chile foi o primeiro país a implementar um mercado competitivo no ano 1982 [35]. A ele se sucederam a Argentina e Peru, no ano 1992, Bolívia e Colômbia, em 1994, enquanto outros países como Brasil, Equador, El Salvador e Panamá realizaram reformas posteriormente.

\footnotetext{
${ }^{1}$ Onde preponderavam estas empresas de "ciclo combinado", ou seja, empresas com segmentos de geração, transmissão, distribuição e comercialização.

${ }^{2}$ A interconexão elétrica e os intercâmbios comerciais de eletricidade poderiam oferecer vantagens aos países integrados em matéria econômica, social e ambiental, permitindo uma melhor utilização de seus recursos energéticos bem como oferecer uma maior segurança e confiança no fornecimento elétrico. De fato, a existência de assimetrias técnicas e de marcos regulatórios poderiam dificultar o estabelecimento destes mercados. Já a sua redução ou homogeneização atrairia maiores investimentos viabilizando importantes projetos de beneficio mútuo.
} 
Por outro lado, no referente às previsões de mercado de energia estudadas neste trabalho deve-se mencionar que um dos objetivos das concessionárias elétricas é a otimização do seu planejamento economico, isto com o intuito de alcançar reduções de custo. A área de previsão de energia elétrica de longo prazo desempenha um papel importante na área de operação e planejamento das empresas concessionárias elétricas.

A demanda de energia de um sistema elétrico comporta-se de forma similar a um termômetro para as atividades econômicas, sociais e políticas de um determinado país. Por exemplo, um aumento no consumo de energia elétrica reflete-se, normalmente, em um aumento no PIB, independente das variáveis responsáveis por esse aumento. Outras atividades macroeconômicas como a produção de insumos, vendas de material de construção, a atividade agro-industrial, etc, constitui-se também em variáveis que tem impacto no consumo de energia, e em consequiência, deverão ser levadas em conta na previsão da energia.

Face a tais ponderações, pode-se adicionar que na perspectiva do planejamento da expansão, vital portanto para manter a dinâmica da economia de um país, destacam-se como insumos fundamentais a previsão de demanda de longo prazo e os incentivos à correta expansão da transmissão.

As previsões de mercado permitem antever necessidades de adequação e reforço do sistema vários anos à frente, permitindo estabelecer a estratégia de expansão mais interessante dos pontos de vista técnico e econômico, enquanto as previsões de médio prazo permitem ir realizando os ajustes de rota em resposta às nuances conjunturais, no âmbito do assim denominado "planejamento tático".

Por outro lado, com o mercado liberado à competição e a flexibilização do planejamento, que passou gradualmente de uma ótica determinativa para uma ótica apenas indicativa, a expansão ótima somente ocorrerá se forem dados os índices econômicos adequados, para estimular respostas convenientes dos Agentes.

Nesse sentido, embora em alguns países o planejamento de transmissão continue determinativo e centralizado, como é o caso do Brasil, a expansão dos meios de produção, em termos de localização, assim como grandes cargas no segmento de consumo, são susceptíveis a sinais econômicos proporcionados pela transmissão. De fato, as tarifas de transmissão podem ter uma componente locacional (tarifa dependente da localização), que incentivam os agentes a, dentro de certos limites, decidirem a localização de suas plantas em pontos onde a necessidade de expansão de transmissão seja minimizada [83].

Conjugando-se as considerações apresentadas com a carência de trabalhos estruturados na esfera acadêmica, no que se refere ao processo de planejamento em sua plena abrangência, optou-se por focar esta Dissertação nesses aspectos, que são dois dos principais insumos do planejamento da expansão no âmbito de sistemas elétricos "desregulamentados", comparando as soluções encontradas para alguns países da América Latina, para os quais as informações disponíveis permitiram aprofundar a análise. 


\subsection{Motivação}

Por tudo que se mencionou, conclui-se que um dos aspectos que merece ser estudado e aprofundado, após o processo desregulamentação, é o esquema de tarifação aplicado ao setor da transmissão. $\mathrm{O}$ estabelecimento de tarifas racionais a serem pagas pelos geradores e consumidores poderá garantir a concorrência à qual se fez referência na Seção 1.1, incentivando o setor da transmissão a viabilizar maiores investimentos e, o mais importante, garantir o fornecimento de energia.

Nos países cujos setores elétricos foram já desverticalizados surgiu, a necessidade de reavaliar e reforçar a estrutura organizacional da área da transmissão. Até agora não existe consenso a respeito de qual é o melhor método de tarifação a ser aplicado ao nível de transmissão. Vários países no mundo adotaram metodologias tarifárias inspiradas em desenvolvimentos de outros países. Porém, nestas metodologias, possivelmente não foram consideradas as características e realidades (elétricas, econômicas e sociais) dos países que as adotaram.

Alguns artigos foram já publicados abordando a análise de modelos tarifários em países da América Latina e no mundo [15], [16]. Porém, estes artigos, bem como outras referências pesquisadas, referemse à década de 1990 quando os mercados elétricos iniciavam a sua liberalização. Recentemente, devido à crise nos seus setores elétricos, alguns países realizaram modificações na regulamentação de seus setores elétricos. Assim, faz-se necessário realizar estudos atualizados que acompanhem e avaliem estas mudanças bem como os resultados obtidos, como produto da aplicação dessas mudanças.

Por outro lado, os investimentos a serem realizados, tanto pelos usuários quanto pelas concessionárias do sistema de transmissão, dependem de um planejamento adequado de suas redes e equipamentos. Isto promove, quase que de forma compulsória, a realização de estudos relacionados com a previsão de energia de curto, médio e longo prazo.

Particularmente, a previsão da demanda de energia de longo prazo torna-se importante para a atividade de comercialização, dentro do novo ambiente competitivo. Esta previsão de energia é necessária para a contratação da energia a ser comprada ou vendida pelas concessionárias. Por exemplo, segundo a referência [52], prevê-se que o consumo de energia elétrica no Brasil, entre 2008 e 2017, deverá apresentar uma taxa média de crescimento de 5,5\% ao ano. A geração hidroelétrica é responsável por quase $80 \%$ do total da energia produzida. Porém, apesar do potencial hídrico já explorado devido ao crescimento contínuo do consumo de eletricidade, consubstanciado pelos resultados de previsão apresentados pelos órgãos nacionais responsáveis, faz-se necessário promover ainda mais projetos para aumentar a capacidade instalada, proporcionando garantia de atendimento principalmente quando de eventuais condições hidrológicas desfavoráveis. Por isso, um planejamento adequado que inclua a previsão de energia, faz parte essencial da cadeia de procedimentos que caracteriza todo sistema elétrico. 
Uma das solicitações importantes na previsão de longo prazo é que o erro seja menor do que uma tolerância prevista, geralmente estabelecida em 5\% [73]. Atualmente, dispõe-se de varias ferramentas de previsão, porém, a obtenção de resultados coerentes não depende apenas de possuir uma boa ferramenta, mas também da metodologia e variáveis explicativas utilizadas no processo de previsão. Por outro lado, eventuais interligações dos sistemas elétricos na América do Sul poderiam trazer alguns benefícios, por exemplo: tornar mais robustos os sistemas, aumentar a flexibilidade, otimizar o despacho, aproveitar as diferenças de consumo horário e sazonal, entre outros. No entanto, devido a que cada país tem seu próprio marco institucional, surge a necessidade de estabelecer mecanismos que permitam definir um marco comum para o desenvolvimento da integração energética para beneficio de todos.

Estas foram as principais razões que motivaram a realização do presente estudo, através do qual pretende-se contribuir e enriquecer as áreas de tarifação nos sistemas de transmissão bem como apresentar uma análise comparativa das metodologias de previsão de longo prazo utilizados nos países Sul Americanos considerados.

\subsection{Objetivos}

Com base nas justificativas apresentadas na seção anterior, bem como de outros aspectos intimamente relacionados a esses pontos, no presente trabalho foram estabelecidos os seguintes objetivos:

a) Descrever a natureza das políticas referentes à estrutura tarifária no setor da transmissão elétrica de alguns dos países da América do Sul. Os países a serem analisados foram escolhidos considerando o seu desempenho econômico e o potencial energético mostrado nos últimos anos. Estes países, bem como o resto dos países da América do Sul, possuem metodologias de tarifação diferentes através das quais promove-se o investimento e desenvolvimento de suas redes de transmissão.

b) Realizar uma análise comparativa dos modelos tarifários nestes mercados elétricos. Com a desverticalização dos mercados elétricos surgiu a discussão a respeito de quais esquemas de tarifação seriam os mais eficientes. Idealmente, cada país teria adotado um tipo de esquema tarifário o mais próximo possível da sua realidade. No entanto, segundo a literatura revisada, alguns países tiveram a necessidade de alterar o modelo adotado devido a que este não se adequava na sua totalidade à realidade do seu sistema, já que o mesmo não satisfazia os investimentos feitos pelo transmissor e, em consequiência, não promovia o desenvolvimento do sistema.

A identificação dos modelos tarifários, bem como dos mercados de países vizinhos, poderia estimular a integração energética, particularmente do setor elétrico. Assim, faz-se necessário explorar os possíveis benefícios de futuras interconexões bem como o seu impacto nas características tarifárias dos países analisados. Estas interconexões elétricas poderiam oferecer 
um importante suporte a prováveis crises de abastecimento elétrico em períodos nos quais as condições hidrológicas sejam desfavoráveis. Lembra-se que a geração básica na maioria dos os países Sul Americanos baseia-se em usinas hidroelétricas e térmicas.

c) Analisar e identificar quais são as variáveis e métodos de previsão de energia adotados pelos países a serem analisados. Isto fará possível comparar e observar se existe relação entre ditas metodologias. Para isso, as metodologias de previsão dos países considerados serão aplicadas aos dados de consumo e demais variáveis explicativas, correspondentes ao sistema Brasileiro. Assim, será possível observar o comportamento destas previsões no Brasil quando aplicadas às metodologias de previsão destes países vizinhos. Estas previsões serão realizadas de forma desagregada, considerando as classes de consumo Residencial, Industrial, Comercial e Rural, que representam aproximadamente $90 \%$ do consumo nacional no Brasil [67].

d) Finalmente, será realizada uma análise comparativa entre as metodologias de previsão de energia utilizadas nos países analisados. Outros resultados importantes e subprodutos encontrados durante o desenvolvimento da pesquisa serão também apresentados ao longo do trabalho.

\subsection{Estado da Arte}

Com o intuito de revisar e coletar o material relacionado ao tópico proposto foi realizada a respectiva pesquisa bibliográfica. Nos artigos [1], [2], [4] e [7], apresentam-se um conjunto de métodos e procedimentos relacionados aos sistemas tarifários nos sistemas de transmissão.

Em [4] faz-se uma descrição das transações do tipo pedágio (wheeling), ou seja, aquelas transações físicas entre um ponto e outro da rede. Neste tipo de transação destacam-se 3 formas de alocação de custos sendo estes: a do tipo rolled-in allocation, a qual por sua vez inclui a metodologia do tipo selo (postage stamp) e a metodologia incremental [5]; a alocação do tipo rota contratual (contract path ou red line allocation) e finalmente a do tipo MW-Milha (MW Mile Allocation) [2], [5], e [7].

Destacam-se também as metodologias baseadas no custo marginal, relacionadas aos preços spot [8]. Os preços spot são determinados a cada instante em função da oferta e da demanda de energia. Segundo [3], os métodos baseados na teoria de custos marginais podem ser classificados em dois tipos: Custo marginal de Longo Prazo (CMLP) e o Custo Marginal de Curto Prazo (CMCP). O CMLP descrito em [3], [10] e [11] entre outros, é atualmente usado pela National Grid Company da Inglaterra. O cálculo do CMLP baseia-se na determinação de uma rede ótima necessária para poder fornecer a demanda existente.

No caso do CMCP, os custos marginais são determinados considerando o atendimento a uma unidade adicional de demanda fornecido ao sistema, mantendo constante os ativos fixos da geração e transmissão [3]. Nesta metodologia a retribuição que percebe a rede de transmissão (Receita Tarifária) 
[1], não é suficiente para remunerar os seus custos; assim, na maioria dos casos este ingresso dever ser complementado através de pedágios ou encargos complementares.

Uma outra metodologia de tarifação atualmente sendo estudada refere-se à teoria de jogos [12], [13] e [14]. O objetivo desta metodologia baseia-se na existência de coalizões entre os agentes do mercado que estabelecem contratos de compra e venda de energia. Cada coalizão é caracterizada, entre outros aspectos, pelo custo de transporte associado à realização da transação.

Outros trabalhos onde são descritas metodologias de precificação e experiências da sua aplicação nos mercados elétricos desverticalizados de alguns países na América do Sul podem ser encontrados em [15], [16]. Ao longo do trabalho, serão também apresentadas outras referências especializadas nas supracitadas metodologias.

No referente à previsão da demanda de energia, a referência [65] apresenta um estudo relacionado à previsão de energia de longo prazo. No mesmo, similar ao estudo aqui apresentado, consideram-se também variáveis explicativas do tipo econométricas é o caso da população e o PIB. Porém, a citada referência está orientada principalmente à previsão espacial de energia.

Por outro lado, em [66] foram utilizadas as Redes Neurais Artificiais (RNA) como uma ferramenta de previsão de energia. Apesar das RNA's não terem sido muito utilizadas pelas concessionárias na previsão de energia de longo prazo, um dos paises considerados no presente estudo utiliza esta técnica de previsão. Outras ferramentas como o software SPSS (Statistical Product and Service Solutions) e o $\mathrm{SAS}^{\odot}$ tem sido aparentemente mais utilizados para a realização desta tarefa.

\subsection{Metodologia Utilizada no Trabalho}

O presente trabalho divide-se em duas partes. A metodologia utilizada em cada uma delas é a seguinte:

i) No referente à análise das metodologias de tarifação no segmento da transmissão dos países analisados aplicou-se uma metodologia do tipo analítico-descritiva.

ii) A metodologia correspondente à segunda parte do trabalho, relacionada às previsões de demanda de energia, está baseada em simulações sucedida de sua correspondente análise comparativa. Os dados de consumo de energia foram obtidos do site da ANEEL (Agência Nacional de Energia Elétrica) [32], em quanto que as tarifas médias por classe de consumo foram obtidas do site da ABRADEE (Associação Brasileira de Distribuidores de Energia Elétrica) [51]. Finalmente, a maioria das variáveis explicativas foram obtidas do banco de dados do IBGE (Instituto Brasileiro de Geografia e Estatística).

\subsection{Estrutura da Dissertação}

O presente trabalho está estruturado em mais quatro capítulos além deste introdutório. 
No Capítulo II apresentam-se os princípios básicos e as diferentes metodologias de tarifação ao nível da transmissão propostas, na literatura. Apresentam-se também as principais vantagens e desvantagens destas metodologias de tarifação propostas.

No Capítulo III são apresentadas as características dos sistemas de transmissão, a estrutura tarifária, os órgãos regulatórios, bem como as políticas de expansão de cinco países da América do Sul que desverticalizaram o seu setor elétrico. Os países estudados são: Argentina, Bolívia, Brasil, Chile e Peru. No final do capítulo, faz-se uma comparação entre os esquemas tarifários dos mencionados países.

No Capítulo IV apresenta-se um estudo comparativo entre as metodologias de previsão da demanda de energia utilizadas nos países em estudo. O objetivo desta análise é identificar quais são os componentes e variáveis utilizados nos métodos adotados pelos países citados bem como observar o comportamento destes métodos de previsão quando aplicados ao caso do Brasil.

Finalmente, no Capitulo V são apresentadas as principais conclusões e sugestões para trabalhos futuros. 


\section{CAPITULO II \\ CONCEITOS BÁSICOS DE TARIFAÇÃO DOS SISTEMAS DE TRANSMISSÃ̃}

\subsection{Introdução}

Neste capítulo serão apresentados os principais métodos de tarifação conhecidos na literatura especializada. Deve-se ressaltar que na prática nenhum destes métodos mostrou ser o ideal para a aplicação em um determinado sistema. Pelo contrário, cada sistema teve que procurar a metodologia e solução que se adaptasse a suas características.

O novo esquema competitivo do setor elétrico redefiniu o papel da transmissão elétrica como monopólio natural e, portanto, um segmento estritamente regulado, dando relevância institucional ao meio físico necessário para a existência do mercado entre geradores e consumidores. Vale ressaltar que a efetividade da criação de um mercado competitivo no setor da geração elétrica depende das políticas adotadas no setor da transmissão [3] e do sinal econômico aos usuários dos serviços de rede.

Os sistemas de transmissão apresentam economias de escala ${ }^{3}$ significativas, fundamentalmente, pela indivisibilidade dos investimentos, como também à necessidade de redundância para cumprir com critérios de segurança. As linhas de transmissão com maior tensão nominal e capacidade de transmissão, tem um menor custo médio por unidade de potência e por $\mathrm{km}$. Devido às características de monopólio natural, existe a necessidade de regulamentação, especialmente nos aspectos de acesso e de tarifação, dada a importância do sistema de transmissão como facilitador da competição entre geradores geograficamente dispersos. Os marcos regulatórios estabelecem esquemas de acesso aberto as redes nas quais os proprietários ou concessionários devem permitir o uso aberto, e não discriminatório, de seu sistema de transmissão e novos sistemas de preços, onde a transmissão é tarifada com base em uma combinação de preços marginais de operação (curto prazo) ou de expansão (longo prazo) e aos encargos adicionais ou pedágios que permitem a alocação do custo da rede a todos os agentes que fazem uso dela, independentemente de seus compromissos comerciais.

\subsection{Principais Requisitos de um Método de Tarifação}

Do ponto de vista econômico, um sistema de tarifação deve fazer parte de um marco regulatório claro e com o objetivo principal de incentivar o desenvolvimento da indústria elétrica assim como permitir uma operação eficiente do sistema. Em virtude das diferentes políticas e diretrizes estabelecidas pelos governos de cada país, os esquemas de tarifação da transmissão adotaram metodologias diferentes, já

\footnotetext{
${ }^{3}$ A economia de escala de uma determinada indústria ocorre quando seus custos médios de longo prazo são decrescentes com os níveis de produção, o que se traduz em custos marginais de longo prazo menores que os custos médios de longo prazo. No setor da transmissão elétrica existem importantes economias de escala que são dadas por custos decrescentes com o aumento da capacidade da linha. Isso significa que resulta mais econômico realizar um maior investimento em uma linha de maior tensão e capacidade que construir duas ou mais linhas de menor capacidade.
} 
que ainda não existem padrões analíticos reconhecidos internacionalmente que permitam avaliar se um determinado esquema de tarifação é adequado econômica e tecnicamente. Frente a esta dificuldade, um dos grupos da Standford Energy Modeling Fórum propôs alguns princípios que devem ser levados em conta durante o desenho das tarifas de transmissão [9], sendo estes:

a) O SISTEMA DE TARIFAÇÃO DEVERÁ PROMOVER O USO EFICIENTE DO SISTEMA DE TRANSMISSÃO: Ou seja, deverá fornecer incentivos de modo a promover o uso eficiente da transmissão. O uso eficiente da transmissão pode ser atribuído à eficiência técnica, o que implica, por exemplo, a redução de perdas na transmissão atingindo assim a eficiência econômica.

b) DEVERÁ FORNECER SINAIS DE ALOCAÇÃO PARA O INVESTIMENTO NA GERAÇÃO E NA DEMANDA. A tarifa de transmissão deve oferecer sinais de incentivo para os agentes (geradores e consumidores) localizados perto ou longe um do outro. Deverá ser economicamente atrativa de modo que para o usuário seja mais interessante utilizar o sistema de transmissão interconectado do que construir o seu próprio sistema de transmissão.

c) DEVERÁ FORNECER SINAIS NECESSÁRIOS DE INVESTIMENTO: O esquema de tarifação e os dividendos pagos aos proprietários das redes de transmissão deverão fornecer incentivos para $\mathrm{o}$ investimento em novas instalações onde e quando for necessário.

d) DEVERÁ RECUPERAR os CUSTOS PELAS INSTALAÇÕES EXISTENTES: O ingresso obtido a partir das tarifas estabelecidas pelo uso dos serviços de transmissão, deverão permitir a recuperação dos custos de investimento, operação e manutenção da rede de transmissão; além de se obter um certo grau de ganho regulamentado. A recuperação dos custos incorridos tem importância principalmente para a manutenção das instalações de transmissão.

e) TODO ESQUEMA DE TARIFAÇÃO DEVERÁ SER TRANSPARENTE E SIMPLES: Refere-se à capacidade de transmitir sinais econômicos corretos a todos os agentes do sistema (geradores, distribuidores e consumidores) e, portanto, mostrar a maior transparência e simplicidade possível.

f) DEVERÁ SER POLITICAMENTE IMPLEMENTÁVEL: O esquema de tarifação deverá ser abrangente e robusto de modo que seja facilmente aceito pelos agentes do sistema a fim de evitar um conflito de interesses. Neste sentido, convém reproduzir o citado por R. Green [9] no sentido que caso forem propostas mudanças no esquema tarifário e existam agentes do mercado que possam ver-se afetados pelas mesmas, estes farão todo o possível para que estas não sejam implementadas, se eventualmente estes agentes tiverem o poder político suficiente. Por isso o esquema de tarifação, caso contemple mudanças no "statuo-quo" deverá contemplar, dentro do possível, os interesses aqueles que já participam no sistema. 
g) DEVERÁ TER a CARACTERística DE ESTABILIDADE: As tarifas de transmissão devem ser razoavelmente estáveis de forma a evitar a exposição a riscos financeiros aos agentes do sistema, fato que seria repassado aos custos de fornecimento do serviço.

Além disso, pode-se acrescentar que uma tarifa ou encargo de transmissão adequado, deve ter como característica a previsibilidade (para melhor orientar decisões de investimento), como também a reprodutibilidade, visando a credibilidade e a confiança dos Agentes.

No item 3.6.8 do Capitulo III será apresentada uma avaliação em relação ao grau de adequação aos supracitados princípios pelas metodologias de tarifação dos países a serem analisados.

\subsection{Definição de um Esquema de Tarifação na Transmissão}

Ao definir um esquema de tarifação dos sistemas de transmissão, deve-se ter em conta as seguintes definições [17]:

- Componente de Custo. Caracterizada a partir de uma divisão do sistema de transmissão segundo os "níveis de tensão" e "áreas elétricas do sistema". Essa divisão é conhecida como componente de custo e está relacionada com a atividade econômica, com a conexão elétrica e com a estrutura de propriedade do sistema.

- Componentes de Tarifa ou de Encargos. Os componentes de custos mencionados anteriormente são por sua vez divididos em distintos componentes de tarifas ou de encargos de transmissão, que posteriormente são aplicados aos usuários do sistema. Esses componentes consideram o uso das instalações (investimentos) e serviços à rede (perdas, qualidade de serviço, etc.).

- Conceito de Acesso à Rede. O conceito de acesso à rede define as regras para conexão ao sistema elétrico que devem ser estritamente observadas pelos Agentes usuários (geradores, comercializadores, consumidores, etc), bem como a forma de realizar os seus pagamentos pelo uso da rede, segundo os princípios estabelecidos nos componentes de custo e tarifa.

- Principio de Uso da Rede. Corresponde à metodologia básica de um sistema para a identificação do uso por parte de um agente, componente de custo da rede para uma determinada componente de tarifa.

\subsection{Metodologias de Cálculo das Tarifas de Uso da Transmissão}

Nesta seção, serão apresentadas as principais metodologias existentes para a tarifação do sistema de transmissão, várias delas atualmente aplicadas no mundo. Deve-se ressaltar que a eficiência econômica dessas variantes constitui-se no requisito mais importante a ser atingido, de tal forma que a metodologia proposta incentive o uso racional dos atuais sistemas de transmissão. Além disso, procura-se simultaneamente minimizar o custo de expansão da transmissão e tornar atraente o custo de acesso à rede para os novos geradores e consumidores [18]. 
Trabalhos como as referências [1], [2], [4], [5], [19], [25] classificam estas metodologias e fazem uma valiosa contribuição em termos de revisão crítica de metodologias tradicionais de tarifação da transmissão.

\subsubsection{Método de Tarifação do Tipo Pedágio (Wheeling)}

Nos sistemas de transmissão, o pedágio que teve sua origem nos EUA, refere-se à tarifa aplicada para o transporte de energia elétrica entre uma entidade de venda e outra de compra, utilizando uma rede de transmissão pertencente a um terceiro [4]. Tipicamente, o pedágio se baseia em um preço unitário por $\mathrm{kWh}$, ou por $\mathrm{kW}$ de potência fornecida, considerando o custo total da capacidade de transmissão do sistema mais o custo adicional devido às perdas. Dentro das transações do tipo wheeling destacam-se três formas de alocação de custos [4], [5], sendo estas: a alocação do tipo rolled-in (Rolled-in allocation), alocação do tipo rota contratual (Contract path ou Red Line allocation) e a alocação MW-Mile.

\subsubsection{Alocação do Tipo Preços Globais (Rolled in Allocation)}

Nesta metodologia os custos totais existentes na rede, desconsiderando os custos de expansão são agregados em espaço e tempo [5]. Assim estes custos totais são assinalados a cada transação wheeling, com base no uso do sistema onde se faz a transação em proporção a uma medida global da rede. A medida de utilização global pode ser a demanda de ponta do consumo, a energia total fornecida, a potência vendida, etc. A seguir são apresentadas algumas das formas nas quais pode-se apresentar esta metodologia de alocação de custos de transmissão:

\section{a) Selo Postal (Postage Stamp)}

Este método de tarifação é um dos mais simples. Os custos de transmissão são alocados em proporção à demanda de cada participante.

Para seu cálculo, considera-se o custo total do serviço de transporte, que será dividido pela medida de uso que cada usuário faz da rede. A tarifa neste método é independente do local em que é injetado a potência, podendo esta estar perto ou longe dos consumidores. O pedágio nesse método será igual para todos os nós do sistema.

Para medir o grau de "uso" do sistema pode ser considerada a potência (MW) consumida ou gerada em uma determinada barra do sistema e em um determinado momento, ou pode-se considerar a energia (MWh) efetivamente consumida ou gerada. Em quaisquer destes casos deve-se especificar o momento no qual foi feita a medição. 
As referências [2], [5] descrevem uma das formas mais comuns de aplicação deste método. O pagamento que se deve efetuar em cada transação bilateral, para fazer uso do sistema de transmissão, será definido segundo:

$$
R_{t}=T C \frac{P_{t}}{P_{\max }}
$$

onde,

$$
\begin{array}{lll}
R_{t} & : & \text { Preço de transmissão para a transação } t \\
T C & : & \text { Custo total do sistema de transmissão } \\
P_{t}: & \text { Potência máxima fornecida a } t \\
P_{\max }: & \text { Potência máxima do sistema (conjunto) }
\end{array}
$$

Este método foi amplamente utilizado nos EUA e Europa [5], além do Brasil, Colômbia, e Peru, entre outros, como um complemento às tarifas e de forma a recuperar os custos totais de transmissão.

\section{b) Métodos de Tipo Incremental}

O custo incremental está definido pela diferença do custo na ausência e na presença de determinada transação ou agente, e pode ser interpretado como o sobrecusto incorrido pela rede de transmissão de modo a acomodar esses novos agentes ou transações.

O conceito da natureza incremental contribui para aumentar a eficiência e racionalidade econômica da utilização das redes de transmissão e para fornecer sinais dirigidos a melhorar a utilização dos sistemas, uma vez que consideram o fator locacional e o sentido dos fluxos de potência [1] [5]. No entanto, têm sido apontadas deficiências e dificuldades na aplicação da metodologia incremental:

- Por um lado, as vantagens decorrentes da melhoria da eficiência econômica são contrabalançadas pelo aumento da complexidade da avaliação dos custos associados a cada transação [19].

- O acréscimo da complexidade na alocação de custos imputados a cada transação ocorre de forma mais evidente se o número de transações presentes for elevado.

O método de tipo incremental pode ser subdividido em:

\section{- Métodos Incrementais de Curto Prazo (MICP).}

Este método permite avaliar e alocar os custos de operação ${ }^{4}$, exploração, manutenção e de oportunidade associados a cada nova transação. Os custos de operação são calculados

\footnotetext{
${ }^{4}$ Do que resulta a denominação "curto prazo"
} 
utilizando um modelo de fluxo ótimo de potência integrando restrições de segurança da rede e de planejamento.

A implementação do MICP pode apresentar algumas dificuldades, a saber:

- A necessidade de fornecer sinais econômicos ao mercado, correspondentes à previsão de custos de operação, exploração, manutenção e de oportunidade para o horizonte em estudo. Essa tarefa pode-se revelar complexa, sobretudo para períodos de análise longos.

- A dificuldade de realizar previsões e tomada de decisões de índole econômica relativa aos contratos de longo prazo utilizando, apenas, informações dos preços de utilização da rede de transmissão de curto prazo.

- A utilização de metodologias envolvendo apenas custos de curto prazo, isto é, não envolvendo custos de investimento para a expansão e reforços das redes, torna insuficiente a remuneração das redes de transmissão.

- Os benefícios obtidos através deste tipo de remuneração compensam apenas os custos de curto prazo decorrentes de uma determinada transação. Com isso as entidades de transmissão ficarão desincentivadas para realizar investimentos dirigidos ao reforço da capacidade disponível ou para a melhoria da qualidade de serviço.

\section{- Método Incremental de Longo Prazo (MILP)}

Permite avaliar os custos de investimento na expansão e reforço das redes ${ }^{5}$, bem como realizar uma estimativa de longo prazo dos custos de operação, manutenção, expansão e de oportunidade necessários para acomodar uma nova transação. A componente dos custos de reforço ou expansão é avaliada para o longo prazo, levando em conta os impactos que a transação ou agente terão no planejamento da rede toda. Esta avaliação incide sobre diversos cenários considerando as previsões relacionadas à evolução da carga em um determinado horizonte. Por outro lado, a sua avaliação prevê a possibilidade dos custos de reforço ou investimento serem negativos, o que indica que uma determinada transação pode permitir anular ou adiar determinados investimentos planejados.

\subsubsection{Alocação do Tipo Rota ou Trajetória Contratual (Contract Path Allocation)}

Este método é também conhecido como Red Line Allocation. Teve sua origem nos EUA e é aplicado considerando o conceito de acesso nó a nó. Neste método calcula-se o custo de uma determinada transação considerando um caminho hipotético que a energia deve percorrer a

\footnotetext{
${ }^{5}$ Do que resulta a denominação "longo prazo"
} 
partir do ponto de fornecimento até o ponto de consumo. Em outras palavras, neste método o preço é alocado com base no uso de cada linha do sistema.

Esta rota é estabelecida com base em um acordo mútuo entre os envolvidos (fornecedores de energia, responsáveis do sistema de transmissão, consumidores, etc) quase que desconsiderando as leis físicas que regem o comportamento elétrico do sistema. O preço alocado à transação será equivalente à soma dos preços nas instalações definidas pela rota contratual [2] [4], [5]. Na Figura 2.1, mostra-se um exemplo de rota contratual entre um gerador (Gn) e uma carga (D).

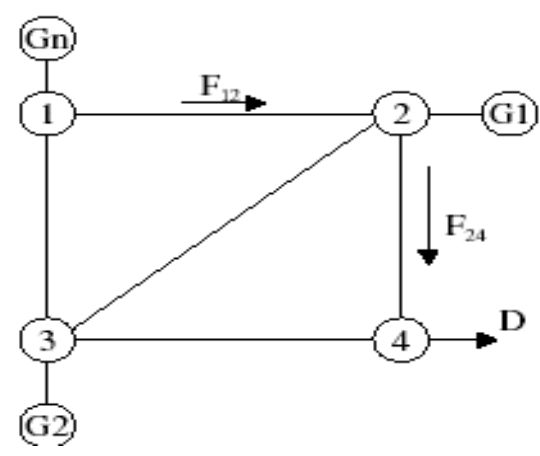

Figura 2.1 Sistema mostrando a metodologia de rota contratual

Nesse caso o usuário D terá sua tarifa $\left(T_{d}\right)$ definida pela seguinte equação:

$$
T_{d}=\alpha\left(C_{12}+C_{24}\right)
$$

onde,

$T_{d} \quad: \quad$ Custo alocado ao agente privado

$C_{12}, C_{24}$ : Custos do circuito 1-2 e 2-4, respectivamente.

$\alpha \quad$ : Fator de negociação

Pode-se observar que esta metodologia ignora a operação real do sistema já que não considera que parte da potência transferida de um ponto até outro pode também fluir através de circuitos fora da trajetória contratada. Assim sendo, as partes envolvidas no contrato fazem uso de linhas pelas quais não estão pagando.

\subsubsection{Alocação do Tipo MW-Milha (MW-Mile Allocation)}

O método chamado de MW-milha foi proposto por Shirmohammadi no ano 1989 [5], [6], e considera como base de cálculo o custo de cada linha e os respectivos fluxos de potência nestas. Como conceito básico perseguido em sua formulação, este método baseia-se no estudo de fluxos de potência múltiplos e busca solucionar os inconvenientes presentes nos métodos de alocação do tipo selo (postage stamp) e a rota contratual (contract path). 
O método trata de refletir, além da incidência que tem as transações sobre os fluxos da rede, a quantidade de rede que é necessário utilizar. Isto significa que não é o mesmo transportar 10 MW a $10 \mathrm{~km}$, que a mesma potência a $100 \mathrm{~km}$. A utilização da rede não é a mesma e isso deve ser considerado.

No método MW-milha, os custos de cada transação wheeling estão baseados no uso dado ao sistema de transmissão. Ou seja, o custo alocado é uma função da quantidade, da rota e da distância percorrida pela potência (energia) negociada.

Segundo as referências [2], [7] esta metodologia toma como base de cálculo o custo de cada linha e os respectivos fluxos de potência nas mesmas. Executa-se um fluxo de potência DC para calcular o aumento do fluxo em cada linha após a inserção de um novo usuário. O usuário pagará pelo incremento resultante em cada linha após seu ingresso na rede e a consideração das solicitações decorrente de sua transação. Na Figura 2.2, mostra-se um exemplo da entrada de um novo gerador $(G n)$ e a variação do fluxo inicial $(F i)$ causado por ele.

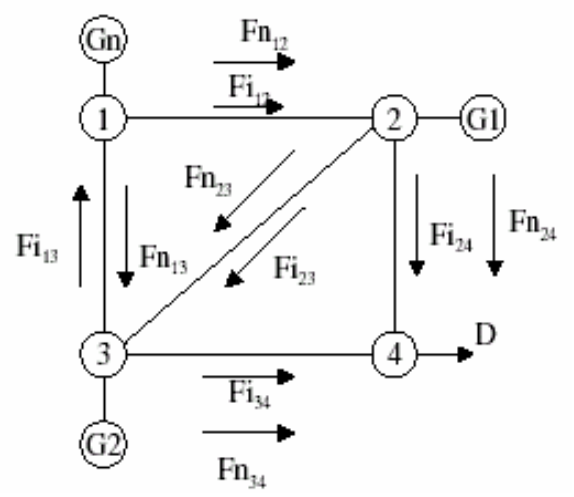

Figura 2.2 Sistema exemplo para a metodologia MW-Milha

Nesse caso, a tarifa ( $T g$ ) para o usuário $G n$ estará definida pela seguinte equação (2.3):

$T g=\frac{C_{12} F n_{12}}{F_{12}}+\frac{C_{13} F n_{13}}{F_{13}}+\frac{C_{23} F n_{23}}{F_{23}}+\frac{C_{24} F n_{24}}{F_{24}}+\frac{C_{34} F n_{34}}{F_{34}}$

A tarifa $(T d)$ para o usuário D estará definida pela equação (2.4):

$T d=\frac{C_{12} F i_{12}}{F_{12}}+\frac{C_{13} F i_{13}}{F_{13}}+\frac{C_{23} F i_{23}}{F_{23}}+\frac{C_{24} F i_{24}}{F_{24}}+\frac{C_{34} F i_{34}}{F_{34}}$

onde,

$F n_{i j}$ : Parcela que flui na linha referente ao novo usuário;

$F i_{i j}$ : o que já fluía na linha antes da inserção do novo usuário;

Fij : a capacidade da linha

$\mathrm{C}_{12}, \mathrm{C}_{13}, \mathrm{C}_{23}, \mathrm{C}_{24}, \mathrm{C}_{34}$ são os custos do circuito 1-2, 1-3, 2-3, 2-4 e 3-4, respectivamente

A principal desvantagem desta metodologia é que não garante a recuperação dos custos fixos, isto é, a somatória de todos os custos obtidos para cada agente, incluindo os nativos, não será 
igual ao custo total do sistema de transmissão. Em termos computacionais, o MW-milha é mais complexo que o método selo.

\subsection{MW-Milha Estendido ou Método do Módulo}

Para evitar o problema da não recuperação total do custo da rede de transmissão apresentado pela metodologia MW - Milha, na fórmula de cálculo da tarifa a capacidade do circuito é substituída pela soma dos módulos nos fluxos de potência efetivos na rede. Desta forma tem-se:

$$
C_{W}=\sum_{t o d o_{-} k} C(k) \frac{\left|\Delta F_{W}(k)\right|}{\left|\Delta F_{W}(k)\right|+\left|F_{B}(k)\right|}
$$

onde,

$$
\begin{array}{lll}
\mathrm{C}_{\mathrm{W}} & : & \text { Custo atribuído ao Agente Privado } \\
\mathrm{C}(\mathrm{k}) & : & \text { Custo do elemento } k \\
\Delta F_{W}(k) & : & \text { Variação do fluxo através do elemento } k \text {, devido ao agente privado } W \\
\mathrm{~F}_{\mathrm{B}}(\mathrm{k}) & : & \text { Fluxo produzido pelos usuários base no elemento } k .
\end{array}
$$

Esta metodologia mostra-se mais simples já que considera a extensão da rede utilizada e garante a neutralidade e a cobertura dos custos. Porém, sob determinadas circunstâncias (transações) nas quais os novos usuários produzem a mesma variação de fluxo, pode ocorrer que a porcentagem do custo total a se pagar por esta variação seja diferente, dependendo do valor de fluxo transportado nos circuitos com a mesma capacidade. Isto faz com que a metodologia seja instável.

Esta deficiência é mostrada através do seguinte exemplo: suponha uma transação que produz uma variação de $20 \mathrm{MW}$ nos circuitos 1 e 2 de uma rede de transmissão, ambos com idênticas capacidades, conforme apresentado na Figura (2.3).
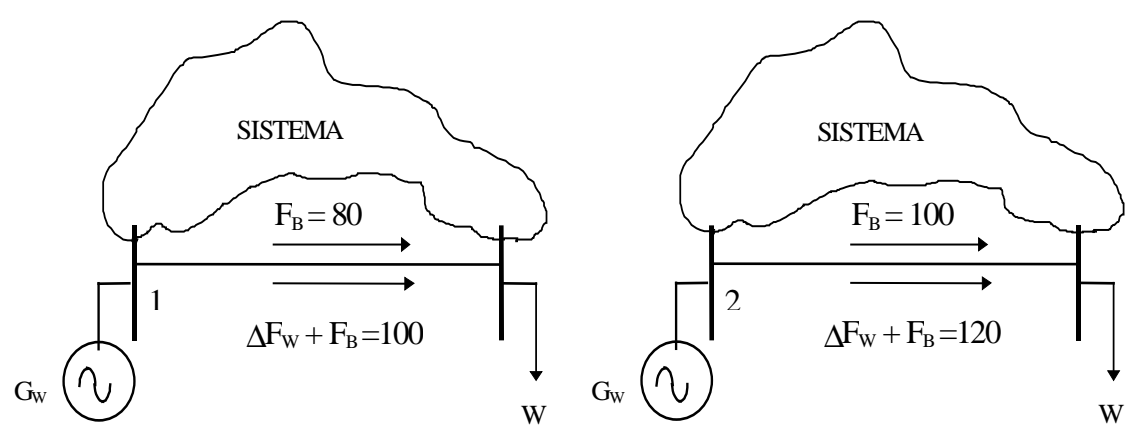

Figura 2.3 Fluxos em dois circuitos diferentes para uma determinada transação

Considerando os valores do fluxo da transação e a variação produzida pelo acessante, a porcentagem do custo total que deverá pagar por cada um deles será: 


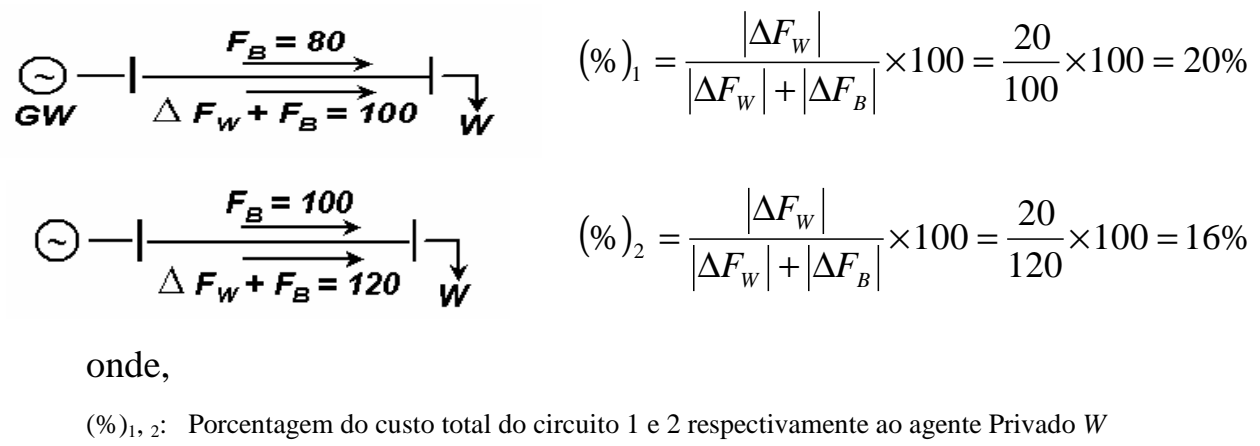

Nestes dois casos, é possível observar que a porcentagem do custo da linha de transmissão a ser pago pelos acessantes em cada situação é diferente, apesar da transação produzir a mesma variação de fluxo entre eles.

\subsubsection{Métodos de Tarifação do Tipo Marginal}

Os métodos de tipo marginal surgiram na década de 1980's [8]. Estes métodos estão relacionados com os chamados preços spot que são determinados a cada instante, em função da oferta e da demanda de energia. Dessa forma, o preço spot em uma determinada barra corresponde ao valor do custo marginal de produção de uma unidade adicional de carga ligada à barra no instante referido.

Em teoria, a adoção de preços spot permite melhorar a eficiência do sistema na medida em que permita transmitir sinais econômicos relativos à utilização das redes de um modo mais eficiente. Estes preços têm ainda a propriedade de serem interpretados como sinais econômicos para os agentes (consumidores e geradores) participantes do mercado elétrico. Os métodos marginais podem ser classificados em dois tipos: Custo Marginal de Curto e de Longo Prazo [3].

\subsubsection{Custos Marginais de Curto Prazo (CMCP)}

No custo marginal de curto prazo (CMCP) ou $S R M C^{\mathbf{6}}$, o preço de compra ou venda da energia é realizado em cada ponto do sistema [1], [3]. Ou seja, a receita que os proprietários da rede têm direito, deve ser calculada considerando os custos marginais de curto prazo da energia, ou potência, em cada barra do sistema. Para um nó em particular, o CMCP refere-se ao custo associado a um incremento de potência injetada no sistema, necessário para responder a incrementos de carga experimentados nesse nó. A receita da rede por esse conceito, chamado de Receita Tarifária (RT) [1], será a diferença entre os custos das injeções e retiradas em cada uma das barras valoradas ao preço de energia e potência dessas barras.

Os custos marginais em cada barra podem ser calculados através de um despacho uninodal, ou multinodal. Assim, é possível calcular as receitas tarifárias por conceito de energia ( $\left.R T_{\text {energia }}\right)$ e de potência $\left(R T_{\text {potência }}\right)$. A soma de ambas as $R T s$ corresponde à Receita Tarifária Total $(R T T)$ :

\footnotetext{
${ }^{6}$ Short Running Marginal Cost
} 
$R T T=R T_{\text {energia }}+R T_{\text {potencia }}$

\section{i) Receita Tarifária por Potência}

Para um despacho multinodal na rede e considerando os custos marginais ( $C M g$ ) correspondentes à potência, é possível definir a receita tarifária para a linha $i$-j:

$R T_{\text {potência }}=P_{j} \rho_{j}^{P}-P_{i} \rho_{i}^{P}$

onde,

$\rho_{i}^{P}$ : $\quad$ Preço nó da potência na barra $i$ (injeção).

$\rho_{j}^{P}: \quad$ Preço nó da potência na barra $j$ (retirada)

$P_{i}: \quad$ Potência injetada no nó $i$

$P_{j}: \quad$ Potência retirada no nó $j$

Caso o despacho seja uninodal e considere apenas o custo marginal por potência, equivalente ao preço da potência para o sistema, a receita tarifária para a linha $i j$ será:

$R T_{\text {potência }}=\left[\left(P_{i}-P_{L_{i j}}\right) F P P_{j}-P_{i} F P P_{i}\right]$ Preço $_{\text {potência }}$

onde,

$\begin{array}{ll}P_{i}: & \text { Potência injetada na barra } i \\ P_{L}: & \text { Perdas da potência na linha } \\ F P P_{i}: & \text { Fator de penalidade da barra } i \\ F P P_{j}: & \text { Fator de penalidade da barra } j\end{array}$

ii) Receita Tarifária por Energia

No caso da receita tarifária por energia, o tratamento basicamente é similar ao caso anterior. As equações utilizadas no inciso $(i)$ são também válidas, porém a potência $(P)$ será substituída pela energia $(E)$. Assim, considerando um despacho multinodal na rede, e considerando como preço de energia, os custos marginais associados ao despacho sob condições de demanda média são possíveis definir a receita tarifária por energia para a linha $i$ a partir da equação (2.9):

$R T_{\text {energia }}=E_{j} \rho_{j}^{E}-E_{i} \rho_{i}^{E}$

onde,

$\rho_{i}^{E}: \quad$ Preço nó da energia na barra $i$ (injeção)

$\rho_{j}^{E}: \quad$ Preço nó da energia na barra $j$ (retiro)

$E_{i}$ : $\quad$ Energia injetada no nó $i$

$E_{j}$ : Energia injetada no nó $j$

Caso o despacho seja uninodal e considere apenas o preço da energia para o sistema, a receita tarifária para uma linha $i, j$, será (equação 2.12): 


$$
R T_{\text {energia }}=\left[\left(E_{i}-P_{L_{i j}}\right) F P E_{j}-E_{i} F P E_{i}\right] \text { Preço }_{\text {energía }}
$$

onde,

$E_{i} \quad$ : Energia injetada na barra $i$

$P_{L} \quad$ : Perdas de energia na linha

$F P E_{i}$ : $\quad$ Fator de penalidade da barra $i$

$F P E_{j}: \quad$ Fator de penalidade da barra $j$

Conforme descrito em [20], em sistemas que apresentam economias de escala, como é o caso da transmissão, a tarifação marginal não permite financiar plenamente os custos totais (por exemplo, no caso Chileno estima-se que em média os custos marginais recuperam apenas $15 \%$ dos custos totais de transmissão). Por este motivo surge a necessidade de recuperar a diferença entre os custos marginais e os custos médios através de outro mecanismo. Esta diferença, chamada de Encargo Complementar, pode ser arrecadada através de diferentes mecanismos os que são descritos no item (2.4.4).

\subsection{Vantagens e Desvantagens do CMCP}

Uma das vantagens do uso da tarifa de CMCP é que os custos por pedágio para qualquer transação de energia variam conforme as variações nos sinais econômicos ótimos durante a operação no curto prazo. Estes custos marginais são também chamados de preços spot. Assim, este método de precificação é capaz de refletir as condições operativas reais das áreas de geração e transmissão, por exemplo, casos de congestão na rede, perdas nas linhas e outras. Contrariamente, caso a magnitude da carga base (carga nativa) seja pequena em comparação com a energia negociada (wheeled power) os preços de $\mathrm{CMCP}$ poderão se localizar longe do custo de operação real da transação wheeling. Por outro lado, a remuneração normalmente é pequena para recuperar os custos devido a reforços na transmissão e, em conseqüência, o CMCP não promove a expansão das instalações de transmissão. Com este método a rede é fixa e o custo para o usuário esta baseado no custo incremental das perdas pelas linhas, as congestões e a redução na confiabilidade. Esta metodologia produz instabilidade e volatilidade nas tarifas, o que poderia eventualmente desincentivar o investimento na geração.

\subsubsection{Custos Marginais de Longo Prazo (CMLP)}

Os métodos marginais de longo prazo como o Investment Cost Relating Pricing (ICRP) e o DCLFP (DC Load Flow Pricing) [3], [10], [11] baseiam-se na determinação de soluções ótimas, que poder ser entendido como o estabelecimento de uma "rede ótima". Esta rede ótima é a rede com custo mínimo que atende à geração e demanda sob condições e padrões de confiabilidade específicos. Segundo [11], por exemplo, o problema de otimização a ser resolvido, no caso do método ICRP, seria: 
$\operatorname{minimizar} \omega=\sum_{i j} l_{i j}\left|p_{i j}\right|(\mathrm{MW} . \mathrm{km})$

sujeito a: $\sum_{j} p_{i j}=P_{i}$

onde,

$l_{i j} \quad$ : Comprimento da linha $i j$

$p_{i j} \quad$ : $\quad$ Fluxo de potência da linha $i j$

$P_{i} \quad$ : Injeção de potência liquida no nó $i$ (condição de demanda pico)

O custo anual de construção da rede será posteriormente calculado multiplicando os MW. km obtidos por uma certa constante de expansão da rede (em US\$/MW/km/ano). Finalmente, a solução do problema de otimização apresentado em (2.11a) poderia ser obtido utilizando técnicas de programação linear.

De forma similar ao método ICRP, o método DCLFP de longo prazo também está baseado na solução de um problema de otimização de uma rede ótima. Segundo [11], o método DCLFP ter-se-ia mostrado mais adequado para o cálculo tarifário devido aos resultados de fluxo de potência mais realistas. A principal desvantagem deste método seria que requer de mais informações de entrada (input) do que o método ICRP.

A metodologia atualmente aplicada no Brasil, segundo a Nota Técnica 003/1999 SRT/ANEEL [54], está baseada em Custos Marginais de Longo Prazo, tratando-se, portanto, de uma variante do método Nodal com algumas particularidades. Estudos mais detalhados em relação a este tipo de metodologia podem ser encontrados na referência [11] assim como nas outras citadas neste item.

\subsection{Vantagens e Desvantagens do CMLP}

Uma das vantagens do CMLP, é que este considera os custos de operação e capital futuro (expansão do sistema). Há alguns que acham que o cálculo do CMLP é mais simples do que o CMCP já que este cálculo está baseado em planos de longo prazo, em conseqüência não precisando de cálculos tão freqüentes quanto o CMCP. Porém, no caso de cálculos com freqüência anual, o tratamento do CMLP precisaria de similares esforços, tanto quanto o CMCP. Ainda mais, existe a desvantagem do método ser afetado por incertezas correspondentes aos valores futuros de fatores importantes para a operação, como são o custo de combustível, crescimento da demanda e outros, que terão impacto no cálculo do CMLP. O CMLP visa ser adequado para aplicações em sistemas com geração predominantemente hidroelétrica onde existe pouca ou nenhuma dependência dos custos associados a combustíveis utilizados e outros custos variáveis. Finalmente, segundo [16], a metodologia baseada no CMLP é mais consistente do que aquela baseada diretamente no CMCP, no sentido que apresenta preços mais estáveis. 


\subsubsection{Diferença Básica entre Custo Marginal e Custo Incremental}

Segundo [85], os termos custo incremental e custo marginal referem-se basicamente ao mesmo conceito. A diferença entre estes custos é que o "custo marginal” é um conceito matemático rigoroso e pode ser calculado quando se tem disponível uma função contínua do custo, se referindo à variação do custo total quando a quantidade produzida varia em uma unidade. Já o "custo incremental" se constitui em uma "proxy" do custo marginal e se aplica ao caso discreto da expansão de uma rede elétrica, por exemplo. Nesse caso, pode ser calculado pelo quociente entre os incrementos de investimento realizados em determinado período, trazidos a uma mesma data econômica via uma taxa de desconto, pelos incrementos de mercado atendido, no mesmo período, também atualizados à mesma referência econômica através de uma taxa de desconto, "atualizando-se" MWh como se faria com unidade monetária.

\subsubsection{Metodologia Nodal}

A metodologia nodal, em uso pela Agência Nacional de Energia Elétrica (ANEEL) órgão regulador do setor elétrico no Brasil [60], foi desenvolvida juntamente com a reestruturação do sistema inglês em 1991. A tarifa nodal procura refletir a variação do custo de expansão do sistema de transmissão devido à presença de cada usuário, e pode ser caracterizada como uma aproximação ao CMLP que estima o impacto de cada usuário (gerador e carga) nos custos da rede [61].

A metodologia nodal se baseia no conceito das tarifas nodais, no qual, todos os usuários do sistema pagam encargos de uso relativos ao ponto (nó) da rede de transmissão/distribuição no qual estão conectados. Assim sendo, os encargos de uso a serem pagos por um agente de geração dependerão apenas de sua localização, independentemente de quem comprará sua energia gerada. O mesmo raciocínio aplica-se aos agentes consumidores, cuja tarifa de uso do sistema elétrico independerá da localização das centrais geradoras das quais adquirem energia.

Como esta tarifa não consegue recuperar a totalidade dos custos da rede de transmissão, existirá a necessidade de aplicar uma parcela complementar [68]. Assim, a tarifa total estará composta pelas seguintes parcelas: tarifa locacional e parcela de ajuste.

- A tarifa locacional se baseia em fatores de sensibilidade dos fluxos nas linhas em função de uma potência incremental injetada na barra. Esses fatores são obtidos através da modelagem do fluxo de potência linearizado ou fluxo CC, que constituem a chamada matriz de sensibilidade ( $\beta$ ). Os encargos resultam proporcionais ao fluxo incremental que cada agente produz em cada elemento da rede e ao custo unitário deste elemento (expresso por unidade de capacidade nominal de transporte), ou seja, a partir dos elementos da matriz $\beta$ é possível calcular os coeficientes $\pi_{j}$. Uma vez determinado um estado operativo de referência, caracterizado pelos fluxos de potência em 
cada elemento do sistema, os agentes que produzem fluxos incrementais com o mesmo sentido que os fluxos de referência deverão assumir encargos por uso, enquanto que aqueles que produzem fluxos incrementais no sentido oposto (contra fluxo) ao de referência recebem créditos pelo uso desse determinado componente da rede. A tarifa locacional $\pi$ para cada barra $j$ do sistema é calculado a partir de (2.12).

$\pi_{j}=\sum_{j=1}^{N_{j}} \frac{C_{j}}{\overline{f_{j}}} \times \beta_{j i}$

onde,

$\pi_{j}:$ Tarifa nodal do nó $j$

$C_{j}$ : Custo do circuito $j$

$f_{i}$ : Capacidade de circuito $j$

$N_{j}$ : Número total de circuitos

$\beta_{j i}$ : Variação de fluxo no circuito $j$ devido á injeção de 1 pu no nó $i$

- A parcela de ajuste é aplicada a todos os agentes para recuperar os encargos necessários e assim poder remunerar à rede de transmissão. Esta parcela de ajuste é calculada a partir de (2.13)

$\Delta=\frac{R A P-\sum_{j=1}^{N j} \pi_{j} \times g_{j}}{\sum_{j=1}^{N} g_{j}}$

onde,

$R A P$ : Receita Anual Permitida para a transmissão

$g_{j} \quad$ : Potencia contratada no nó $j$

$\Delta$ : Parcela de Ajuste

\subsubsection{Metodologias para o Cálculo da Parcela Complementar (Pedágio)}

O uso do custo marginal mostrou-se como uma das metodologias mais utilizadas não só nos países analisados mas também em vários outros do mundo. Ele tem a propriedade de direcionar aos investidores a minimizar os custos e produção de energia elétrica assim como a expansão da rede. Porém, algumas limitações foram observadas, entre elas: a remuneração apenas parcial dos custos da rede de transmissão, sendo necessária a aplicação de uma parcela complementar. Para o cálculo desta parcela complementar foram propostas algumas metodologias destacando-se as seguintes:

- Esquema de preços Ramsey. Este método proposto por P. Ramsey [19], tenta compensar a receita obtida mediante os custos marginais, através da alteração dos mesmos, utilizando para isso termos aditivos ou multiplicativos. Os custos marginais são modificados atendendo à elasticidade de cada demanda, de forma que o comportamento ótimo não seja alterado. Como resultado, incrementam-se os preços das demandas mais inelásticas e mantêm-se inalteradas as demandas mais elásticas.

Este procedimento possui a desvantagem de precisar informações muito completas o que normalmente não é fácil de se obter. Isto complica a aplicação deste método. Por outro lado, 
o método pode resultar discriminatório para os usuários, já que aqueles consumidores que possuam uma menor sensibilidade ao preço (menor elasticidade), teriam que suportar o maior peso de correção dos custos marginais.

- Esquema Baseado em uma Medida Independente. Consiste no uso de uma medida independente (por exemplo, a potência firme, a potência média ou a capacidade instalada de geração) sobre a qual é rateada a parcela adicional. Este método é equivalente ao método do tipo selo, no qual calcula-se um fator através do qual se obtém a proporção em que será distribuído o pedágio (pagamento complementar) entre os geradores e/ou consumidores.

Uma das vantagens deste método seria a simplicidade de seu cálculo [21]. Porém, a ausência de uma discriminação geográfica não permite dar sinais adequados de localização e, conseqüentemente, não dá sinais de eficiência de custos sobre os geradores participantes do sistema.

- Rateio por Potência Firme. Neste método a parcela adicional é distribuída entre os geradores do sistema em proporção a sua potência firme. A potência firme é definida como aquela que pode fornecer uma unidade geradora nas horas de ponta com elevada segurança. Este método é utilizado no Peru.

Para ratear o encargo adicional com base na potência firme, estima-se um fator pelo qual se deverá multiplicar o pedágio. Este fator está expresso conforme a seguinte equação:

$$
F_{j}=\frac{{\text { Pot } . \text { Firme }_{j}}_{\text {Pot }_{\text {Firme }}}}{\sum_{i} \text { Pon }}
$$

onde,

$i$ : Qualquer unidade geradora no sistema

$j:$ Unidade geradora

- Rateio por Capacidade Instalada de Geração: De forma similar ao anterior neste método considera-se uma medida independente como é a capacidade instalada de geração, assim estima-se um fator que permite distribuir proporcionalmente o pagamento adicional entre os geradores do sistema. Este fator é calculado segundo a equação (2.15).

$G_{j}=\frac{\text { CapacidadeInstaladaGerador }_{j}}{\sum_{i} \text { CapacidadeInstaladaGerador }_{i}}$ 


\section{- Esquemas Baseados no Uso do Sistema (Áreas de Influência)}

Este outro esquema de alocação, baseado no uso natural econômico do sistema, identifica as solicitações impostas sobre as instalações de transmissão. Por outro lado, o esquema fornece sinais da necessidade de expansão do sistema, que deve ser considerado pelos geradores e consumidores no momento da tomada de decisões de localização. A seguir apresentam-se os principais métodos utilizados para estimar o uso do sistema pelos agentes participantes:

Áreas de Influência. O método das áreas de influência é um dos mais utilizados para alocar a chamada parcela complementar [19], [22]. Este método é utilizado nos sistemas elétricos da Argentina e Chile [16], porém com diversas variantes. No caso do Chile, a legislação elétrica define a área de influência "como o conjunto de instalações do sistema elétrico, direta e necessariamente afetados pela injeção de potência e energia de uma usina geradora" (DFL1). A área de influência é determinada considerando os tramos do sistema nos quais ocorrem incrementos ou reduções dos seus fluxos de potência diante de incrementos ou diminuições oriundas da potência injetada por um determinado gerador. O pedágio ou parcela de ajuste que pagam os agentes do sistema, no caso chileno é igual a:

$P d g=V N R+C O E M-R T$

onde,

VNR : Valor Novo de Reposição

COEM: Custo de Operação e Manutenção

$R T$ : Receita Tarifaria

Caso as instalações sendo utilizadas estejam dentro da área de influência, os geradores deverão pagar um pedágio básico pelo uso destas, o qual é independente do local e da quantidade de potência e energia comercializadas. Este pedágio é distribuído entre os usuários das instalações em proporção à potência máxima transmitida (2.17):

$\%$ Participacao $_{i, j}=\frac{\text { Pot.MaxTransmitida }}{i, j}$

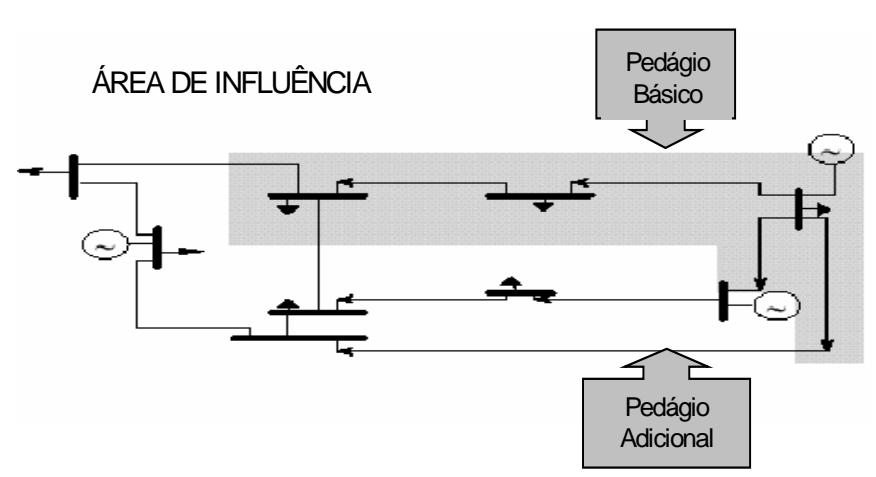

Figura 2.4 Exemplo do uso da área de influência 
Caso um gerador comercialize energia fora da sua área de influência, este deverá pagar um pedágio adicional pelo uso das instalações adicionais o qual é calculado da mesma forma que o pedágio básico.

ii) Fatores de Distribuição. Este método está baseado na análise tradicional de segurança e contingências do sistema elétrico, os quais levam em conta a configuração da rede. Procura-se obter índices do uso da rede baseados na sua configuração, podendo ser analisada através de: Fatores de Distribuição de Variações na Injeção de Potência (GSDF), Fatores de Distribuição Generalizados de Geração (GGDF) e os Fatores de Distribuição de Carga (GLDF).

\subsubsection{Método Baseado na Teoria de Jogos}

Vários autores têm formulado modelos utilizando a Teoria de Jogos para representar as condições de funcionamento dos sistemas elétricos no ambiente de mercado [23], [24] e [25]. Esta metodologia procura identificar, através do estudo de equilíbrios utilizado na teoria de jogos, o benefício que os agentes obtêm do sistema. Na teoria de jogos é possível classificar um determinado problema, neste caso a alocação de custos, em dois grandes grupos: os jogos cooperativos e os jogos não cooperativos [26].

A diferença entre estes tipos de jogos é que nos jogos não cooperativos não está permitida a formação de coalizões sendo a mais indicada para enfrentar situações derivadas da concorrência. Nos jogos cooperativos está permitida a formação de coalizões sendo uma das aplicações a solução de problemas de alocação de custos na transmissão.

O método pode ser aplicado tanto para o cálculo do custo total de transmissão quanto para o calculo da parcela complementar (pedágio) dentro do esquema de custo marginal. Outras aplicações correspondem à construção de circuitos, aquisição de recursos auxiliares, faixas de passagem, etc, necessários para transportar a energia gerada até a demanda, o que ocorre de maneira compartilhada por um conjunto de agentes.

Pela sua vez, dentro da teoria de jogos "cooperativos" têm sido propostas diversas metodologias, por exemplo: o valor de Shapley, do Núcleo, de Aumann-Shapley, etc. Informações mais detalhadas a respeito destes métodos podem ser encontradas na referência [58].

Segundo a literatura consultada, um jogo cooperativo está formado por um conjunto de $N$ jogadores que se unem para formar coalizões com o objetivo de maximizar ou minimizar uma função característica. Pela sua vez, esta função característica fornece o custo total a cada uma das coalizões (agentes do sistema). Os jogadores podem se agrupar de diferentes formas segundo os seus interesses e conveniência. As coalizões são mutuamente exclusivas, ou seja, formada uma coalizão S não haverá 
possibilidade de seus participantes fazerem acordos com outros participantes fora da coalizão. $\mathrm{O}$ objetivo principal consiste em que os agentes que fazem uso do sistema de transmissão sejam alocados com custos que possuam características de equidade, racionalidade eficiência e estabilidade [26].

Como premissa básica, esta metodologia pressupõe o comportamento racional dos jogadores, o qual é discutível. Além de uma considerável informação para sua aplicação, como por exemplo: identificação das transações no sistema, e outros, podem ser necessários recursos computacionais relativamente complexos para o cálculo de fluxos de potência desta seção (Cfr. [58], para maior informação a respeito destes e outros aspectos). 


\section{CAPITULO III}

\section{CARACTERÍSTICAS E ESQUEMAS TARIFÁRIOS UTILIZADOS NO SEGMENTO DA TRANSMISSÃO PARA OS PAISES SELECIONADOS}

Neste capítulo serão apresentadas as principais características dos sistemas de transmissão, as estruturas tarifarias, os órgãos regulatórios bem como as políticas de expansão da rede da Argentina, Bolívia, Brasil, Chile e Peru.

\subsection{ARGENTINA}

A Argentina na atualidade comercializa energia com o Brasil e com Chile. Possui dois mercados atacadistas associados a dois sistemas interconectados que ainda permanecem isolados um do outro, sendo estes [27]:

- O SADI (Sistema Argentino de Interconexão) que atende boa parte do país exceto a região da Patagônia. O SADI é o principal ator do MEM (Mercado Elétrico Atacadista).

- O MEMSP (Mercado Elétrico Atacadista do Sistema da Patagônia), que fornece energia à região da Patagônia, exceto o extremo sul do país.

Ambos os mercados operam com regras de funcionamento similares. Porém os preços são diferentes em função das condições particulares de oferta e demanda de cada mercado. Segundo os dados do ENRE (Ente Regulador de Eletricidade), no ano 2006, a Argentina possuía uma capacidade instalada de 24029 MW, distribuída da seguinte forma: a geração hidrelétrica representava 42\%, a termoelétrica $54 \%$ e a nuclear $4 \%$. Conforme mostrado na Tabela 3.1, em Dezembro de 2004, existiam mais de 40 usinas geradoras (agentes do mercado) que participam do mercado Argentino.

Tabela 3.1 Evolução do número de Agentes participantes no MEM Argentino

\begin{tabular}{|c|c|c|c|c|c|c|c|c|c|c|c|c|}
\hline & $\begin{array}{c}\text { Dez } \\
93 \\
\end{array}$ & $\begin{array}{c}\text { Dez } \\
94 \\
\end{array}$ & $\begin{array}{c}\text { Dez } \\
95 \\
\end{array}$ & $\begin{array}{c}\text { Dez } \\
96 \\
\end{array}$ & $\begin{array}{c}\text { Dez } \\
97 \\
\end{array}$ & $\begin{array}{c}\text { Dez } \\
98 \\
\end{array}$ & $\begin{array}{c}\text { Dez } \\
99 \\
\end{array}$ & $\begin{array}{c}\text { Dez } \\
\text { 00 }\end{array}$ & $\begin{array}{c}\text { Dez } \\
01\end{array}$ & $\begin{array}{c}\text { Dez } \\
02 \\
\end{array}$ & $\begin{array}{c}\text { Dez } \\
03\end{array}$ & $\begin{array}{c}\text { Dez } \\
04\end{array}$ \\
\hline Autoprodutores & 2 & 5 & 9 & 9 & 11 & 12 & 12 & 13 & 12 & 13 & 14 & 14 \\
\hline Grandes Usuario Mayores & 18 & 80 & 208 & 265 & 350 & 392 & 409 & 397 & 384 & 322 & 300 & 308 \\
\hline Grandes Usuarios Particulares & -- & -- & -- & -- & -- & -- & 26 & 58 & 51 & 57 & 32 & 30 \\
\hline Transmisores AT/DT y PAFTT & 7 & 14 & 21 & 21 & 25 & 30 & 47 & 58 & 62 & 66 & 61 & 62 \\
\hline Distribuidores & 26 & 25 & 26 & 28 & 31 & 31 & 50 & 57 & 61 & 66 & 65 & 65 \\
\hline Cogeradoras & $\begin{array}{ll}- \\
\end{array}$ & -- & $\begin{array}{ll}-- \\
\end{array}$ & -- & 2 & 3 & 3 & 3 & 3 & 3 & 3 & 3 \\
\hline Comercializadores & -- & -- & $\begin{array}{ll}-- \\
\end{array}$ & -- & -- & 1 & 2 & 3 & 4 & 4 & 4 & 5 \\
\hline PAFTT não Agentes & $\begin{array}{ll}-- \\
\end{array}$ & -- & 11 & 16 & 20 & 30 & 25 & 26 & 31 & 38 & 26 & 29 \\
\hline TOTAL & 76 & 155 & 519 & 841 & 1280 & 2045 & 2166 & 2096 & 2486 & 2570 & 1585 & 1745 \\
\hline
\end{tabular}

Fonte: CAMMESA

Conforme mencionado em [27], a quantidade de agentes que participam no MEM, tanto no lado da oferta quanto da demanda, foi aumentando após a reestruturação do setor. A determinação do preço no mercado atacadista é realizada de forma horária e a partir do custo marginal. Assim, o preço da energia no mercado spot fica disponível a cada hora. O preço da eletricidade em cada nó vinculado ao 
mercado é igual ao preço no mercado menos o valor das perdas marginais devidas ao transporte da energia [28].

\subsubsection{A Transformação do Setor Elétrico Argentino}

Como aconteceu na maioria dos países, a reestruturação do setor elétrico propôs melhorar a eficiência produtiva através da competição promovendo a participação do capital privado e protegendo os interesses dos usuários. Esse processo de transformação foi efetuado no período 1992-1993 resultando na desintegração do anterior sistema elétrico vertical para o novo sistema desverticalizado.

\section{a) Legislação Elétrica}

No Quadro 3.1 são apresentadas as principais leis que promoveram o processo de desverticalização na Argentina:

Quadro 3.1 Principais normas e regulamentos no setor elétrico Argentino

\begin{tabular}{|l|l|}
\hline \multicolumn{1}{|c|}{ Lei/ Decreto } & \multicolumn{1}{c|}{ Descrição } \\
\hline Lei 24065/ 1991 & Regime da Energia Elétrica: Livre acesso \\
\hline Decreto 1398/1992 & Regulamento da lei 24065 \\
\hline
\end{tabular}

Entre os objetivos básicos estabelecidos na Lei 24065/ 1991 (Art. 2), estão:

- Proteção de direitos dos usuários.

- Promover a competitividade dos mercados de produção e demanda de energia elétrica e incentivar os investimentos e assim assegurar o fornecimento de longo prazo.

- Promover a operação, confiabilidade, igualdade e livre acesso e uso dos serviços e instalações de transporte e distribuição de eletricidade.

- Regulamentar as atividades de transporte e administração da eletricidade, garantindo que as tarifas aplicadas aos serviços sejam justas e razoáveis.

- Incentivar o fornecimento, transporte, distribuição e uso eficiente da eletricidade, fixando uma metodologia tarifária apropriada.

- Fomentar os investimentos privados da produção, transporte e distribuição de energia elétrica, garantindo a competitividade dos mercados.

\section{b) Organização Institucional do Sistema Elétrico}

Antes da promulgação das leis No 24065 e No 15336 que hoje fazem parte do "Marco Regulatório Elétrico", o setor se encontrava estruturado através de um esquema de integração vertical, ou seja, as empresas integradas verticalmente eram responsáveis de todas as atividades da indústria elétrica (geração, transporte e distribuição). Resultado da promulgação destas leis foram criadas as seguintes instituições (Figura 3.1):

- Secretaria de Energia. Segundo o Art. 36 da Lei 15336, a função desta secretaria é a de definir políticas para o setor e supervisionar seu cumprimento, outorgar o reconhecimento de 
Agentes do MEM (Mercado Elétrico Atacadista), autorizar as Ampliações da Rede segundo o Art. 31 da lei 24065 .

- Ente Regulador da Eletricidade (ENRE). Tem por função regular as atividades da transmissão e a distribuição da eletricidade. O ENRE tem também a função de proteger aos usuários, bem como promover a competitividade dos mercados de geração e demanda de eletricidade (Art.54 da Lei 24065/1991). Por outro lado, é responsável pela emissão de regulamentações relacionadas a normas e procedimentos técnicos, medição e faturação, controle e uso de medidores, qualidade do serviço, estabelecimento das bases para o cálculo de tarifas; aplicar punições e outras.

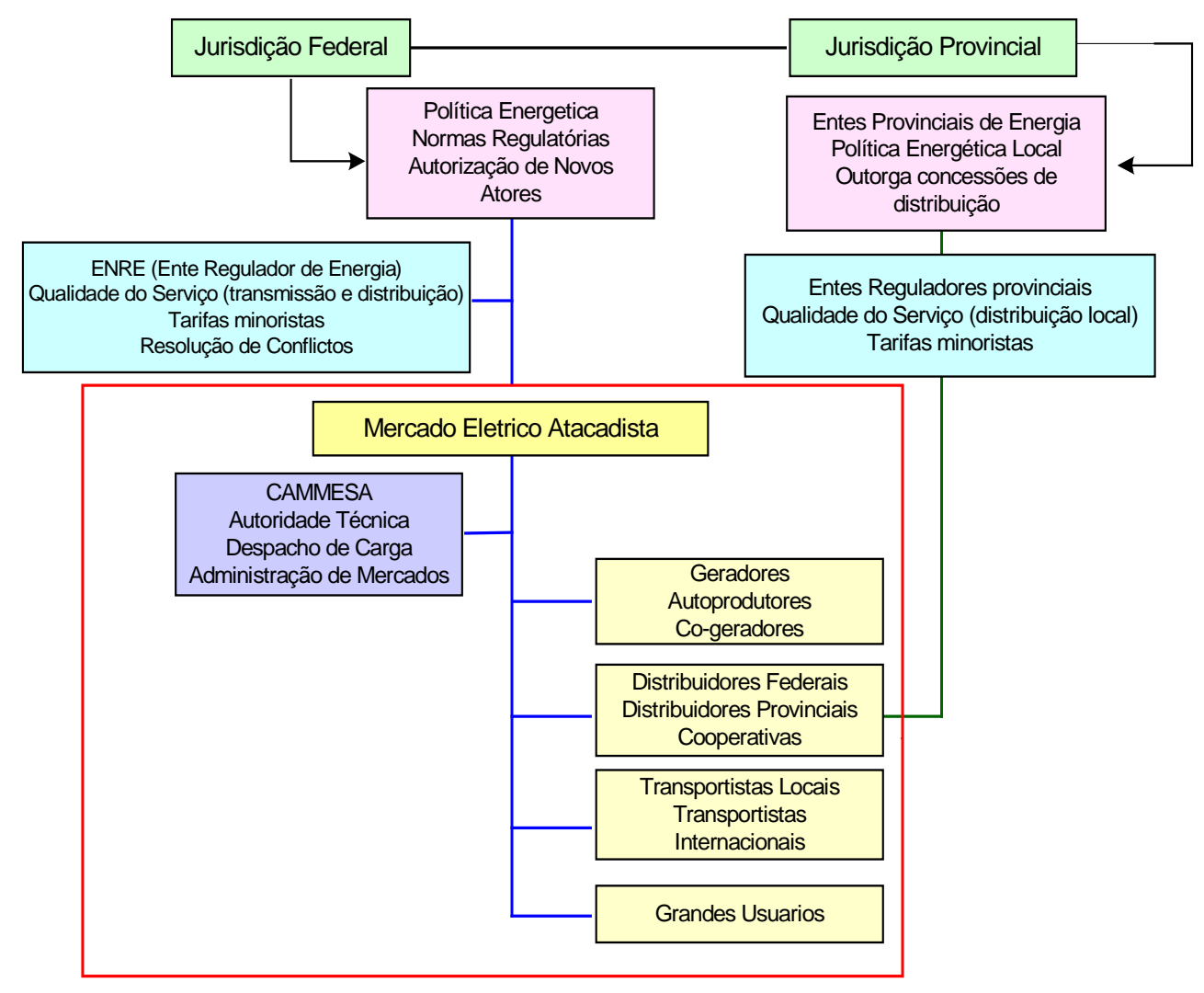

Fonte: CEPAL

Figura 3.1 Organização institucional do sistema elétrico Argentino

- Companhia Administradora do Mercado Atacadista de Eletricidade (CAMMESA). Responsável pelo despacho de energia no SADI (Sistema Argentino de Interconexão). É também responsável de supervisionar as atividades do DNDC (Despacho Nacional de Cargas), órgão constituído sob a forma de uma sociedade anônima.

\subsubsection{A Atividade da Transmissão}

A Lei 24065, no seu Art. 22 estabelece o principio de livre acesso à rede de transmissão. A rede de alta tensão (com linhas de $500 \mathrm{kV}$ ) é considerada como um serviço público pela legislação e seus preços 
de energia são determinados pelo MEM. Já no Sistema Elétrico da Patagônia (MEMSP), o preço é determinado dentro de sua própria rede. A rede de alta tensão foi concedida a uma única empresa (TRANSENER com aproximadamente $8.800 \mathrm{~km}$ ).

\section{a) Tensões do sistema de transmissão}

Conforme apresentado na Tabela 3.2, a transmissão em alta tensão entre as distintas regiões é realizada por linhas de $500 \mathrm{kV}, 400 \mathrm{kV} 132 \mathrm{kV}$.

Tabela 3.2 Níveis de tensão e comprimento $(\mathrm{km})$ das linhas no sistema Argentino

\begin{tabular}{|l|r|r|r|r|}
\hline \multicolumn{1}{|c|}{ Sistema de Transmissão } & 500kV & 220kV & 132kV & \multicolumn{1}{c|}{ TOTAL } \\
\hline \hline Comprimento AT & 9101 & 562 & 6 & $\mathbf{9 6 6 9}$ \\
\hline Região Cuyo & & 634 & 611 & $\mathbf{1 2 4 5}$ \\
\hline Região Comahue & & & 929 & $\mathbf{9 2 9}$ \\
\hline Região Buenos Aires & & 177 & 5419 & $\mathbf{5 5 9 6}$ \\
\hline Região NEA & & 30 & 1022 & $\mathbf{1 0 5 2}$ \\
\hline Região NOA & & & 3234 & $\mathbf{3 2 3 4}$ \\
\hline \hline Distribuição Principal (regional) & & 841 & 11215 & $\mathbf{1 2 0 5 6}$ \\
\hline
\end{tabular}

\section{b) Concessionárias de Transmissão}

$\mathrm{Na}$ Argentina a função da transmissão foi concedida a dois tipos de concessionárias:

- A primeira (TRANSENER S.A.) administra a rede principal em alta tensão (linhas de 500 $\mathrm{kV})$.

- Seis concessionárias regionais (Figura. 3.2) com tensões na faixa de $132 \mathrm{kV} \leq$ Tensão $\leq 400 \mathrm{kV}$, sendo elas: a Empresa de Transporte de Energia Elétrica por distribuição Troncal da Província de Buenos Aires (TRANSBA S.A.), Empresa de Distribuição Troncal de Cuyo S.A. (DISTROCUYO S.A.), Empresa de Transporte de Energia Elétrica por Distribuição Troncal do Noroeste Argentino S.A. (TRANSNOA S.A.), Empresa por Distribuição Troncal do Nordeste Argentino (TRANSNEA S.A.) a Empresa de Distribuição Troncal de COMAHUE e a Empresa de Distribuição Troncal da Região da Patagônia (TRANSPA S.A.).

\section{c) Método Base de Tarifação}

A metodologia adotada na Argentina está baseada em custos marginais de curto prazo e com encargos por conexão. 

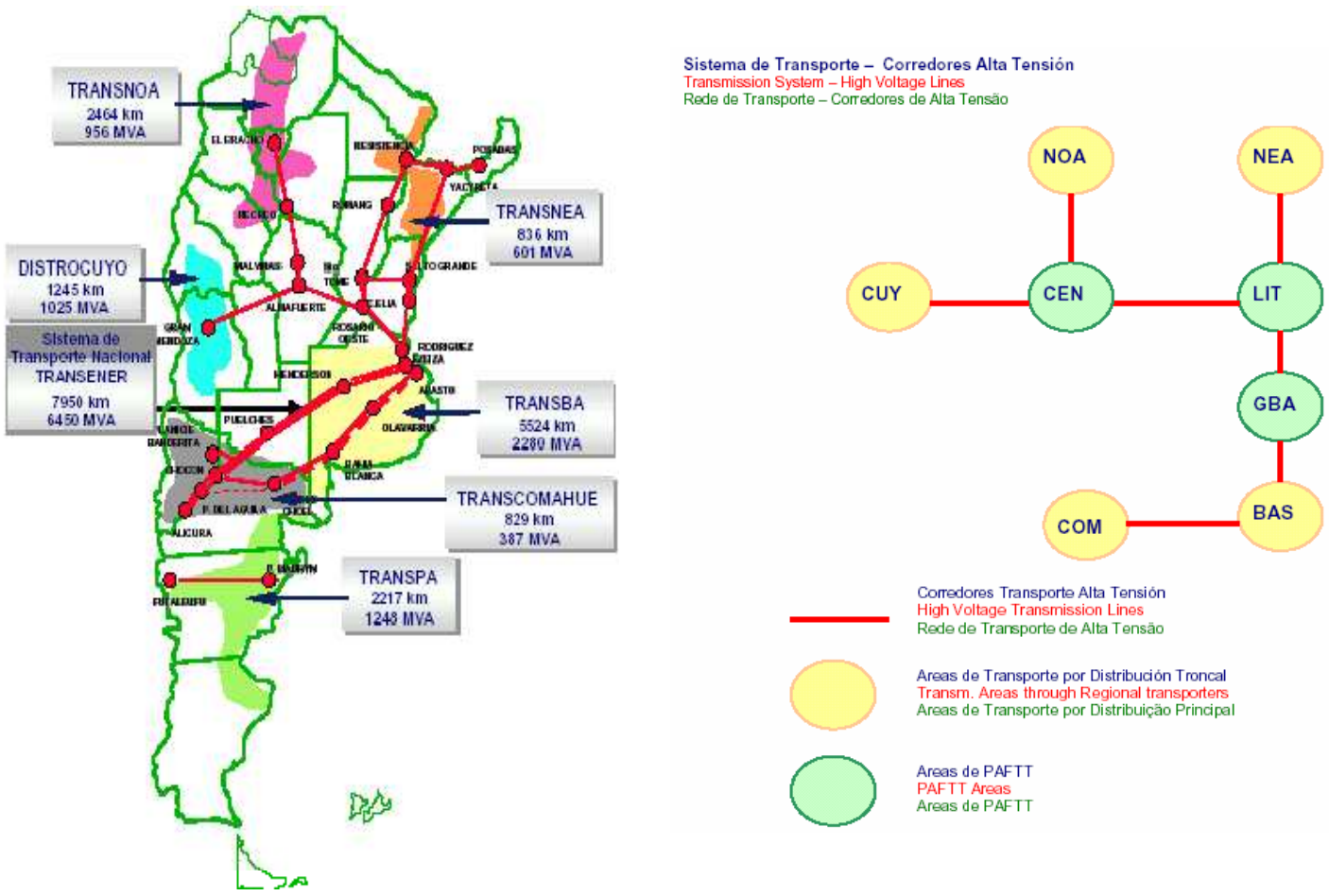

Fonte: ENRE

Figura 3.2 Empresas de transmissão na Argentina

\subsubsection{Regulamentação dos Preços da Transmissão}

A Lei 24065 Art. 22 estabelece que as tarifas aplicadas no serviço de transmissão deverão oferecer aos transportadores, que operem de forma econômica, a oportunidade de obter receitas suficientes para satisfazer os custos operativos aplicáveis ao serviço destes. Os contratos de concessão aos transportadores deverão incluir um quadro tarifário inicial que será válido por um período de cinco (5) anos (Lei 24065 Art. 42).

\subsubsection{Mecanismo de Remuneração}

As concessionárias de transmissão perceberão as seguintes receitas, a partir das distintas remunerações estabelecidas na legislação (Art. 36 da Lei $\mathrm{N}^{\circ} 24.065$ ), [29].

- Remuneração por Energia Elétrica Transportada (REET). Quantia fixa anual estabelecida para um período de cinco anos a serem pagos em doze (12) quotas mensais iguais, que deve corresponder à média do valor das perdas da energia transportada.

- Remuneração por Capacidade de Transporte (RCT). É um encargo que reflete os custos de operação e manutenção do sistema de transmissão (alta tensão). Este encargo é definido pela Secretaria de Energia durante a programação sazonal sobre as bases dos importes estabelecidos no contrato de concessão da TRANSENER. Os usuários do sistema em questão serão os que contribuam com a remuneração deste conceito. 
- Remuneração por Conexão $(\mathbf{R C})$. Esta remuneração é paga pelos serviços de conexão à rede oferecida aos usuários. Este encargo também é definido pela Secretaria de Energia durante a programação sazonal sobre a base dos importes estabelecidos no contrato de concessão da TRANSENER.

\subsubsection{Mecanismo de Arrecadação}

Para o recebimento dos recursos necessários para a cobertura das remunerações recorre-se a:

i) Arrecadação ${ }^{7}$ Variável Total por Energia Elétrica Transportada (RVT). Esta arrecadação surge da soma da Arrecadação Variável Total por Transporte de Energia $(R V T E)$ e à Arrecadação Variável por Potência Vinculada (RVTP).

$R V T=R V T E+R V T P$

onde,

(RVTE): Arrecadação Variável Total por transporte de Energia que corresponde à diferença entre o valor da energia no nó de despacho e de injeção. Os preços nos distintos nós são definidos segundo o valor marginal das perdas originadas na transmissão. Este encargo é equivalente à Receita Tarifária de Energia em outros países.

(RVTP): Arrecadação Variável por Potência Vinculada que corresponde à diferença entre a montante que pagam por potência os consumidores do Mercado Elétrico Atacadista (MEM) e o que foi orçamentado na programação sazonal que devem obter os geradores pela venda de potência.

O cálculo do RVTE esta dada a partir da seguinte equação (3.2):

$$
R V T E L_{i}=P N_{n r} * E_{n r}-P N_{n e} * E_{n e}
$$

onde, $P N$ é igual a:

$$
P N=P M * F N
$$

onde,

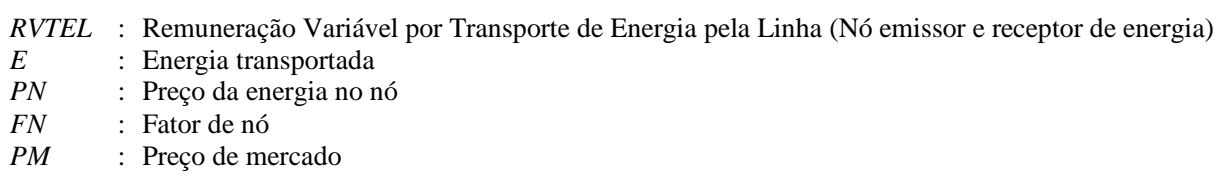

Por tanto, a arrecadação variável total por transporte de energia é:

$$
R V T E=\sum_{I} R V T E L_{i}
$$

O cálculo do $R V T P$ está dado por:

$$
R V T P=P D G U-P G E N
$$

onde,

$P D G U$ : Pagamento mensal por potência dos distribuidores, geradores e usuários.

$P G E N$ : Pagamento previsto na programação sazonal aos geradores para sua venda de potência

\footnotetext{
${ }^{7}$ Arrecadação: Recaudación (em Espanhol)
} 
ii) Encargos por Conexão. Estes encargos provêm dos custos dos equipamentos de conexão e transformação, necessários para conectar os usuários à rede de transmissão. Este encargo é rateado entre os usuários segundo a sua potência máxima requerida.

iii) Encargos Complementares. Caso a remuneração por energia elétrica transportada (REET) mais a remuneração por capacidade de transporte $(R C T)$ seja maior do que a Arrecadação Variável Total $(R V T)$ pela energia transportada, a diferença será financiada através de encargos complementares que serão rateados entre os usuários segundo o uso que fazem das linhas.

Na Figura 3.3 apresenta-se um resumo da forma de remuneração da transmissão na Argentina.
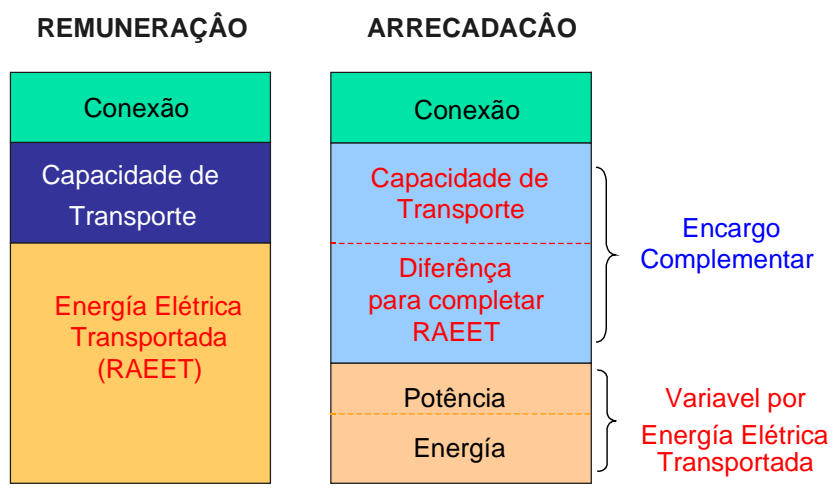

Figura 3.3 Resumo da forma de remuneração da transmissão na Argentina.

\subsubsection{Qualidade de Serviço do Sistema de Transmissão}

Quanto às disposições sobre a qualidade do serviço, o Anexo 16 de CAMMESA (Regime de Qualidade de Serviços e Punições do Sistema de Transmissão -TRANSENER S.A.) estabelece que as saídas de serviço e indisponibilidade da rede serão penalizadas. As sanções que forem aplicadas à concessionária serão depois remuneradas aos usuários do sistema de transmissão (geradores, distribuidores ou grandes usuários). A concessionária de transmissão não poderá ser penalizada por um montante anual maior ou igual a $10 \%$ da sua receita total anual, e tampouco por um valor mensal maior a $50 \%$ da sua receita total mensal.

\subsubsection{Expansão da Rede de Transmissão}

\subsubsection{Expansão da Rede Local}

$\mathrm{Na}$ Argentina as ampliações do sistema de transmissão são responsabilidade dos agentes do Mercado Elétrico Atacadista (MEM) [29], assim existiria um planejamento do tipo descentralizado. Um agente do MEM que precise materializar ou melhorar sua conexão ao sistema de transmissão em alta tensão deve apresentar à concessionária de transmissão (TRANSENER) uma solicitação de Acesso e Ampliação, segundo estabelecido no 
Regulamento de Conexão e Uso e o Regulamento de Acesso à Capacidade Existente e Ampliação do Sistema de Transmissão. Estes regulamentos podem ser encontrados no Anexo 16 dos "Procedimentos para a Programação da Operação, Despacho de Cargas e o Cálculo de preços" publicados pela CAMMESA. A construção da ampliação solicitada deve seguir como base algum dos mecanismos estabelecidos, sendo estes:
○ Concurso Público
- Contrato entre Partes
○ Concurso Aberto.
○ Ampliação Menor

- Concurso público. Este procedimento (Figura. 3.4) tem como objetivo viabilizar aquelas ampliações de grande porte que geram benefícios a uma região elétrica ou ao sistema como um todo. Este procedimento deverá também ser aprovado pelo ENRE e por mais do $70 \%$ dos beneficiários. A construção destas linhas, licitada publicamente, é financiada através de um montante estabelecido e compartilhado por todos os beneficiários, como também por uma parcela das receitas resultantes das linhas já existentes. Segundo a TRANSENER, por exemplo, em Audiência Pública, um grupo de terceiros, que não esteja interessado na ampliação da rede, poder-se-ia opor à mesma na hipótese de que sua porcentagem de benefícios seja maior ou igual a $30 \%$. A construção, operação e manutenção da ampliação é outorgada a uma concessionária independente que apresente a melhor oferta no concurso público.

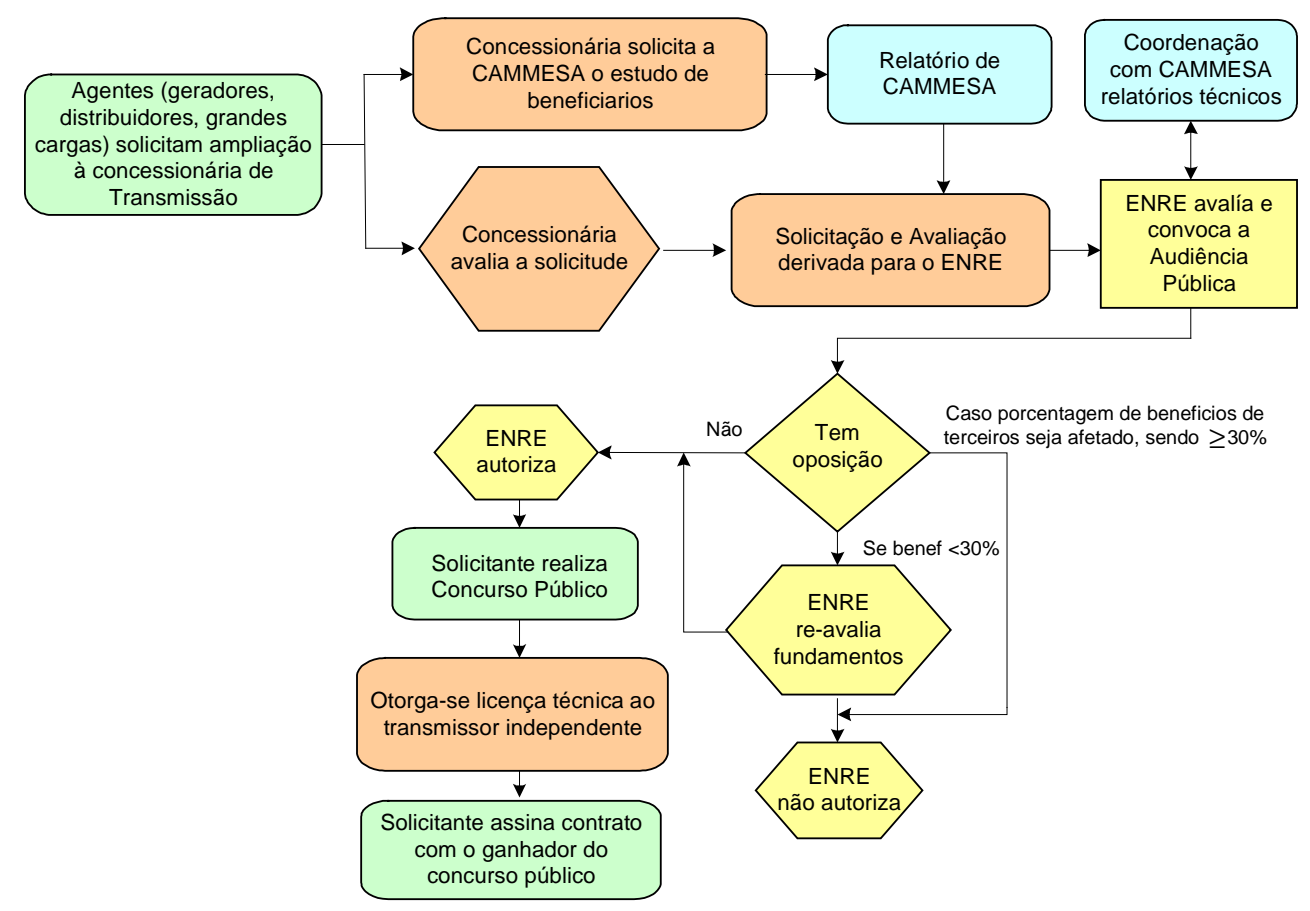

Figura 3.4 Procedimento de expansão através de concurso público (fonte: TRANSENER) 
- Contrato entre partes. Esta alternativa requer também da aprovação do ENRE e por 100\% dos beneficiários (Figura. 3.5). O financiamento é de responsabilidade das partes envolvidas. Já sua construção poderá ser conveniada entre as partes; isto devido à inexistência de uma parcela compartilhada pelos usuários.

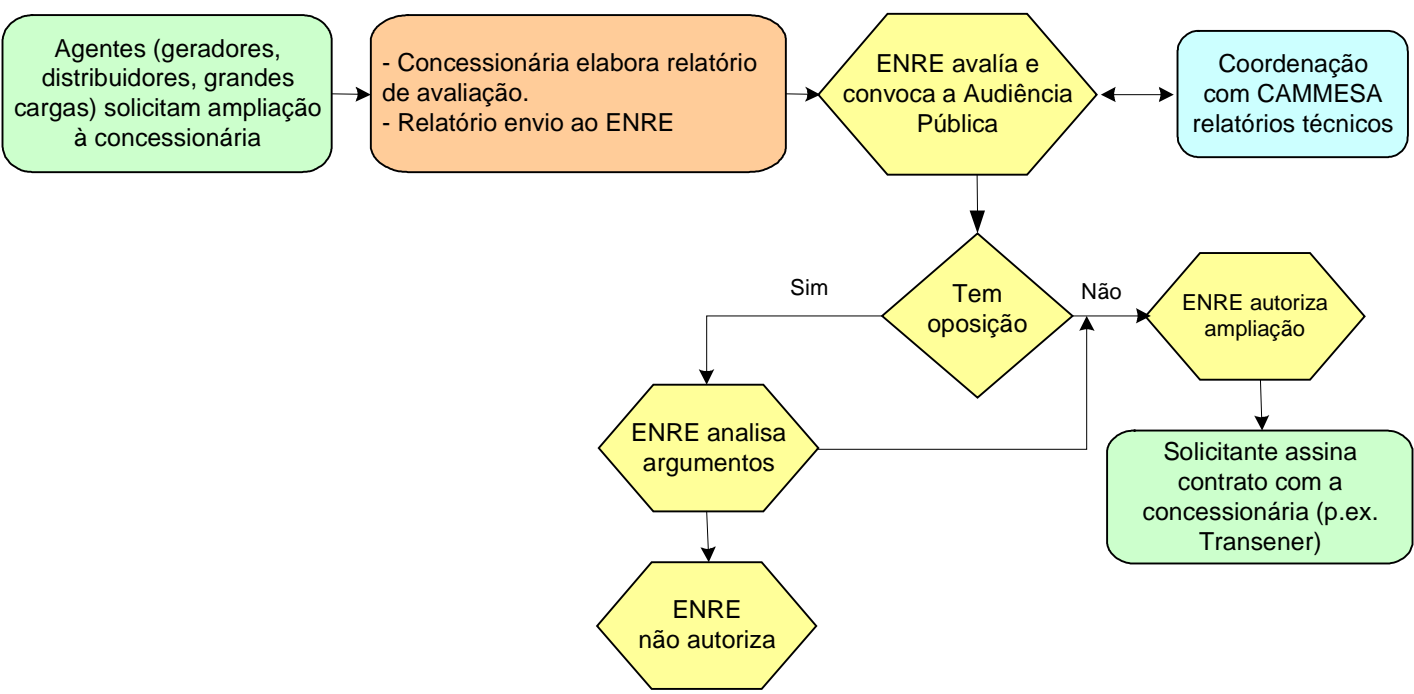

Figura 3.5 Procedimento de expansão através de contrato entre partes (fonte: TRANSENER)

- Concurso Aberto. Este procedimento é aplicável à construção de novas linhas e estações transformadoras no Sistema de Transmissão Elétrica em Alta Tensão. Permite aos interessados realizar uma determinada ampliação, estabelecer a participação que cada um terá no financiamento do projeto. Definido quem pagará a ampliação, não é permitido transferir os custos de amortização aos usuários existentes que façam uso das novas instalações, porém os investidores adquirem os direitos de congestão e perdas das instalações que se efetuem. A construção da expansão poderá ser feita através de algum dos seguintes procedimentos:

- Acordo entre partes

- Concurso público

- Ampliação por alocação de direitos financeiros

Este procedimento requer a realização de uma Audiência Pública a fim de se considerar os aspectos ambientais e verificar o impacto da ampliação sobre a qualidade no SADI (Sistema Argentino de Interconexão).

- Ampliações Menores. Consideram-se ampliações menores aquelas que não superam os US\$. 600 mil. Estes investimentos são realizados pela concessionária de transmissão e financiados pelos beneficiários diretos da ampliação, os quais estabelecem um contrato entre partes, ou entre os distintos beneficiários, segundo as proporções que determine o ENRE. Na Figura 3.6, retirada do site da TRANSENER, mostra-se a seqüência seguida 
pelos agentes interessados pela ampliação até a outorga do contrato à empresa que desenvolverá a ampliação.

- Para as ampliações de maior valor a legislação contempla dois regimes: o Contrato entre partes e o Concurso Público.

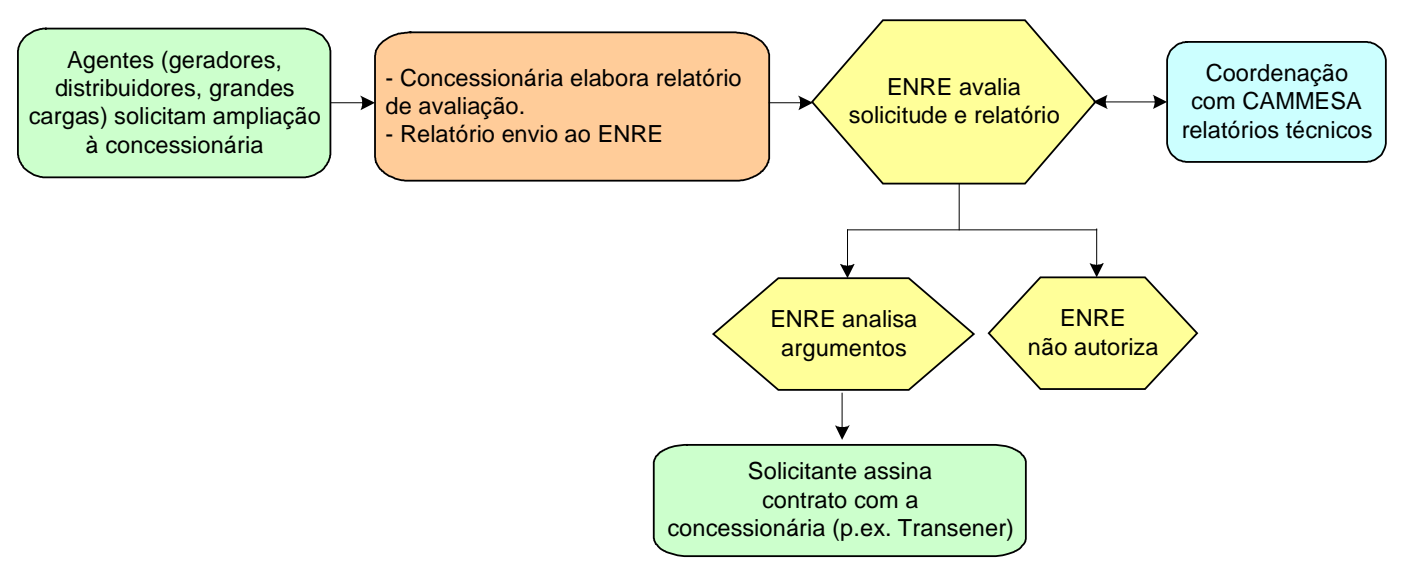

Figura 3.6 Procedimento de expansão para Ampliações Menores (fonte: TRANSENER)

\subsubsection{Expansão das Conexões Internacionais}

A importação de energia é tratada de forma similar a um gerador que adiciona energia ao MEM, assim esta deverá pagar os respectivos encargos de transmissão. A exportação é considerada como uma demanda agregada ao MEM na fronteira, e deverá pagar os respectivos encargos de transmissão incluindo as perdas. No referente às integrações subregionais a Argentina tem o seguinte marco jurídico:

- Segundo a Lei 24065 (Art. 34), a importação e exportação de energia elétrica deverão ser previamente autorizadas pela Secretaria de Energia dependente do Ministério de Economia, Obras e Serviços públicos.

- No Decreto $N^{0}$ 2473/1992, está definido o regulamento para o acesso à capacidade existente, de conexão e uso do sistema.

- Na Resolução 21/1997 (Secretaria de Energia) regulamenta-se o processo para solicitar a concessão de transporte de energia elétrica para interconexões internacionais.

\subsection{BOLÍVIA}

A oferta de eletricidade na Bolívia está baseada em centrais de geração hidrelétrica e termoelétrica. A potência instalada ao nível nacional a Dezembro de 2006 foi de 1432 MW. A produção de eletricidade no SIN, oferecida no Mercado Elétrico Atacadista, é realizada pelas empresas Corani, Guaracachi, Valle Hermoso, COBEE, Rio Elétrico, Hidroelétrica Boliviana, SYNERGIA e CECBB. Em 2006, a 
potência instalada no SIN foi de 1183 MW equivalente a $83 \%$ da potência instalada total. Na Tabela 3.3 mostra-se a composição da potência instalada no SIN, bem como nos sistemas isolados.

Tabela 3.3 Potência instalada no SIN e sistemas isolados na Bolívia

\begin{tabular}{|c|c|c|c|c|c|c|}
\hline \multirow{2}{*}{ Empresa } & \multicolumn{2}{|c|}{ Hidrelétrica } & \multicolumn{2}{|c|}{ Termoelétrica } & \multicolumn{2}{|c|}{ TOTAL } \\
\hline & MVA & MW & MVA & MW & MVA & MW \\
\hline \multicolumn{7}{|c|}{ SISTEMA INTERCONECTADO NACIONAL } \\
\hline CORANI & 173,70 & 147,30 & & & 173,70 & 147,30 \\
\hline EGSA & & & 428,71 & 354,59 & 428,71 & 354,59 \\
\hline EVH & & & 257,30 & 222,25 & 257,30 & 222,25 \\
\hline COBEE & 239,66 & 210,25 & 37,26 & 29,80 & 276,92 & 240,5 \\
\hline CECBB & & & 119,06 & 101,20 & 119,06 & 101,20 \\
\hline ERESA & 24,49 & 19,78 & & & 24,49 & 19,78 \\
\hline HB & 100,48 & 90,35 & & & 100,48 & 90,35 \\
\hline SYNERGIA & 8,70 & 7,60 & & & 8,70 & 7,60 \\
\hline \multicolumn{7}{|l|}{ UNAGRO $(*)$} \\
\hline Total S.I.N. & 547,03 & 475,28 & 842,33 & 707,84 & 1389,36 & 1183,12 \\
\hline \multicolumn{7}{|c|}{ SISTEMAS ISOLADOS } \\
\hline SETAR & 9,30 & 8,00 & 50,35 & 35,56 & 59,65 & 43,56 \\
\hline ENDE & & & 34,23 & 27,34 & 34,23 & 27,34 \\
\hline CRE & & & 40,30 & 32,03 & 40,30 & 32,03 \\
\hline GENERGYS & & & 4,58 & 3,66 & 4,58 & 3,66 \\
\hline GESA & & & 6,08 & 5,02 & 6,08 & 5,02 \\
\hline CSSA & & & 2,12 & 1,70 & 2,12 & 1,70 \\
\hline TRANSREDES & & & 11,22 & 9,54 & 11,22 & 9,54 \\
\hline VINTAGE & & & 4,35 & 3,70 & 4,35 & 3,70 \\
\hline PECOM & & & 1,47 & 1,25 & 1,47 & 1,25 \\
\hline СНАCO & & & 4,73 & 4,02 & 4,73 & 4,02 \\
\hline Cooperativas & & & 37,96 & 30,36 & 37,96 & 30,36 \\
\hline Auto produtores & & & 109,38 & 87,50 & 109,38 & 87,50 \\
\hline Total Isolado & 9,30 & 8,00 & 306,76 & 241,67 & 316,06 & 249,67 \\
\hline TOTAL & 556,33 & 483,28 & 1149,09 & 949,51 & 1705,41 & 1432,79 \\
\hline
\end{tabular}

No mercado elétrico boliviano coexistem dois sistemas, cada um deles com características próprias, sendo estes: o Sistema Interconectado Nacional (SIN), os Sistemas Isolados. Na Figura 3.7 pode-se observar a participação de cada sistema na capacidade instalada do SIN.

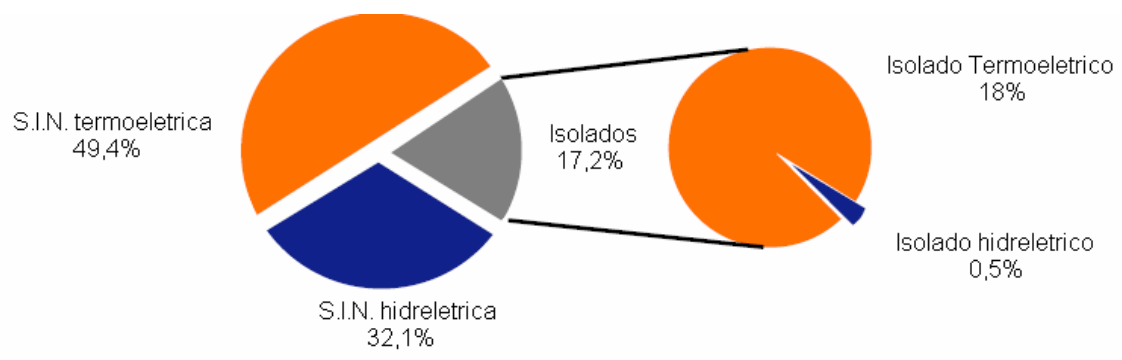

Figura 3.7 Participação dos subsistemas na capacidade instalada no mercado Boliviano

Na Figura 3.8 mostra-se uma síntese das empresas de geração e das empresas de distribuição conectadas ao SIN. O comportamento do setor elétrico Boliviano, de forma similar ao que acontece nos outros países, está altamente influenciado pelo desempenho da economia, isto devido a que o mercado elétrico fornece aos setores produtivos e à população o insumo básico que é a eletricidade. Assim, o comportamento do mercado elétrico e a abrangência deste serviço oferecem uma idéia a respeito do grau de desenvolvimento da economia e da qualidade de vida da população. 
GERADORA

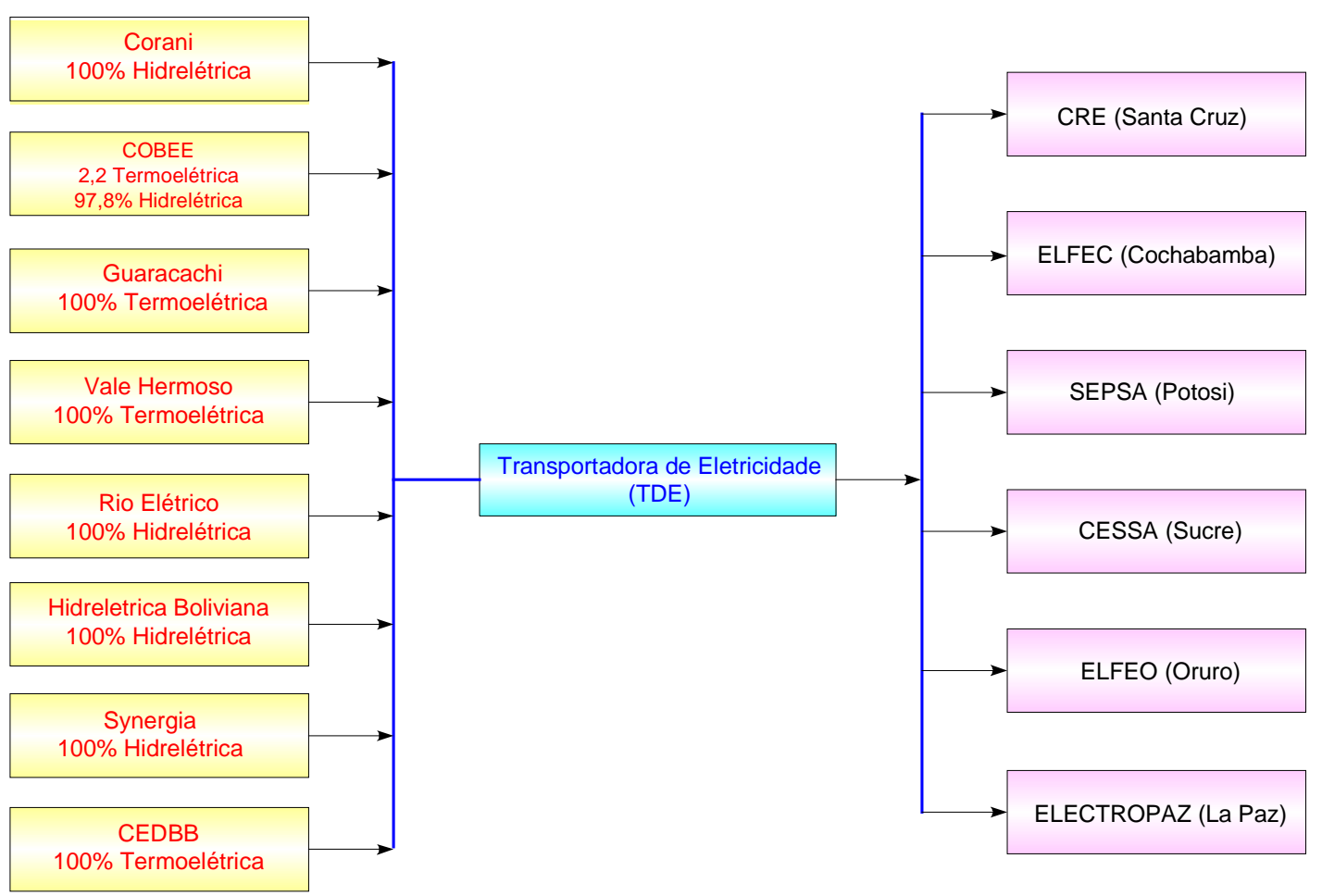

Figura 3.8 Participação das empresas de geração e distribuidoras no SIN

\subsubsection{A Transformação do Setor Elétrico Boliviano}

Na Bolívia, a reestruturação do setor elétrico ocorreu no ano 1994 resultando na desverticalização das atividades de geração, transmissão e distribuição existente no Sistema Interconectado Nacional (SIN). O objetivo principal da referida reestruturação foi o de estabelecer um mercado elétrico atacadista competitivo.

Antes do processo de reestruturação, o setor elétrico boliviano estava constituído apenas por duas grandes empresas: a estatal ENDE (Empresa Nacional de Eletricidade) criada em 1962, e pela COBEE-BPCo (Compañia Boliviana de Energia Elétrica-Bolivian Power \& Company) criada em 1925. A ENDE e a COBEE atuavam de forma monopólica no setor elétrico [30].

Em 1994, antes da reforma do setor elétrico, a ENDE possuía supremacia no país (Tabela 3.4). Na geração, ENDE tinha o 72,2\% da capacidade instalada no SIN e nos Sistemas Isolados. Já a COBEE possuía o $27,8 \%$ de capacidade instalada. No setor da distribuição $41 \%$ correspondia à COBEE, enquanto que 59\% às distribuidoras de ENDE e a outras privadas dentro do SIN. 
Tabela 3.4 Atividades de geração, transmissão e distribuição antes da reestruturação

\begin{tabular}{|c|c|c|}
\hline \multicolumn{3}{|c|}{ GERAÇÃO* } \\
\hline & Capacidade Instalada & $(\%)$ \\
\hline ENDE (SIN) & 461,3 MW & 72,2 \\
\hline COBEE (SIN) & $177,8 \mathrm{MW}$ & 27,8 \\
\hline *Não inclui os sistemas isolados & & \\
\hline \multicolumn{3}{|c|}{ TRANSMISSÃO } \\
\hline \multirow{2}{*}{\multicolumn{3}{|c|}{$\begin{array}{l}\text { ENDE (SIN) } \\
\text { Cobee (SIN) }\end{array}$}} \\
\hline & & \\
\hline \multicolumn{3}{|l|}{ DISTRIBUIÇÃO } \\
\hline COBEE: Eletropaz- ELFEO- SEYSA (SIN) & & 41 \\
\hline ENDE: CRE-CESSA-SEPSA-ELFEC (privadas SIN) & & 59 \\
\hline
\end{tabular}

Fonte: Superintendência de Eletricidade

Pode-se ver que os três setores elétricos estavam em mãos de apenas duas empresas. Após o processo de desregulamentação, aumentou o número de participantes no mercado elétrico. Em conseqüência, a capacidade instalada no sistema foi também incrementada atingindo os valores relatados na seção 3.2.

\section{a) Legislação Elétrica}

No Quadro 3.2 são mostradas as principais regulamentações existentes no setor elétrico Boliviano.

Quadro 3.2 Principais normas e regulamentos no setor elétrico Boliviano

\begin{tabular}{|l|l|}
\hline \multicolumn{1}{|c|}{ Lei/ Decreto } & \multicolumn{1}{c|}{ Descrição } \\
\hline Lei 1604/ 1994 & Nova Lei de Eletricidade \\
\hline Decreto 26093/2001 & $\begin{array}{l}\text { Novo Regulamento de operação do Mercado Elétrico (ROME), aprovado em Março de } \\
2001 .\end{array}$ \\
\hline Decreto 26094/ 2001 & $\begin{array}{l}\text { Novo Regulamento de Preços e Tarifas (RPT) da Lei de Eletricidade, aprovado em } \\
\text { Março de 2001. }\end{array}$ \\
\hline Decreto 24043/1995 & Regulamento da Lei de Eletricidade \\
\hline Decreto 24711/1997 & Regulamento de Qualidade de Transmissão, aprovado em Julio de 1997. \\
\hline Lei 1600 & Sistema de regulamentação Setorial (SIRESE) aprovado em Outubro de 1994. \\
\hline
\end{tabular}

Segundo dados da Superintendência de Eletricidade, até o ano 1994 o setor elétrico boliviano era regulamentado pelo Código de Eletricidade (DS 08438 de 31/07/1968), baseado numa estrutura com integração vertical e controlado pela estatal ENDE. Este código concedia a ENDE os direitos de ser a entidade técnica autárquica responsável de regular, fiscalizar, coordenar e fomentar as atividades da indústria elétrica no país. Permitia-se a existência de empresas privadas dentro da indústria elétrica e regulamentava a relação destas empresas com o Estado. As tarifas eram fixadas com base no valor do investimento sobre a concessão outorgada à concessionária.

\section{b) Organização Institucional do Sistema Elétrico}

Após a promulgação da Lei de Eletricidade vigente, as instituições públicas mais importantes do setor elétrico na Bolívia são (Figura 3.9):

\section{- Vice Ministério de Eletricidade, Energias Alternativas e Telecomunicações}

(VMEEAT), entidade dependente do Ministério de Hidrocarbonetos e Energia . É o ente regulador e responsável de formular a política elétrica do país, além de propor normas que posteriormente deverão ser aplicadas pela SDE (Secretaria de Eletricidade). 
- Superintendência de Eletricidade, criada conforme a Lei do Sistema de Regulamentação Setorial No. 1600 (28/10/1994) e da Lei de Eletricidade No. 1604 (21/12/1994), como um organismo com jurisdição nacional que cumpre a função de regular as atividades da indústria elétrica.

- Comitê Nacional de Despacho de Carga (CNDC), criado segundo o Artigo 18 da Lei de Eletricidade (1604/1994). É responsável pela administração do mercado atacadista. Controla a operação do SIN de modo a garantir o fornecimento de energia aos usuários. É o encarregado de calcular os preços de nó no SIN. Além disso, está encarregada de determinar os modelos matemáticos que irão simular o comportamento da energia no sistema e que serão depois apresentados à Superintendência de Eletricidade. O CNDC está organizado em um Comitê de Representantes e uma Unidade Operativa. O Comitê de Representantes se reúne pelo menos uma vez ao mês e adota resoluções sobre o funcionamento do Sistema Interconectado e do Mercado Elétrico Atacadista. A Unidade Operativa é o órgão executivo do CNDC. Realiza as tarefas relacionadas com a operação do sistema elétrico no marco da normativa vigente e das decisões do Comitê de Representantes.

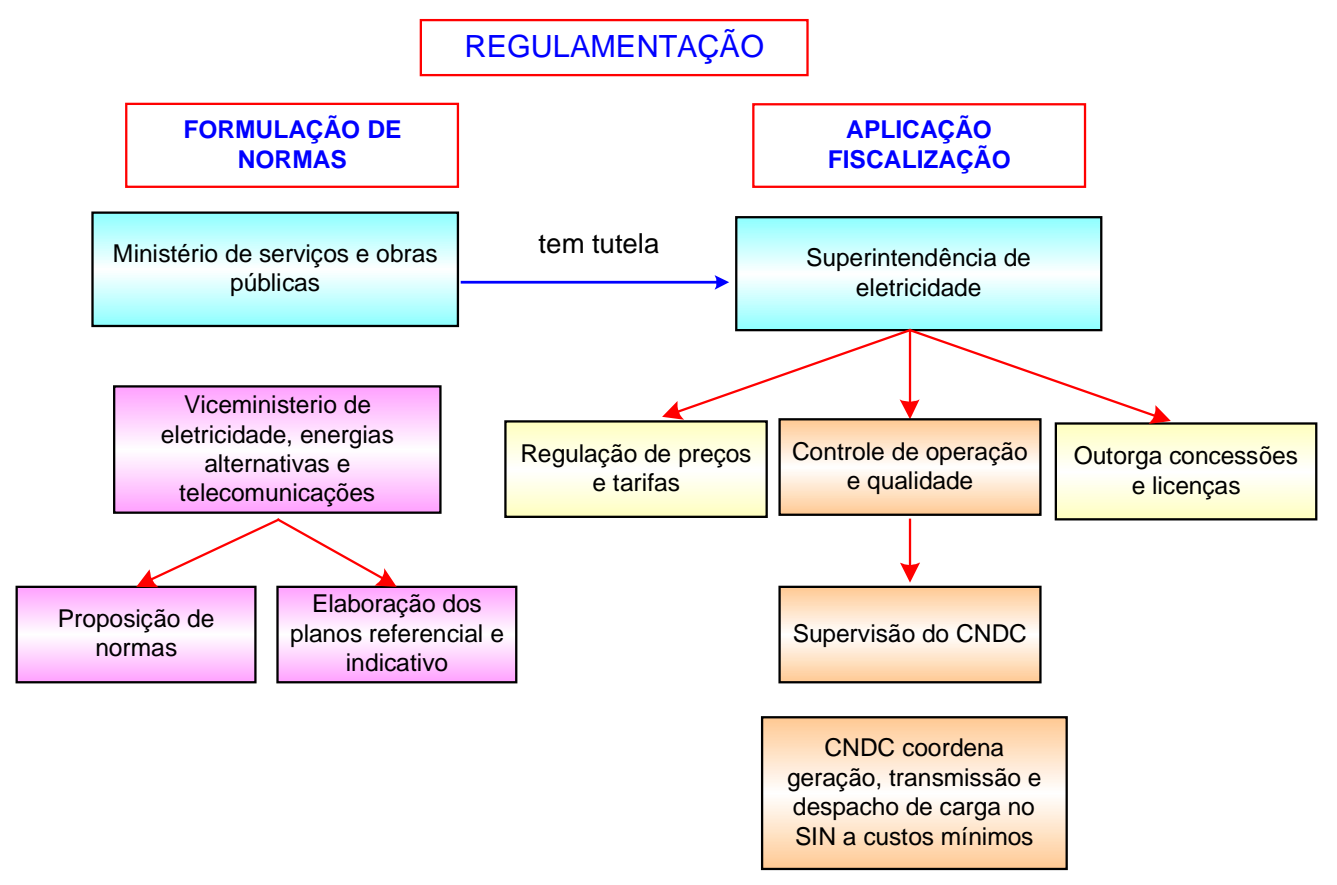

Figura 3.9 Marco institucional do setor elétrico Boliviano

\subsubsection{O Sistema de Transmissão}

Segundo o Regulamento de Operação do Mercado Elétrico Atacadista (D.S. 24043/1995, Art. 19) estabelecem-se as seguintes obrigações específicas para este setor: 
- Permitir o livre acesso (indiscriminatório) à rede de transmissão a todo agente do mercado que a solicite.

- Cumprir com a proibição de compra e venda de eletricidade a terceiros.

- Informar aos agentes do mercado sobre a evolução previsível (período semestral) da demanda de capacidade de transporte e de oferta deste serviço para os seguintes quatro anos.

a) Concessionárias de Transmissão. Segundo o CNDC, as concessionárias de transmissão que operam atualmente são:

- Transportadora de Eletricidade S.A. (TDE); que opera com linhas de transmissão de 230 kV,115 kV e $69 \mathrm{kV}$ dentro do STI (Sistema Troncal de Interconexão). Possui alcance nacional. Seu principal acionista é a empresa espanhola Rede Elétrica Internacional S.A.

- Interconexão Elétrica Bolívia S.A. (ISA Bolívia); que também opera ao nível de transmissão dentro do STI (Sistema Troncal de Interconexão). Os seus principais acionistas são as empresas colombianas: Interconexão Elétrica S.A. e a TRANSELCA-ESP.

- Mercados Elétricos S.A. (MERELEC); empresa que não faz parte do STI. Possui linhas em $115 \mathrm{kV}$ e menores. Esta empresa é privada com acionistas nacionais e alcance local.

- São Cristobal Transmissora de Eletricidade S.A. (São Cristobal S.A.); atualmente tem uma linha em construção de $230 \mathrm{kV}$. Não faz por enquanto parte do STI. De forma similar à anterior, é de propriedade privada com acionistas nacionais, e possui alcance local.

b) Níveis de Tensão do Sistema. As tensões de transmissão utilizadas no sistema Boliviano são: $230 \mathrm{kV}, 115 \mathrm{kV}$ e $69 \mathrm{kV}$ (Figura 3.10).

c) Método Base de Tarifação. A metodologia de tarifação adotada pelo sistema Boliviano é a do Custo Marginal de Curto Prazo, apresentada no Capítulo II.

\subsubsection{Regulamentação dos Preços da Transmissão}

A atividade da transmissão elétrica na Bolívia esta regulamentada e os preços são aprovados semestralmente pela Superintendência de Eletricidade para cada componente do sistema (cada componente do sistema é operativamente independente). 


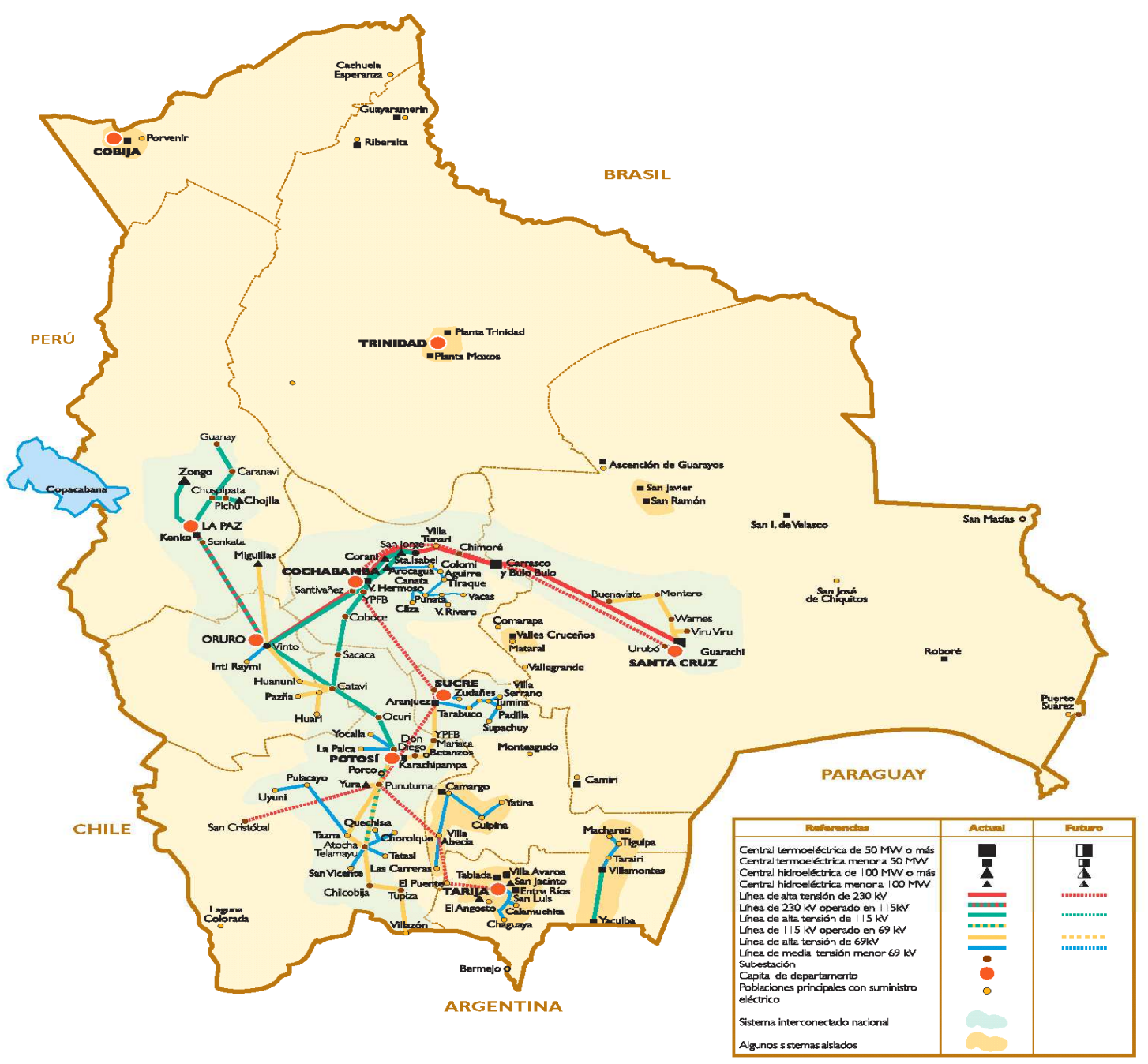

Figura 3.10 Sistema Interconectado Nacional Boliviano

\subsubsection{Mecanismo de Remuneração}

Conforme a regulamentação vigente (Regulamento de Preços e Tarifas D.S. 24043, Cap. II) estabelece-se um preço máximo de transmissão que deve ser pago pelos geradores conectados ao STI (Sistema Troncal de Interconexão).

Este preço deve cobrir o Custo Anual da Transmissão, que é determinado através da soma do Custo Anual de Investimento (CAI) e o Custo Anual de Operação, Manutenção e Administração (COMA) do Sistema de Transmissão Economicamente Adaptado (3.6) estabelecido pela Superintendência de Eletricidade.

$C A T=C A I+C O M A$

onde,

CAT : Custo Anual da Transmissão

CAI : Custo Anual do Investimento

COMA : Custo de Operação, Manutenção e Administração 
i) O Custo Anual do Investimento de cada instalação é calculado multiplicando o valor do investimento pelo fator de recuperação do capital obtido a uma taxa de atualização de $10 \%$ a.a. considerando um período de pagamento de 30 anos.

ii) O Custo Anual de Operação, Manutenção e Administração, equivale a 3\% do valor do investimento considerando um período de quatro anos. Estes custos são atualizados semestralmente conjuntamente com a nova determinação dos pedágios.

\subsubsection{Mecanismo de Arrecadação}

A arrecadação pelo uso da transmissão é realizada de forma similar ao caso Chileno, ou seja, através de uma receita tarifária ${ }^{8}$ mais o pedágio [31].

- Receita Tarifária. Calculada em função da potência e energia entregues e retiradas nas barras, valorizadas com as suas respectivas tarifas nestas barras. Este valor é determinado pelo CNDC (Art. 27 a, DS 24043). A receita tarifária é obtida da diferença entre as retiradas valorizadas de energia e potência de ponta e as injeções valorizadas de energia e potência de ponta respectivamente, nos diferentes nós do STI. Considera-se como injeção de potência de ponta nos nós de geradores aquela que resulta de despachar a potência firme das centrais geradoras. Essa valorização é realizada utilizando os custos marginais de curto prazo de energia e potência utilizadas pelo CNDC (Comitê Nacional de Despacho de Carga), para determinar as transações entre os agentes no mercado spot.

- Parcela Complementar ou Pedágio. Os agentes geradores e consumidores pagam pelo uso do sistema de transmissão um pedágio, que resulta da diferença entre o Custo Anual de Transmissão (equação 3.7) e a receita tarifária anual. $\mathrm{O}$ montante do pedágio correspondente aos Geradores é alocado com base na energia total injetada (Art. 29, DS 24043). No caso dos Consumidores, o pedágio é alocado em base á potência de ponta estimada, ou seja, o pedágio não considera a distância entre os centros de geração e consumo (Art. 30, DS 24043).

No ano 2006 o pedágio médio anual foi de 2,98 US\$/kW, $41 \%$ maior do que no 2005, devido à incorporação de varias instalações de transmissão [59].

$$
\text { Pedagio }=C A T-R T
$$

onde,

$C A T:$ Custo Anual de Transmissão

$R T$ : Receita Tarifaria

\footnotetext{
${ }^{8}$ Receita Tarifaria $=$ Ingresso Tarifário (IT) segundo legislação
} 
Segundo [37], o rateio destes pagamentos inicialmente era realizado através da metodologia das áreas de influência. Os geradores pagavam de forma proporcional a sua potência firme, entanto que os consumidores pagavam em proporção a sua potência de ponta. Porém, nesta metodologia, surgia uma barra marginal e aqueles consumidores conectados a essa barra não pagavam pedágio. Esta situação criava uma certa instabilidade que era refletida em fortes variações na tarifa dos consumidores a cada semestre. Devido a problemas deste tipo, optou-se por mudar para a metodologia de pedágio do tipo selo, onde o custo das instalações do STI é coberto em 75\% pelos consumidores (distribuidores e consumidores não regulados, em proporção a sua demanda máxima) e os restantes $25 \%$ dos custos são cobertos pelos geradores, em proporção a sua energia injetada ao sistema. A metodologia do tipo selo é considerada previsível, fácil de se reproduzir e que resolveu, em grande parte, o problema da expansão do sistema de transmissão.

A título de exemplo, na Tabela 3.5 são apresentados os pagamentos por conceito de pedágio de duas geradoras, a Empresa Electrica Corani S.A. (Hidroelétrica) e a Empresa Electrica Guaracachi S.A. (Termoelétrica) para as empresas de transmissão: TDE e ISA Bolívia, correspondentes ao mês de Maio de 2006. Apenas para fins comparativos a taxa de cambio nesse mês era de 8B $\$ /$ US\$.

Tabela 3.5 Pagamentos por conceito de pedágios gerador-transmissor na Bolívia

\begin{tabular}{|l|c|c|}
\hline \multicolumn{1}{|c|}{ Geradora } & $\begin{array}{c}\text { Corani S.A } \\
\text { (Hidroelétrica) }\end{array}$ & $\begin{array}{c}\text { Guaracachi S.A } \\
\text { (Termoelétrica) }\end{array}$ \\
\hline Energia Injetada (MWh) & 67309 & 97372 \\
\hline Pedágio para TDE (Bs/MWh) & 12,003 & 12,003 \\
\hline Pedágio para ISA ((Bs/MWh) & 7,578 & 7,578 \\
\hline Pagamento a TDE (Bs) & 807908 & 1168756 \\
\hline Pagamento a ISA (Bs) & 510066 & 737885 \\
\hline Pagamento Total (Bs) & 1317974 & 1906641 \\
\hline
\end{tabular}

Na Tabela 3.6 apresenta-se o custo por conceito de pedágio que foi pago em Maio de 2006 por uma das concessionárias de distribuição (Cooperativa Rural de Electrificación CRE) às empresas de transmissão (TDE e ISA Bolívia).

Tabela 3.6 Pagamento por conceito de pedágios (distribuidor ao transmissor)

\begin{tabular}{|l|c|}
\hline \multicolumn{1}{|c|}{ Distribuidora } & CRE Ltda \\
\hline Potência de ponta (MW) & 285530 \\
\hline Pedágio para TDE $(\mathrm{Bs} / \mathrm{kW})$ & 17,327 \\
\hline Pedágio para ISA $(\mathrm{Bs} / \mathrm{kW})$ & 10,259 \\
\hline Pago a TDE $(\mathrm{Bs})$ & 4947378 \\
\hline Pago a ISA (Bs) & 2929252 \\
\hline Pago Total $(\mathrm{Bs})$ & 7876630 \\
\hline
\end{tabular}




\subsubsection{Qualidade de Serviço do Sistema de Transmissão}

A qualidade de transmissão no SIN está regulamentada (Regulamento de Qualidade da Transmissão) pelo que a TDE, principal empresa de transmissão, está obrigada a cumprir com determinados indicadores relacionados à disponibilidade das instalações e interrupções na freqüência de operação. Valores que ultrapassem os limites fixados no regulamento serão penalizados com a redução na remuneração da empresa.

Segundo o Art.8 (Cap. III) do Regulamento de Qualidade de Transmissão, os indicadores de qualidade de transmissão aplicáveis a cada componente do sistema de transmissão, que são calculados anualmente, são os seguintes:

a) A freqüência de desconexões da instalação em um período anual.

b) A duração média de desconexões da instalação, determinada através da soma dos tempos de indisponibilidade da instalação e dividida entre o número de desconexões por ano.

$$
D=\frac{\text { Duração_das_Desconexõe } s_{-}(\min )}{\text { Número _de_Desconexõe } s_{-}}
$$

Estes parâmetros serão registrados e classificados da forma seguinte:

- Índices atribuíveis ao transmissor

- Índices atribuíveis aos usuários do sistema de transmissão ou terceiros.

Na Tabela 3.7 apresentam-se os índices de indisponibilidade da Empresa de Transmissão Elétrica (TDE). Este índice é definido pela duração e freqüência ponderada de indisponibilidade, por km de linha, que a empresa de transmissão deve cumprir perante a Superintendência de Eletricidade (Resolução. N 001/2006). Nesta tabela observa-se também que para o período Nov. 2005 - Out. 2006 foi estimada a aplicação de uma redução nas remunerações da TDE, em US\$ 4749, devido a uma falha permanente ocasionada pela explosão de um pára-raios na linha Santa Isabel-Arocagua, por ter ultrapassado a duração mínima de interrupção exigida. Já nos dois primeiros meses do período elétrico de 2007, foram registrados 23 desconexões provocadas por descargas atmosféricas, só uma desconexão foi atribuída a TDE; porém, esta não excedeu os limites de freqüência nem de duração, de modo que não houve punição alguma nesse período.

Tabela 3.7 Índices de indisponibilidade da TDE na Bolívia

\begin{tabular}{|c|c|c|c|c|c|c|}
\hline Período Elétrico & 2003 & 2004 & 2005 & 2006 & 2006 & 2007 \\
\hline Meses Avaliados & Nov02-Out03 & Nov03-Out04 & Nov04-Out05 & Nov05-Out06 & Nov05-Dez05 & Nov05-Dez06 \\
\hline Desconexões Totais & 69 & 47 & 102 & 62 & 16 & 23 \\
\hline $\begin{array}{l}\text { Número de desconexões atribuíveis a } \\
\text { TDE a efeitos de punição }\end{array}$ & 24 & 15 & 31 & 20 & 2 & 1 \\
\hline $\begin{array}{l}\text { Porcentagem de desconexões } \\
\text { atribuíveis a TDE }\end{array}$ & $34,78 \%$ & $31,91 \%$ & $30,39 \%$ & $32,26 \%$ & $12,50 \%$ & $4,34 \%$ \\
\hline Porcentagem de reconexão com sucesso & $45,0 \%$ & $48,0 \%$ & $45,0 \%$ & $46,0 \%$ & $50,0 \%$ & $48,0 \%$ \\
\hline $\begin{array}{l}\text { Porcentagem de componentes que } \\
\text { excedem o limite de freqüência }\end{array}$ & $6,25 \%$ & $0,00 \%$ & $4,35 \%$ & $0,00 \%$ & $0,00 \%$ & $0,00 \%$ \\
\hline $\begin{array}{l}\text { Porcentagem de componentes que } \\
\text { excedem o limite de duração média }\end{array}$ & $12,50 \%$ & $0,00 \%$ & $17,39 \%$ & $4,36 \%$ & $0,00 \%$ & $0,00 \%$ \\
\hline
\end{tabular}

Fonte: Transmissora de Eletricidade S.A. (TDE) 


\subsubsection{Expansão da Rede de Transmissão}

\subsubsection{Expansão da Rede Local}

Segundo o Art. 8 (Regulamento de Preços e Tarifas) estabelece-se que a expansão das instalações de transmissão é responsabilidade dos usuários, o que significa que as empresas de transmissão não tem a obrigação legal para ampliar a rede de transmissão existente, assim existiria um planejamento do tipo descentralizado. Para isso, deve-se conveniar a modalidade de seu financiamento ou pagamento com o transmissor. As expansões precisarão a aprovação da Superintendência de Eletricidade, através da respectiva licença de transmissão. Para a incorporação de novas instalações no STI (Sistema Troncal de Interconexão), que serão pagas pelos agentes do Mercado Elétrico Atacadista, requer-se uma apresentação de proposta ao CNDC, órgão que deverá analisar e avaliar o estudo apresentado pelo solicitante para depois derivá-lo à Superintendência de Eletricidade [41].

Os documentos utilizados como referência para a determinação de necessidades de expansão da transmissão são a Programação de Operação de Médio Prazo, que semestralmente elabora o CNDC com um horizonte de planejamento de quatro (4) anos, e os relatórios semestrais elaborados pelos transmissores sobre a oferta e demanda de capacidade de transporte para os seguintes quatro (4) anos.

Custos Adicionais pela Conexão á Rede. Segundo o Art. 9 (Regulamento de Preços e Tarifas), o custo das instalações que não pertençam ao STI será pago pelos usuários que pleiteiem essas instalações. As instalações que possuam licença de transmissão são de acesso aberto e deverão ser remuneradas independentemente dessas mesmas instalações estarem disponibilizadas através de convenio com um usuário particular.

\subsubsection{Expansão das Conexões Internacionais}

As exportações e importações de eletricidade, bem como as interconexões internacionais, estão também reconhecidas na Lei de Eletricidade (Art 9) e no RCIIE (Regulamento de Comercialização e Interconexões Internacionais de Eletricidade, DS $N^{\circ}$ 25986/11/2000) que prevê o comercio internacional no mercado spot através de contratos. A Superintendência de Eletricidade outorga as licenças que permitem tanto a interconexão internacional, assim como a importação e exportação de energia.

A interconexão internacional deve ser realizada segundo as políticas estabelecidas pelo Poder Executivo. No momento, desconhece-se a existência de instalações de transmissão destinadas a interconexão internacional. 


\subsection{BRASIL}

A rede básica do sistema de transmissão Brasileiro está formada pelo SIN (Sistema Interligado Nacional) e pelos Sistemas Isolados, localizados no Norte do país. O SIN é responsável pelo atendimento de aproximadamente $98 \%$ do mercado Brasileiro. Em 2007, a capacidade instalada do SIN atingiu 109.327,4 MW (Tabela 3.8), dos quais 74.936,9 MW correspondem a usinas hidrelétricas e 21.229,0 MW a usinas térmicas [32].

Tabela 3.8 Capacidade instalada segundo o tipo de geração (MW) no Brasil

\begin{tabular}{|l|r|r|r|}
\hline \multicolumn{5}{|c|}{ Capacidade Instalada até 31/12/2007 } \\
\hline \multicolumn{1}{|c|}{ Tipo } & Quantidade & Potência (MW) & Porcentagem \\
\hline UHE $^{*}$ & 158 & 74936,9 & $74,67 \%$ \\
UTE & 995 & 21229,0 & $21,15 \%$ \\
PCH & 294 & 1820,3 & $1,81 \%$ \\
CGH & 215 & 112,3 & $0,11 \%$ \\
UTN & 2 & 2007,0 & $2,00 \%$ \\
EOL & 16 & 247,1 & $0,25 \%$ \\
SOL & 1 & 0,02 & $0,00 \%$ \\
\hline SUBTOTAL & $\mathbf{1 6 8 1}$ & $\mathbf{1 0 0 3 5 2 , 6 2}$ & $\mathbf{1 0 0}$ \\
\hline \multicolumn{4}{|c|}{8975} \\
\hline Importação** & 8 & $\mathbf{1 0 9 3 2 7 , 6}$ \\
\hline TOTAL & $\mathbf{1 6 8 9}$ & $\mathbf{1 0 8 , 9 \%}$ \\
\hline
\end{tabular}

* Considerada Itaipú nacional (7000 MW)

** Considerada importação de Itaipú (6455 MW)

Fonte: ANEEL

\subsubsection{A Transformação do Setor Elétrico Brasileiro}

No Brasil, as reformas no setor elétrico começaram em 1996, de forma a promover um ambiente competitivo na geração e fazendo com que o papel da expansão do parque gerador esteja distribuído entre os diversos agentes de forma descentralizada. Alem disso, buscou-se realçar o papel da iniciativa privada no processo, particularmente no que se refere aos investimentos. Por outro lado, tanto a transmissão quanto a distribuição ainda permanecem regulamentados, por estarem caracterizados como setores com monopólio natural.

a) Legislação Elétrica. As principais normas e regulamentos aplicados no sistema elétrico brasileiro podem ser resumidos conforme Quadro 3.3 que se segue.

b) Organização Institucional do Sistema Elétrico. São vários os agentes que participam de forma ativa no mercado elétrico, tanto nas transações de energia quanto na operação, fiscalização e regulamentação do setor, sendo estes:

- Conselho Nacional de Política Energética (CNPE). Entidade vinculada à Presidência da República e presidida pelo Ministro de Estado de Minas e Energia (Art.2, lei 9478/1997). Define a política energética nacional de modo a garantir a existência do marco político necessário para assegurar o suprimento energético. 
Quadro 3.3 Principais normas e regulamentos no setor elétrico Brasileiro

\begin{tabular}{|c|c|}
\hline Lei/ Decreto & Descrição \\
\hline Lei 10848/2004 & $\begin{array}{l}\text { Reestrutura o Setor Elétrico e define o novo modelo de Comercialização de Energia Elétrica. } \\
\text { Foi instituída a CCEE e criada pelo Decreto no } 5.177 / 04 \text {, absorveu as funções do MAE e suas } \\
\text { estruturas organizacionais e operacionais. Entre suas principais obrigações estão: a apuração do Preço } \\
\text { de Liquidação de Diferenças (PLD), utilizado para valorar as transações realizadas no mercado de } \\
\text { curto prazo; a realização da contabilização dos montantes de energia elétrica comercializados; a } \\
\text { liquidação financeira dos valores decorrentes das operações de compra e venda de energia elétrica } \\
\text { realizadas no mercado de curto prazo e a realização de leilões de compra e venda de energia no } \\
\text { Ambiente de Contratação Regulada (ACR), por delegação da ANEEL. }\end{array}$ \\
\hline Lei 10847/2004 & Criação da Empresa de Pesquisa Energética (EPE) \\
\hline Lei $10762 / 2003$ & Dispõe a Criação do programa de Emergência e de Apoio aos Concessionários de Distribuição. \\
\hline Lei $10438 / 2002$ & $\begin{array}{l}\text { Dispõe a recomposição tarifária, a criação do Programa de Incentivo ás Fontes Alternativas de Energia } \\
\text { Elétrica (Proinfa) e estabelece a universalização do serviço público de energia elétrica. }\end{array}$ \\
\hline Lei $10433 / 2002$ & Dispõe a criação do Mercado Atacadista de Energia Elétrica (MAE) \\
\hline Lei $9648 / 2001$ & Modificação das Leis 8987/1995, 9074/1995, 9247/1996 e reestruturação da ELETROBRAS. \\
\hline Lei 9478/1997 & $\begin{array}{l}\text { Criação do Conselho Nacional de Política Energética - CNPE, órgão de assessoramento do Presidente } \\
\text { da República para a formulação de políticas e diretrizes de energia. }\end{array}$ \\
\hline Lei $9427 / 1996$ & $\begin{array}{l}\text { Criação da Agência Nacional de Energia Elétrica (ANEEL) cujo regulamento foi definido no Decreto } \\
\text { 2335/1997. }\end{array}$ \\
\hline Lei 9074/1995 & $\begin{array}{l}\text { Estabelecimento das normas para outorgar ou prorrogar as concessões elétricas; introdução das figuras } \\
\text { do Consumidor Livre. E do Produtor Independente de Energia. }\end{array}$ \\
\hline
\end{tabular}

- Ministério de Minas e Energia (MME). Organismo governamental responsável pela administração e entrega de permissões de uso dos recursos energéticos, geopolíticos e minerais de Brasil (Decreto 5267/2004).

- Agência Nacional de Energia Elétrica (ANEEL). Organismo estatal, porém que funciona de forma independente do governo. Tem como atribuições: regular e fiscalizar a geração, a transmissão, a distribuição e a comercialização da energia elétrica, atendendo reclamações de agentes e consumidores e em beneficio da sociedade; mediar os conflitos de interesses entre os agentes do setor elétrico e entre estes e os consumidores; conceder, permitir e autorizar instalações e serviços de energia; garantir tarifas justas; zelar pela qualidade do serviço; estimular a competição entre os operadores e assegurar a universalização dos serviços. Em suma a missão da ANEEL é proporcionar condições favoráveis para que o mercado de energia elétrica se desenvolva com equilíbrio entre os agentes e em benefício da sociedade (Art. 2, Lei 9427/1996).

- Empresa de Pesquisas Energéticas (EPE). Vinculada ao ministério de Minas e Energia (Art. 1, Lei 10847/2004). Instituição responsável de prestar serviços na área de estudos e pesquisas destinadas a fomentar o planejamento do setor energético, tais como energia elétrica, petróleo, gás natural e seus derivados, carvão mineral, fontes energéticas renováveis e eficiência energética, entre outras (Art. 2, Lei 10847/2004). 
- Operador Nacional do Sistema Elétrico (ONS). Organismo privado sem fins lucrativo, responsável pela operação centralizada e coordenado do sistema elétrico (geração e transmissão). Responsável também pela viabilização e expansão dos sistemas de transmissão. O ONS trabalha sob a fiscalização e regulamentação da ANEEL (Art. 13, Lei 9648/1998).

- Câmara de Comercialização de Energia Elétrica (CCEE). Entidade privada sem fins lucrativos e sob fiscalização da ANEEL (Art. 1, Decreto 5177/2004). Tem por finalidade viabilizar a comercialização da energia elétrica no SIN.

- Comitê de Monitoramento do Setor Elétrico (CMSE). Avalia permanentemente a segurança e continuidade do fornecimento elétrico em todo o país (Lei 10848/2004).

Na Figura 3.11 mostra-se a atual estrutura física e comercial do mercado elétrico Brasileiro.

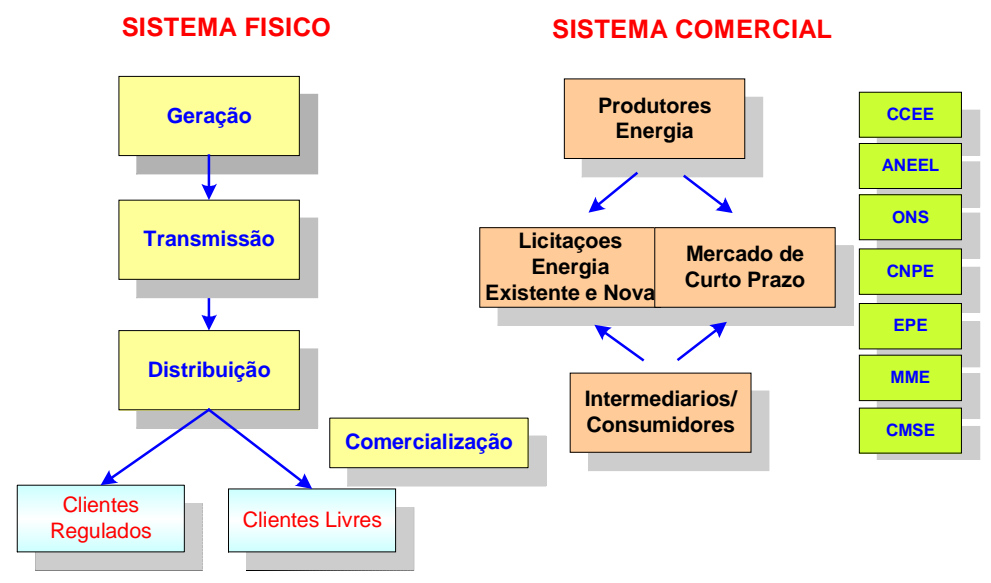

Figura 3.11 Esquema físico e comercial do sistema elétrico Brasileiro

\subsubsection{O Sistema de Transmissão}

Na Figura 3.12 mostra-se a configuração atual do SIN, bem como as futuras ampliações.

a) Tensões no sistema de transmissão. Devido à extensão territorial e ao parque gerador predominantemente hidroelétrico, o SIN abrange vários níveis de tensão na faixa de $230 \mathrm{kV}$ a 750 $\mathrm{kV}(\mathrm{CA}) \mathrm{e} \pm 600 \mathrm{kV}(\mathrm{CC})$.

b) Concessionárias de Transmissão. No Quadro 3.4 são listadas as principais concessionárias de transmissão no SIN [62]. 


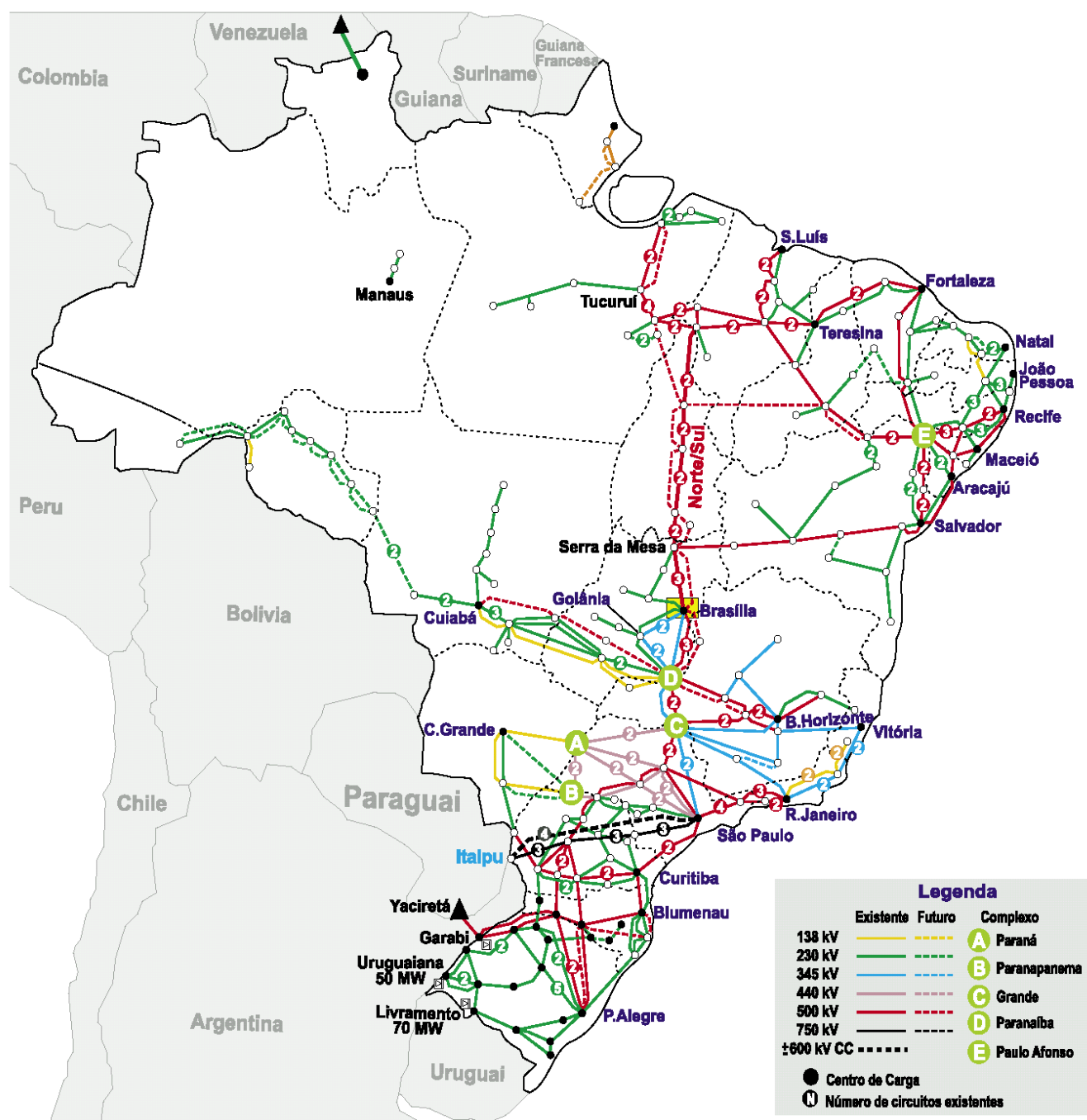

Fonte: ONS

Figura 3.12 Linhas em alta tensão que compõem o SIN

\subsubsection{Regulamentação de Preços na Transmissão}

O atual modelo de despacho e formação de preços no Brasil foi concebido com base na experiência de outros mercados de energia elétrica [33]. Porém, estes sistemas elétricos possuem características técnicas e operacionais relativamente diferentes do existente no Brasil. Devido à natureza predominantemente hidráulica do parque gerador, o Brasil decidiu adotar o modelo de despacho centralizado do tipo tight pool, no qual o ONS decide o montante a ser despachado por cada usina integrante do sistema interligado, isto com base em uma cadeia de modelos de otimização de uso da água estocada nos reservatórios. Para efeitos de comercialização de energia no Mercado de Curto Prazo e da fixação de preços nesse mercado, o conjunto do sistema foi subdividido em submercados [34]. 
Quadro 3.4 Principais concessionárias de transmissão no SIN

\begin{tabular}{|c|c|}
\hline Concessionária & Área de Concessão \\
\hline $\begin{array}{l}\text { Centrais Elétricas do Norte do Brasil S.A. - } \\
\text { (ELETRONORTE). }\end{array}$ & Regiões centro e norte do país. \\
\hline $\begin{array}{l}\text { Companhia de Eletricidade do Estado da } \\
\text { Bahia -(COELBA). }\end{array}$ & Estado da Bahia \\
\hline FURNAS Centrais Elétricas S.A. & $\begin{array}{l}\text { Regiões sul, sudeste e norte do país; é também a transmissora } \\
\text { da energia de Itaipu Binacional ao sudeste do país. }\end{array}$ \\
\hline TSN - Transmissora Sudeste Nordeste S.A & $\begin{array}{l}\text { Estados de Goiás e Bahia-Interconexão nordeste-sudeste do } \\
\text { país. }\end{array}$ \\
\hline Inabensa Brasil Ltda. & Estados de Alagoas Pernambuco e Paraíba \\
\hline $\begin{array}{l}\text { Expansão - Transmissão de Energia } \\
\text { Elétrica Ltda. }\end{array}$ & $\begin{array}{l}\text { Estado de Goiás e Distrito Federal - expansão da interconexão } \\
\text { Norte-Sul }\end{array}$ \\
\hline Novatrans Energia S.A. & $\begin{array}{l}\text { Estados de Goiás, Tocantins, Maranhão e Distrito Federal - } \\
\text { Interconexão Norte-Sul II }\end{array}$ \\
\hline $\begin{array}{l}\text { Companhia de Transmissão de Energia } \\
\text { Elétrica Paulista (CTEEP). }\end{array}$ & Estado de São Paulo \\
\hline $\begin{array}{l}\text { Companhia Estadual de Energia Elétrica } \\
\text { (CEEE). }\end{array}$ & Estado do Rio Grande do Sul \\
\hline $\begin{array}{l}\text { Companhia Energética de Minas Gerais } \\
\text { (CEMIG). }\end{array}$ & Estado de Minas Gerais. \\
\hline $\begin{array}{l}\text { Companhia Hidroelétrica do São Francisco } \\
\text { (CHESF). }\end{array}$ & Nordeste do país. \\
\hline COPEL Transmissão. S.A. & Estado do Paraná \\
\hline ELETROSUL Centrais Elétricas S.A. & Regiões Sul e Centro-oeste do país \\
\hline $\begin{array}{l}\text { ENTE - Empresa Norte de Transmissão de } \\
\text { Energia S.A. }\end{array}$ & $\begin{array}{l}\text { Estados de Maranhão e Pará, expansão da interconexão Norte- } \\
\text { Nordeste. }\end{array}$ \\
\hline
\end{tabular}

O preço spot de energia para a liquidação de diferenças (PLD: Preço de Liquidação de Diferenças) é calculado semanalmente pela CCEE, para cada submercado e para cada patamar de demanda, tomando como base o Custo Marginal de Operação. Estes submercados estão constituídos pelo sistema Norte, Nordeste, Sudeste/Centro Oeste e Sul. Os submercados são regiões geográfica e eletricamente próximas ${ }^{9}$, de modo que é possível fixar um único preço dentro delas.

A metodologia nodal adotada pode ser definida como uma metodologia próxima ao Custo Marginal de Longo Prazo e que tem como proposta básica a cobrança do uso da rede em função do nó de conexão do usuário, o que a classifica como uma metodologia com características locacionais [61].

\subsubsection{Mecanismo de Remuneração}

Para fins de remuneração, as instalações das concessionárias de transmissão foram classificadas em três tipos:

- A Rede Básica constituída por linhas cuja tensão é igual ou maior a $230 \mathrm{kV}$.

- As instalações com tensão igual ou maior a $230 \mathrm{kV}$, mas que são classificadas como instalações de conexão de uso exclusivo de um determinado gerador ou consumidor.

- As instalações com tensão menor a $230 \mathrm{kV}$, classificadas como demais instalações de transmissão.

Segundo a Resolução No 167/2000 da ANEEL, o transmissor terá direito a receber uma receita pelos serviços através da chamada Receita Anual Permitida $(R A P)$.

\footnotetext{
${ }^{9}$ Isto é, regiões em que não há restrições elétricas de natureza estrutural internamente às suas fronteiras
} 
Conforme a Nota Técnica No 014/2005 SRT/ANEEL, a RAP da empresa $i$ (para cada período anual) vem definida como:

$R A P_{i}=R B S E_{i}+R B N I_{i}+R P C_{i}+P A_{i}$

onde,

$i$ : período anual de prestação do serviço público da transmissão (período entre 01/julho e 30/junho do próximo ano).

RBSE (Receita do Sistema Existente): Segundo Resolução 167/2000, esta receita é reajustada anualmente através do Índice Geral de Preços Atacadistas (IGPM).

$R B N I$ (Receita das Novas Instalações): Autorizada após a Resolução 167/2000.

$R P C$ (Receita das Instalações de Conexão)

$P A$ (Parcela de Ajuste): a ser adicionada ou subtraída no RAP para o mesmo período, de forma a compensar o excesso ou déficit da arrecadação do período anterior.

Os contratos de concessão na transmissão são geralmente estabelecidos para um período de 30 anos. Prevêem-se revisões da RAP (a cada quatro anos) e dos reajustes tarifários anuais conforme o IGPM.

Segundo a Resolução normativa No 257 (06/03/2007) da ANEEL, a remuneração anual está formada pela remuneração ao capital, através do Custo Anual de Ativos Elétricos (CAAE) e pelo custo de Administração, Operação e Manutenção (CAOM). Segundo a Nota Técnica ${ }^{\circ}$ 068/2006-SRT da ANEEL, o Custo Anual de Ativos Elétricos Totais resulta da soma das parcelas referentes ao sistema existente (RBSE) e as novas instalações (RBNI).

\subsection{Receitas por Remuneração dos Ativos}

Para efeitos de remuneração por este conceito, as instalações da Rede Básica dividem-se em:

- Instalações existentes. Aos quais se remunera o capital investido e é coberto o custo da depreciação dos ativos destinados a prestar o serviço.

- Novas Instalações Autorizadas. Para as instalações de transmissão autorizadas pela ANEEL, tem-se uma receita anual (RBNI) que remunera o investimento realizado na implantação de novas instalações e substituição ou alterações nas instalações existentes da rede básica.

- Novas Instalações Licitadas. Trata-se de instalações novas cuja construção, operação e manutenção é concedida através de licitação ou leilão. O valor da receita anual permitida $(R A P)$ do transmissor resulta da proposta fornecida no leilão e paga a partir da entrada em operação comercial da instalação e por um período de 30 anos, sendo objeto de ajustes segundo o estabelecido no contrato de concessão.

\subsection{Receitas por Remuneração de Custos de Operação e Manutenção}

A ANEEL remunera à empresa um custo operativo eficiente padrão, calculado a partir das condições reais da área geográfica da concessão. Os custos cobertos incluem a operação e manutenção das redes elétricas, gestão comercial, direção e administração. 


\subsubsection{Mecanismo de Arrecadação}

As formas de custeio e arrecadação de encargos das instalações de transmissão destinadas à formação da Rede Básica estão definidas no Art. 9 da Lei N 9427/1996.

A arrecadação pelo uso da transmissão (TUST ${ }_{\mathrm{B}}$ ) no caso do Brasil é dada pela soma das seguintes parcelas:

- Tarifa Locacional: $\pi_{B}(\$ / M W)$

- Parcela de Ajuste: $\pi_{\text {Ajuste }}(\$ / M W)$

$$
\begin{aligned}
& \operatorname{TUST}_{B}=\pi_{B}+\pi_{\text {Ajuste }} \\
& \operatorname{TUST}_{B}=\sum_{L=1}^{N L} \beta_{L B} C_{L} \text { Fpond }_{L}+K
\end{aligned}
$$

- Tarifa Locacional (TUST). As Tarifas de Uso do Sistema de Transmissão (TUST) são calculadas através da metodologia nodal que fornece um sinal econômico locacional, conforme preconizado na Legislação (Res. ANEEL 281/99 e 282/99). As tarifas são reajustadas anualmente na mesma data em que ocorrem os reajustes das Receitas Anuais Permitidas (RAP) das concessionárias de transmissão. Esse período tarifário inicia-se em 01/julho do ano de publicação das tarifas até 30/junho do ano subseqüente.

A partir de Junho de 2004 a TUST passou a ter duas parcelas:

TUST $_{\mathrm{RB}}$ (parcela principal da TUST): Aplicada sobre as instalações de transmissão integrantes da Rede Básica com tensões iguais ou superiores a $230 \mathrm{kV}$, utilizadas para promover a otimização dos recursos elétricos e energéticos do sistema e, portanto, gera tarifas aplicáveis a todos os usuários. Seu cálculo é realizado a partir de simulações no programa Nodal, que utiliza como dados de entrada a configuração da rede, representada por suas linhas de transmissão, subestações, geração e carga, uma receita total a ser arrecadada e alguns parâmetros estabelecidos por meio da Resolução n ${ }^{\circ}$ 117, de 2004 [34]. TUST $_{\mathrm{FR}}$ : referida às instalações integrantes da Rede Básica, localizadas na fronteira entre a Rede Básica (tensão igual ou superior a $230 \mathrm{kV}$ ) e a rede de distribuição (tensão inferior a $230 \mathrm{kV}$ ), correspondente aos transformadores abaixadores e suas conexões. A TUST $T_{\mathrm{FR}}$ engloba também as Demais Instalações de Transmissão (DIT's) de uso compartilhado entre os agentes setoriais regulados. Esta remuneração é obtida a partir do rateio da receita associada às instalações de fronteira e das DIT's [34].

A Tarifa Locacional é calculada a partir da equação (3.12). O termo $F p o n d_{L}$ depende do carregamento dos circuitos: 
$\pi_{B}=\sum_{L=1}^{N L} \beta_{L B} C_{L}$ Fpond $_{L}(\$ / \mathrm{MW})$

O fator de ponderação $\left(\right.$ Fpond $\left._{L}\right)$ será igual a zero caso o fluxo de potência no elemento de transmissão $L$ estiver abaixo de um porcentual mínimo da sua capacidade, e será igual a 1 (um) se estiver acima do limite máximo informado. Se o fluxo estiver entre o mínimo e o máximo, há uma interpolação linear e o fator de ponderação $F p o n d_{L}$ terá um valor entre zero e um (Figura 3.13).

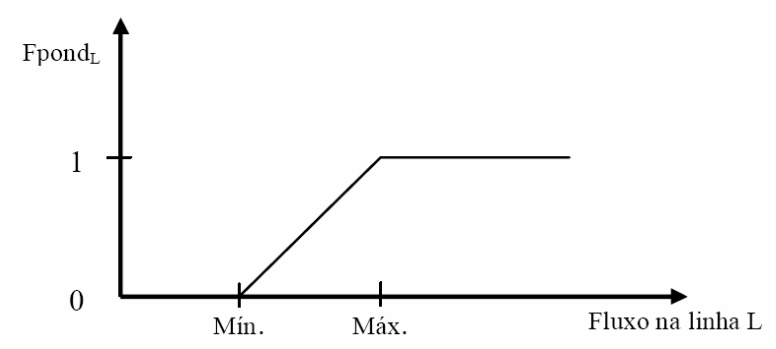

Figura 3.13 Fator de Ponderação

Para o cálculo das tarifas devem ser considerados os seguintes parâmetros associados ao fator de ponderação dos fluxos:

- Geradores: fluxo mínimo $=30 \%$; máximo $=60 \%$ da capacidade da linha.

- Consumidores: fluxo mínimo $=40 \%$; máximo $=80 \%$ da capacidade da linha.

Uma das aplicações visualizadas para o fator Fpond $_{\mathrm{L}}$ é o tratamento diferenciado das linhas com baixo carregamento ou linhas de otimização energética, de interligação entre bacias ou regiões (por exemplo a interligação Norte-Sul), nas quais o sentido dos fluxos é variável em função da hidrologia. Para esses tipos de linhas deseja-se que não haja qualquer sinalização locacional pelo seu uso, deixando que sua contribuição para a cobertura da receita autorizada seja feita pela parcela de ajuste da tarifa. Nesses casos, elevando-se o valor do limite mínimo adequadamente, as linhas com baixos fluxos ficarão fora do cálculo da parcela locacional da tarifa.

- Parcela de Ajuste, como a tarifa locacional não recupera a totalidade dos custos de transmissão [68], já que o valor calculado é menor ou igual ao valor da rede, por tal motivo adiciona-se uma parcela de ajuste conhecida como parcela selo que é aplicada a todos os agentes (geradores e consumidores) de forma a recuperar os encargos necessários para a remuneração da rede de transmissão (3.13). 
$\pi_{\text {ajuste }}=\frac{R A-\sum_{b=1}^{N B} \pi_{b} \times G_{b}-d_{b}}{\sum_{b=1}^{N B} G_{b}+d_{b}}(\$ / \mathrm{MW})$

onde,

RA: Receita Anual a ser recuperada para remunera a rede (\$)

$\pi_{b}:$ Tarifa locacional na barra $b$

$\mathrm{G}_{\mathrm{b}}$ : geração na barra $b(\mathrm{MW})$;

$\mathrm{d}_{\mathrm{b}}$ : demanda na barra $b(\mathrm{MW})$;

NB : Número total de barras

- $\quad$ Ajuste para Geradores (3.14):

$$
\pi_{\text {ajuste__eradores }}=\frac{R A_{\text {geradores }}-\sum_{b=1}^{N B} \pi_{b} \times G_{b}}{\sum_{b=1}^{N B} G_{b}}\left(\$ / \mathrm{MW}_{\text {instalado }}\right)
$$

onde,

$R A_{\text {geradores }}:$ Montante da Receita Anual de transmissão atribuída aos geradores (50\% da receita total)

$\pi_{b}:$ Tarifa locacional na barra $b$

$G_{b} \quad$ : Capacidade instalada de geração na barra $b$

NB : Número total de barras

- Ajuste para Consumidores.

Similarmente, a parcela de ajuste para os consumidores é calculada a partir de (3.15):

$$
\pi_{\text {ajuste_consumidores }}=\frac{R A_{\text {consumidores }}-\sum_{b=1}^{N B} \pi_{b} \times d_{b}}{\sum_{b=1}^{N B} d_{b}}(\$ / \mathrm{MW})
$$

onde,

$R A_{\text {consumidores }}$ : Montante da Receita Anual de transmissão atribuída aos geradores (50\% da receita total)

$\pi_{b}:$ Tarifa locacional na barra $b$

$d_{b} \quad$ : demanda máxima na barra $b$

NB : Número total de barras

\subsubsection{Qualidade de Serviço do Sistema de Transmissão}

Segundo a ANEEL (Resolução Normativa No. 270/2007) foram estabelecidas as disposições relativas à qualidade do serviço público de transmissão associada à disponibilidade das instalações integrantes da Rede Básica. Entre os pontos mais importantes desta Normativa destacam-se: 
- A qualidade do serviço público de transmissão de energia elétrica será medida com base na disponibilidade e na capacidade plena das FTs (Função Transmissão), sendo estas consideradas indisponíveis quando ocorrer desligamento programado ou outros desligamentos ou atrasos na entrada em operação.

- O pagamento base de uma FT estará sujeito a desconto da Parcela Variável por Indisponibilidade e da Parcela Variável por Restrição Operativa Temporária.

- O período de Atraso na Entrada em Operação de uma FT, a ser apurado pelo ONS, a partir da hora zero do dia subseqüente à data estabelecida, será considerado como indisponibilidade por Atraso na Entrada em Operação, resultando em desconto no correspondente Pagamento Base, conforme critérios estabelecidos desta Resolução.

- Quando uma FT de linha de transmissão contiver equipamentos integrantes de mais de uma concessão de transmissão, aplicar-se-ão a essa FT os dispositivos desta Resolução, sendo os descontos das parcelas variáveis da FT imputados às concessionárias de transmissão responsáveis pelos eventos associados a tais descontos, cabendo ao ONS coordenar a apuração dos referidos eventos.

- O ONS encaminhará anualmente à ANEEL um relatório técnico de desempenho das FTs descritas no "caput", referindo-se, no mínimo, ao número, duração e responsabilidade dos desligamentos e das restrições operativas temporárias, bem como dos descontos das parcelas variáveis associadas, ocorridos no período [37].

\subsubsection{Expansão da Rede de Transmissão}

O mecanismo para a expansão da rede básica de transmissão troncal do sistema brasileiro baseia-se no planejamento determinativo centralizado. A construção, operação e manutenção das obras inclusas na Rede Básica são concedidas ao ofertante que solicite a menor receita anual nos leilões realizados.

\subsubsection{Expansão da Rede Local}

As propostas de expansão da transmissão são realizadas pelo ONS por meio do Plano de Ampliações e Reforços (PAR) e mediante acordo operacional com a Empresa de Pesquisas Energéticas (EPE). O PAR, dentro de um horizonte de planejamento de dois anos, informa anualmente os locais onde são necessários reforços ou ampliações de forma a manter o desempenho adequado da rede, garantir o funcionamento pleno do mercado e possibilitar o livre acesso ao sistema.

Uma vez decidida a realização de uma expansão, são realizados procedimentos de leilão público para eleger o investidor responsável da construção, operação e manutenção das novas instalações. 


\subsubsection{Expansões das Conexões Internacionais}

Segundo a convenção de comercialização de energia elétrica expedida pela Câmara de Comercialização de Energia Elétrica (CCEE) e autorizada pela ANEEL (Resolução Normativa n 109 de 26-outubro-2004) referente às transações internacionais, a importação é considerada para efeitos de pagamento pelo uso das redes, similar a uma usina térmica localizada na fronteira do país, enquanto que para a exportação é atribuída uma representação similar a uma carga.

$\mathrm{Na}$ atualidade, além do projeto binacional de Itaipu, envolvendo Brasil e Paraguai, a configuração atual contempla interligações do Brasil com a Argentina, Uruguai e Venezuela. A possibilidade de ampliação dessas interligações ou o estabelecimento de novos pontos de interligação tem sido objeto de análises específicas pelo MME [52].

\section{- Interconexão Elétrica Brasil-Paraguai}

A usina hidroelétrica de Itaipu foi o resultado de negociações entre estes dois países durante a década de 1960. Em 1966, ambos os países assinaram a "Ata de Iguaçu", uma declaração conjunta que manifestava a disposição para estudar o aproveitamento dos recursos hidráulicos pertencentes em condomínio aos dois países. Em 17 de maio de 1974, foi criada a entidade binacional Itaipu, para gerenciar a construção da usina. O início efetivo das obras ocorreu em 1975. A capacidade instalada da usina foi elevada para 14.000 MW com a entrada em operação da última unidade geradora a princípios de 2007, completando o projeto original de 20 máquinas. Da subestação de Itaipu transmite-se energia aos centros de consumo utilizando dois sistemas de transmissão, o primeiro com uma tensão de $750 \mathrm{kV}$ (CA) e o segundo em $500 \mathrm{kV}$ (CC).

\section{- Interconexão Elétrica Brasil-Argentina}

O Brasil possui duas interligações elétricas com a Argentina, ambas foram realizadas utilizando estações conversoras de freqüência $50 / 60 \mathrm{~Hz}$ do tipo back-to-back. A primeira estação conversora, com potência de $50 \mathrm{MW}$, está localizada na cidade de Uruguaiana, sendo conectada ao sistema Argentino através de uma linha de transmissão em $132 \mathrm{kV}$, entre a subestação de Uruguaiana no Brasil e a subestação de Passo de los Libres, na Argentina. A segunda estação conversora, Garabi, possui uma potência de $2200 \mathrm{MW}$, e está conectada, no lado Argentino, com a subestação de Rincón, através de uma linha de transmissão em 500 kV, e no lado Brasileiro à subestação de Garabi.

\section{- Interconexão Elétrica Brasil-Uruguai}

A interligação Brasil-Uruguai é realizada através de uma estação conversora de freqüência $50 / 60 \mathrm{~Hz}$, back-to-back, com uma potência instalada de 70 MW. No lado Uruguaio tem-se a subestação de Rivera, e no lado Brasileiro a subestação de Santana do Livramento. 
Atualmente está em estudo um novo ponto de interligação entre as subestações de San Carlos no Uruguai e uma futura subestação na região de Candiota (Brasil). No lado Uruguaio está prevista a construção de uma linha de transmissão em $500 \mathrm{kV}(50 \mathrm{~Hz})$ entre São Carlos e a estação conversora de freqüência (back-to-back) de 500 MW situada, provavelmente, na cidade de Melo (Uruguai), que estará vinculada à subestação de Candiota através de linha em $500 \mathrm{kV}$, previamente abaixada para 500/230 kV. Esta interligação visa, inicialmente, a exportação de energia do Brasil para o Uruguai, condicionada à disponibilidade de unidades térmicas não despachadas ou de fontes hidrelétricas que apresentem energia vertida turbinável.

\section{- Interconexão Elétrica Brasil-Venezuela}

A interligação Brasil-Venezuela é realizada através de um sistema de transmissão envolvendo tensões de 230/400 kV que conecta a subestação de Boa Vista no Brasil à subestação de El Guri, na Venezuela. A capacidade deste sistema é de 200 MW.

\section{- Importação}

A importação de energia elétrica é tida como uma fonte alternativa para ampliar a oferta de energia dentro do sistema elétrico Brasileiro. No período 1996-2002 a ANEEL autorizou a importação de $2.570 \mathrm{MW}$ de potência dos países vizinhos, conforme descrito na Tabela 3.9:

Tabela 3.9 Importação de energia (em operação) no Brasil

\begin{tabular}{|c|c|c|c|c|c|}
\hline $\begin{array}{c}\text { EMPRESA } \\
\text { AUTORIZADA }\end{array}$ & ORIGEM & $\begin{array}{l}\text { POTÊNCIA } \\
\text { (MW) }\end{array}$ & $\begin{array}{l}\text { PONTO DE } \\
\text { ENTREGA }\end{array}$ & RESOLUÇÃO & $\begin{array}{c}\text { DATA DE } \\
\text { ENTREGA EM } \\
\text { OPERAÇÃO }\end{array}$ \\
\hline ELETROBRAS & $\begin{array}{c}\text { Argentina } \\
\text { Paso de Los Libres }\end{array}$ & 50 & Uruguaiana/RS & $\begin{array}{c}\text { Portaria /DNAEE n } \\
324 \text { de 5/4/1994 }\end{array}$ & Maio/1996 \\
\hline COPEL & Paraguai & 50 & $\begin{array}{l}\text { Área de concessão } \\
\text { da COPEL - Paraná }\end{array}$ & $\begin{array}{c}\text { Resolução n }{ }^{\circ} 091 \mathrm{de} \\
02 / 03 / 2005\end{array}$ & Julho/1999 \\
\hline CIEN & $\begin{array}{l}\text { Argentina } \\
\text { Garabi }\end{array}$ & 1.000 & SE Ita-SC & $\begin{array}{c}\text { Resolução } n^{\circ} 130 \text { de } \\
29 / 4 / 1998\end{array}$ & Maio/2000 \\
\hline CIEN & $\begin{array}{l}\text { Argentina } \\
\text { Garabi }\end{array}$ & 100 & SE Ita-SC & 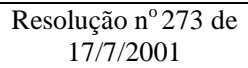 & Maio/2000 \\
\hline ELETROBRAS & $\begin{array}{l}\text { Uruguai } \\
\text { Rivera }\end{array}$ & 70 & $\begin{array}{c}\text { Santana do } \\
\text { Livramento 2-RS }\end{array}$ & $\begin{array}{c}\text { Resolução } \mathrm{n}^{\circ} 15 \mathrm{de} \\
14 / 01 / 2000\end{array}$ & Janeiro /2001 \\
\hline ELETRONORTE & Venezuela & 200 & Boa vista-PR & $\begin{array}{c}\text { Resolução n⿳20201 de } \\
6 / 6 / 2001\end{array}$ & Julho/2001 \\
\hline CIEN & $\begin{array}{l}\text { Argentina } \\
\text { Garabi }\end{array}$ & 1.100 & SE Ita -SC & $\begin{array}{c}\text { Resolução } \mathrm{n}^{\circ} 117 \text { de } \\
18 / 3 / 2002\end{array}$ & Agosto/2002 \\
\hline
\end{tabular}

Fonte: ANEEL

\subsubsection{Exemplos de Aplicação da Metodologia Locacional ao Caso do Sistema Brasileiro}

Na Figura (3.14) a seguir, pode-se observar que, para a determinação dos encargos de uso na transmissão, (TUST) são considerados aspectos como a configuração da rede, o tipo de usuário (geração ou carga), assim como os custos de investimento referenciais. Os preços nodais ajustados considerando uma mesma referência (barra) estabelecem que $T U S T_{\text {Geraşão }}=-T U S T_{C \arg a}$ para um nó 
qualquer do sistema. Ou seja, a TUST aplicada uma nova carga (agente) conectada em uma barra $i$ será igual ao caso do ingresso de um novo gerador nessa barra, mas com sinal trocado.

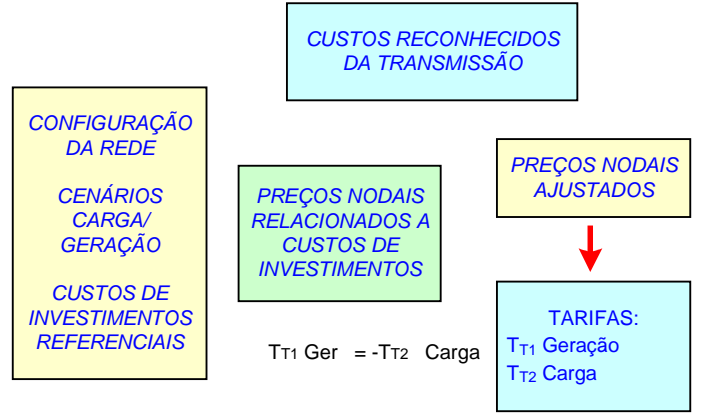

Figura 3.14 Determinação dos Encargos de Uso-TUST

Por outro lado, na Figura 3.15 estão sendo apresentadas de forma meramente esquemática, a rede local e as conexões da rede básica considerados na metodologia nodal, quando aplicadas ao caso do estado de São Paulo.

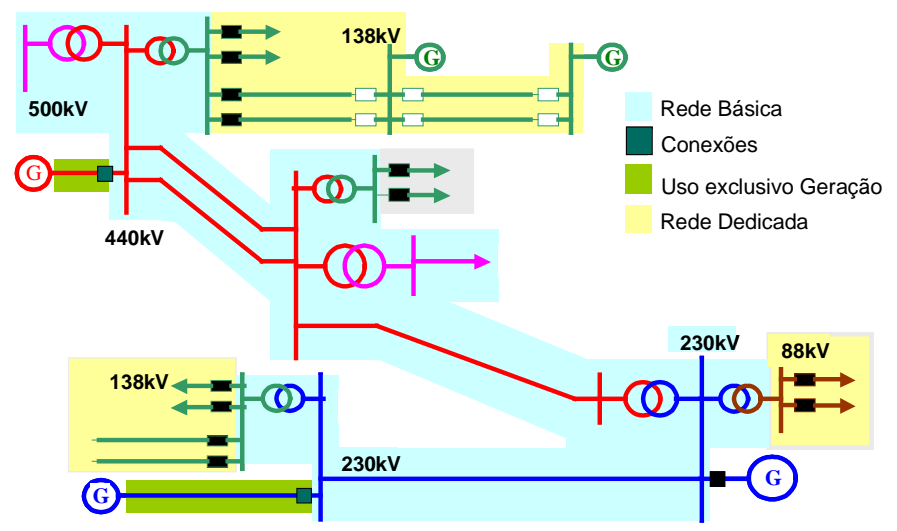

Figura 3.15 Sistema de Transmissão Rede Básica, Conexões e Rede Local

Nas Figuras 3.16(a) e (b) mostram-se exemplos de encargos, obtidos através de simulação com o Programa Nodal da ANEEL, caracterizando as diferenças devido às injeções e retiradas de potência para o caso das regiões elétricas do Estado de São Paulo. No caso das injeções (Figura 3.16a) pode-se ver que os encargos médios das regiões elétricas são menores perto dos centros de carga (isso pelo pouco uso das redes de transmissão), enquanto que estes encargos são maiores longe dos centros de consumo. Um panorama quase que contrário acontece no caso dos encargos por retiradas (Figura 3.16b), onde se observam menores encargos em regiões próximas aos pontos onde existe geração instalada. 


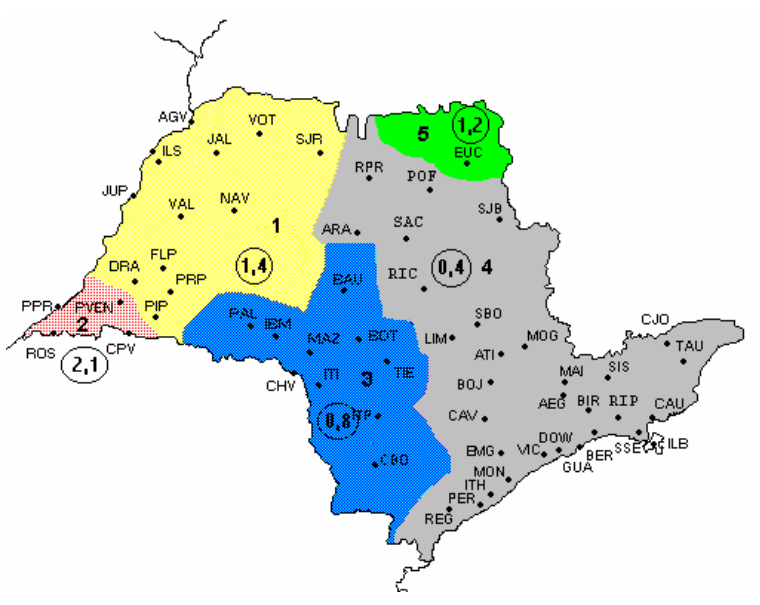

(a)

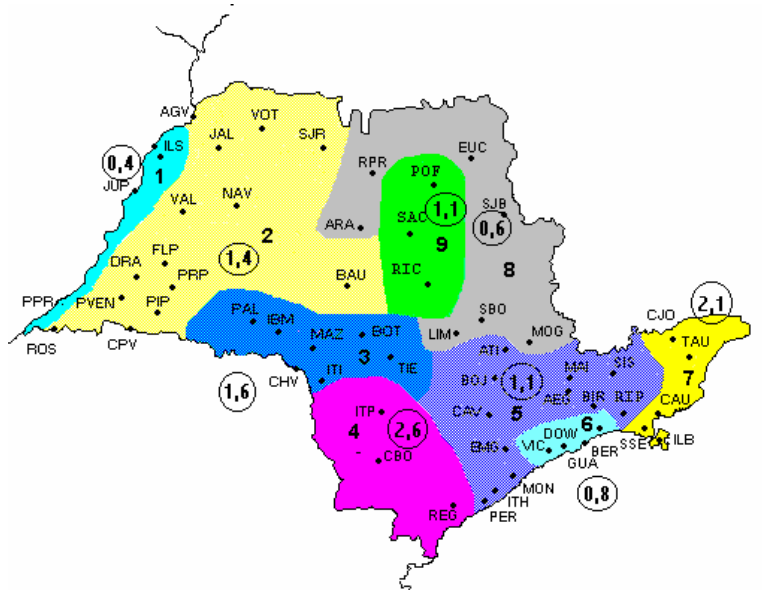

(b)

Figura 3.16 Encargos correspondentes a: (a) Injeções, (b) Retiradas

Um exemplo mostrando o caso dos encargos aplicáveis a agentes geradores considerando a agregação por zonas, na região Sudeste do Brasil, pode ser visto na Figura 3.17. Podem ser observadas as zonas de carga (com sinal negativo) e a zona de geração, neste caso constituído por Itaipu.

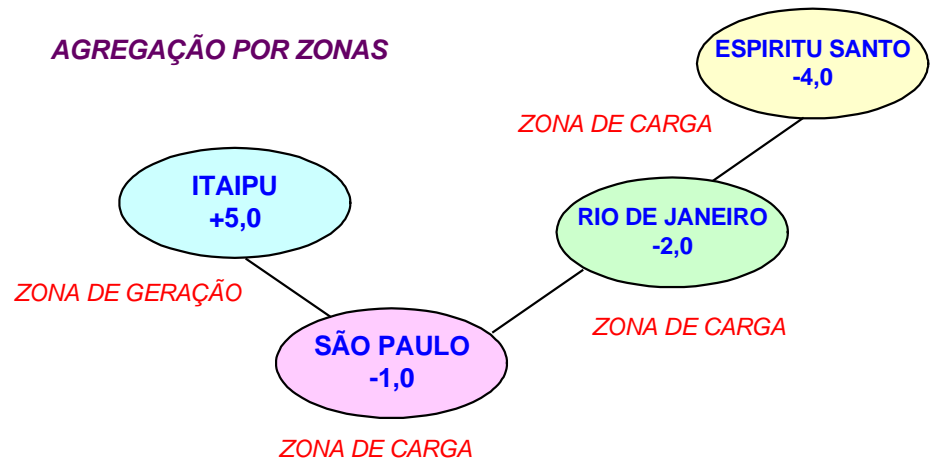

Figura 3.17 Tarifas Nodais: encargos na transmissão segundo zonas de geração ou carga

Como outro exemplo, os encargos de transmissão estabelecidos para algumas plantas térmicas que chegaram a ser projetadas para instalação no Estado de São Paulo, podem ser vistos na Figura 3.18. Diferentemente dos casos anteriores, neste exemplo mostram-se situações particulares de encargos. Pode-se ver que o valor médio dos encargos deste grupo de UTE's está entorno de 0,8-1,0 R\$/kWmês. De fato, estes valores apresentarão diferenças no caso de plantas térmicas localizadas em outros estados, como no Nordeste, que estejam dispostas a suprir de energia aos grandes centros de consumo na região Sul e Sudeste do país. 


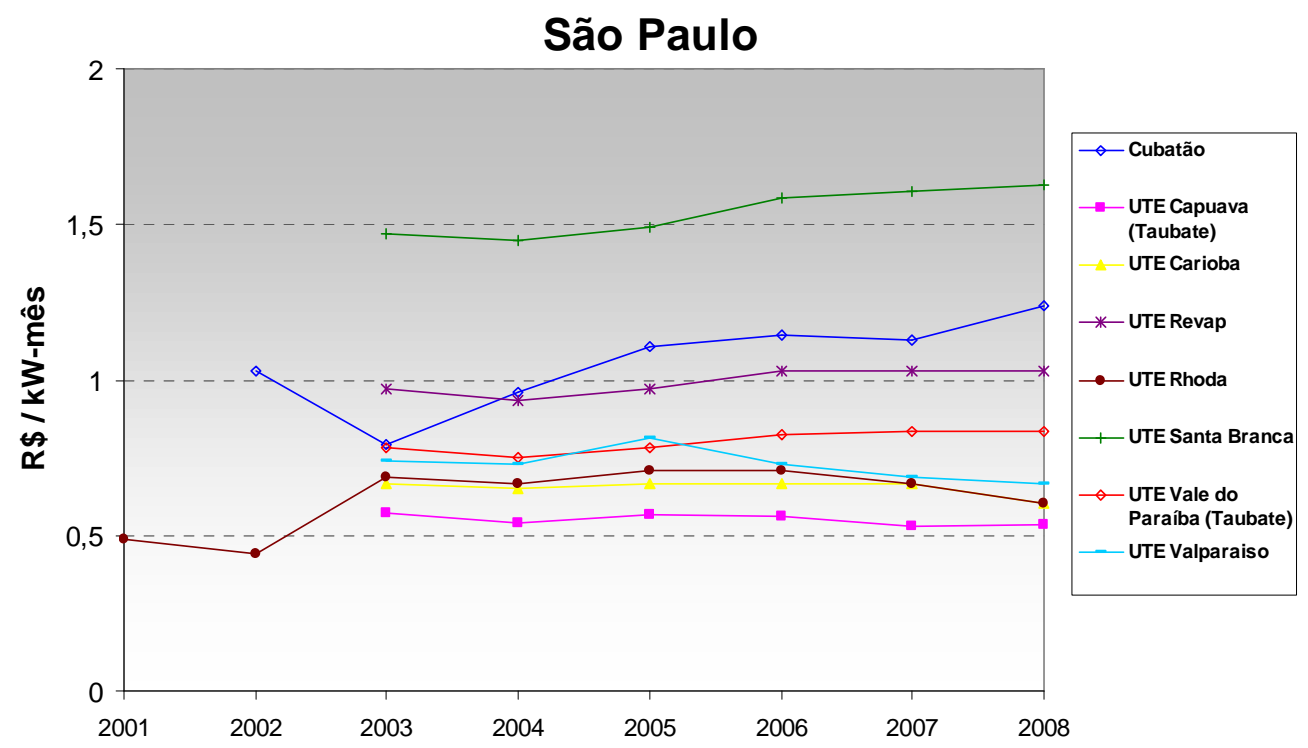

Figura 3.18 Tarifas de transmissão estabelecidas e pagas por plantas térmicas

\subsection{CHILE}

Atualmente, o setor elétrico chileno está constituído quase que exclusivamente por empresas com capitais privados. O Estado faz o papel de regulador, fiscalizador e incentiva os investimentos através do CNE (Comissão Nacional de Energia). O mercado elétrico chileno está formado por quatro sistemas elétricos independentes [35], sendo estes (Figura 3.19):

- Sistema Interconectado Central (SIC)

- Sistema Interconectado do Norte Grande (SING)

- Sistema Aysen

- Sistema Magallanes

O Sistema Interconectado Central (SIC) atende aproximadamente a 92\% da população. No ano 2006 a potência instalada do SIC era de 8273,6 MW sendo a geração hidroelétrica a mais predominante (Tabela 3.10). O Sistema Integrado do Norte Grande (SING) é o segundo maior sistema interconectado, sendo a geração térmica a mais predominante. Neste sistema atende-se principalmente a consumidores industriais (mineiros). No ano 2006, a potência instalada do SING foi de 3595,8 MW.

Tabela 3.10 Potência instalada segundo o tipo de geração no Chile (31/12/2006)

\begin{tabular}{|l|r|r|r|r|}
\hline \multirow{2}{*}{ Sistema } & \multicolumn{2}{|c|}{ Potência Instalada Total } & \multicolumn{2}{c|}{$\begin{array}{c}\text { Total } \\
\text { Sistema (MW) }\end{array}$} \\
\cline { 2 - 4 } & \multicolumn{1}{|c|}{$\begin{array}{c}\text { Térmica } \\
\text { (MW) }\end{array}$} & \multicolumn{1}{c|}{$\begin{array}{c}\text { Hidráulica } \\
\text { (MW) }\end{array}$} & \multicolumn{1}{c|}{$\begin{array}{c}\text { Eólica } \\
\text { (MW) }\end{array}$} & 3595,8 \\
SING & 3583,0 & 12,8 & 0,0 & 8273,6 \\
SIC & 3575,0 & 4698,6 & 0,0 & 33,3 \\
AYSÉN & 13,7 & 17,6 & 2,0 & 65,2 \\
MAGALLANES & 65,2 & 0,0 & 0,0 & 11967,2 \\
\hline Total Nacional & 7236,9 & 4729,0 & 2,0 & \\
\hline
\end{tabular}

Fonte: Anuário CDEC-SIC, Estadísticas de operación CDEC-SIC 


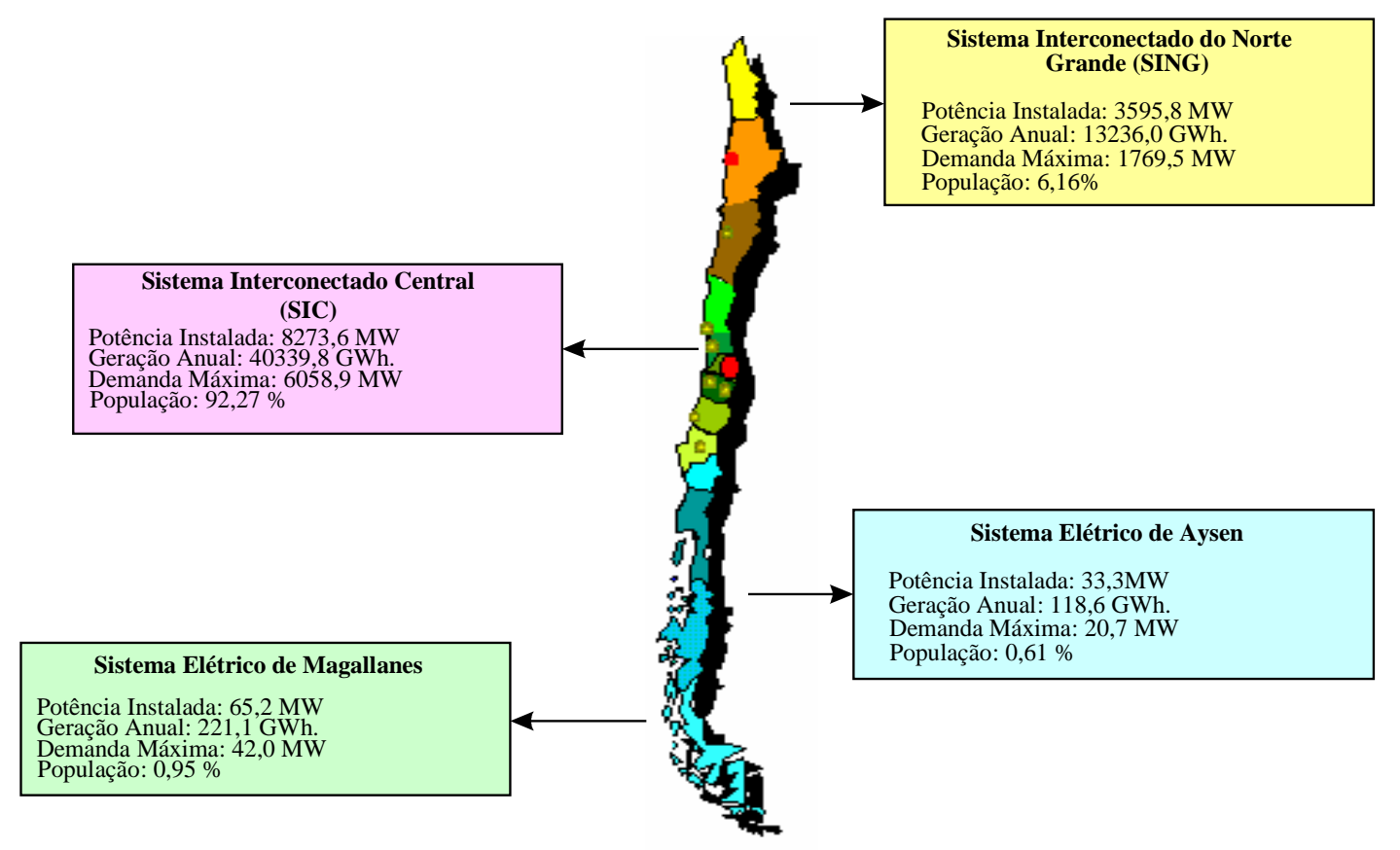

Figura 3.19 Principais sistemas elétricos no Chile (Fonte: CDEC- 2006)

\subsubsection{A Transformação do Setor Elétrico Chileno}

\section{a) Legislação do Setor Elétrico}

O mercado elétrico Chileno foi o "pioneiro" no mundo na abertura e liberalização de seu setor elétrico. A reestruturação deste setor iniciou-se em 1978 [35]. No ano 1982, foi promulgada a Lei Geral de Serviços Elétricos (DFL No. 1) que regula a industria elétrica. A operação dos centros de despacho econômico de carga foi regulamentada através do DS No. 6 de 1985. Na Quadro 3.5 apresentam-se as principais leis e decretos que fazem parte da normativa legal atualmente em vigência para esse segmento.

Quadro 3.5 Leis, Decretos e principais modificações à regulamentação Chilena

\begin{tabular}{|l|l|}
\hline \multicolumn{1}{|c|}{ Lei/ Decreto } & \multicolumn{1}{c|}{ Descrição } \\
\hline D.F.L 1/1982 & Lei Geral de Serviços Elétricos \\
\hline DS 119/1989 & Estabelecimento das sanções em matéria de eletricidade e combustíveis. \\
\hline Decreto Supremo 327/1998 & Regulamento da Lei Geral de Serviços Elétricos \\
\hline Decreto Supremo 158/2003 & $\begin{array}{l}\text { Mudanças ao transporte de eletricidade com novas metodologias para o cálculo de } \\
\text { pedágios. }\end{array}$ \\
\hline Lei 19613/1999 & Novas definições sobre qualidade de serviço e racionamento (Art. 99bis) \\
\hline Lei 19940/2004 & $\begin{array}{l}\text { Lei Curta I. Que modificou o DFL-1. Regula o sistema de transporte e tarificação } \\
\text { da energia elétrica. }\end{array}$ \\
\hline Lei 20018/2005 & Lei Curta II. Que regulamenta aspectos relacionados com a geração. \\
\hline
\end{tabular}

\section{- A Lei Curta I (Lei 19940/2004)}

A Lei 19940, conhecida como "Lei Curta I", foi promulgada com o intuito de aprimorar a legislação referente à remuneração da transmissão, remuneração de serviços complementares, fixação de tarifas de distribuição e solução de divergências. Quanto à transmissão elétrica, esta lei re-desenhou o sistema de transmissão, dividindo-o em três subsistemas: Principal, Subtransmissão 
e Adicional, modificando assim o cálculo do pedágio e estabelecendo novas normas para os estudos de expansão e desenvolvimento do sistema principal a serem realizados a cada quatro anos. Esta lei também estabelece que o preço do transporte em sistemas medianos (1.5 MW e 200 MW) seja realizado com base no custo incremental de desenvolvimento, no lugar da média do custo marginal, que era aplicado antes da promulgação desta lei.

\section{- $\quad$ A Lei Curta II (Lei 20018/2005)}

A Lei Curta II, que foi um complemento às mudanças feitas pela Lei Curta I, foi promulgada em Maio de 2005. O objetivo desta lei é de outorgar segurança aos investimentos orientados ao fornecimento elétrico de longo prazo. Além disso, esta lei protege aos consumidores frente a eventuais crises energéticas, especialmente do suprimento de gás natural (devido à instabilidade energética acontecida na Argentina, principal fornecedora de gás natural à industria Chilena).

\section{b) Organização Institucional do Setor Elétrico}

O mercado elétrico Chileno possui quatro instituições principais: o Comitê de Despacho Econômico de Carga (CDEC), a Comissão Nacional de Energia (CNE), o Ministério de Economia e, a Superintendência de Eletricidade e Combustíveis (SEC). A seguir serão descritas as principais atribuições destas instituições:

- Ministério de Economia, Fomento e Reconstrução. Responsável pelo cumprimento das leis através da Superintendência de Eletricidade e Combustíveis (SEC), sem prejudicar as atribuições conferidas tanto à Comissão Nacional de Energia (CNE) e ao próprio Ministério de Economia (Art.9, DFL 1/1982). É também responsável de fixar os preços das tarifas propostas pelo CNE (Art. 92, DFL 1/1982).

- Superintendência de Eletricidade e Combustíveis (SEC). Responsável de controlar o cumprimento das normativas de qualidade e segurança do serviço. É também responsável de apoiar ao Ministério nos trâmites para outorgar as concessões definitivas e outorgar as concessões regionais a serem solicitadas pelas empresas de transmissão.

- Comissão Nacional de Energia (CNE). Órgão de maior hierarquia do poder Executivo é responsável por propor políticas para o setor, bem como de regulamentar as atividades estabelecidas na lei, por exemplo, a regulamentação das tarifas no segmento de transmissão troncal e de subtransmissão. Define as bases técnicas para estabelecer os critérios de determinação dos pedágios e os preços nestes segmentos.

- A Comissão Nacional do Meio Ambiente (CONAMA). Órgão encarregado de aplicar o Sistema de Avaliação de Impacto Ambiental (SEIA). A normativa ambiental exige aos projetos de transmissão se submeter ao SEIA. Os projetos propostos não podem operar caso não cumpram de forma satisfatória com os requisitos ambientais. 
- Centro de Despacho Econômico de Carga (CDEC). Órgão encarregado da coordenação da operação de curto prazo. É também responsável de determinar os pagamentos entre empresas, produto das transferências de energia e potência no mercado de curto prazo. O CDEC está formado pelas próprias empresas geradoras e transmissoras que são também as que o financiam. Corresponde ao CDEC, através de sua Direção de Pedágios, a determinação específica do valor dos pedágios de injeção e de retirada que constitui a remuneração dos sistemas de transmissão troncal.

\subsubsection{O Sistema de Transmissão}

As instalações dos sistemas de transmissão principal e dos sistemas de subtransmissão de cada sistema elétrico estão submetidas a um regime de acesso aberto, podendo ser utilizadas por terceiros sob condições técnicas e econômicas não discriminatórias.

a) Tensões do Sistema. No sistema Chileno as tensões utilizadas no nível de transmissão são: 500 kV, $220 \mathrm{kV}, 154 \mathrm{kV}, 110 \mathrm{kV}$ e $66 \mathrm{kV}$.

b) Concessionárias de Transmissão. Na Tabela 3.11 mostram-se as principais concessionárias de transmissão existentes no SIC e no SING, bem como a porcentagem que representam estas instalações nestes sistemas.

Tabela 3.11 Principais Concessionárias de Transmissão no SIC e no SING (Dez. 2004)

\begin{tabular}{|l|l|l|}
\multicolumn{3}{|c}{ SIC } \\
\hline Proprietário & $\begin{array}{c}\text { km de } \\
\text { linha }\end{array}$ & \multicolumn{1}{c|}{$\%$} \\
\hline HQI & $7.890,2$ & $53,8 \%$ \\
\hline Gener & 578,3 & $3,9 \%$ \\
\hline Colbún & 806,4 & $5,5 \%$ \\
\hline Pangue & 517,4 & $3,5 \%$ \\
\hline Guacolda & 202,7 & $1,4 \%$ \\
\hline Ibener & 36,0 & $0,2 \%$ \\
\hline Chilquinta & 319,3 & $2,2 \%$ \\
\hline Chilectra & 456,7 & $3,1 \%$ \\
\hline Transquillota & 15,9 & $0,1 \%$ \\
\hline CGE & $2.337,6$ & $15,9 \%$ \\
\hline Conafe & 5,4 & $0,0 \%$ \\
\hline Emelat & 228,6 & $1,6 \%$ \\
\hline Emelectric & 333,1 & $2,3 \%$ \\
\hline Emelat & 228,6 & $1,6 \%$ \\
\hline $\begin{array}{l}\text { Min. } \\
\text { Valparaíso }\end{array}$ & 164,7 & $1,1 \%$ \\
\hline Hasa & 17,7 & $0,1 \%$ \\
\hline HGV & 51,4 & $0,4 \%$ \\
\hline P. Alto & 10,7 & $0,1 \%$ \\
\hline STS & 526,6 & $3,6 \%$ \\
\hline Petropower & 1,3 & $0,0 \%$ \\
\hline R. Maipo & 26,5 & $0,2 \%$ \\
\hline Puyehue & 86,6 & $0,6 \%$ \\
\hline Capullo & 55,0 & $0,4 \%$ \\
\hline Total & $\mathbf{1 4 . 6 6 8 , 1}$ & $\mathbf{1 0 0 , 0 \%}$ \\
\hline
\end{tabular}

\begin{tabular}{|l|l|l|}
\hline \multicolumn{1}{|c|}{ Proprietário } & $\begin{array}{c}\text { km de } \\
\text { linha }\end{array}$ & \multicolumn{1}{c|}{$\%$} \\
\hline AES Gener & 604,6 & $10,1 \%$ \\
\hline Edelnor & 1047,4 & $17,6 \%$ \\
\hline Electroandina & 1036,8 & $17,4 \%$ \\
\hline Norgener & 310,0 & $5,2 \%$ \\
\hline Transelec Norte & 957,8 & $16,1 \%$ \\
\hline Transemel & 74,4 & $1,2 \%$ \\
\hline Collahuasi & 437,0 & $7,3 \%$ \\
\hline Chuquicamata & 23,9 & $0,4 \%$ \\
\hline Escondida & 901,0 & $15,1 \%$ \\
\hline $\begin{array}{l}\text { Fundición Alto } \\
\text { Norte }\end{array}$ & 4,0 & $0,1 \%$ \\
\hline $\begin{array}{l}\text { Minera Cerro } \\
\text { Colorado }\end{array}$ & 61,0 & $1,0 \%$ \\
\hline Minera el Tesoro & 90,0 & $1,5 \%$ \\
\hline Minera La Cascada & 55,0 & $0,9 \%$ \\
\hline Minera Meridian & 63,0 & $1,1 \%$ \\
\hline Minera Michilla & 72,0 & $1,2 \%$ \\
\hline Quebrada Blanca & 18,0 & $0,3 \%$ \\
\hline Zaldivar & 208,2 & $3,5 \%$ \\
\hline Total & $\mathbf{5 9 6 4 , 0}$ & $\mathbf{1 0 0 , 0 \%}$ \\
\hline
\end{tabular}


Segundo a Lei de Eletricidade, não existe um monopólio legal a favor de uma única empresa de transmissão em alta tensão. Porém, boa parte das instalações de transmissão no SIC (154-220 kV e $500 \mathrm{kV}$ ) é administrada pela empresa privada Hidro Quebec-Transelec Chile S.A., a qual também administra parte do Sistema Interconectado do Norte Grande (SING), [36].

(c) Método Base de Tarifação. Tarifação Nodal baseada em custos marginais de curto prazo e com encargos por conexão.

\subsubsection{Regulamentação dos Preços de Transmissão}

Um dos temas mais debatidos no setor da transmissão foi a tarifação e expansão da rede de alta tensão. Segundo [28], as fórmulas estabelecidas nos DS No.6/1985, No. 327/1997, e modificados pela Resolução Ministerial No. 52/ 2002 e pelo DS No. 158/2003, não permitiam que o proprietário do sistema de transmissão recuperasse, de forma satisfatória, a totalidade de seus custos associados (custo de capital, de operação e manutenção) desincentivando assim as expansões necessárias na rede de transmissão. Face a este problema, introduziram-se importantes mudanças ao DFL-1982, através da Lei 19940 (Lei Curta I), que tem como um de seus principais objetivos permitir que o proprietário da rede de transmissão recupere todos os seus custos de capital e operação através do estabelecimento de tarifas regulamentadas para a rede principal.

A seguir será descrito o tratamento referente ao pagamento dos sistemas de transmissão antes e depois da formulação da denominada Lei Curta I:

\section{a) Antes da Reforma.}

A legislação assegurava aos proprietários dos sistemas de transmissão o pagamento pelo custo do investimento das instalações na forma do um Valor Novo de Reposição ou Substituição (VNR). O pagamento era efetuado pelos geradores segundo o uso que estes faziam das instalações (transformação e transmissão) do sistema. Estas instalações deviam fazer parte da área de influência do gerador. Pela legislação Chilena, definia-se a "área de influência" como o conjunto de linhas, subestações e outras instalações do sistema elétrico diretamente afetadas pela injeção de potência, e energia, de uma determinada usina de geração.

- Receita Tarifária. Na legislação Chilena esta receita é conhecida como Ingresso Tarifário (IT) e corresponde à diferença produzida ao valorizar as injeções e retiradas (potência e energia) com os preços nodais vigentes em cada nó da área de influência (Art. 51C do DFL $\mathrm{N}^{\mathrm{o}} 1 / 82$ ). Este valor era estimado para um período de cinco anos sobre a base dos preços de nó vigentes na data de determinação do pedágio e sob condições normais de operação (Art. $3^{\circ}$ do DFL-1/1982). 
$R T=($ Preço 2) $E-($ Preço 1) $(E+L)$

onde,

$R T$ : Receita Tarifaria

$E$ : Energia transmitida no tramo 1-2

$L$ : Perdas de transmissão do tramo 1-2

- Pedágio Básico. Segundo o Art. 51 do DFL-1/1982 e o Art. 88 do DS 327, o pedágio básico resulta da soma das anualidades correspondentes aos custos de operação, manutenção e investimento nas linhas, subestações e outras instalações envolvidas numa área de influência, subtraindo a receita tarifária anual. A anualidade do investimento calcula-se a partir do $V N R$, considerando a vida útil das instalações em 30 anos, e uma taxa de atualização (10\%) para o cálculo dos preços de nó. Este pedágio básico pode ser representado pela seguinte expressão:

$P d g=A V N R+C O M A-R T$

onde,

COMA : Custo de Operação e Manutenção

$R T$ : Receita Tarifária

AVNR : Anualidade do Valor Novo de Reposição (Substituição)

$$
A V N R=\frac{V N R^{*} r}{1-\left(\frac{1}{1+r}\right)^{n}}
$$

onde,

AVNR: $\quad$ Anualidade do Valor Novo de Reposição (Substituição)

$r \quad: \quad$ Taxa de desconto real anual $(\approx 10 \%)$

$n \quad: \quad$ Horizonte de avaliação $(\approx 30$ anos $)$

- Quanto aos pedágios adicionais, segundo o Art. 51E do DFL-1/1982 e o Art. 91 do DS 327, para a comercialização de energia fora de sua área de influência, o gerador devia pagar um pedágio adicional ao proprietário das instalações envolvidas. Este pedágio era calculado da forma similar ao pedágio básico.

\section{b) Posterior à Reforma.}

A lei vigente (Lei 19940) segmenta o sistema de transmissão Chileno em três subsistemas: Sistema de Transmissão Troncal, Sistema de Subtransmissão e Sistemas Adicionais [63]. 
- Sistema de Transmissão Troncal (STT) Constituído pelas linhas e subestações elétricas que são economicamente eficientes e necessárias para possibilitar o fornecimento da totalidade da demanda do respectivo sistema elétrico. Segundo o Art. 71-2 da Lei Curta, as instalações do STT deverão cumprir com as seguintes características:

i) Possuir fluxos de potência cuja variação seja relevante em magnitude e sentido de modo a fornecer uma demanda com diferentes cenários (geração, contingências e falhas).

ii) Ter um nível de tensão nominal igual ou maior a $220 \mathrm{kV}$.

iii) A magnitude dos fluxos não deverá estar determinada apenas pelo consumo de um determinado número de consumidores e/ou geradores.

iv) A linha de transmissão deverá estar composta por tramos com fluxos bidirecionais relevantes.

O STT apresenta uma área de influência comum (Figura 3.15) definida pelo Art. 71-30(c) da Lei Curta I. A referida área refere-se a área fixada para efeitos de remuneração do Sistema Troncal e constituída pelo conjunto mínimo de instalações entre dois nós do sistema, no qual possam-se cumprir pelo menos as seguintes características:

- A AIC (Área de Influência Comum) deve totalizar pelo menos o 75\% da injeção de energia e $75 \%$ da demanda, sendo que os geradores deverão cobrir o $80 \%$ dos custos e os consumidores $20 \%$, rateados em função das injeções esperadas e as retiradas esperadas respectivamente.

- Das instalações principais (troncais) que não pertençam ao AIC, os geradores a montante pagam $100 \%$ das instalações que possuem fluxos até a mesma. Os consumidores a jusante pagam $100 \%$ das instalações que tem fluxos na saída da mesma.

Na Figura 3.20, o gerador G1 assume o custo do tramo utilizado quando o fluxo flui em direção do AIC, enquanto que a demanda D1 não paga nada. Por outro lado, o gerador G2 não paga nada pelo fluxo que flui entre o AIC e este. A demanda D2 assume o pagamento pelo uso deste segundo tramo, isso quando D2>G2 ou se D2 decide comprar energia diretamente do AIC.

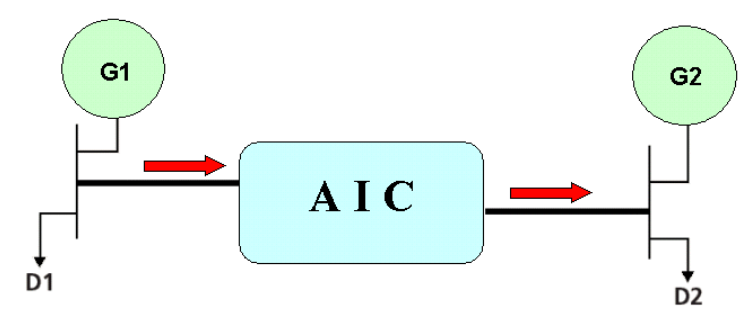

Figura 3.20 Área de Influência Comum 
- Sistema de Subtransmissão (SST). Cada um dos sistemas de subtransmissão estará constituído pelas linhas e subestações elétricas as quais deverão estar predispostas para o fornecimento exclusivo a grupos de consumidores finais livres ou regulados (Art. 71-3 da Lei Curta I). Desde o ponto de vista operativo, estas instalações servem para tomar a energia do Sistema Troncal e transportá-la até a entrada dos sistemas de distribuição para seu posterior direcionamento aos clientes finais localizadas nessas zonas.

- Sistema de Transmissão Adicional (STA). Constituído pelas instalações de transmissão de uso particular, constituídas por linhas elétricas disponíveis para a injeção de energia ao sistema por parte de centrais ou para a retirada de grandes clientes. No caso em que terceiros façam uso delas estabelece-se um procedimento de acordo bilateral, que em caso de discrepâncias deve ser solucionado no esquema de resolução de conflitos instaurado na lei. (Art. 71-4 da Lei Curta I).

\subsubsection{Mecanismo de Remuneração}

De forma similar à Lei anterior (DFL 1) o transmissor terá direito a receber uma remuneração que permitirá a este recuperar seus custos de capital e operação. Segundo [29], as receitas do transmissor dependem do sistema ao qual pertencem. No caso do Sistema de Transmissão Troncal (SST) a remuneração depende do fato de se tratar de instalações existentes ou novas. Para as instalações existentes, determina-se para cada tramo o "valor anual da transmissão por tramo" (VATT), composto pela anualidade do "Valor de Investimento" (VI) do tramo, mais os correspondentes custos anuais de operação, manutenção e administração (COMA).

$V A T T=V I+C O M A$

onde,

$V I \quad:$ Anualidade do valor de Investimento das instalações do ST, que substitui ao antigo conceito de $V N R$

COMA : Corresponde ao custo anual da operação, manutenção e administração do tramo

O Valor de Investimento $(V I)$ de uma instalação de transmissão é a soma dos custos de aquisição e instalação de seus componentes, segundo os valores do mercado.

No artigo 71(9-10-11) da Lei Curta I, menciona-se que a remuneração às instalações existentes é determinada pelo VI (Anualidade do Valor Novo de Investimento) das instalações a preços de mercado atuais. A Anualidade do VI é calculado considerando a vida útil econômica de cada tipo de instalação que o compõe segundo o regulamento e considerando a taxa de desconto de $10 \%$ real anual.

A cada quatro anos, a Comissão Nacional de Energia fixa as tarifas pelo uso do sistema troncal baseado em um estudo de expansão deste sistema para os próximos 10 anos. Este estudo é determinado por consultores independentes e deve entregar entre outros: o $V I$ e o COMA das instalações do sistema troncal, novas instalações candidatas a formar parte desde 
sistema e as novas instalações ou expansões requeridas e que deverão fazer parte desse sistema.

\subsubsection{Mecanismo de Arrecadação}

A receita tarifária (mantida vigente na Lei 19940) resulta da aplicação dos custos marginais de curto prazo (preços spot) esperados no sistema em relação às injeções e retiradas de potência e energia nesse tramo [37].

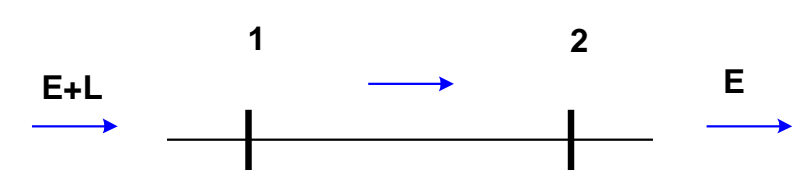

$R T=($ Preço 2) $E-($ Preço 1) $(E+L)$

onde,

$R T$ : Receita Tarifaria

$E$ : Energia Transmitida no tramo

$L$ : Perdas de transmissão do tramo

Em relação aos pedágios, estes são determinados de forma similar à metodologia previa à reforma, ou seja, resulta da diferença entre o Valor Anual da Transmissão por Tramo (VATT) e as receitas percebidas por conceito de receitas tarifárias $(R T)$.

$P d g=(V I+C O M A)-R T$

Conforme equação (3.19), VI+COMA = VATT

Ter-se-á então,

$P d g=V A T T-R T$

O pedágio é pago pelos geradores em função da injeção de energia e pelos consumidores em função da retirada de energia.

Já no caso do Sistema de Subtransmissão (Artigo 71-36 da Lei Curta I), o valor anual estará baseado nas instalações economicamente adaptadas à demanda projetada para um período de 4 a 10 anos, que minimize questões como o custo atualizado de investimento, operação e contingências, eficientemente operadas, e que considere separadamente os seguintes componentes:

$C_{S S T}=A V I+C O M A+$ CperMed $_{(P, E)}$

onde,

$\mathrm{C}_{S S T} \quad$ : Custo do Sistema Secundário de Transmissão

$\operatorname{CperMed}_{(P, E)}$ : Custo das perdas médias de subtransmissão de potência e energia

Para a determinação dos pedágios (Art. 71-37 Lei 19940), em cada barra de retirada do SST são estabelecidos preços por unidade de energia e de potência (pedágios de subtransmissão), 
os quais, uma vez adicionados aos preços de nó, nas suas respectivas barras de injeção, constituem os preços de nó nas suas respectivas barras de retirada, de forma que satisfaçam os custos anuais além dos custos de energia e potência injetada.

\subsubsection{Qualidade de Serviço do Sistema de Transmissão}

Segundo o Art. 5-71 da Comissão Nacional de Energia (03/2005), relacionada às Normas Técnicas de Segurança e Qualidade de Serviço, estabelece-se que a qualidade de fornecimento do sistema de transmissão será avaliada através da freqüência de interrupções no fornecimento de potência e do tempo total de interrupção da energia. Será considerada como instalação afetada (linha), aquela cuja saída de serviço produza a interrupção do fluxo de potência nesta. As interrupções deverão ser medidas pelos índices de continuidade FMIK e TTIK:

$$
\begin{gathered}
F M I K=\frac{\sum_{i=1}^{n} k V A f s_{i}}{k V A_{\text {inst }}} \\
T T I K=\frac{\sum_{i=1}^{n} k V A f s_{i} * T f s_{i}}{k V A_{\text {inst }}}
\end{gathered}
$$

onde,

$K V A f s_{\mathrm{i}}$ : Potência interrompida no ponto de conexão, expressa em (kVA). Nos casos em que não exista equipamento de transformação, será computada a potência que estava sendo transportada antes da interrupção através da instalação afetada. De não resultar possível a sua determinação, esta será considerada igual à potência máxima transportada pela instalação que foi afetada no período controlado.

KVAinst: Potência instalada no ponto de conexão, expressa em (kVA). Nos casos em que não exista equipamento de transformação, será considerada a potência máxima transportada pela instalação no período controlado.

$\mathrm{Tfs}_{\mathrm{i}} \quad$ : Tempo de duração de cada interrupção.

$N \quad$ : Número de interrupções no período controlado.

\subsubsection{Expansão da Rede de Transmissão}

Uma das características mais distintivas da Lei 19940 (Lei Curta I) é a introdução de um processo centralizado e multilateral para decidir a expansão ou desenvolvimento da transmissão troncal, substituindo assim o esquema descentralizado ${ }^{10}$ de acordos bilaterais estabelecidos na anterior lei (DFL 1). Já no referente ao sistema de subtransmissão (SST), foi adotado o esquema centralizado e unilateral segundo o critério do operador.

\subsubsection{Expansão Local}

- Sistema Troncal. Conforme o Art. 71-12 da Lei Curta I, a cada quatro (4) anos é realizado um estudo da rede de transmissão troncal para distintos cenários de expansão da geração e de interconexões com outros sistemas elétricos, cujo processo de elaboração é dirigido e coordenado pela CNE (Comissão Nacional de Energia).

\footnotetext{
${ }^{10} \mathrm{O}$ modelo foi considerado inadequado particularmente nos sistemas de maior tensão e ou de maior uso compartilhado.
} 
O estudo é realizado considerando instalações que resultem economicamente eficientes e necessárias para o desenvolvimento do respectivo sistema elétrico nas distintas alternativas de expansão.

O Centro de Despacho Econômico de Carga (CDEC) analisa os benefícios e os incrementos no pedágio provocados pelo plano de expansão. As ampliações de instalações existentes são responsabilidade do proprietário, enquanto que as novas obras são leiloadas internacionalmente. No caso do sistema adicional de transmissão, as expansões são efetuadas segundo acordo entre partes.

Anualmente, o CDEC analisa a consistência entre os resultados deste estudo e o desenvolvimento efetivo em matéria de investimento na geração e evolução da demanda. O resultado desta análise permite a emissão de um informe ao CNE conjuntamente suas propostas relacionadas às obras que se devem realizar ou iniciar nos próximos 12 meses, e assim garantir o fornecimento à demanda. Pela sua vez, em um prazo de 30 dias depois de ter recebido o informe do CDEC, a CNE apresenta o plano de expansão para os próximos 12 meses.

- Expansões Construídas a Risco do Investidor. No Art. 71-45 (Lei Curta I) estabelece-se que qualquer empresa elétrica interessada em desenvolver, operar ou utilizar o sistema de interconexão, poderá, através de um procedimento público, ser convocada segundo um processo de negociação aberto, com a finalidade de determinar as características técnicas e prazos de entrada em operação de determinado projeto de transmissão.

\subsubsection{Expansão das Conexões Internacionais}

Conforme enunciado por [38], apesar do Chile ter sido o pioneiro na desregulamentação de seu setor elétrico (iniciado em 1982), o esquema regulatório Chileno ainda não incorporou uma normativa que regule a interconexão internacional.

Não existe interconexão internacional que vincule o sistema Chileno com os sistemas de outros países. Atualmente tem-se conhecimento da existência de protocolos de integração energético subscrito com a Argentina, que estabelecem condições básicas de reciprocidade para materializar intercâmbios de energia elétrica.

\subsection{PERU}

A capacidade instalada de geração no Peru, a Dezembro de 2006, era de 6548MW, o que representou um incremento de 5,6\% em relação à capacidade instalada em 2005. As usinas hidroelétricas tinham em 2006, uma potência instalada de 3208 MW o que representava $49 \%$ do total. Já a capacidade instalada da geração térmica era de 3339 MW, que representava 51\% do total (Figura 3.11). Por outro lado, a capacidade instalada do SEIN (Sistema Elétrico Integrado Nacional), em 2006, representava 
85\% do total, enquanto que a dos Sistemas Isolados (SSAA) representou 15\%. Na Figura 3.21 mostrase também a distribuição da potência instalada no sistema Peruano.

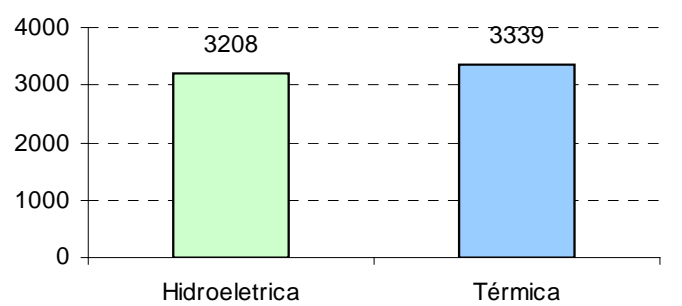

(a)

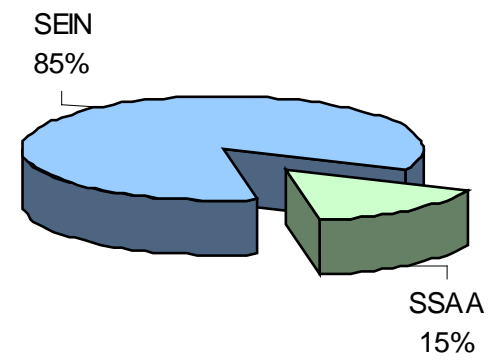

(b)

Figura 3.21 (a) Potência instalada por tipo de geração

(b) Potência instalada no SEIN e no SSAA

\subsubsection{A Transformação do Setor Elétrico Peruano}

Em 1992, foi aprovada a reforma do setor elétrico Peruano com a promulgação da Lei de Concessões Elétricas (LCE) e oficializada através do DS-009-1993-EM. A LCE, baseada nas experiências Chilena, Argentina e da Grã Bretanha [39], foi implantada com a finalidade de incentivar um mercado eficiente e competitivo. A lei introduziu a segmentação das atividades de geração, transmissão e distribuição do setor elétrico, além de promover a especialização das empresas elétricas em cada uma dessas atividades. Foi também estabelecido o regime de liberalização de preços, a fim de que o fornecimento de energia possa ser efetuado de forma competitiva [40].

\section{a) Legislação do setor Elétrico}

A legislação elétrica Peruana está formada pelas seguintes leis e normas (Quadro 3.6):

Quadro 3.6 Principais normas e regulamentos no setor elétrico Peruano

\begin{tabular}{|l|l|}
\hline \multicolumn{1}{|c|}{ Lei/ Decreto } & \multicolumn{1}{c|}{ Descrição } \\
\hline Decreto Lei 25844/1992 & Lei de Concessões Elétricas: Livre acesso ao mercado elétrico. \\
\hline Decreto Supremo 009-93 & Regulamento da Lei de Concessões Elétricas. \\
\hline Decreto Supremo 020-97 EM & Norma técnica de Qualidade dos Serviços Elétricos \\
\hline $\begin{array}{l}\text { Resolução Diretorial 049-99- } \\
\text { EM/DGE }\end{array}$ & $\begin{array}{l}\text { Norma Técnica para a Coordenação da operação em Tempo Real dos Sistemas } \\
\text { interconectados }\end{array}$ \\
\hline Lei 27838 & Lei de Transparência e Simplificação dos procedimentos Regulatorios de Tarifas \\
\hline \multirow{5}{*}{ Normas } & Norma técnica para a Coordenação da Operação dos Sistemas Interconectados \\
\cline { 2 - 2 } & $\begin{array}{l}\text { Procedimento para o Pagamento dos Custos Eficientes ao Coordenador da Operação do } \\
\text { SEIN e as Entidades Delegadas }\end{array}$ \\
\cline { 2 - 2 } & $\begin{array}{l}\text { Critérios, Metodologia e Formulários para a Apresentação de propostas dos Sistemas } \\
\text { Secundários de Transmissão. }\end{array}$ \\
\cline { 2 - 2 } & $\begin{array}{l}\text { Procedimentos para afixação de Tarifas e Compensações para Sistemas Secundários de } \\
\text { Transmissão à entrada de novas centrais de geração. }\end{array}$ \\
\hline Lei 28832/2006 & Lei para Assegurar o Desenvolvimento Eficiente da Geração Elétrica \\
\hline
\end{tabular}

Na Figura 3.22 apresenta-se, de forma sucinta a cronologia do marco legal atualmente vigente no mercado elétrico Peruano. 


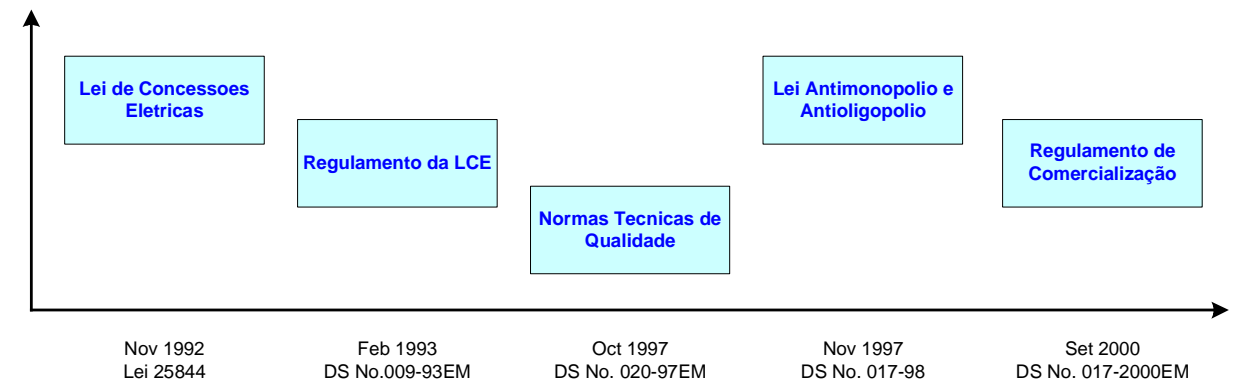

Fonte: OSINERG

Figura 3.22 Cronologia atual do marco elétrico Peruano

\section{b) Organização Institucional do Setor Elétrico}

Os principais entes que regulamentam o setor elétrico Peruano são:

- Ministério de Energia e Minas (MEM). Responsável pelo cumprimento da Lei de Concessões Elétricas (Art.1. Lei 25844/1992) além de outorgar concessões e autorizações as empresas de transmissão (Art. 6, Lei 25844/1992).

- Órgão Supervisor do Investimento em Energia e Minas (OSINERGMIN). Este órgão é responsável de supervisar e fiscalizar o cumprimento das disposições legais e técnicas das atividades que desenvolvidas nos subsetores de eletricidade e hidrocarbonetos. A partir de 2001, a CTE (Comissão de Tarifas Elétricas) e o OSINERG se integraram num só órgão regulador.

- Comitê de Operação Econômica do Sistema Interconectado Nacional (COES-SINAC). Composto pelos titulares das centrais de geração e da transmissão no país. Este comitê tem por objetivo coordenar as operações a um custo mínimo além de garantir a segurança do fornecimento de energia e promover o uso adequado dos recursos (Art. 39, Lei 25844/1992).

- Os clientes ou usuários. Divididos em duas categorias: clientes livres e clientes regulados.

- As empresas elétricas. Que podem ser as geradoras, transportadoras e distribuidoras, que operam de forma independente.

\subsubsection{O Sistema de Transmissão}

A LCE garante o livre acesso às linhas de transmissão do sistema. Não existem restrições do tipo legal e nem monopólios a favor de uma única empresa de transmissão. A atividade da transmissão poderá ser desenvolvida por qualquer pessoa natural ou jurídica, nacional ou estrangeira, proprietária da nova instalação. 
O Sistema de Transmissão elétrico do Peru está constituído pelo chamado Sistema Elétrico Interconectado Nacional (SEIN), mostrado na Figura 3.23, possui aproximadamente $8125 \mathrm{Km}$ de linhas de transmissão, das quais, 2955 pertencem ao sistema principal.

a) Tensões do Sistema. As linhas de transmissão operam com tensões de $220 \mathrm{kV}$ e $138 \mathrm{kV}$. O resto pertence a sistemas secundários de menor tensão.

b) Concessionárias de Transmissão. Na atualidade, as empresas que participam na atividade da transmissão elétrica, são:

- Consorcio Energético Huancavelica S.A (CONENHUA)

- Consorcio Trans Mantaro S.A (TRANSMANTARO)

- $\quad$ Red Eléctrica del Sur S.A (REDESUR)

- ETESELVA S.A

- Red de Energía del Perú S.A (REPSA)

- Interconexao Electrica ISA Peru S.A. (ISAPERU)

A maioria destas empresas de transmissão, que tem alcance nacional possui capitais privados.

\subsubsection{Regulamentação de Preços na Transmissão}

No Art. 42 da LCE estabelece-se que os preços regulados deverão refletir os custos marginais de suprimento de energia e serão estruturados de modo a promover a eficiência do setor. Por outro lado, no Art. 44 desta mesma lei estabelece-se que as tarifas de transmissão e distribuição serão reguladas pelo OSINERG, independentemente da energia ser vendida para o Serviço Público de Eletricidade (SPE) ou para o Mercado Livre. No caso destes últimos, os preços de geração serão obtidos segundo acordo entre partes. As vendas de energia e potência não destinadas ao SPE deverão considerar obrigatoriamente, e de forma separada, os preços conveniados na barra de referência da geração, bem como os encargos de transmissão, distribuição e comercialização.

Segundo [21], para a determinação dos encargos de transmissão o Sistema de Transmissão Peruano foi dividido em dois subsistemas: o Sistema Principal de Transmissão, que é aquele onde o fluxo de energia pode fluir em duas direções, razão que não permite identificar exatamente quais geradores e quais distribuidores usam a infraestrutura, e um Sistema Secundário, onde o fluxo da energia é unidirecional e, portanto, possibilita a identificação dos usuários. 


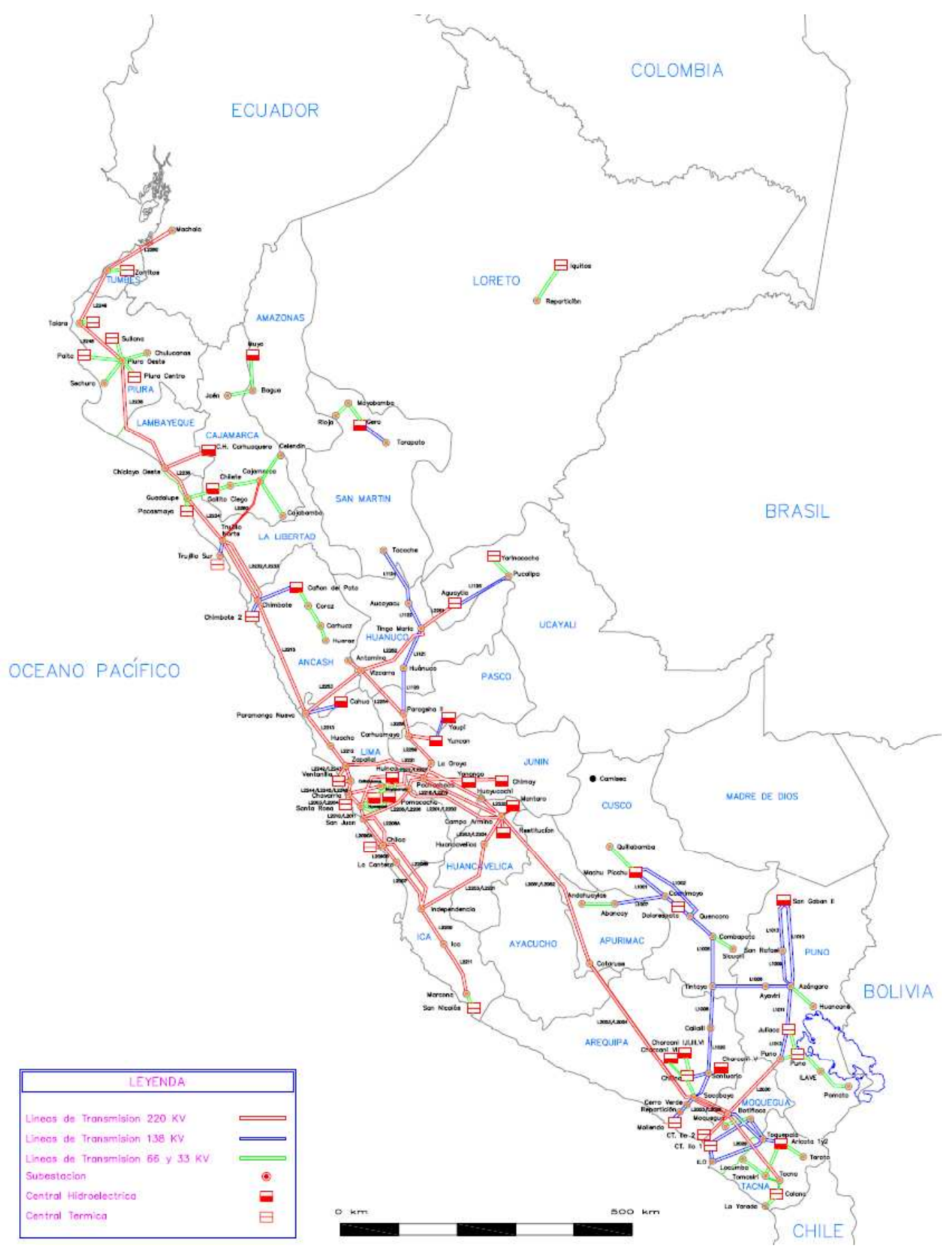

Fonte: Ministério de Minas e Energia

Figura 3.23 Mapa mostrando o Sistema Elétrico Interconectado Peruano (SEIN)

A cada quatro anos o MEM (Ministério de Energia e Minas) redefine quais linhas são consideradas principais e secundárias. Foi assim que em Novembro de 2002, com a promulgação da LCE, foram criados os dois sistemas de transmissão nacionais atualmente em serviço:

a) Sistema Principal de Transmissão (SPT). É o sistema de transmissão comum ao conjunto de geradores do SEIN, que permite o intercâmbio de energia e a sua livre comercialização. Segundo o Art. 132 da LCE, as instalações de alta ou extra alta tensão (138 ou 220 kV) estão 
inclusas no SPT. As condições e critérios que se devem cumprir, de forma simultânea, para que uma instalação seja incorporada ao Sistema Principal de Transmissão são as seguintes: (i) O fluxo de energia em uma mesma direção devera ser inferior a 90\% da energia total transportada pela instalação, o que será calculado para um período projetado de cinco anos. (ii) O beneficio econômico proporcionado aos consumidores deverá estar entorno de $70 \%$ do total dos benefícios trazidos pela instalação, os quais serão calculados para um período projetado de cinco anos.

b) Sistema Secundário de Transmissão (SST). Definido como a parte do sistema de transmissão destinada a transmitir energia para um distribuidor ou consumidor final a partir de uma barra do SPT. Fazem parte deste sistema as instalações que vinculam um sistema de geração e uma barra do SPT. Na Figura 3.24 mostram-se as características e classificação do SPT e o SST no sistema elétrico Peruano.

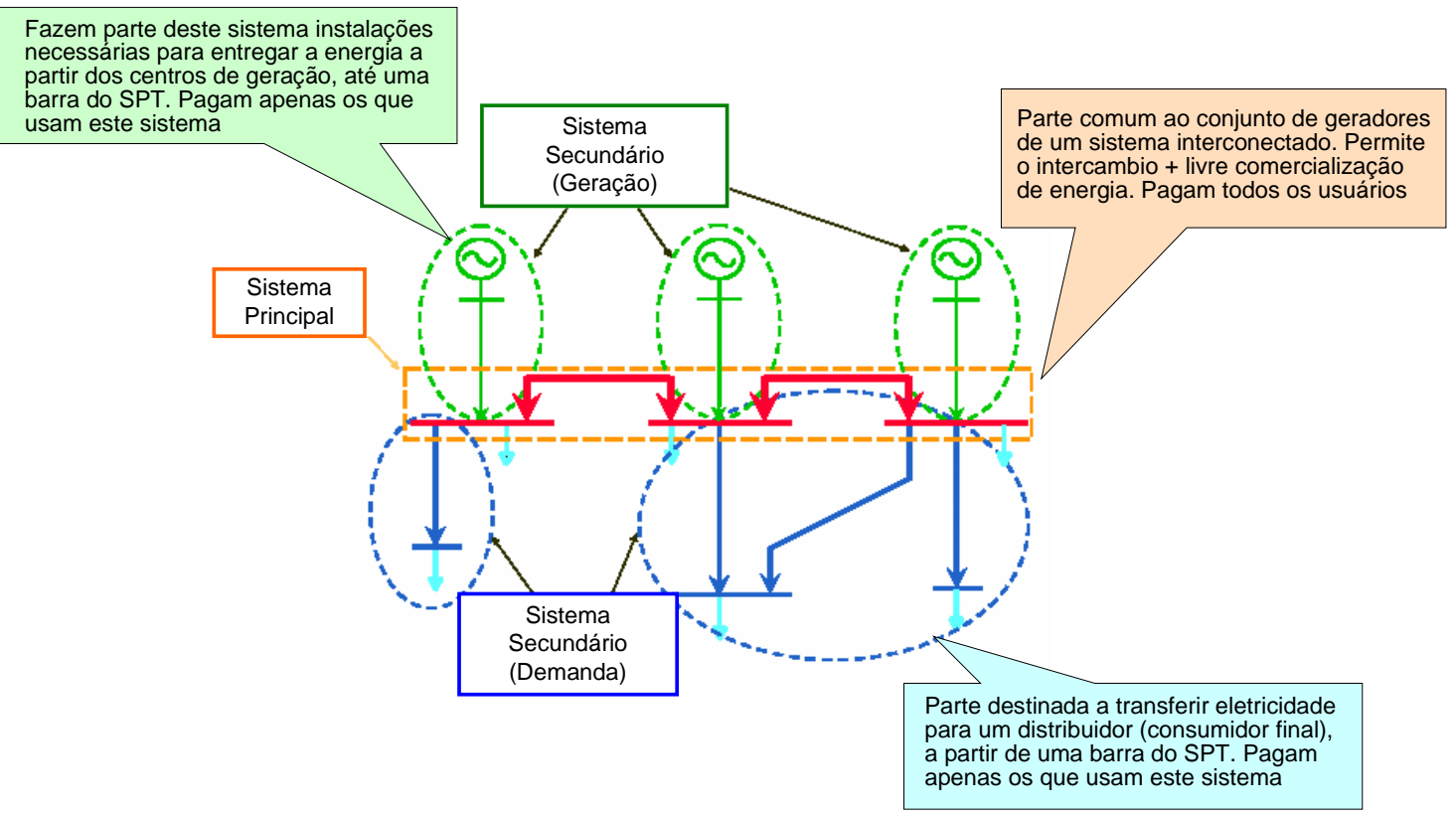

Fonte: OSINERG

Figura 3.24 Classificação dos sistemas de transmissão

c) Método Base de Tarifação. Tarifação Nodal baseada em custos marginais de curto prazo, além de encargos por conexão.

\subsubsection{Mecanismo de Remuneração}

Em relação ao SPT, a Lei de Concessões Elétricas estabelece os seguintes pontos (Art. 58 e 59 da LCE):

- Os geradores conectados ao SPT deverão pagar mensalmente ao mesmo uma parcela de compensação de modo a cobrir o Custo Total de Transmissão (CTT). 
- Tanto os sistemas que compõem o SPT, quanto os do SST, deverão permitir aos geradores comercializar potência e energia em qualquer de suas barras.

- O CTT deve considerar a anualidade de investimento (linhas, subestações, centro de controle, telecomunicações) e os custos padrões de operação e manutenção (incluindo gestão, segurança, etc.) do Sistema Economicamente Adaptado (SEA) ${ }^{11}$.

$$
C T T=A V N R+C O E M
$$

- A anualidade do investimento é calculada considerando o (VNR) Valor Novo de Reposição, a vida útil (instalação de transmissão, 30 anos) e a Taxa de Atualização estabelecida em (12\%).

Já no relacionado ao Sistema Secundário de Transmissão (SST), a Lei de Concessões Elétricas estabelece que (Art. 49 da LCE): O preço em barras do SST deverá incluir o custo médio do SEA. O custo médio engloba os custos médios de investimento mais os custos de operação e manutenção $(C O E M)$ em condições de eficiência.

Na Figura 3.25 pode-se observar a premissa sob a qual baseia-se um SEA, no qual existe um equilíbrio entre a oferta e demanda. Ou seja, se o custo investido nas instalações de transmissão fosse maior (instalações sobredimensionadas) este poderá ser refletido nos agentes que utilizam a rede. Este custo poder-se-á refletir em um maior VNR e COEM, o que não é conveniente para os demais agentes.

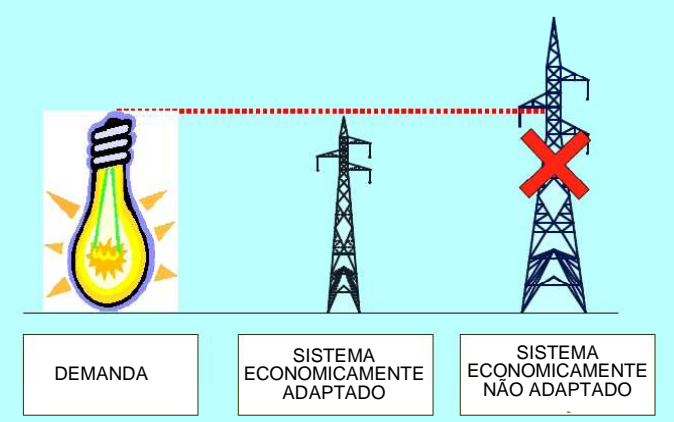

Figura 3.25 Sistema Economicamente Adaptado

Na Figura 3.26 reflete-se o mecanismo do sistema de preços nas instalações de transmissão.

\footnotetext{
${ }^{11}$ Sistema elétrico onde existe equilíbrio entre a oferta e a demanda de energia, procurando o menor custo e mantendo a qualidade do serviço.
} 


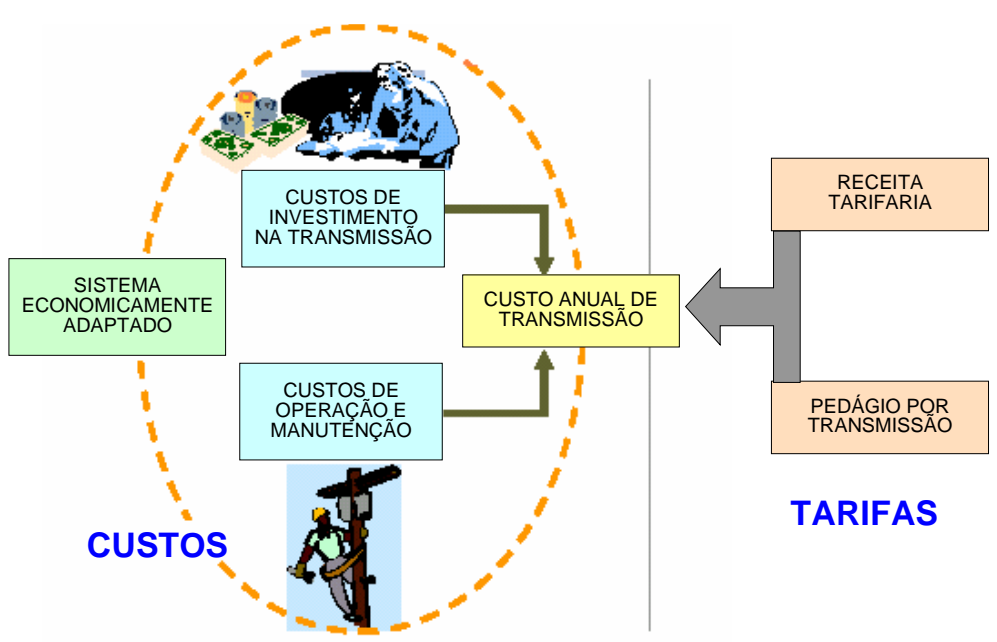

Figura 3.26 Sistemas de preços segundo o SEA Peruano (Fonte: OSINERG)

\subsubsection{Mecanismo de Arrecadação}

Segundo [24], o consumidor final paga o Custo Total de Transmissão através de dois encargos: a Receita Tarifária $(R T)$ e o Pedágio $(P d g)$, conforme o critério Marginal.

$C T T=R T+P d g$

onde,

CTT : Custo Total de Transmissão (anual)

$R T$ : Receita Tarifária baseado nos custos marginais

$P d g$ : Pedágio (cargo complementar para cobrir o CTT)

\section{a) Receita Tarifária nas Linhas Principais:}

A Receita Tarifária ou Ingresso Tarifário é calculado em função da potência e energia entregue e retirada em barras, sem incluir o respectivo pedágio (Art. 60(a) DL 25584). A $R T$ por energia no SPT é determinado através do modelo PERSEO. A $R T$ por potência (anual) resulta da diferença entre os fatores de perdas marginais calculados para cada elemento do sistema de transmissão.

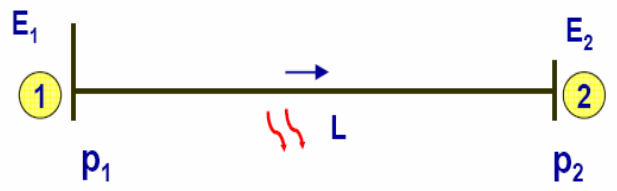

O Ingresso Tarifário é igual a:

$R T=R T_{\text {potência }}+R T_{\text {energia }}$

$R T=\left(P_{2} P_{p 2}-P_{1} P_{p 1}\right)+\left(E_{2} P_{e 2}-E_{1} P_{e 1}\right)$

onde,

$R T \quad$ : Receita Tarifária

$P_{1}, P_{2}$ : Potência de entrega e retirada, respectivamente

$E_{1}, E_{2}: \quad$ Energia de entrega e retirada, respectivamente

$P_{p l}, P_{p 2}$ : Preços de potência em barras de entrega e retirada, respectivamente

$P_{e l}, P_{e 2}$ : Preços de energia em barras de entrega e retirada, respectivamente 
O pedágio por conexão resulta da diferença entre o Custo Total de Transmissão (CTT) e a $R T$.

$P d g=V N R+C O E M-R T$

Como $V N R+C O E M=C T T$, segundo (3.21), então o pedágio por conexão é igual a:

$P d g=C T T-R T$

Os pedágios do SPT são fixados a cada ano em moeda nacional (Soles). As fórmulas de atualização do pedágio consideram a taxa de câmbio da moeda e o índice de preços atacadista publicado pelo Instituto Nacional de Estatística e Informática (INEI).

\section{b) Receita Tarifária nas Linhas Secundárias:}

No caso das redes secundárias, onde é possível identificar os usuários que geram os fluxos de energia, foram estabelecidas duas formas de pagamento, isto segundo as linhas que sejam utilizadas pelos geradores, para se conectar ao SPT (linhas de Geração), ou se estas forem usadas pelos distribuidores para se conectar aos usuários finais (linhas de Demanda):

- Sistema Secundário de Geração. Os ingressos são pagos pelos geradores que utilizam as instalações. O pagamento ao transmissor é feito ao final de cada mês e está baseado na mensalidade dos custos médios anuais, usando uma taxa de $12 \%$ a.a. Este valor é arrecadado pelo COES e é reajustado mensalmente segundo a variação da taxa de câmbio.

- Sistema Secundário de Demanda. Neste caso, o regulamento da LCE (Art.139), estabelece-se um encargo de pedágio secundário unitário a ser pago pelos consumidores. Este pedágio unitário resulta da relação entre a energia e a potência transportada, é atualizada, para um horizonte de 15 anos. O pedágio em cada instalação é calculado através da diferença entre o custo anual de transmissão e o ingresso tarifário. A fórmula utilizada é a seguinte:

$$
P S=\frac{\sum_{i=1}^{n} \frac{C T-R T_{i}}{(1+a)^{i}}}{\sum_{i=1}^{n} \frac{D e m_{i}}{(1+a)^{i}}}
$$

onde,

PS : Pedágio secundário unitário

$C T$ : Custo anual esperado aplicado à anualidade do $V N R$ para ao sistema secundário, ou seja, $C T=V N R+C O E M$

$\operatorname{Dem}_{i}$ : $\quad$ Demanda esperada para o ano $i$

$R T_{i}$ : Ingresso tarifário estimado para o ano $i$

$\alpha \quad$ : Taxa de atualização definida na LCE

$i \quad$ : Período anual

c) Contratos Boot. O procedimento de remuneração das instalações utiliza também os conceitos de $I T$ e pedágios $(C T T=R T+P d g)$. 


\subsubsection{Expansão do Sistema de Transmissão}

\subsubsection{Expansão Local}

Segundo a Lei 28832/2006 ${ }^{12}$, chamada de "Projeto de Lei para Assegurar o Desenvolvimento Eficiente da Geração Elétrica", além do Sistema Principal e Secundário, criaram-se um Sistema Garantido e um Sistema Complementar de transmissão e que entraram em operação comercial logo após a promulgação desta Lei. O desenvolvimento das novas ampliações é realizado segundo o referido Plano de Expansão atualizado e publicado a cada 2 anos (Art.21/Lei 28832). A Lei 28832 estabelece que o Comitê de Operação Econômica do Sistema (COES) tem a responsabilidade de elaborar e propor o Plano de Transmissão para o Ministério de Minas de Energia e Minas (EMINEM) com previa aprovação do OSINERG. Ou seja, o planejamento da expansão seria do tipo centralizado.

O Sistema Garantido de Transmissão está formado pelas instalações dentro do Plano de Expansão da Transmissão e cuja concessão e construção resulta de um processo de licitação pública. Neste sistema o prazo máximo de concessão é de trinta (30) anos (operação comercial), mais o tempo necessário para sua construção (Art. 22/Lei 28832).

O OSINERG aloca as compensações para remunerar a base Tarifária das novas instalações do Plano de Expansão em proporção ao beneficio econômico que as instalações proporcionam aos usuários e geradores.

Por outro lado, o Sistema Complementar de Transmissão está formado pelas instalações que fazem parte do Plano de Expansão de Transmissão, em que a construção é o resultado da iniciativa de um ou vários agentes (geradores, transmissores, distribuidores e usuários livres) ou formado pelas instalações que não fizerem parte do Plano de Expansão da Transmissão (Art. 27/Lei 8832).

Quanto às novas instalações, o OSINERGMIN estabelece uma base tarifária que considera os critérios estabelecidos na LCE para o caso dos sistemas Secundários de Transmissão.

\subsubsection{Expansão das Conexões Internacionais}

No momento em que o presente trabalho estava sendo realizado, não se tinha conhecimento preciso se o Peru tinha intercâmbios de energia elétrica internacionais. Segundo referências, existem apenas alguns projetos na Comunidade Andina que estão em etapa de avaliação. Para esse fim, o governo Peruano, através o DS 045-2004-EM tinha aprovado o Regulamento de Importação e Exportação de Eletricidade (RIEE) ${ }^{13}$ no marco das disposições contidas na decisão 536 da Comissão de Integração Elétrica na Comunidade Andina.

\footnotetext{
${ }^{12}$ Esta nova lei estabelece que o Comitê de Operação Econômica do Sistema (COES) tem a responsabilidade de elaborar a proposta do plano de expansão de transmissão para sua aprovação pelo MEM previa aprovação da OSINERG.

${ }^{13}$ Resolução que pode ser observada na sua integra no Anexo E.
} 
- Interconexão Peru - Equador: Segundo [55] a infra-estrutura da interconexão Peru Equador está concluída, porém devido a problemas principalmente de regulamentação não está operando de forma contínua. A configuração desta interconexão é radial permitindo a transferência de carga entre ambos paises. Dita interconexão foi executada em três etapas:

Etapa 1: Linha de transmissão Zorritos - San Ildenfonso (230 kV), Circuito trifásico simples com capacidade de desenho $100 \mathrm{MW}$.

Etapa 2: Primeira fase da construção da subestação conversora back-to-back localizada em Zarumilla. Através desta interconexão foi possível conectar Zorritos-Zarumilla-São Ildefonso. Capacidade de 100 MW.

Etapa 3: Que corresponde à segunda fase da subestação conversora back-to-back bem como aos reforços no sistema de transmissão de modo incrementar a capacidade de transmissão para $250 \mathrm{MW}$.

- Interconexão Peru - Bolívia: Segundo dados do Ministério de Minas e Energia, já foi revisada a viabilidade econômica para uma linha de interconexão de $150 \mathrm{MW}$ e $220 \mathrm{kV}$ entre a subestação Kenko (Bolívia) e Puno (Peru). Na Tabela 3.12 apresentam-se os custos de investimento correspondentes a dita interconexão. Ressalta-se que esta interconexão precisaria da construção de uma estação conversora to tipo back-to-back (60 Hz no Peru e $50 \mathrm{~Hz}$ na Bolívia) na fronteira entre ambos os países.

Tabela 3.12 Avaliação econômica da interconexão Peru-Bolívia (Estimativa de custos de investimento)

\begin{tabular}{|c|l|c|r|}
\hline Item & \multicolumn{1}{|c|}{ Peru - Descrição } & $\begin{array}{c}\text { Comprimento } \\
(\mathbf{k m})\end{array}$ & $\begin{array}{c}\text { Total } \\
\text { Milhões US\$ }\end{array}$ \\
\hline 1 & Linha 220kV Puno- Azángaro & 115 & 17.1 \\
\hline 2 & Linha 220kV Puno-Fronteira & 120 & 17.7 \\
\hline 3 & $50 \%$ estação conversora Back-to Back & & 23.0 \\
\hline \multicolumn{2}{|c|}{ Total Parcial } & 57.8 \\
\hline
\end{tabular}

\begin{tabular}{|c|l|c|r|}
\hline Item & \multicolumn{1}{|c|}{ Bolívia - Descrição } & $\begin{array}{c}\text { Comprimento } \\
(\mathbf{k m})\end{array}$ & $\begin{array}{c}\text { Total } \\
\text { Milhões US\$ }\end{array}$ \\
\hline 1 & Reforço de linhas (estimativa) & 150 & 21.3 \\
\hline 2 & Linha 220kV Kenko-Fronteira & 110 & 16.5 \\
\hline 3 & $50 \%$ estação conversora Back-to Back & & 23.0 \\
\hline \multicolumn{3}{|c|}{ Total Parcial } \\
TOTAL & $\mathbf{1 1 8 . 6}$
\end{tabular}

Fonte: Plano referencial de eletricidade - 2005 (Ministério de Energia e Minas) 


\subsection{Comparações de Modelos Tarifários dos Países Analisados}

Nesta seção será apresentada uma análise relacionada à regulamentação na transmissão dos cinco países analisados, bem como outras características inerentes a estes modelos.

\subsubsection{Características Gerais dos Sistemas de Transmissão}

Antes das reformas institucionais os sistemas de transmissão estavam constituídos e controlados por apenas uma ou duas empresas. Após o processo desregulamentação estabelecido durante a década de 1990, constatou-se que os países considerados adotaram estruturas institucionais e modelos regulatórios baseados na existência de livre acesso às redes, o que determina a existência de um mercado competitivo. Conforme apresentado no Quadro 3.7, o livre acesso ás redes de transmissão permitiu o ingresso de novas empresas. Porém, no caso da Argentina, a administração da rede principal $(500 \mathrm{kV})$ ainda está a cargo de um único operador (TRANSENER). De fato, existem também outras empresas regionais conectadas a esta rede troncal. No caso do Chile, apesar de não existir um monopólio no segmento da transmissão, quase a totalidade da rede pertence à empresa HQI-Transelec Chile. Na Bolívia, Brasil e Peru existem várias empresas de transmissão.

Quadro 3.7 Principais características e empresas de transmissão dos países analisados

\begin{tabular}{|c|c|c|c|c|c|}
\hline & ARGENTINA & BOLÍVIA & BRASIL & CHILE & PERU \\
\hline Tensões do sistema & $500 \mathrm{kV}, 400 \mathrm{kV}, 132 \mathrm{kV}$ & $230 \mathrm{kV}, 115 \mathrm{kV}, 69 \mathrm{kV}$ & $\begin{array}{c}750 \mathrm{kV}, 500 \mathrm{kV}, 440 \mathrm{kV} \\
345 \mathrm{kV}, 230 \mathrm{kV} \text { e } 138 \\
\mathrm{kV}, 600 \mathrm{kV}(\mathrm{CC})\end{array}$ & $\begin{array}{c}500 \mathrm{kV}, 220 \mathrm{kV}, 154 \mathrm{kV} \\
110 \mathrm{kV}, 66 \mathrm{kV}\end{array}$ & $220 \mathrm{kV}, 138 \mathrm{kV}$ \\
\hline $\begin{array}{l}\text { Freqüência de } \\
\text { operação }\end{array}$ & $50 \mathrm{~Hz}$. & $50 \mathrm{~Hz}$. & $60 \mathrm{~Hz}$. & $50 \mathrm{~Hz}$. & $60 \mathrm{~Hz}$. \\
\hline $\begin{array}{l}\text { Empresas de } \\
\text { transmissão }\end{array}$ & $\begin{array}{l}\text { TRANSENER assim } \\
\text { como outras empresas } \\
\text { regionais }(*) \text {. }\end{array}$ & $\begin{array}{l}\text { TDE, ISA-Bolívia, } \\
\text { MERELEC e São } \\
\text { Cristobal (as últimas duas } \\
\text { não fazem parte do SIN). }\end{array}$ & $\begin{array}{l}\text { Várias empresas de } \\
\text { transmissão }(* *) . \\
\text { Principais redes são } \\
\text { controladas pela estatal } \\
\text { ELETROBRAS. }\end{array}$ & $\begin{array}{l}\text { HQI-Transelec Chile } \\
\text { abrange grande parte do } \\
\text { sistema de transmissão. }\end{array}$ & $\begin{array}{l}\text { Várias empresas de } \\
\text { transmissão (***). }\end{array}$ \\
\hline \multicolumn{6}{|c|}{$\begin{array}{l}\text { Acesso ao sistema de transmissão: } \\
\text { istem procedimentos de conexão à rede. O transmissor não comercializa energia e não está }\end{array}$} \\
\hline
\end{tabular}

(*) TRANSBA, DISTROCUYO, TRANSNOA, TRANSNEA, TRANSPA, TRANSCOMAHUE.

(**) CEEE (Companhia Estadual de Energia Elétrica), CEMIG (Companhia Energética de Minas Gerais), CHESF (Companhia Hidroelétrica do São Francisco), COPEL (Companhia Paranaense de Energia), CTEEP (Companhia de Transmissão de Energia Elétrica Paulista S.A.), ELETRONORTE (Centrais Elétricas do Norte do Brasil S.A.), EPTE (Empresa Paulista de Transmissão de Energia Elétrica S.A.), ELETROSUL (Empresa Transmissora de Energia Elétrica do Sul do Brasil S.A.), FURNAS Centrais Elétricas S.A, além de um grande número de TIE -Transmissores Independentes de Energia, detentores da concessão de uma ou mais linhas de transmissão através de licitações públicas.

(***) CONENHUA (Consorcio Energético Huancavelica S.A), TRANSMANTARO (Consorcio Trans Mantaro S.A.), REDESUR (Red Eléctrica del Sur S.A.), ETESELVA S.A, TRASANDINA (Compañia Transmisora Andina S.A.), Interconexión Eléctrica ISA Perú S.A, Red de Energía del Perú S.A.

Foi também constatado que os sistemas de transmissão dos países analisados, principalmente a do Brasil, Argentina e Chile, se caracterizam por abranger grandes distâncias e serem pouco malhadas, o que comprometeria a confiabilidade do sistema em contingência simples, para as situações de redes radiais e circuito singelo. 


\subsubsection{Modelos de Tarifação Adotados}

No Quadro 3.8 pode-se observar que todos os países analisados adotaram o modelo de tarifa marginal de curto (CMCP) ou de longo prazo (CMLP). Porém, conforme descrito no Capítulo II (Análise de Metodologias Tarifárias), no que se refere à parcela complementar, foram adotadas metodologias diferentes, conforme será apresentado no item 3.6.4.

\subsubsection{Mecanismo de Remuneração}

O esquema predominante para remunerar a rede de transmissão consiste em calcular uma remuneração específica para os ativos e para os custos de operação, manutenção e administração (Quadro 3.8). No referente à retribuição pelos investimentos realizados, a solução mais comum adotada foi a de aplicar um custo chamado de Valor Novo de Reposição ou de Substituição (VNR) dos ativos (equivalente ao custo de investimento, no Brasil). De modo a retribuir os custos de administração, operação e manutenção, a solução adotada em quase todos os casos analisados é a de remunerar através de um valor padrão, obtido a partir das estimativas de custos que teria uma empresa eficiente.

Quadro 3.8 Método base de tarifação, custos e remuneração ao transmissor

\begin{tabular}{|c|c|c|c|c|c|}
\hline & ARGENTINA & BOLÍVIA & BRASIL & CHILE & PERU \\
\hline Modelo adotado & \multicolumn{2}{|c|}{ CMCP } & $\begin{array}{l}\text { Metodologia Nodal } \\
\text { próximo ao CMLP }\end{array}$ & \multicolumn{2}{|c|}{ CMCP } \\
\hline $\begin{array}{l}\text { Mecanismo de } \\
\text { Arrecadação }\end{array}$ & $\begin{array}{l}\text { Custos variáveis: } \\
R V T=R V T_{E}+R V T_{P} \\
\text { Custos fixos: } \\
\text { i) Encargo } \\
\text { Complementar: } \\
C C=R E E T+R C T-R V T \\
\text { ii) Encargo por conexão. } \\
\text { Consideram-se áreas de } \\
\text { influência/estampilha }\end{array}$ & $C T=R T+P d g$ & $\begin{array}{l}\text { Tarifa Locacional } \\
\text { Remuneração pelo uso da } \\
\text { transmissão através da } \\
\text { tarifa } \\
T U S T=T U S T_{R B} \\
+T U S T_{F R} . \\
T U S T=\text { Tarifa } \\
\text { Locacional+Parcela de } \\
\text { Ajuste }\end{array}$ & $\begin{array}{l}\text { Receita Tarifária e } \\
\text { Receita por Pedágio do } \\
\text { tipo selo. } \\
V A T T=R T+P d g \\
\text { O pedágio é cobrado } \\
\text { segundo a área de } \\
\text { influência ( } 80 \% \text { é pago } \\
\text { pelos geradores e } 20 \% \\
\text { pelas cargas) e estampilha }\end{array}$ & $C A T=R T+P d g$ \\
\hline \multicolumn{6}{|c|}{ Legenda: } \\
\hline & 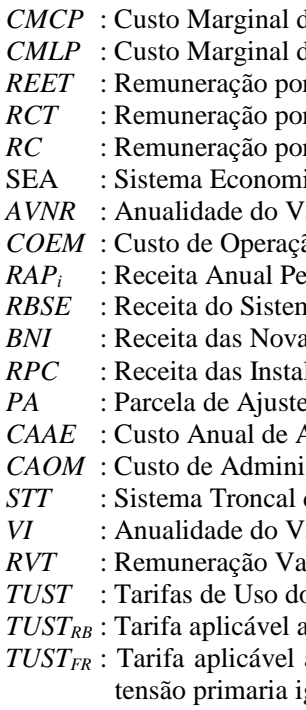 & $\begin{array}{l}\text { le Curto Prazo } \\
\text { le Longo Prazo } \\
\text { r Energia Elétrica Transı } \\
\text { r Capacidade de Transpe } \\
\text { r Conexão } \\
\text { icamente Adaptado } \\
\text { alor Novo de Reposição } \\
\text { à e Manutenção } \\
\text { rmitida } i \\
\text { na Existente } \\
\text { s Instalações } \\
\text { lações de Conexão } \\
\text { Ativos Elétricos } \\
\text { stração Operação e Man } \\
\text { de Transmissão } \\
\text { alor Novo de Investimen } \\
\text { riável Total por Energia } \\
\text { Sistema de Transmissã } \\
\text { todos os usuários do SI } \\
\text { à concessionária o perm } \\
\text { gual ou superior a 230k }\end{array}$ & ssiótrica Transportada & ue utiliza transformadores & s de potência com \\
\hline
\end{tabular}




\subsubsection{Mecanismo de Arrecadação}

O esquema de arrecadação predominante na rede de transmissão dos países analisados está composto de dois encargos. O primeiro encargo, que corresponde às perdas marginais, custos de manutenção e/ou recuperação de investimentos, é chamado, dependendo do país, de Receita Tarifaria (Bolívia, Perú, Chile), Arrecadação Variável de Transmissão (Argentina) ou Tarifa Locacional (Brasil). Este encargo resulta da diferença entre as energias de entrada e saída da linha valorizadas ao preço de seus respectivos nós (entradas e saídas), é dizer, este encargo deve-se basicamente às perdas marginais da rede que são as que produzem a diferença de preços nos extremos da linha.

O segundo encargo, chamado de Encargo Complementar ou Pedágio, tem o objetivo de complementar os custos incorridos, permitindo a recuperação dos investimentos e custos de operação e manutenção pela empresa de transmissão, permitindo assim viabilizar a empresa. Existem distintos critérios para calcular este cargo complementar conforme mencionado no Capítulo II deste trabalho. Através desta pesquisa foi verificado que os métodos utilizados para o cálculo do encargo complementar foram as de Área de Influência (Argentina e Chile) e do tipo Selo (Bolívia, Brasil e Peru).

Alguns países estabeleceram porcentagens fixas de pagamentos do pedágio entre geradores e consumidores. No caso da Bolívia, esta participação é de 25\% para os geradores, distribuída de forma proporcional á energia injetada, e 75\% para as cargas (demanda). No caso do Peru as geradoras pagam o $100 \%$ do pedágio.

No Brasil, o RAP (Receita Anual Permitida) é dividido em parcelas iguais entre geradores (50\%) e consumidores $(50 \%)$ para depois se aplicar a metodologia Nodal, com ajuste do valor baseado nos custos incrementais utilizando uma componente do tipo selo.

No caso de Chile, cujo sistema de transmissão está dividido em três sistemas (Sistema Troncal, Sistema de Subtransmissão e Sistema Adicional) a solução adotada para se aplicar o encargo complementar (adicional) é um pouco mais complexa, já que os geradores pagam em função da injeção de energia, enquanto que os consumidores em função da energia retirada. No caso do sistema de transmissão troncal, é estabelecida uma Área de Influência Comum (AIC), que totaliza aproximadamente $75 \%$ da injeção de energia e $75 \%$ da demanda e na qual os geradores devem cobrir $80 \%$ dos custos e os consumidores o restante $20 \%$, rateados em função das injeções e retiradas esperadas.

Na Argentina, este encargo complementar é arrecadado em proporção à participação dos distintos agentes do mercado e segundo o grau de uso das instalações. Quanto aos encargos pelo uso da rede de transmissão a serem pagos pelas transações internacionais, a solução adotada foi a de tratar as exportações de forma similar a cargas conectadas ao sistema, enquanto que as importações de forma similar a geradores conectados ao sistema. 


\subsubsection{Mecanismos de Expansão}

Na transmissão, um aspecto que precisou maior atenção foi o referente aos mecanismos de expansão da rede. Alguns países como Argentina, Chile e Peru, modificaram suas regulamentações ao perceber que os sinais para a expansão da transmissão não eram adequados. Segundo o estudo realizado ao longo deste capítulo, existem duas formas de proporcionar a expansão da transmissão, que diferem no grau de intervenção do ente regulador sobre as decisões dos agentes. Nos casos do Brasil, Chile e Peru utiliza-se o planejamento centralizado, onde as ampliações não são propostas pelas empresas transmissoras ou outros agentes, mas sim são formuladas no âmbito das atividades de um Agente Planejador. Uma vez definidos, sua construção é submetida a processos competitivos (leilão de concessão público). Por outro lado, nos casos da Argentina e Bolívia, utiliza-se um planejamento descentralizado, no qual os agentes decidem a expansão segundo os sinais que recebem do mercado.

Por outro lado, constatou-se que em todos os casos analisados, as empresas de transmissão existentes estão obrigadas a aceitar a conexão de novas instalações à sua rede. O procedimento aplicado na maior parte dos casos analisados para a execução de obras de expansão da transmissão baseia-se na realização de leiloes ou concurso público (Quadro 3.9), após o qual determina-se a concessionária que construirá a nova obra, bem como a remuneração que esta receberá. Porém, segundo a legislação elétrica de alguns países, existe também a possibilidade de concessão direta das obras, especialmente aquelas de menor porte.

Quadro 3.9 Expansão do sistema de transmissão

\begin{tabular}{|c|c|c|c|c|c|}
\hline & ARGENTINA & BOLÍVIA & BRASIL & CHILE & PERU \\
\hline $\begin{array}{c}\text { Mecanismo de } \\
\text { expansão da rede }\end{array}$ & $\begin{array}{l}\text { a) Concurso Público } \\
\text { b) Acordo entre partes } \\
\text { c) Ampliações Menores }\end{array}$ & \multicolumn{2}{|c|}{ Leilão Público } & $\begin{array}{l}\text { Sistema Troncal: } \\
\text { a) Leilão Internacional } \\
\text { para novas ampliações } \\
\text { Sistema Adicional } \\
\text { b) Acordo entre partes }\end{array}$ & Leilão Público \\
\hline Impulsor das Obras & \multicolumn{2}{|c|}{ Agentes } & Estado & Estado & Estado \\
\hline
\end{tabular}

\subsubsection{Conexões Internacionais}

No referente às conexões internacionais (Quadro 3.10), um dos aspectos técnicos a ser levado em conta é a frequiência $(\mathrm{Hz})$ de operação de cada país (Quadro 3.7). A construção de estações conversoras do tipo back-to-back poderia dificultar, face ao acréscimo de custos, a concretização de acordos binacionais para negociar energia. Por outro lado, superada esta barreira os ganhos nos países envolvidos seriam significativos, como é o caso da usina binacional de Itaipu, entre Brasil e Paraguai. A Argentina, Bolívia e Brasil já tem definidas as políticas de importação e exportação de eletricidade. No caso de Chile e Peru, não foi possível obter informação neste respeito. 
Quadro 3.10 Conexões internacionais

\begin{tabular}{|c|c|c|c|c|c|}
\hline & ARGENTINA & BOLÍVIA & BRASIL & CHILE & PERU \\
\hline & \multicolumn{3}{|c|}{$\begin{array}{l}\text { Importação: considerada de forma similar ao caso de geração adicionada ao } \\
\text { sistema. } \\
\text { Exportação: considerada de forma similar ao caso de demanda adicionada ao } \\
\text { sistema. }\end{array}$} & \multicolumn{2}{|c|}{$\begin{array}{l}\text { Não se dispõe de informação ou ainda não existe } \\
\text { regulamentação neste respeito. }\end{array}$} \\
\hline $\begin{array}{c}\text { Conexão } \\
\text { Internacional }\end{array}$ & $\begin{array}{l}\text { Com Uruguai: hidrelétrica } \\
\text { de Salto Grande (1890 } \\
\text { MW). } \\
\text { Com Paraguai: } \\
\text { hidrelétrica de Yacyretá } \\
(1700 \text { MW). } \\
\text { Com o Brasil: } \\
\text { Uruguaiana }(50 \mathrm{MW})\end{array}$ & $\begin{array}{l}\text { Com o Brasil: Mato } \\
\text { Grosso do Sul (80 MW). }\end{array}$ & $\begin{array}{l}\text { Com Argentina: Garabi } \\
(2000 \text { MW). } \\
\text { Com Venezuela: Boa } \\
\text { Vista (200 MW). } \\
\text { Com Paraguai: a } \\
\text { binacional de Itaipú } \\
\text { (14000 MW) e Foz do } \\
\text { Iguaçu (70 MW). } \\
\text { Com Uruguai: projeto } \\
\text { Santana do } \\
\text { Livramento/Rivera (70 } \\
\text { MW). }\end{array}$ & $\begin{array}{l}\text { Ainda não existem } \\
\text { interconexões apenas } \\
\text { protocolos com a } \\
\text { Argentina. }\end{array}$ & $\begin{array}{l}\text { Com o Equador: Infra- } \\
\text { estrutura concluída, } \\
\text { porém problemas de } \\
\text { regulamentação } \\
\text { dificultam sua operação. }\end{array}$ \\
\hline
\end{tabular}

\subsubsection{Contribuição do Usuário Final aos Diferentes Segmentos do Sistema Elétrico}

$\mathrm{Na}$ tarifa do usuário final estão inclusos os custos destinados a todos os segmentos do sistema. $\mathrm{Na}$ Tabela 3.13 está sendo mostrada esta contribuição porcentual aproximada dos países nos quais foi possível obter esta informação. Claramente, pode-se ver que na maioria dos casos o setor da transmissão recebe a menor contribuição por parte do usuário final. Por exemplo, na Argentina, o segmento da transmissão recebe aproximadamente 6,6\% do total; no Brasil este valor é de 6,5\% e, finalmente, no Peru é de $14 \%$.

Tabela 3.13 Distribuição da tarifa do usuário final aos diferentes segmentos do sistema

\begin{tabular}{|l|c|c|c|c|c|}
\cline { 2 - 6 } \multicolumn{1}{c|}{} & Geração & Distribuição & Transmissão & Outros & Total \\
\hline Argentina $^{14}$ & $16,5 \%$ & $39,0 \%$ & $16,5 \%$ & $28,0 \%$ & $100 \%$ \\
\hline Bolívia & $56 \%$ & $30 \%$ & $14 \%$ & - & $100 \%$ \\
\hline Brasil (ANEEL) & $29 \%$ & $26,8 \%$ & $6,5 \%$ & $37,7 \%$ & $100 \%$ \\
\hline Chile & - & - & - & - & - \\
\hline Peru (OSINERG) & $55 \%$ & $31 \%$ & $14 \%$ & - & $100 \%$ \\
\hline
\end{tabular}

\subsubsection{Grau de Aproximação do Modelo de Tarifação aos Requisitos do Grupo Standford}

Nesta seção faz-se uma análise para avaliar o grau no qual as metodologias adotadas pelos países analisados cumprem com os requisitos do Standford Energy Modelling Fórum, descritos no Capítulo II (Seção 2.2). Segundo relatos da literatura especializada [79], a nível internacional ainda não existe uma modalidade de regulamentação tarifária ou de remuneração única que permita lograr o cumprimento simultâneo desses princípios. Deve-se ressaltar que esta análise (Quadro 3.11) é produto principalmente do estudo realizado nesta pesquisa, bem como de dados obtidos de alguns agentes do mercado nos respectivos países. O objetivo para se apresentar o grau de adaptabilidade destes requisitos ao Standford Fórum em formato de quadro deve-se à facilidade que oferece para identificar as características inerentes a determinado país.

\footnotetext{
${ }^{14}$ Dados do Ministério de Economia e Produção
} 
Quadro 3.11 Grau de aproximação do modelo de tarifação aos princípios do Stanford Energy Modeling Fórum

\begin{tabular}{|c|c|c|c|c|c|}
\hline \multirow{2}{*}{ Principio do Sistema de Tarifação } & \multicolumn{5}{|c|}{ Adaptabilidade aos Requisitos do Grupo Standford } \\
\hline & ARGENTINA & BOLÍVIA & BRASIL & CHILE & PERU \\
\hline \multirow{3}{*}{$\begin{array}{l}\text { a) Deverá promover a eficiência } \\
\text { operacional dia-a-dia do mercado } \\
\text { elétrico }\end{array}$} & \multirow{2}{*}{\multicolumn{5}{|c|}{$\begin{array}{l}\text { Considerando que em todos os países analisados a tarifa de transmissão possui uma componente diretamente associada aos custos do sistema (diretamente, via custo marginal de } \\
\text { operação, ou indiretamente, via sinal locacional para estimular a escolha de conexão em ponto que menos penalize o sistema), pode-se afirmar que a preocupação com a eficiência } \\
\text { operacional está presente em todos os casos. } \\
\text { No que se refere à expansão eficiente, o fato de todos os países analisados possuírem um órgão que coordene a operação do sistema, cuja tarefa principal é assegurar que em todo } \\
\text { momento a geração seja igual à demanda de energia, e que o sistema tenha suficiente capacidade de reserva para lidar com eventuais contingências (vide Capítulo III), garante a } \\
\text { aderência a este principio. Segundo relatos destes órgãos, a coordenação do sistema deu sinais, em menor ou maior grau, para a expansão do mesmo. Isto foi possível perceber } \\
\text { observando a evolução da potência instalada de cada país (no período 1995-2006) e o crescimento da demanda do sistema. Por outro lado, devem também ser levados em conta aspectos } \\
\text { políticos, econômicos e a estabilidade do modelo tarifário. A seguir apresenta-se o grau de aderência deste principio em relação à expansão do sistema: }\end{array}$}} \\
\hline & & & & & \\
\hline & \multicolumn{2}{|c|}{$\begin{array}{l}\text { Na Argentina e na Bolívia, foi possível observar que os sinais de } \\
\text { eficiência na expansão não foram tão significativos. Isto com base nos } \\
\text { projetos de expansão concretizados no supracitado período [29], [59]. Os } \\
\text { leilões para a expansão neste período foram escassos. }\end{array}$} & $\begin{array}{l}\text { Existem sinais de eficiência na } \\
\text { expansão [52]. Vários leilões com } \\
\text { concorrência aceitável. }\end{array}$ & $\begin{array}{l}\text { Sinais moderados de eficiência } \\
\text { na expansão [70]. }\end{array}$ & $\begin{array}{l}\text { Existem sinais de eficiência na } \\
\text { expansão [55]. Similar ao caso do } \\
\text { Brasil. }\end{array}$ \\
\hline b) Deverá fornecer sinal locacional & \multicolumn{5}{|c|}{$\begin{array}{l}\text { O sistema de preços nodais, baseado em custos marginais de curto e longo prazo, oferece sinais locacionais aos agentes do sistema. Estes agentes do sistema (geradores, consumidores) } \\
\text { são cobrados no nó mais próximo ao qual estão conectados, incentivando assim o uso eficiente da rede de transmissão. }\end{array}$} \\
\hline $\begin{array}{l}\text { c) Deverá fornecer sinais necessários } \\
\text { de investimento ao sistema de } \\
\text { transmissão }\end{array}$ & \multicolumn{2}{|c|}{$\begin{array}{l}\text { Na Argentina e na Bolívia, os sinais de investimento se ajustam } \\
\text { primordialmente às necessidades do sistema, isto apesar destes países } \\
\text { possuírem planos decenais de expansão. A tarifação baseada no CMCP } \\
\text { adotada desincentiva a promoção de sinais de investimento devido à } \\
\text { volatilidade que apresenta e a não inclusão de investimentos de longo } \\
\text { prazo. Modelos de expansão descentralizados. }\end{array}$} & \begin{tabular}{|l|} 
O fato da metodologia de tarifação \\
estar baseada no CMLP, na teoria, \\
prevê o fornecimento de sinais de \\
investimento através \\
planejamento do da expansão do \\
sistema. Modelo centralizado. \\
\end{tabular} & $\begin{array}{l}\text { Similar ao caso da Argentina e } \\
\text { Bolívia. Modelo de expansão } \\
\text { centralizado. }\end{array}$ & $\begin{array}{l}\text { Apesar do modelo CMCP } \\
\text { estabelecido houve sinais de } \\
\text { investimento. Modelo } \\
\text { expansão centralizado. }\end{array}$ \\
\hline $\begin{array}{l}\text { d) Deverá compensar aos proprietários } \\
\text { pelas instalações existentes }\end{array}$ & \multicolumn{5}{|c|}{ Em todos os casos analisados os proprietários recuperam o investimento pelas instalações existentes. Porém, isto foi possível após algumas reformas nos marcos regulatórios. } \\
\hline \multirow[b]{2}{*}{$\begin{array}{l}\text { e) Deverá mostrar ser um mecanismo } \\
\text { transparente e simples }\end{array}$} & \multicolumn{5}{|c|}{ A simplicidade das metodologias destes países apresenta um trade-off entre a simplicidade (método selo) e a entrega de sinais adequados (área de influência). } \\
\hline & $\begin{array}{ll}\text { Relativamente } & \text { complexo. Parcela } \\
\text { complementar } & \text { utiliza método de } \\
\text { área de } & \text { influência, ruja } \\
\text { implementação } & \text { requer cálculos } \\
\text { adicionais. } & \end{array}$ & $\begin{array}{l}\text { Relativamente simples pelo fato da } \\
\text { parcela complementar ser do tipo } \\
\text { selo. Esta parcela, não discrimina a } \\
\text { locação dos agentes. }\end{array}$ & Similar ao caso da Bolívia. & Similar o caso da Argentina. & Similar ao caso da Bolívia. \\
\hline \multirow[b]{2}{*}{$\begin{array}{l}\text { f) Deverá ser politicamente } \\
\text { implementável }\end{array}$} & \multicolumn{5}{|c|}{ Os sistemas tarifários destes países tiveram que fazer algumas modificações nos esquemas tarifários de modo a satisfazer os interesses dos agentes do mercado. } \\
\hline & 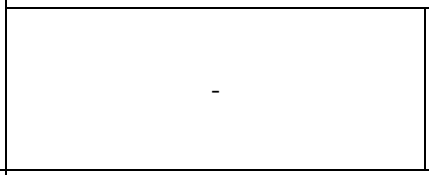 & $\begin{array}{l}\text { Modificou-se a regulamentação } \\
\text { tarifaria por causa da parcela } \\
\text { complementar (pedágio) }\end{array}$ & $\begin{array}{l}\text { Houveram leves mudanças de } \\
\text { aperfeiçoamento mas que não } \\
\text { impactaram de forma significativa } \\
\text { no modelo. }\end{array}$ & $\begin{array}{l}\text { O sistema de transmissão, como } \\
\text { agente do mercado, não tinha } \\
\text { incentivo para a sua expansão. } \\
\text { Após Lei Curta I foi corrigido } \\
\text { este fato. }\end{array}$ & $\begin{array}{l}\text { Lei } 28832 \text { (2006) criou dois } \\
\text { subsistemas de transmissão } \\
\text { adicionais com o intuito de } \\
\text { garantir o desenvolvimento da } \\
\text { geração elétrica. }\end{array}$ \\
\hline $\begin{array}{l}\text { g) Deverá mostrar a característica de } \\
\text { estabilidade. }\end{array}$ & \multicolumn{5}{|c|}{$\begin{array}{l}\text { A estabilidade no sentido clássico de preços com nível aceitável de volatilidade ao longo do tempo, está suportada pelo fato de que os componentes associados ao custo do sistema } \\
\text { (custo marginal de operação ou custo marginal de expansão), que quando soladamente aplicadas podem dar margem a forte volatilidade, são complementados por uma componente de } \\
\text { selo que garante a recuperação dos custos de investimento e operação "suavizando" as variações. A estabilidade no sentido de que "tarifa estável" é aquela em que há incentivo aos } \\
\text { agentes para pertencer ao "condomínio de transmissão", posto que esta solução é menos onerosa que construir suas próprias instalações exclusivas, é proporcionada pela presença dos } \\
\text { componentes associados aos custos, que podem ser custos de operação nodais ou custos nodais de expansão. }\end{array}$} \\
\hline
\end{tabular}




\subsection{Relação entre a Previsão de Mercado e a Expansão do Sistema de Transmissão}

Conforme estabelecido nos objetivos desta pesquisa, no próximo capítulo serão apresentados os resultados de previsão de energia que foram obtidos a partir das metodologias de previsão adotadas nos países consideradas.

A finalidade deste estudo teve sua origem na seguinte questão: Quais seriam os principais drivers ou fatores para uma expansão adequada da rede de transmissão?

A resposta a esta questão indica que os sinais econômicos provenientes da tarifa utilizada são fundamentais, sendo que este foi o tema deste capítulo; mas as projeções de mercado são indispensáveis para decisão das ampliações, reforços de rede e novas instalações que devem ser implementados no sistema existente, a fim de garantir a qualidade de serviço.

Pode-se ver na Figura 3.27, que a análise de previsão oferece sinais do crescimento de mercado em um determinado período futuro (por exemplo, através do plano decenal de expansão) ao planejador do sistema, o qual estabelecerá em que grau e que parte do sistema de transmissão precisará de expansão. Esta expansão do sistema poderá ser feita, conforme mostrado na Figura 3.27, através do concurso publico (licitação) ou por concessão direta. Esta última opção poderá, por exemplo, ser aplicada no caso de concessões menores.

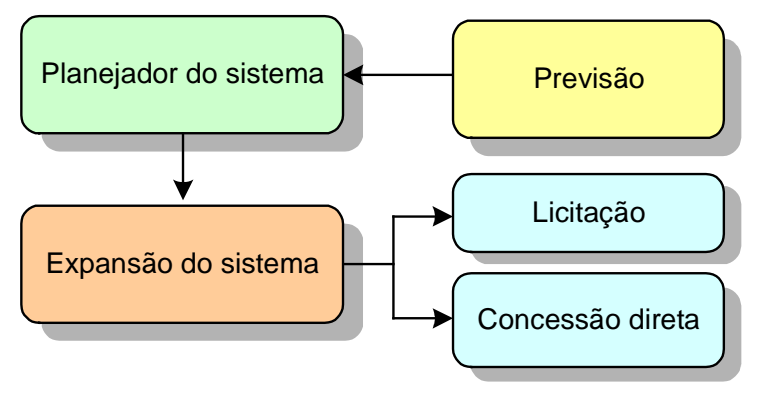

Figura 3.27 Seqüência e vínculo entre previsão e expansão do sistema

Por exemplo, o Brasil passou por um racionamento de energia entre junho de 2001 a fevereiro de 2002. Segundo a referência [72], este racionamento deveu-se principalmente à falta de investimento no setor elétrico bem como à escassez de chuvas no período pré-racionamento, isto apesar dos estudos de previsão realizada em anos precedentes. Isto ratifica o fato que toda projeção deverá estar diretamente acompanhada de seu respectivo investimento em novas instalações. 


\section{CAPITULO IV}

\section{ANÁLISE COMPARATIVA DE MÉTODOS DE PREVISÃO DE ENERGIA}

\subsection{Introdução}

Neste Capítulo, apresenta-se um estudo comparativo entre as metodologias de previsão da demanda de energia de longo prazo utilizadas na Argentina, Bolívia, Brasil, Chile e no Peru. As referidas previsões foram realizadas para as classes de consumo Residencial, Industrial, Comercial e Rural. No Brasil, estas classes de consumo são responsáveis aproximadamente por $90 \%$ do consumo nacional [67]. Assim, pode-se dizer que a análise destas quatro classes de consumo refletem, com boa aproximação, o comportamento do consumo total no Brasil. O objetivo principal desta análise é identificar quais são os componentes e variáveis explicativas utilizados para a realização de prognósticos de mercado nos países citados, bem como observar o comportamento das previsões no Brasil, quando são aplicadas as metodologias de previsão destes países vizinhos ao seu mercado consumidor.

A previsão da energia elétrica para um determinado ano é indispensável para a avaliação e adequação das redes de transmissão e distribuição, bem como para a construção de novas usinas, aquisição de novas unidades geradoras e construção de linhas de transmissão.

De forma geral, a previsão de carga (energia) pode ser dividida em três categorias: as previsões de "curto prazo", que normalmente abrangem períodos de uma hora até uma semana; as previsões de "médio prazo", que normalmente abrangem períodos de uma semana até um ano; e as previsões de "longo prazo", que abrangem horizontes maiores do que um ano.

As previsões de curto e médio prazo são importantes para uma boa operação do sistema. Já as previsões de longo prazo, são realizadas visando o planejamento e a expansão do sistema, bem como os estudos de retorno de investimento, orçamento de combustíveis na geração, etc. Devido às incertezas que caracterizam o processo de previsão de longo prazo, resulta difícil de obter-se precisões similares àquelas realizadas com um horizonte menor (curto e médio prazo). Do ponto de vista teórico e prático, a previsão de longo prazo caracteriza um diferente problema em relação à previsão de curto prazo, posto que as variáveis explicativas do comportamento de carga são distintas.

\subsection{Métodos de Previsão de Médio e Longo Prazo}

O processo de previsão de longo prazo inicia-se com a seleção das variáveis explicativas que influenciam a demanda de eletricidade, por exemplo: o PIB (Produto Interno Bruto), as tarifas nas diferentes classes de consumo, população e outras. Nas previsões de médio e longo prazo, é comum o uso de métodos como o chamado de end-use (usuário final), ou métodos econométricos e, inclusive, uma combinação das duas vertentes metodológicas. 


\section{a) Método End-use}

No método end-use, estima-se o consumo de energia elétrica utilizando informação do usuário final. Ou seja, são considerados fatores como: os equipamentos elétricos dos usuários, a idade destes equipamentos, o tamanho das casas, os hábitos dos usuários, assim como as mudanças na população. Idealmente, este método é muito preciso, porém, é muito sensível à quantidade e qualidade de informação do usuário final, fato que tem restringido bastante sua utilização prática [80].

\section{b) Métodos Econométricos}

O método econométrico utilizado neste trabalho, combina os conceitos econômicos e técnicas estatísticas para prever a demanda de eletricidade. No método econométrico adotado são consideradas como variáveis explicativas a renda per capita (PIB per capita), preços da eletricidade, crescimento demográfico e outros. Este método estima as relações existentes entre o consumo de energia (variável dependente) e os fatores que influenciam o consumo desta energia. Estas relações podem ser realizadas através do método dos mínimos quadrados ou através de séries temporais (time series). Justifica-se a utilização do PIB como uma das principais variáveis explicativas do mercado de energia elétrica, na medida em que essa variável mede o nível de produção real e o desempenho da atividade econômica de um país em um determinado período.

\section{c) Métodos com Séries Temporais (Time series)}

Tem como base a hipótese que o histórico de dados possui uma estrutura interna caracterizada por autocorrelação, tendência, ou variação sazonal. Os métodos de previsão baseados em series temporais evidenciam e exploram estas estruturas. Os métodos mais comuns envolvendo series temporais são: ARMA (Autoregressive Moving Average), ARIMA (Autoregressive Integrated Moving Average), ARMAX (Autoregressive Moving Average with Exogenous Variables), e ARIMAX (Autoregressive Integrated Moving Average with Exogenous Variables). Os modelos ARMA são normalmente usados para processos estacionários, enquanto que o ARIMA [81] (também conhecido como método Box \& Jenkins), que na realidade é uma extensão do modelo ARMA, é recomendado para processos não estacionários. Nos modelos ARMA e ARIMA utilizam-se como únicos parâmetros de entrada o consumo (carga) de energia e o tempo. Na prática, esses métodos tem sido bastante utilizados quando a variável a ser projetada tem regularidade estatística e o horizonte é de curto prazo.

Por outro lado, vários métodos de previsão envolvendo inteligência artificial [42], [43], e que mostraram ter bons resultados, foram também propostos nas últimas décadas, entre os quais se destacam: as Redes Neurais Artificiais (RNA) [48], [46], [82], Sistemas Especialistas (Expert 
Systems) [44], lógica fuzzy [46], decomposição de wavelets [45], e outros [47]. Vale frisar que as três últimas técnicas de previsão listadas foram aplicadas com sucesso na previsão de curto prazo [49], de âmbito do planejamento da operação. No Anexo A são resumidos conceitualmente esses métodos.

\section{d) Redes Neurais}

As Redes Neurais Artificiais (RNA ou ANN - Artificial Neural Networks) caracterizam uma técnica de previsão amplamente utilizada já a partir dos anos 1990. Estas redes neurais são, em essência, circuitos não lineares que têm a capacidade de realizar o ajuste de curvas não lineares. As RNA funcionam de forma similar à operação dos neurônios no cérebro. Basicamente, o cérebro está constituído de bilhões destas unidades simples de processo biológico, todos fortemente interconectados e operando em paralelo. No cérebro, cada neurônio pega valores de entrada (input) de outros neurônios, aplica uma função de transferência, que é enviada como saída (output) à próxima camada de neurônios. Pela sua vez, estes neurônios enviam os seus outputs a outras camadas de neurônios utilizando conexões em cascata. De forma semelhante, as redes RNA estão formadas de várias centenas ou milhares de unidades de processo simples, conectadas em paralelo e passando informação às camadas subseqüentes [46], [82]. A arquitetura mais popular de RNA para previsão de carga é chamada de back propagation. As RNA com esta arquitetura usam funções continuamente avaliadas e de aprendizagem supervisionada.

\subsection{Principais Variáveis Explicativas}

Sabe-se que nos estudos de previsão de curto e médio prazo é comum o uso de variáveis exógenas de natureza climática ou aquelas que possuem um comportamento cíclico. Devido a sua natureza e características inerentes, nas previsões de longo prazo aqui desenvolvidas, utilizaram-se como variáveis explicativas, conforme estabelecido nas metodologias consideradas, as variáveis do tipo econométricas.

Um modelo econométrico vem a ser uma relação funcional entre uma variável dependente (neste caso a demanda de energia elétrica) e outra ou outras variáveis independentes ou explicativas da primeira, por exemplo, o PIB (Produto Interno Bruto) per capita nacional e/ou o crescimento demográfico (população) que afetam e condicionam o desenvolvimento e comportamento do mercado elétrico. Estes dados foram obtidos das referências [51], [52] e [53].

a) Produto Interno Bruto (PIB). Representa a soma (em valores monetários) de todos os bens e serviços finais produzidos em uma determinada região (qual seja, países, estados, cidades), durante um período determinado (mês, trimestre, ano, etc). O PIB é um dos indicadores mais utilizados na macroeconomia com o objetivo de mensurar a atividade econômica de uma região. 
b) População. Conforme aumenta a população de um determinado país, aumentam também os diferentes serviços à população como: demanda de produtos eletrônicos, moradia, transporte, serviços públicos, etc. Assim, pode-se dizer que a demanda de energia elétrica aumenta em proporção ao crescimento populacional. No caso do Brasil, a média anual da taxa de crescimento populacional, segundo o IBGE, é de aproximadamente 2,91\%. Na atualidade o Brasil possui uma população estimada em 189.832.095 milhões de habitantes, sendo que a maioria desta população está concentrada nas grandes cidades. Segundo dados do World Bank [71], no Brasil 5,1 \% da população não tinha acesso ao serviço de eletricidade em 2006. O uso de outras variáveis explicativas, além das apresentadas, será esclarecidos na devida oportunidade.

\subsection{Preparo e Tratamento de Dados}

As séries históricas das energias anuais utilizadas nas previsões corresponderam ao período 19962006, obtendo-se um total de 11 amostras. Com a finalidade de evitar a incidência do período de racionamento, ocorrido no Brasil no período Junho 2001 a Fevereiro 2002, sobre as previsões, a série histórica correspondente ao período 1996-2000 e correspondente ao consumo total das classes de consumo, teve que ser ajustada (Figura 4.1) para depois ser redistribuída sobre as classes de consumo consideradas (segundo a participação porcentual destas).

O ajuste do histórico de consumo total do período pré-racionamento emula um comportamento mais eficiente do consumo. É como se a mudança nos hábitos de consumo, e a sua conseqüente redução da demanda de energia, tivesse já acontecido no período 1996 a 2000.

No consumo Residencial, por exemplo, estes novos hábitos de consumo manifestaram-se através do uso de lâmpadas compactas de baixo consumo e a substituição dos velhos aparelhos eletrodomésticos e outros equipamentos por outros mais eficientes no seu consumo. Similares medidas tiveram que ser adotadas nas outras classes de consumo. A redução do consumo no período 1996-2000, após realizar o ajuste, foi de aproximadamente 20\% (Figura 4.1b). Relatos do ONS do ano 2002 indicam também uma redução do consumo (período de racionamento) dessa ordem.

O horizonte de previsão estabelecido foi de seis anos (2012). A ferramenta utilizada neste estudo foi o software $\mathrm{SAS}^{\Theta}[50]$ atualmente utilizado por muitas companhias elétricas no mundo todo para este tipo de tarefa. Durante a simulação das metodologias foram formuladas as condições para representar três cenários futuros: cenário otimista, médio e conservativo. 


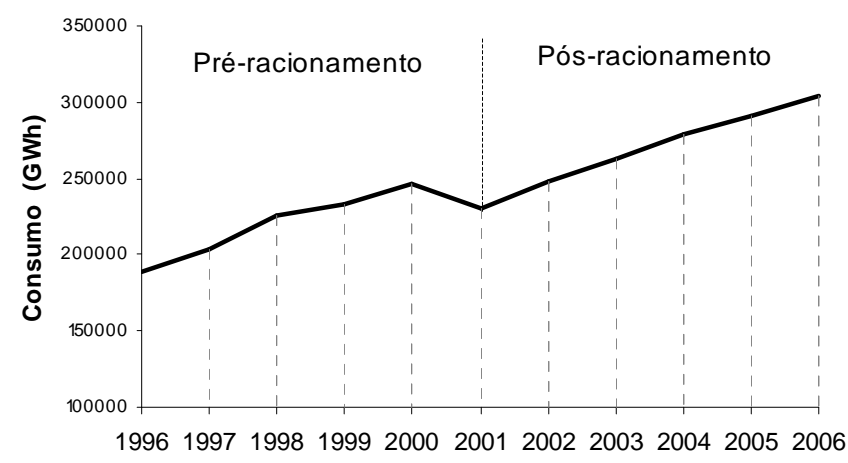

(a)

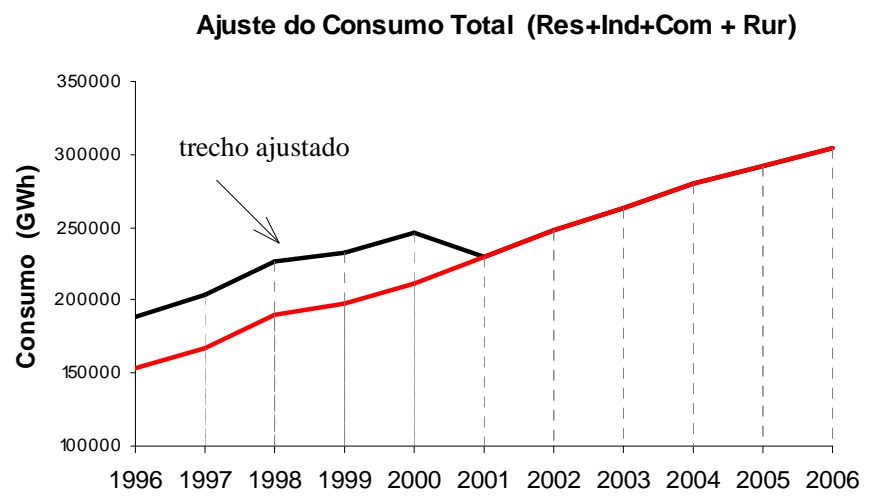

- com racionamento —ajustada

(b)

Figura 4.1 Ajuste do consumo "total" devido ao período de racionamento:

(a) Curva não ajustada, (b) Curva ajustada (linha vermelha).

\subsubsection{Outros Métodos de Regressão Comumente Utilizados dentro do SAS}

Convém ressaltar que se optou por realizar a previsão através de outros métodos de regressão ${ }^{15}$ (cujas características são brevemente comentadas a seguir) em situações em que: o impacto das variáveis explicativas não foi considerado relevante ou quando o histórico de consumo não conseguiu ser corrigido através das variáveis econométricas devido ao comportamento de sua tendência (aumentos ou reduções súbitas). Destaca-se entre estes métodos:

- Simple Exponential Smoothing: Este método de previsão é o mais utilizado em processos de previsão. Precisa pouco esforço computacional e é utilizado principalmente em casos onde os dados do histórico e a tendência são horizontais, ou seja, não existe variação cíclica ou alguma outra forma de tendência diferente da mencionada.

\footnotetext{
${ }^{15}$ Estes métodos de regressão são também chamados de automatic model fitting.
} 
- Linear (Holt) Exponential Smoothing: Utilizado em dados históricos sem comportamento sazonal, porém que apresentam alguma outra tendência. Utilizado também quando a série histórica apresenta uma tendência linear simples.

- Double (Brown) Exponential Smoothing: Este método aplica a regressão exponencial simples (Single exponential smoothing) duas vezes. Utilizado quando a série histórica não é estacionária.

- Damped Trend Exponential Smoothing. Utilizado quando a série histórica possui dados que mostram um aumento (redução) significativo, especialmente no final da série histórica, evitando-se desta forma o estabelecimento de projeções com crescimento (ou queda) muito elevado (muito baixo). Por exemplo, este método é útil para projetar casos onde existe saturação de mercado.

Estes métodos de regressão foram os que melhor se ajustaram ao histórico de dados (dispersos), em relação a outros disponíveis e, em conseqüência, ofereceram uma tendência de crescimento compatível com este histórico. Desta forma evitaram-se previsões horizontalmente constantes ou decrescentes, produto da aplicação estritamente matemática de determinado método de regressão.

Na Figura 4.7, por exemplo, no caso da previsão do consumo Industrial, foi utilizado o método de regressão linear (Holt) exponential smoothing, isto devido a que quando processadas a série histórica de consumo, assim como as variáveis explicativas consideradas, obteve-se um resultado de previsão inconsistente, daí o uso deste método de regressão nesta classe.

\subsection{Metodologias de Previsão de Longo Prazo dos Países Analisados}

Nesta seção serão apresentadas as diferentes metodologias de previsão da demanda de energia utilizadas na Argentina, Bolívia, Brasil, Chile e no Peru. Deve-se ressaltar que alguns dos modelos de previsão utilizados (Chile, Bolívia) foram obtidos a partir de concessionárias de distribuição específicas, enquanto que as demais metodologias foram obtidas dos órgãos responsáveis pela previsão de energia a nível nacional. O motivo de ter-se adotado as metodologias de determinadas concessionárias, no caso dos países inicialmente mencionados, deveu-se à dificuldade de obter os modelos de previsão nacionais. Durante a simulação das metodologias aqui apresentadas, obtiveramse três cenários futuros: otimista, provável e conservativo. No trabalho apenas serão apresentados os cenários futuros "médios" (prováveis).

\subsubsection{Metodologia de Previsão Utilizada no Brasil}

Segundo o Plano decenal de Expansão de Energia 2007-2016, apresentado pela Empresa de Pesquisa Energética - EPE [52], a metodologia adotada para a elaboração das projeções de mercado é elaborada por subsistemas elétricos e por classe de consumo (residencial, industrial, comercial e outras). Com base nas premissas estabelecidas nesta referência [52], foram obtidas as variáveis econométricas a serem utilizadas na metodologia representativa do Brasil (Figura 4.2). 


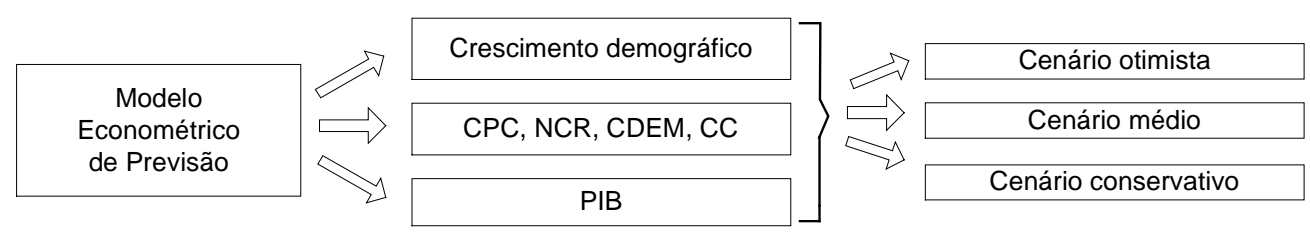

Figura 4.2 Modelo econométrico de previsão que representa ao sistema Brasileiro

onde,

CPC : Consumo médio por Consumidor Residencial

NCR : Número de Consumidores Residenciais

CDEM : Crescimento Demográfico (População)

CC : Consumo Comercial

Assim, no caso do Brasil, foram consideradas como variáveis de regressão as seguintes [52]:

- Residencial: Consideram-se dois parâmetros básicos, o consumo médio por consumidor residencial (CPC) que resulta da relação entre o consumo anual de energia e o número de consumidores da classe residencial; além da relação entre o número de consumidores residenciais (NCR) e a população (CDEM).

- Industrial: PIB per capita nacional.

- Comercial: Relação do consumo comercial per capita (CC) e a população (CDEM), além do PIB per capita.

- Rural: PIB per capita nacional e consumo industrial.

O fato de terem sido escolhidas as supracitadas variáveis explicativas, como base da previsão, deve-se às seguintes razões:

- Na classe residencial, o número de consumidores de classe residencial bem como o crescimento demográfico condiciona o desenvolvimento e expansão desta classe.

- Na classe industrial, considera-se que o PIB per capita reflete de forma direta a atividade e o comportamento desta classe de consumo, de modo que a sua tendência pode ser tomada como um indicador da futura atividade industrial.

- Na classe comercial, considera-se que além do próprio consumo a população e o PIB per capita irão influenciar a trajetória do crescimento no consumo.

- Classe rural são consideradas como variáveis explicativas o PIB per capita (pela movimentação do agro-negócio) e o comportamento do setor industrial (vinculo com a agroindústria).

De fato, poder-se-ia ter uma melhor precisão nos prognósticos se estas classes de consumo fossem abertas em subclasses, obtendo-se o total por classe, ou o total nacional, através da soma de todas as subclasses e classes consideradas. Estas previsões poderiam também ser realizadas discriminando o consumo em cargas vegetativas, cargas maiores e cargas novas.

Pelo fato do PIB per capita Brasileiro (R $\$ / h a b)$ ter uma incidência significativa na previsão, apresentase a seguir (Figura 4.3) a projeção desta variável econométrica que será posteriormente utilizada como 
uma das variáveis de regressão seja de forma direta ou em combinação com outras variáveis. Pode-se observar que, neste caso, o PIB per capita apresenta um crescimento quase que estável diferente ao comportamento observado em outros países como na Argentina e Uruguai que no período 2000-2001 tiveram depressões marcantes.

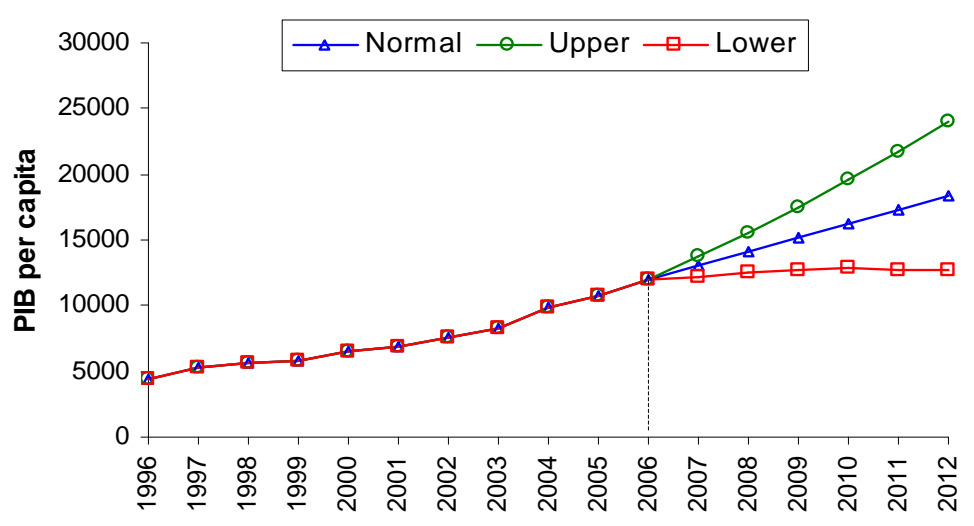

Figura 4.3 Previsão do PIB per capita Brasileiro

O limite de confiança especificado no software utilizado nas simulações foi de 95\%. A linha (verde) superior representa o cenário otimista, a linha média (azul) representa o cenário normal, enquanto que a linha (vermelha) inferior representa o cenário conservativo. Em relação ao por que na metodologia de previsão Brasileira não são consideradas as tarifas médias como variáveis explicativas, similar à metodologia utilizada no Peru, existem algumas hipóteses.

Um deles é que no Brasil o crescimento percentual da tarifa industrial média, no período 1996-2006, conforme disponibilizado em [51], mostrou uma variação significativa (vide Tabela 4.1), principalmente nos anos 1997, 1998, 2004, 2005 e 2006. Vale lembrar que a tarifa de energia elétrica evolui em função de uma série de fatores, mas principalmente em função da evolução dos custos operacionais e do esforço de investimento para proporcionar a expansão do sistema. Disso pode-se concluir que na ausência de economias de escala importantes, a tarifa cresce em função do mercado, havendo nítida correlação entre essas variáveis.

No caso Brasileiro, a tarifa foi administrada pelo Governo durante um importante período da evolução do setor elétrico, constituindo-se instrumento de política econômica na medida em que foi muito utilizada como instrumento para gerenciar a inflação. Por isso mesmo, nesse período, a tarifa não evoluiu condicionada por suas variáveis naturais (evolução dos custos e do porte do sistema), mas sim apresentou um comportamento errático e muito difícil de modelar, impedindo o desenvolvimento de cenários prospectivos para o futuro. Esta pode ser uma das razões pelas quais, na metodologia Brasileira, desconsidera-se o uso das tarifas médias como uma das variáveis de regressão. 
Tabela 4.1 Crescimento porcentual das tarifas no Brasil

\begin{tabular}{|l|r|}
\hline \multicolumn{2}{|c|}{ Residencial Média } \\
\hline ANO & $\begin{array}{c}|c| \\
\text { TAXA DE } \\
\text { CRESCIMENTO }\end{array}$ \\
\hline 1996 & ----- \\
\hline 1997 & $12,4 \%$ \\
\hline 1998 & $5,3 \%$ \\
\hline 1999 & $10,1 \%$ \\
\hline 2000 & $14,4 \%$ \\
\hline 2001 & $13,2 \%$ \\
\hline 2002 & $16,7 \%$ \\
\hline 2003 & $14,1 \%$ \\
\hline 2004 & $13,0 \%$ \\
\hline 2005 & $7,6 \%$ \\
\hline 2006 & $1,3 \%$ \\
\hline
\end{tabular}

\begin{tabular}{|l|r|}
\hline \multicolumn{2}{|c}{ Industrial Média } \\
\hline ANO & $\begin{array}{c}\text { TAXA DE } \\
\text { CRESCIMENTO }\end{array}$ \\
\hline 1996 & ---- \\
\hline 1997 & $8,2 \%$ \\
\hline 1998 & $3,5 \%$ \\
\hline 1999 & $11,6 \%$ \\
\hline 2000 & $12,5 \%$ \\
\hline 2001 & $15,7 \%$ \\
\hline 2002 & $16,5 \%$ \\
\hline 2003 & $16,8 \%$ \\
\hline 2004 & $22,6 \%$ \\
\hline 2005 & $34,9 \%$ \\
\hline 2006 & $12,3 \%$ \\
\hline
\end{tabular}

\begin{tabular}{|c|r|}
\hline \multicolumn{2}{|c}{ Comercial Média } \\
\hline ANO & $\begin{array}{c}\text { TAXA DE } \\
\text { CRESCIMENTO }\end{array}$ \\
\hline 1996 & ----- \\
\hline 1997 & $8,4 \%$ \\
\hline 1998 & $3,3 \%$ \\
\hline 1999 & $9,1 \%$ \\
\hline 2000 & $12,4 \%$ \\
\hline 2001 & $14,2 \%$ \\
\hline 2002 & $18,8 \%$ \\
\hline 2003 & $13,3 \%$ \\
\hline 2004 & $13,4 \%$ \\
\hline 2005 & $10,2 \%$ \\
\hline 2006 & $4,4 \%$ \\
\hline
\end{tabular}

\begin{tabular}{|l|r|}
\hline \multicolumn{2}{|c}{ Rural Média } \\
\hline ANO & $\begin{array}{c}\text { TAXA DE } \\
\text { CRESCIMENTO }\end{array}$ \\
\hline 1996 & ----- \\
\hline 1997 & $8,1 \%$ \\
\hline 1998 & $2,9 \%$ \\
\hline 1999 & $9,0 \%$ \\
\hline 2000 & $13,1 \%$ \\
\hline 2001 & $14,0 \%$ \\
\hline 2002 & $80,0 \%$ \\
\hline 2003 & $-22,5 \%$ \\
\hline 2004 & $13,7 \%$ \\
\hline 2005 & $8,4 \%$ \\
\hline 2006 & $5,4 \%$ \\
\hline
\end{tabular}

Um comportamento similar, variação na taxa de crescimento, pôde ser observado nas tarifas médias das outras classes de consumo (Tabela 4.1), o que pode ser traduzido em um desincentivo para se utilizar nas previsões. Por outro lado, deve-se mencionar que na maioria dos países Sul-Americanos, as tarifas de eletricidade estão referenciadas ao dólar americano, fato que ofereceria uma certa estabilidade ao sistema tarifário e às previsões.

Conforme pode ser observado na Figura 4.4, a evolução do custo das tarifas médias não apresenta uma tendência estável. Claramente, os custos em todas as classes de consumo apresentaram uma queda em 2006, enquanto que no período 2000-2004 aproximadamente a maioria destas, excetuando a classe rural, tiveram um crescimento significativo. 


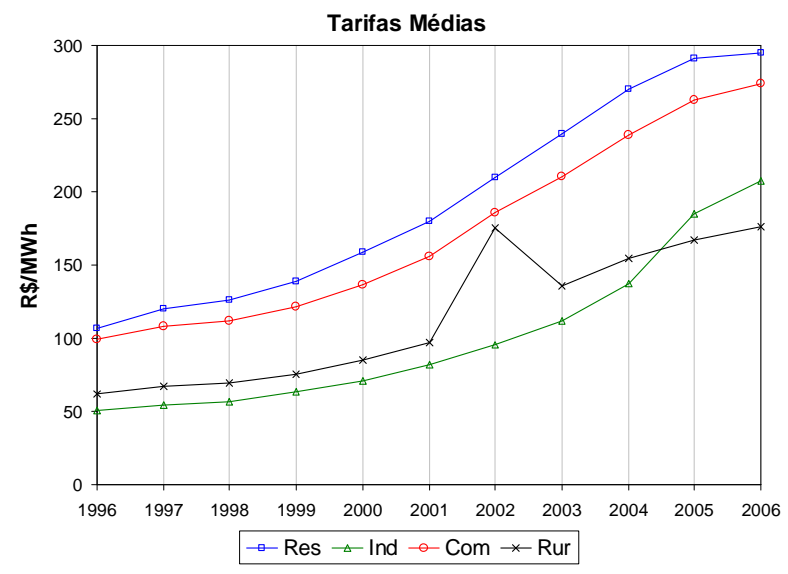

Figura 4.4 Evolução das tarifas médias por classe de consumo

\subsubsection{Previsão Utilizando a Metodologia do Brasil}

Na Figura 4.5 apresentam-se os resultados de previsão obtidos da metodologia citada no item 4.5.1. Os valores do MAPE (Mean Absolute Percentage Error) correspondentes a esta e as outras metodologias estão sendo apresentadas no item 4.6.
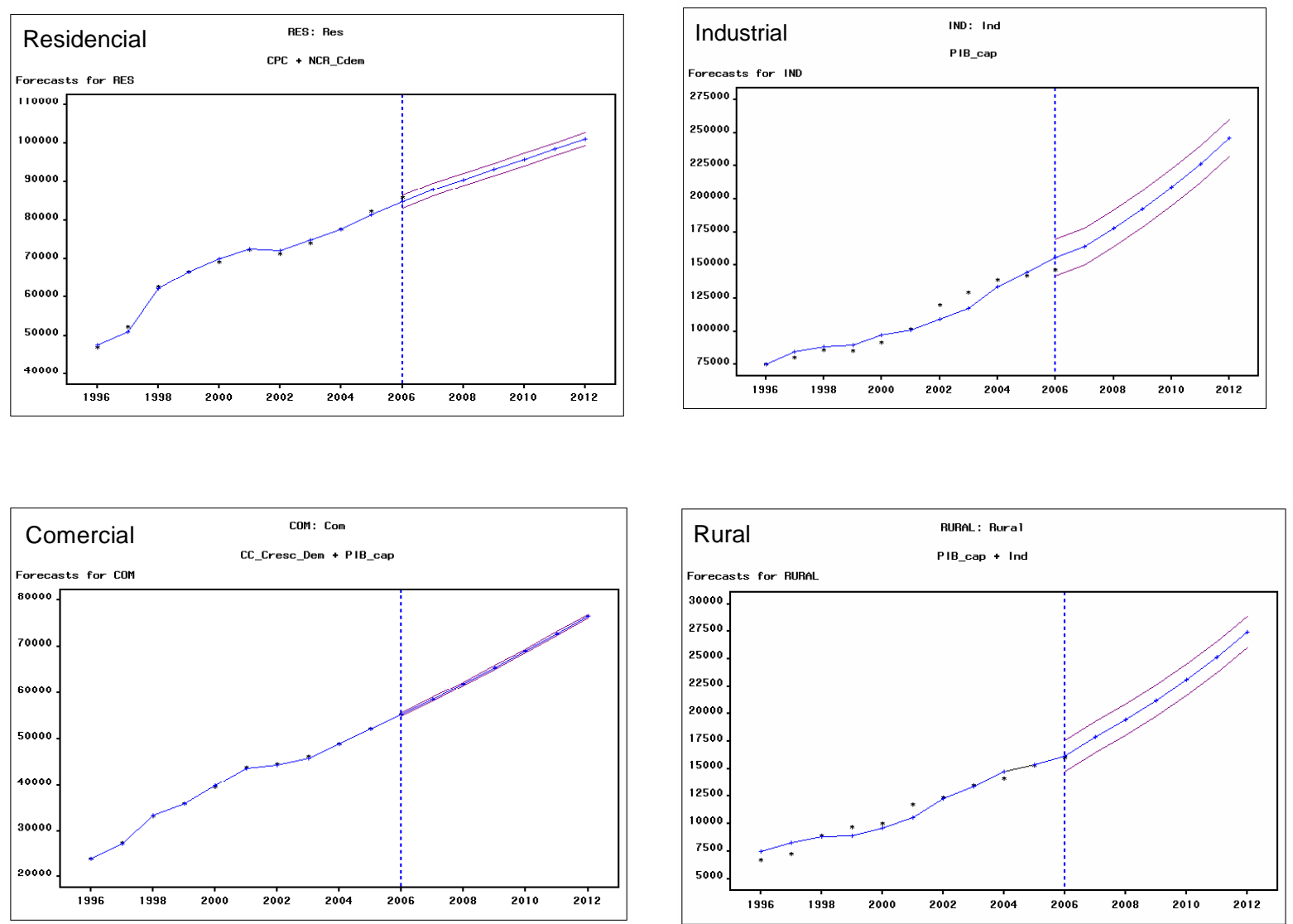

Figura 4.5 Resultados de previsão, metodologia do Brasil (previsão em GWh) 


\subsubsection{Metodologia de Previsão Utilizada no Peru}

Segundo o Plano Referencial de Eletricidade 2005-2015 (Ministério de Minas e Energia) [55] os estudos de projeção da demanda de energia do Sistema Elétrico Integrado Nacional (SEIN) são realizados agrupando dois grandes tipos de cargas: Cargas Vegetativas e Cargas Maiores. As Cargas Vegetativas correspondem principalmente à demanda do mercado regulamentado, considerando que este tipo de demanda é susceptível à modelagem através de técnicas estatísticas, precisando de dados para esse fim. As Cargas Maiores (cargas especiais e grandes projetos) são analisadas de forma separada, sendo seus resultados adicionados sobre aqueles do modelo estatístico. No modelo Econométrico utilizado participam como variáveis explicativas: o PIB (Produto Interno Bruto), a população e a tarifa média da respectiva classe de consumo. Na Figura 4.6 sintetizam-se as metodologias de previsão utilizadas no Peru.

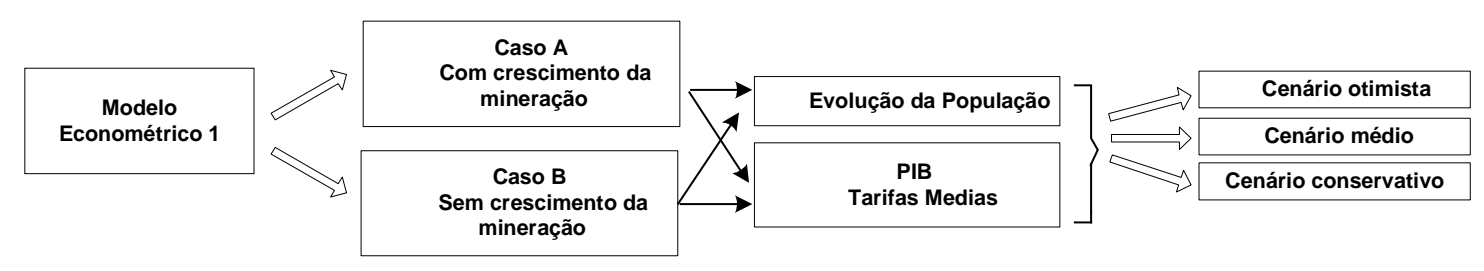

(a)

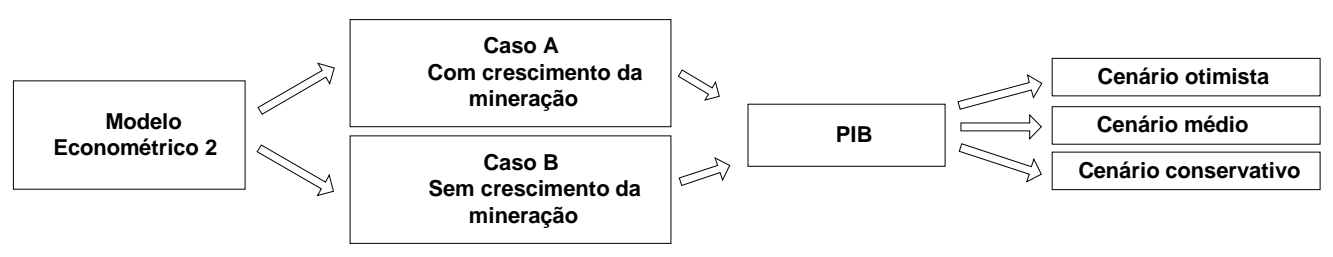

(b)

Figura 4.6 Modelos econométricos de previsão utilizados no Peru

O Modelo Econométrico 2 (Figura 4.6b) é utilizado basicamente para verificar desempenho do Modelo Econométrico 1, pois como aconteceu em anos passados com o modelo utilizado na Argentina, o uso exclusivo do PIB, que poderia não estar correlacionado com o crescimento do sistema elétrico, poderia comprometer os resultados da previsão.

Pôde-se constatar que o modelo econométrico de previsão utilizado no Peru tem muita semelhança com aquele utilizado na Colômbia [56], já que ambas as metodologias utilizam como variáveis explicativas o PIB, o crescimento demográfico e as tarifas médias de consumo das respectivas classes de consumo.

\subsubsection{Previsão Utilizando a Metodologia do Peru}

Na Figura 4.7 apresentam-se os resultados de previsão correspondente às classes de consumo Residencial, Industrial, Comercial e Rural obtidas a partir da metodologia (caso A) mostrada na Figura 4.6(a). 

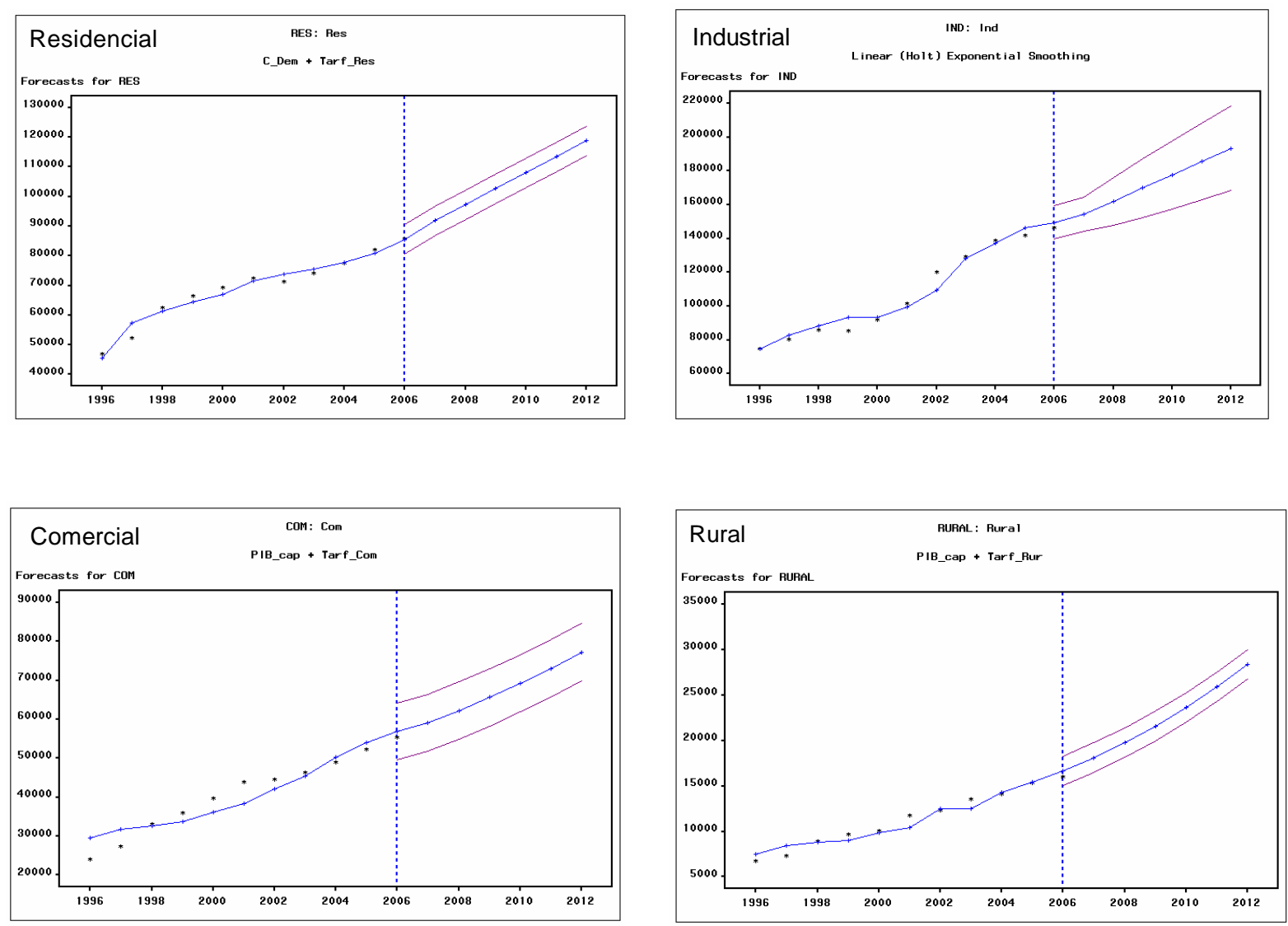

Figura 4.7 Resultados da previsão, metodologia do Peru (previsão em GWh)

\subsubsection{Metodologia de Previsão Utilizada na Argentina}

Até o ano 2000, a metodologia de previsão utilizada na Argentina estava baseada em um modelo econométrico. Nesse contexto estimava-se a evolução da demanda de energia elétrica considerando principalmente o PIB. O PIB estava relacionado com a demanda de energia através de uma função exponencial:

$$
\operatorname{Dem}=a(P I B)^{b}
$$

Os valores de $a$ e $b$ tinham que ser previamente calculados. Porém, o problema fundamental apresentava-se na relação de ambas variáveis (demanda e PIB), isto devido a que a economia Argentina apresentou nos últimos anos dois períodos recessivos muito marcantes. Durante estes períodos, a evolução do PIB não era acompanhado pelo consumo de energia elétrica. Ou seja, não mostrava correlação com os índices agregados da atividade econômica.

Isso motivou a procurar outros métodos alternativos, bem como variáveis econômicas que acompanhassem a evolução do consumo e demanda da energia elétrica. Após algumas análises realizadas pelo seu setor de planejamento, concluiu-se que os resultados obtidos utilizando a teoria das 
Redes Neurais Artificiais (RNA) mostravam-se aceitáveis para os estudos de previsão, já que estas também permitem a inclusão de variáveis relacionadas com o consumo de energia. De forma similar ao procedimento realizado por outras ferramentas de regressão e projeção, as Redes Neurais, devidamente treinadas, podem ser aplicadas tanto à previsão de consumo global quanto às classes de consumo Residencial, Industrial, Comercial e outros. Entre as variáveis explicativas utilizadas como input no modelo baseado em RNAs, estão (Figura. 4.8):
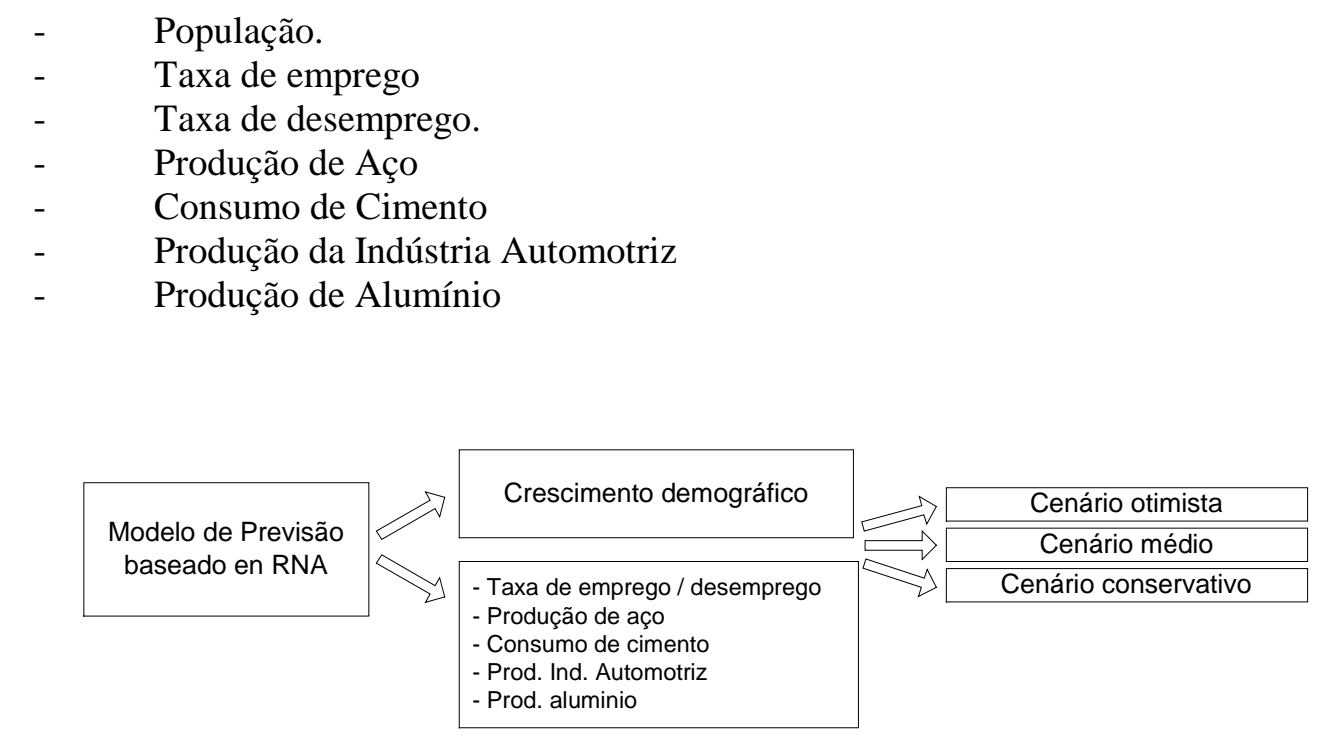

Figura 4.8 Modelo econométrico de previsão que representa ao sistema Argentino

A taxa de desemprego é calculada considerando a porcentagem entre a população ocupada e a população total. Conforme mencionado na parte introdutória deste capítulo, a aplicação das redes neurais envolve o conceito de treinamento ao invés do ajuste das variáveis explicativas. De fato, a aplicação desta técnica de previsão requer um histórico de consumo relativamente grande.

De forma similar ao realizado pela Secretaria de Energia [57], para a previsão de energia serão utilizadas como input no software $\mathrm{SAS}^{\oplus}$ as mesmas variáveis explicativas que são aplicadas nas RNAs anteriormente descritas.

\subsubsection{Previsão Utilizando a Metodologia da Argentina}

Na Figura 4.9 são apresentados os resultados de previsão quando utilizada a metodologia da Argentina. Ressalta-se que para todas as metodologias consideradas estão sendo utilizados os dados de consumo das diferentes classes e demais variáveis do Brasil. Pode-se observar que a curva de regressão utilizado neste modelo teve um bom ajuste sobre os dados do histórico de consumo, mostrando assim um consistente fator de correlação. 

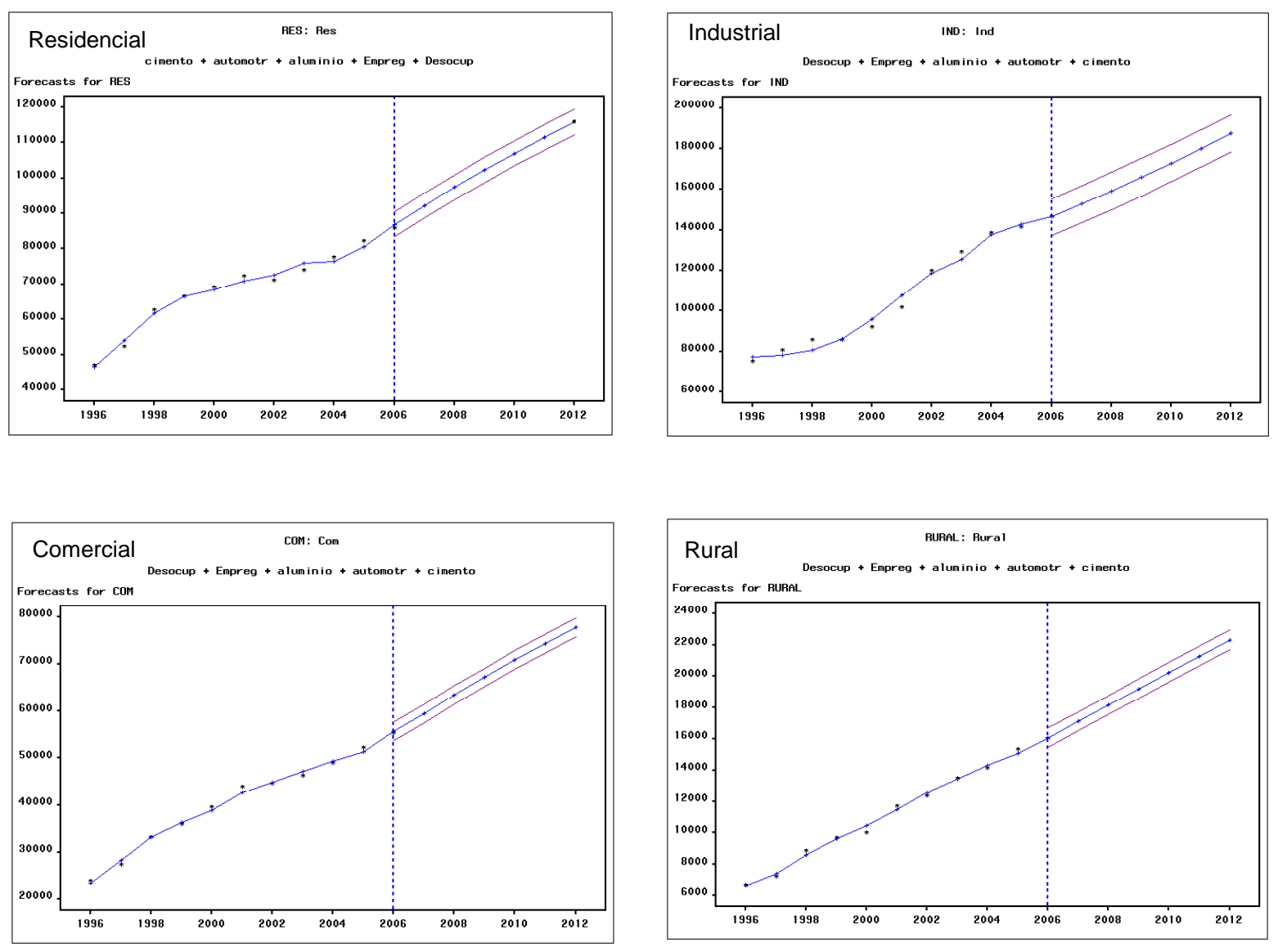

Figura 4.9 Resultados de previsão, metodologia da Argentina (previsão em GWh)

\subsubsection{Metodologia de Previsão Utilizada na Bolívia}

No caso da Bolívia, o método de previsão utilizado corresponde a uma das concessionárias de distribuição $^{16}$, mesmo que foi proporcionado pela Superintendência de Eletricidade [64] e ratificada pela concessionária para ser utilizada em 2007. As variáveis explicativas que fazem parte do modelo econométrico são mostradas na Figura 4.10.

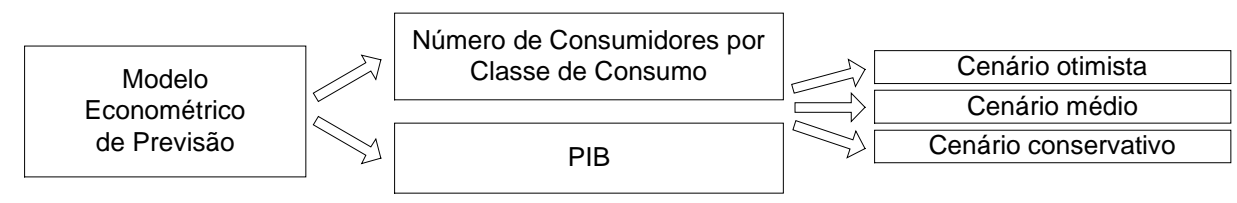

Figura 4.10 Modelo econométrico de previsão que representa ao sistema Boliviano

\footnotetext{
${ }^{16}$ Concessionária ELFEO (Empresa de Luz e Força Elétrica de Oruro)
} 
Neste caso o PIB per cápita constitui-se na variável principal para a aplicação desta metodologia. As principais características na previsão das classes de consumo Residencial, Industrial, Comercial e Rural são as seguintes:

- Classe Residencial: No caso do consumo residencial, além do PIB per capita, considera-se a evolução do número de consumidores desta classe, ou seja, a variável população não é utilizada de forma direta como nas metodologias anteriores. Isto se deve a que, como acontece em todos os países em desenvolvimento, nem todos os seus habitantes têm acesso ao serviço básico de energia elétrica.

- Classes Comercial, Industrial e Rural: Nestas classes de consumo, o PIB per capita constituise também na principal variável econométrica a ser utilizada.

\subsubsection{Previsão Utilizando a Metodologia da Bolívia}

Na Figura 4.11 apresentam-se os resultados de previsão obtidos a partir da metodologia que representa à Bolívia.
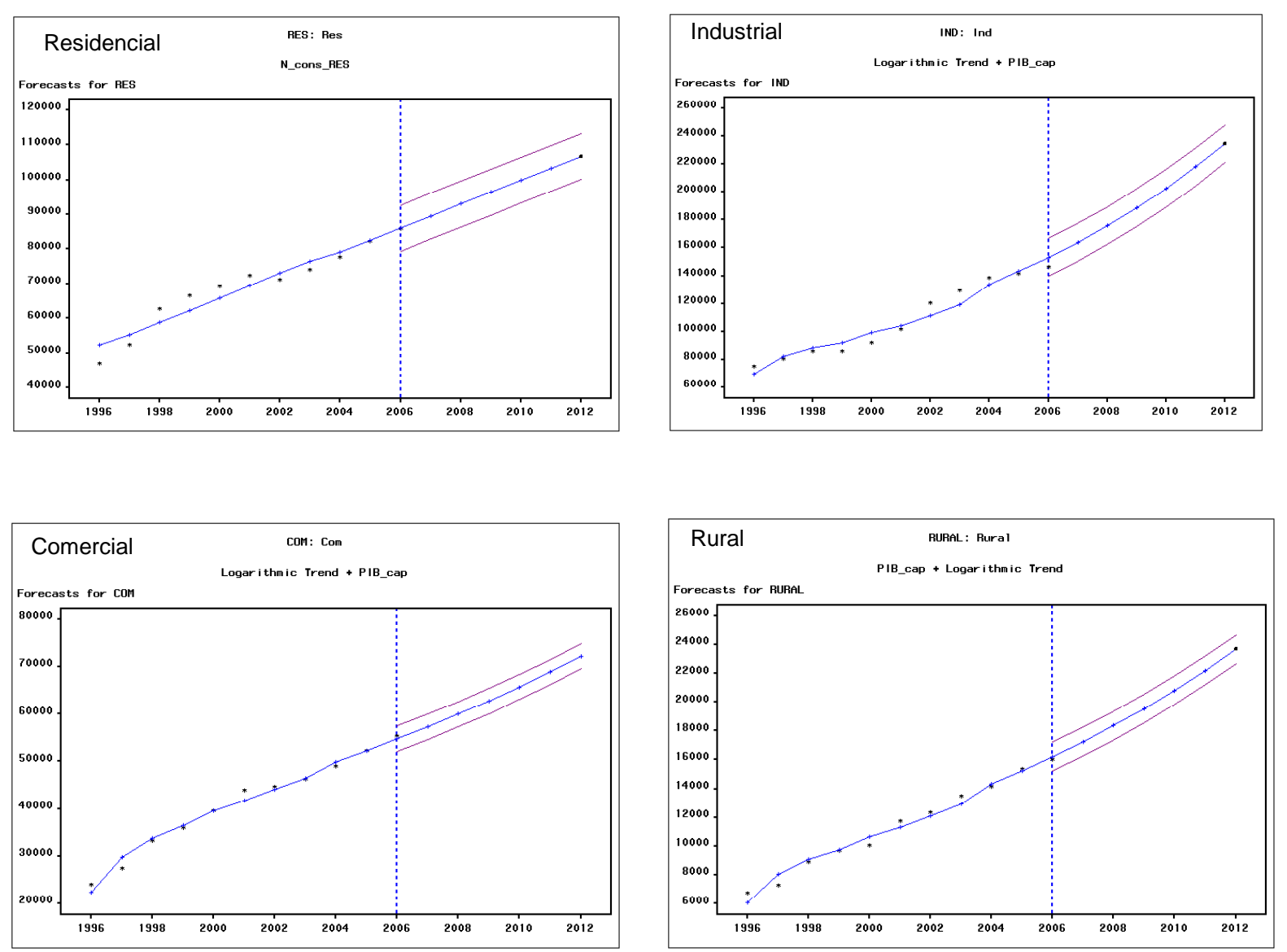

Figura 4.11 Resultados de previsão, metodologia da Bolívia (previsão em GWh) 


\subsubsection{Metodologia de Previsão Utilizada no Chile}

A metodologia de previsão aqui apresentada foi obtida do Plano Quadrienal 2004-2008 [70] apresentado por uma das Concessionárias de Distribuição ${ }^{17}$ à Superintendência de Eletricidade e Combustíveis (SEC) do Chile. Neste caso, o comportamento das variáveis dependentes (consumo Residencial, Industrial, Comercial e Rural) vem influenciadas pelas seguintes variáveis econométricas:

- Produto Interno Bruto (PIB)

- Construção Civil (habitacional)

- Evolução do crescimento populacional

- Índice Nacional de Preços ao Consumidor ${ }^{18}$

- Índice de Preços por Atacado ${ }^{19}$

Nesta metodologia, assim como nas outras apresentadas, parte-se do principio que o consumo da energia elétrica está diretamente relacionado com o crescimento econômico. A variável principal variável independente nesta metodologia é o PIB, já que este, conforme mencionado na parte introdutória deste capítulo mede o nível de produção real e o desempenho da atividade econômica de um país em um determinado período.

No período 1994-2003, o PIB Chileno teve um crescimento aproximado de 4,45\%. Assim, as projeções apresentadas ao SEC consideraram que o PIB cresceria com uma taxa levemente maior de 4,5\% entre 2004-2008 e posteriormente, nos próximos 4 anos, a uma taxa de $4 \%$ ao ano. Na Figura 4.12 são mostradas as variáveis econométricas que compõem este modelo.

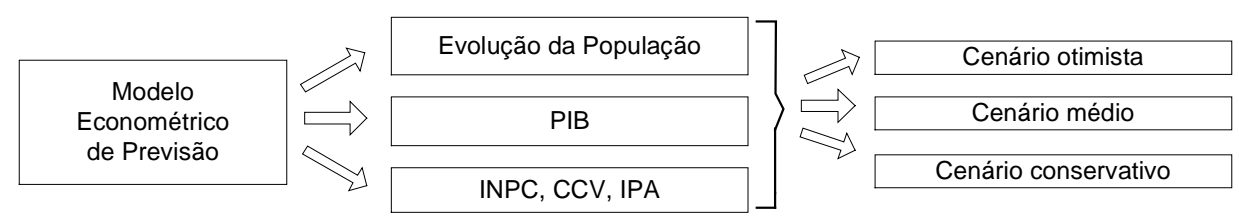

Figura 4.12 Modelo econométrico de previsão que representa ao sistema Chileno

onde,

$C C V$ : Construção Civil (Habitacional)

INPC : Índice Nacional de Preços ao Consumidor (valor médio)

IPA : Índice de Preços por Atacado

As principais características na previsão das classes de consumo consideradas são as seguintes:

- Classe Residencial: A previsão desta classe considera como variáveis econométricas ao crescimento populacional (CDEM) e à Construção Civil Habitacional (CCV).

- Classe Industrial: Considera como variáveis ao PIB, bem como ao Índice de Preços por Atacado (IPA).

\footnotetext{
${ }^{17}$ COPELEC (Cooperativa Elétrica de Chillan) que atende aos usuários na região 8 do país.

${ }^{18}$ INPC: Mede a variação do custo de vida das famílias com rendimento assalariado mensal de 1 a 8 salários mínimos [53].

${ }^{19}$ IPA: Média ponderada de preços dos 25 produtos mais importantes comercializados no País. Em outras palavras mede a evolução dos preços nas transações interempresariais e abrangem varias etapas do processo produtivo, anteriores ás vendas no varejo [69].
} 
- Classe Comercial: Considera como variáveis ao PIB e ao Índice Nacional de Preços ao Consumidor (INPC).

- Classe Rural: Nesta classe de consumo o PIB (per capita) e o Índice de Preços por Atacado (IPA) constituem-se nas variáveis com incidência direta na previsão.

\subsubsection{Previsão Utilizando a Metodologia do Chile}

Na Figura 4.13 apresentam-se os resultados de previsão obtidos utilizando a metodologia descrita no item e 4.5.5. O erro porcentual absoluto médio (MAPE- Mean Absolute Porcentage Error) do ajuste correspondente a esta metodologia, pode também ser visto na Tabela 4.2.
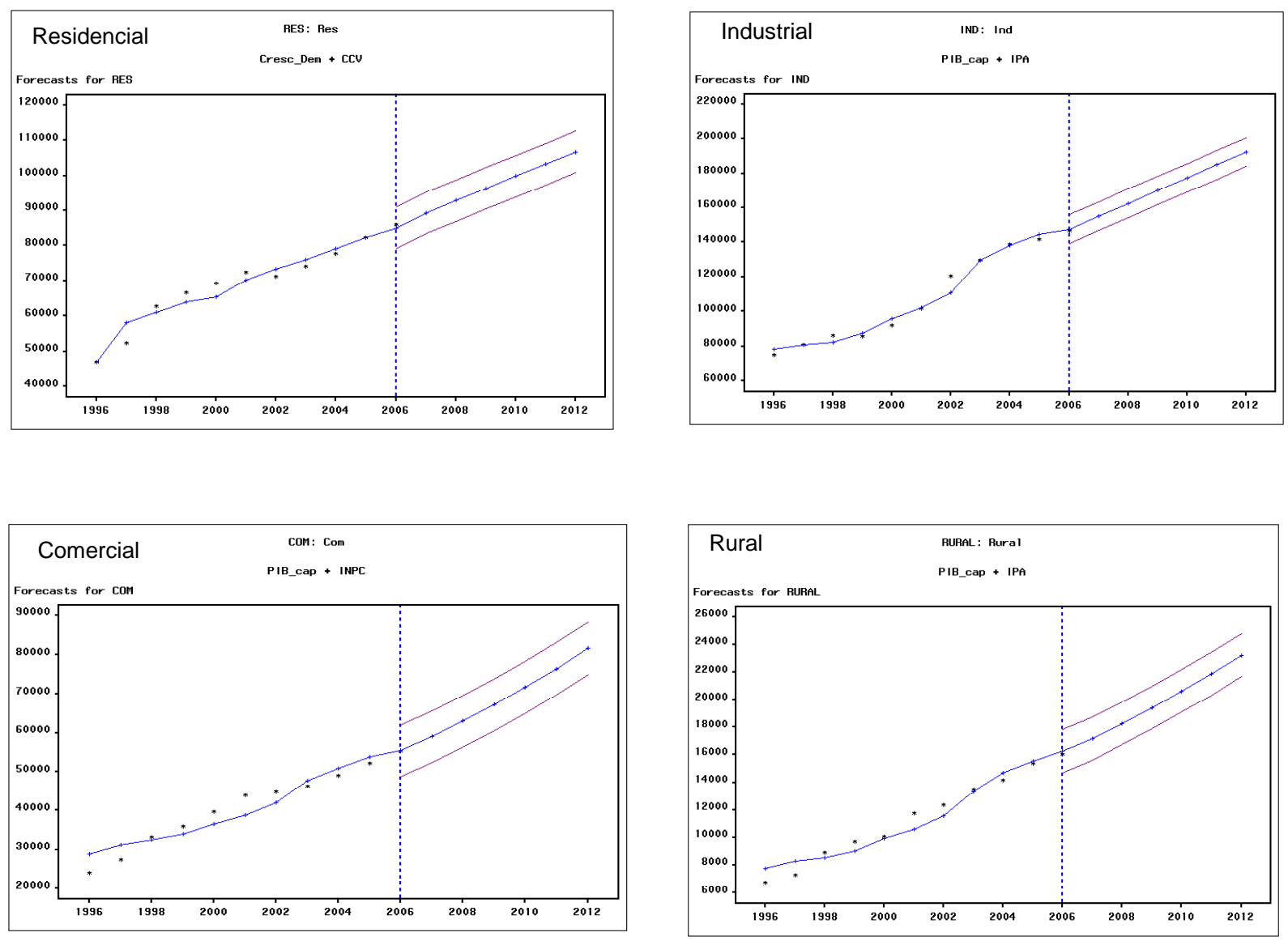

Figura 4.13 Resultados da Previsão, metodologia do Chile (previsão em GWh) 


\subsection{Valores do MAPE}

$\mathrm{Na}$ ferramenta de simulação utilizada (software $\mathrm{SAS}^{\complement}$ ), foi especificada como medida de erro na previsão a variável MAPE (Mean Absolute Percentage Error) comumente utilizada na avaliação de métodos de previsão. O MAPE é uma medida da acurácia de uma série temporal ajustada, especialmente de tendência, em relação aos valores reais. Valores do MAPE $\leq 20 \%$ são mais aceitáveis [50]. Na Tabela 4.2, mostram-se os valores do MAPE obtidos no processo de previsão para as diferentes metodologias e classes de consumo consideradas. Percebe-se que nas classes residencial e comercial o valor do MAPE, correspondente à metodologia do Brasil, teve o menor valor. No caso industrial e rural as metodologias do Chile e Argentina respectivamente, tiveram os menores valores.

Tabela 4.2 Valores do MAPE obtidos com as diferentes metodologias e classes de consumo

\begin{tabular}{|c|c|c|c|c|c|}
\hline \multirow[b]{2}{*}{ CLASSE } & ARGENTINA & BOLIVIA & BRASIL & PERU & CHILE \\
\hline & \multicolumn{5}{|c|}{ M A P E (\%) } \\
\hline Residencial & 1,58 & 4,26 & 0,91 & 2,76 & 3,16 \\
\hline Industrial & 2,58 & 4,89 & 4,50 & 3,20 & 2,44 \\
\hline Comercial & 1,54 & 2,61 & 0,37 & 7,67 & 7,04 \\
\hline Rural & 1,63 & 3,77 & 4,97 & 5,77 & 5,92 \\
\hline
\end{tabular}

\subsection{Comparação e Análise dos Resultados de Previsão Obtidos}

De modo a se ter uma melhor visão em relação a se uma determinada metodologia é mais ou menos conservativa, foram comparados os resultados de previsão do Brasil com os dos outros países. $\mathrm{Na}$ Figura 4.14 estão sendo mostrados os resultados de previsão correspondentes às quatro classes de consumo consideradas (Residencial, Industrial, Comercial e Rural).

i) No caso Residencial (Figura 4.14a) observa-se que as curvas de previsão do Peru e da Argentina mostram ser mais otimistas em relação às demais. Isto significa que as variáveis econométricas destes dois países, e de forma similar aqueles no segundo grupo (Brasil, Bolívia e Chile), produzem resultados próximos.

ii) Na classe Industrial (Figura 4.14b) pode-se observar, por um lado, que as variáveis explicativas de Brasil e Bolívia, e por outro da Argentina, Chile e Peru geram resultados quase próximos.

iii) Na classe comercial (Figura 4.14c), não se pôde observar uma diferença substancial entre os resultados obtidos com os modelos utilizados. Contudo, o modelo de previsão do Chile gerou uma curva mais otimista em relação às demais metodologias.

iv) De forma similar a (i) e (ii), nas previsões correspondentes à classe Rural (Figura 4.14d) observam-se dois grupos. Por um lado, as metodologias de Peru e do Brasil, cujas variáveis utilizadas produzem resultados próximos e, por outro lado, os resultados das metodologias correspondentes à Argentina, Bolívia e Chile.

Percebe-se que a aderência dos resultados entre si, nas diferentes classes de consumo, depende das 
variáveis econométricas utilizadas para alimentar o modelo de projeção. Por outro lado, com exceção da metodologia adotada nos últimos anos pela Argentina, o resto dos países analisados mostraram semelhanças, principalmente no relacionado às variáveis econométricas consideradas.

\section{Residencial}

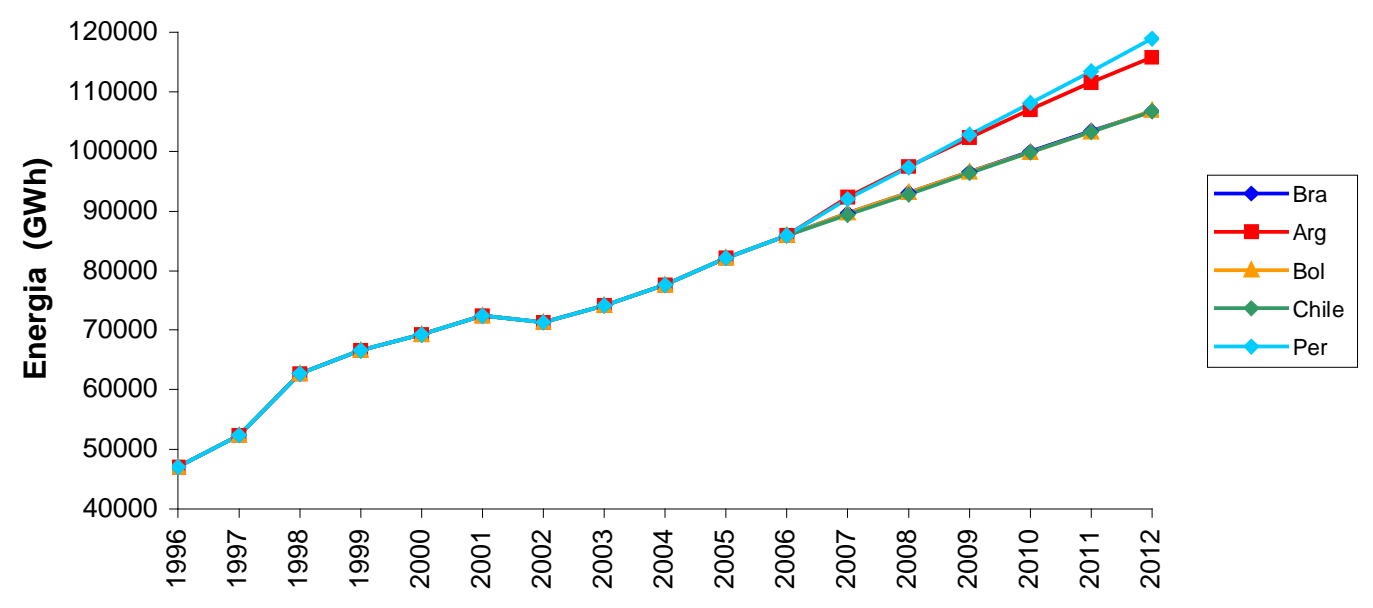

(a)

\section{Industrial}

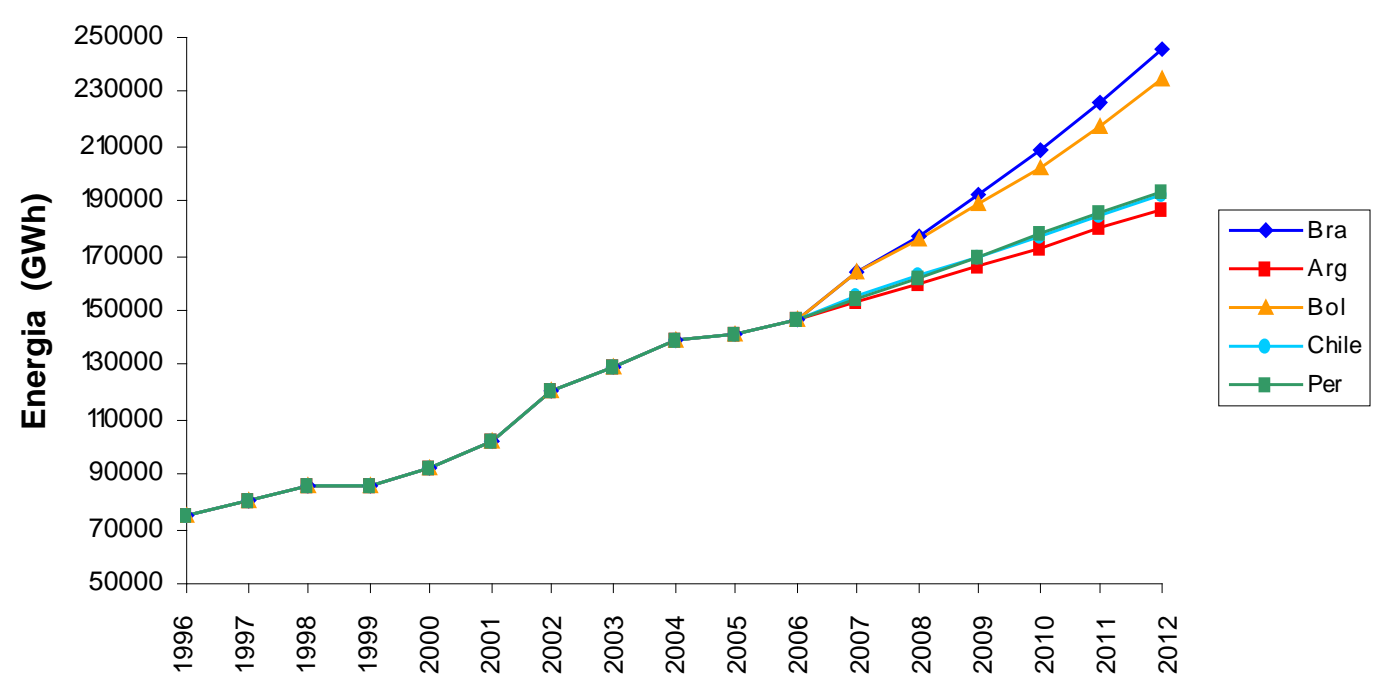

(b) 


\section{Comercial}

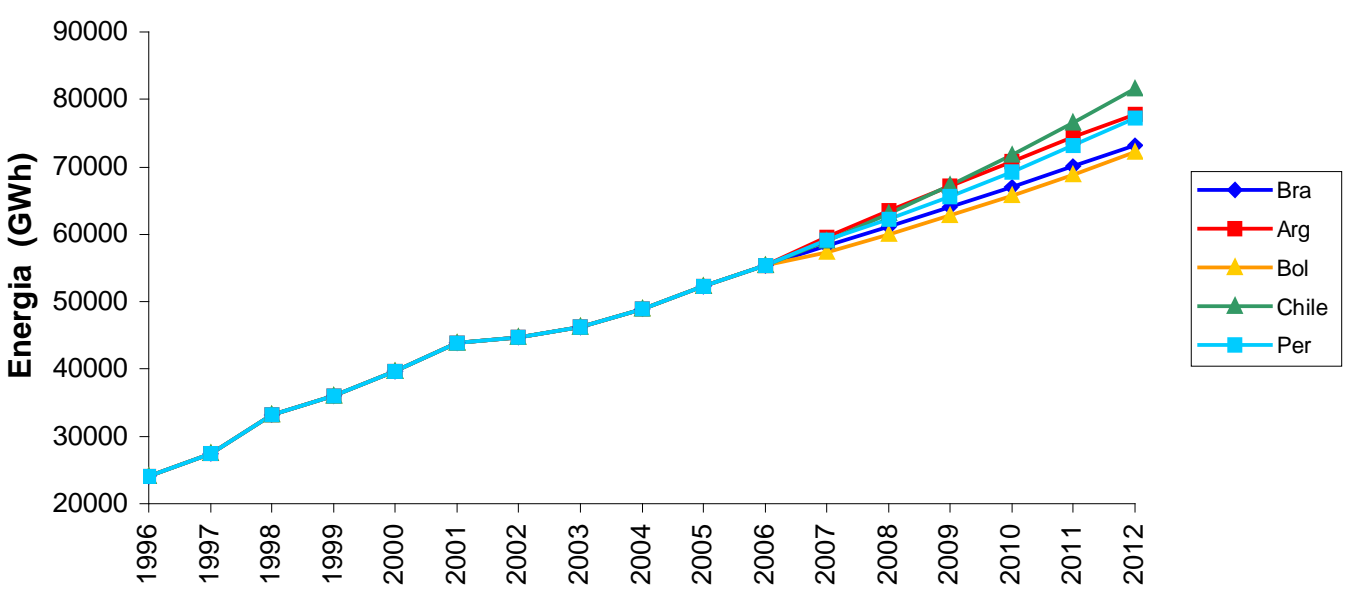

(c)

\section{Rural}

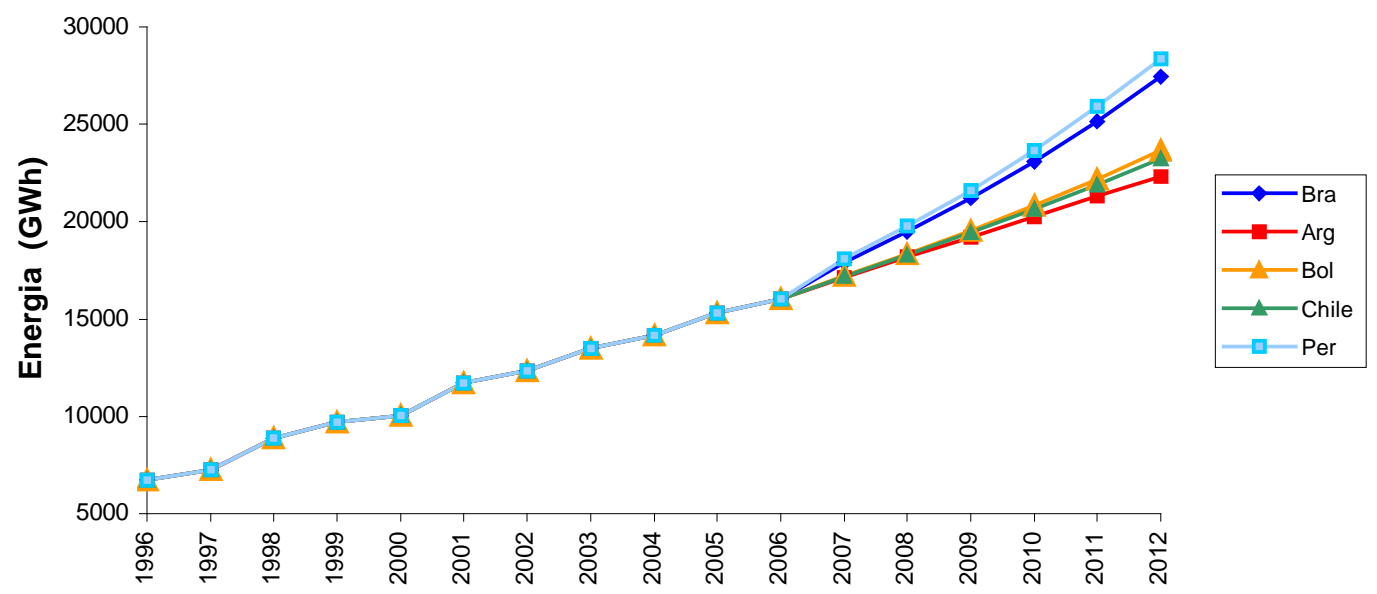

(d)

Figura 4.14. Resultados da previsão de energia, classes: (a) Residencial, (b) Industrial, (c) Comercial, (d) Rural

Estes resultados de comparação das previsões de forma individual entre a metodologia de previsão do Brasil com cada um dos outros países podem ser observados no Anexo D. 


\subsubsection{Diferenças Relativas entre as Metodologias dos Países Analisados com a do Brasil}

As diferenças relativas porcentuais dos métodos de previsão dos quatro países considerados em relação à metodologia do Brasil podem ser vistas na Tabela 4.3. As referidas diferenças relativas foram obtidas utilizando a expressão (4.2)

$$
\operatorname{Dif} \operatorname{Rel}(\%)=\frac{(B-A)}{A} * 100 \%
$$

onde,

A : Valores previstos(2007-2012) obtidos com a metodologia do Brasil

$B$ : Valores previstos (2007-2012) obtidos com a metodologia dos outros países

Tabela 4.3 Diferenças relativas porcentuais na previsão (período 2007-2012) em relação à metodologia do Brasil

\begin{tabular}{|c|c|c|c|c|c|}
\hline \multirow[b]{2}{*}{ Classe } & \multirow[b]{2}{*}{ Ano } & \multicolumn{4}{|c|}{ BRASIL (Termo A na equação 4.2) } \\
\hline & & Argentina & Bolívia & Chile & Peru \\
\hline \multirow{6}{*}{ Residencial } & 2007 & $2,89 \%$ & $-0,055 \%$ & $-0,359 \%$ & $2,54 \%$ \\
\hline & 2008 & $4,62 \%$ & $-0,062 \%$ & $-0,281 \%$ & $4,56 \%$ \\
\hline & 2009 & $6,00 \%$ & $-0,068 \%$ & $-0,206 \%$ & $6,44 \%$ \\
\hline & 2010 & $7,07 \%$ & $-0,074 \%$ & $-0,135 \%$ & $8,19 \%$ \\
\hline & 2011 & $7,89 \%$ & $-0,080 \%$ & $-0,066 \%$ & $9,82 \%$ \\
\hline & 2012 & $8,50 \%$ & $-0,085 \%$ & $-0,001 \%$ & $11,35 \%$ \\
\hline \multirow{6}{*}{ Industrial } & 2007 & $-6,95 \%$ & $-0,096 \%$ & $-6,00 \%$ & $-5,53 \%$ \\
\hline & 2008 & $-10,33 \%$ & $-1,03 \%$ & $-8,73 \%$ & $-8,49 \%$ \\
\hline & 2009 & $-13,71 \%$ & $-1,96 \%$ & $-11,69 \%$ & $-11,65 \%$ \\
\hline & 2010 & $-17,09 \%$ & $-2,89 \%$ & $-14,83 \%$ & $-14,96 \%$ \\
\hline & 2011 & $-20,47 \%$ & $-3,82 \%$ & $-18,10 \%$ & $-18,39 \%$ \\
\hline & 2012 & $-23,83 \%$ & $-4,72 \%$ & $-21,45 \%$ & $-21,88 \%$ \\
\hline \multirow{6}{*}{ Comercial } & 2007 & $2,19 \%$ & $-1,52 \%$ & $1,43 \%$ & $1,59 \%$ \\
\hline & 2008 & $3,77 \%$ & $-1,83 \%$ & $3,12 \%$ & $1,92 \%$ \\
\hline & 2009 & $4,93 \%$ & $-1,96 \%$ & $5,00 \%$ & $2,51 \%$ \\
\hline & 2010 & $5,71 \%$ & $-1,90 \%$ & $7,05 \%$ & $3,33 \%$ \\
\hline & 2011 & $6,17 \%$ & $-1,67 \%$ & $9,26 \%$ & $4,37 \%$ \\
\hline & 2012 & $6,35 \%$ & $-1,25 \%$ & $11,61 \%$ & $5,63 \%$ \\
\hline \multirow{6}{*}{ Rural } & 2007 & $-4,28 \%$ & $-3,56 \%$ & $-3,99 \%$ & $1,21 \%$ \\
\hline & 2008 & $-6,61 \%$ & $-5,68 \%$ & $-6,09 \%$ & $1,59 \%$ \\
\hline & 2009 & $-9,29 \%$ & $-7,79 \%$ & $-8,32 \%$ & $2,00 \%$ \\
\hline & 2010 & $-12,25 \%$ & $-9,86 \%$ & $-10,63 \%$ & $2,43 \%$ \\
\hline & 2011 & $-15,42 \%$ & $-11,86 \%$ & $-13,01 \%$ & $2,89 \%$ \\
\hline & 2012 & $-18,73 \%$ & $-13,80 \%$ & $-15,42 \%$ & $3,38 \%$ \\
\hline
\end{tabular}

O sinal negativo presente em alguns dos valores mostrados na Tabela 4.3 indica que o valor de previsão da curva do Brasil, em um determinado ano, é inferior ao valor do mercado obtido para o próprio Brasil, a partir da metodologia do País com o qual está sendo comparado. Ou seja, os valores de A (Brasil) são mais conservativos do que os valores de B (outros países).

Nota-se que no caso Residencial, os valores oriundos das metodologias de Bolívia e Chile apresentam diferenças relativas pequenas em relação aos valores de A, corroborando assim o mencionado no item (4.7i). Já os valores porcentuais das curvas da Argentina e Peru são maiores e, em conseqüência, 
provocando um distanciamento do anterior grupo de curvas. Um fato similar (países com diferenças relativas pequenas e grandes) observa-se nos casos Industrial e Rural, o que dá origem à formação de clusters (grupos) a partir do ano 2007. Percebe-se, na maioria dos casos, que para anos mais distantes no futuro a diferença porcentual relativa é maior fato inerente às técnicas de previsão de longo prazo.

\subsubsection{Análise de Sensibilidade das Metodologias Utilizadas}

Outro aspecto de interesse consistiu em realizar um teste de sensibilidade para avaliar qual metodologia fornece os resultados mais próximos dos valores reais. Para isso, considerou-se o histórico de dados 1996 até 2003, sendo que a previsão correspondeu ao período 2004-2007 (Figura 4.15). Resultado deste teste foi possível observar que as variáveis utilizadas em alguns dos países considerados (para cada classe de consumo) poderiam fornecer resultados mais próximos dos valores reais de consumo quando aplicadas ao caso do Brasil. Por exemplo, observou-se que o uso das metodologias do Chile, Bolívia, Argentina e Peru poderiam fornecer resultados mais próximos nas classes de consumo residencial, industrial, comercial e rural, respectivamente.

Porém, isso não quer dizer que estas variáveis sejam as melhores para serem aplicadas, já que se deve levar em conta que o referido teste de sensibilidade teve o seu histórico de dados reduzido a oito amostras (1996 - 2003) ao invés de onze (1996-2006) o que pode ter influenciado nos resultados. Lembra-se que o histórico considerado em qualquer estudo de previsão tem impacto direto sobre os resultados [84].

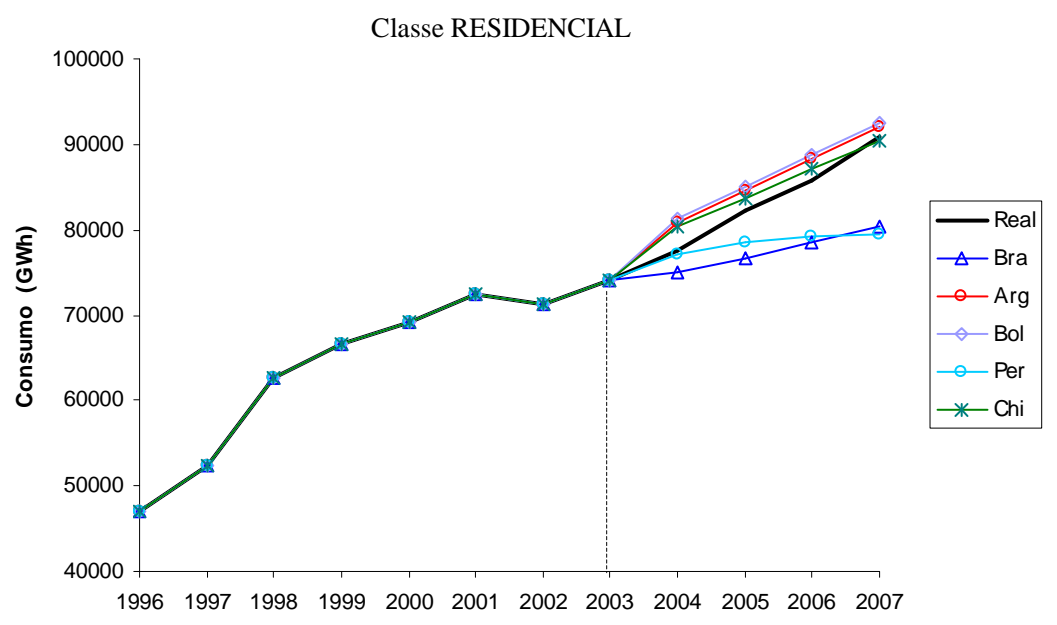

(a) 


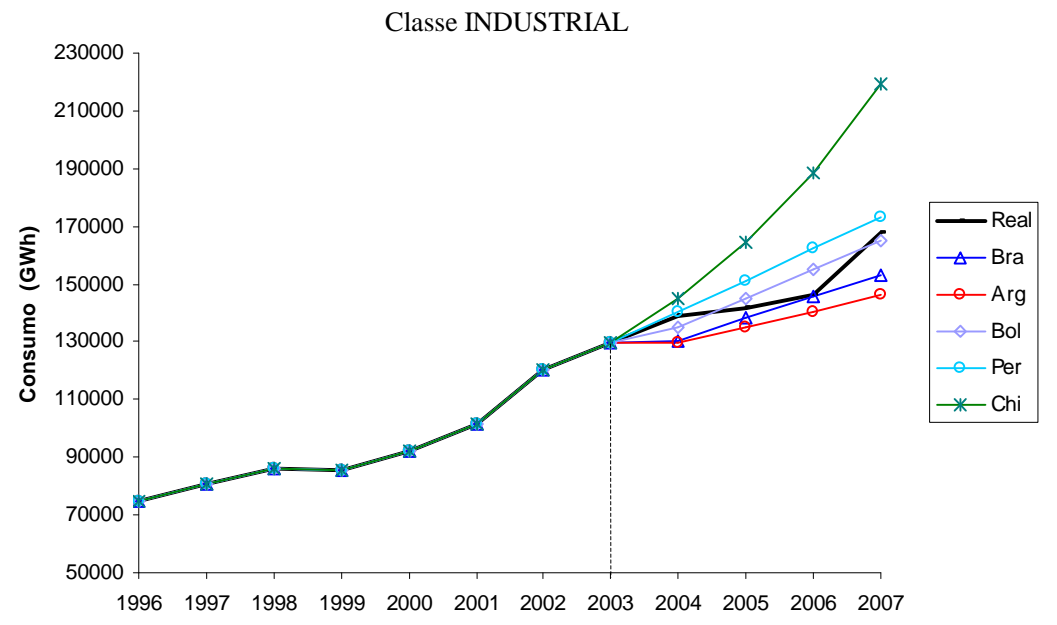

(b)

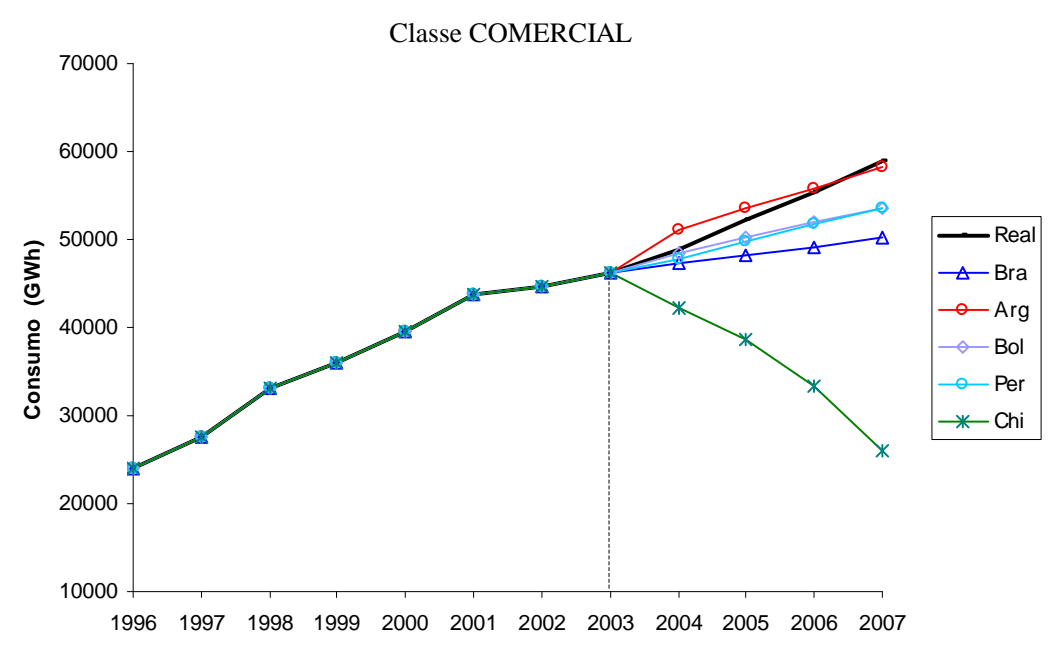

(c)

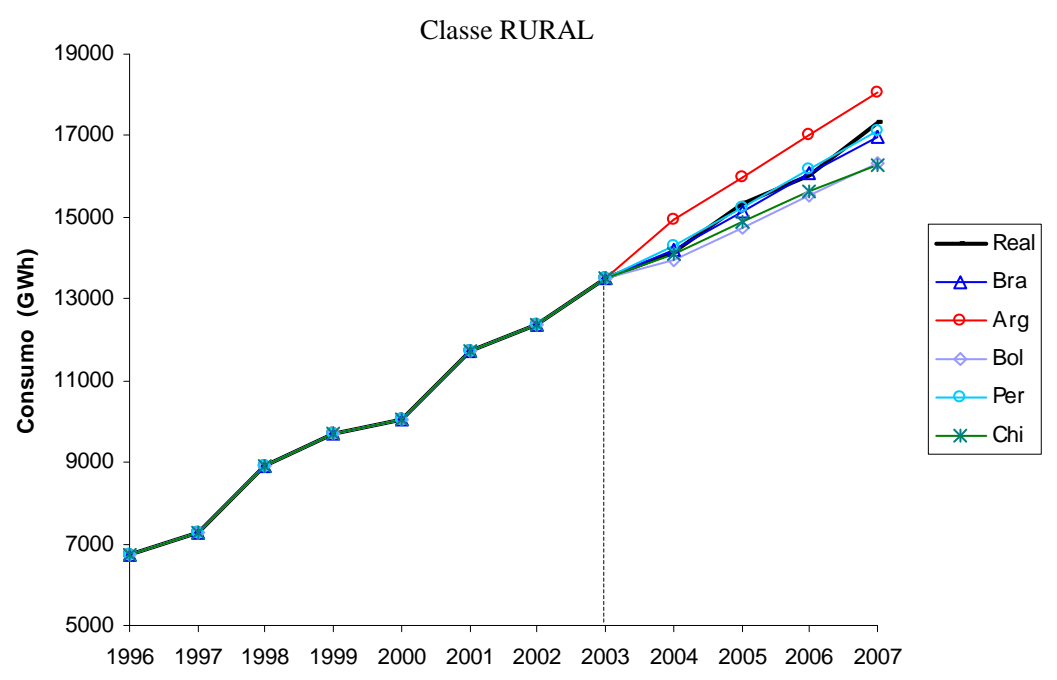

(d)

Figura 4.15 Teste de sensibilidade nas classes: (a) Residencial, (b) Industrial, (c) Comercial e (d) Rural 


\subsection{Elasticidade-Renda e a Previsão}

O conceito de "elasticidade-renda" da demanda de energia, que resulta da relação entre a variação do consumo de energia elétrica $(\Delta \% E E)$ em um determinado período, e o crescimento da economia $(\triangle \% P I B)$ no mesmo período, foi inclusa pela EPE (Empresa de Pesquisa Energética) no plano decenal apresentado em [78], como uma outra variável explicativa para a previsão da demanda de energia elétrica. A elasticidade-renda, que possui um valor adimensional, pode ser representada através da equação (4.3):

$$
\xi=\frac{\Delta \% E E}{\Delta \% P I B}
$$

Apesar de que na metodologia representativa correspondente ao Brasil, utilizada anteriormente neste trabalho (item 4.5.1) e publicada também pela EPE [52], não incluía o conceito de elasticidade, foram feitos alguns testes considerando esta variável econométrica, isto de modo a observar o grau de incidência sobre a previsão. Os resultados destes testes serão apresentados no presente item.

Já a "elasticidade da demanda" propriamente dita, é geralmente utilizada para descrever as tendências futuras do consumo de eletricidade pelo consumidor final. Neste caso, segundo [75] e [76], o consumo de energia elétrica é normalmente inelástico (valores menores do que 1,0), devido a que a concessionária de distribuição exerce um certo monopólio, regulado pelo governo, sobre os consumidores. Assim, a elasticidade-preço da demanda de energia geralmente apresenta valores que variam na faixa aproximada de $-0,1$ a $-0,6[76]$.

Percebe-se que a diferença principal entre a "elasticidade-renda" e a "elasticidade-preço" é que a primeira refere-se à medida de quanto à quantidade demandada de um bem varia em relação às variações na renda dos consumidores; enquanto que a segunda refere-se à resposta dos consumidores frente a mudanças nos preços. No Anexo B apresenta-se uma síntese do conceito de elasticidade e sua relação com o consumo de eletricidade. Nos testes de previsão apresentados a seguir, a variável elasticidade-renda foi considerada junto com as demais variáveis anteriormente utilizadas nas quatro classes de consumo.

Pode-se observar (Figura 4.16) que a inclusão da elasticidade-renda não teve impacto considerável na previsão em relação ao caso sem elasticidade (Figura. 4.4 no item 4.5.1.1). Este fato pode ser melhor observado na Tabela 4.4, na qual, mostra-se a diferença porcentual da previsão correspondente ao ano 2012 e cujos valores são inferiores a 3,5\%. Esta diferença porcentual foi calculada tomando como referência os valores obtidos "sem" o uso da elasticidade-renda (item 4.5.1.1). 

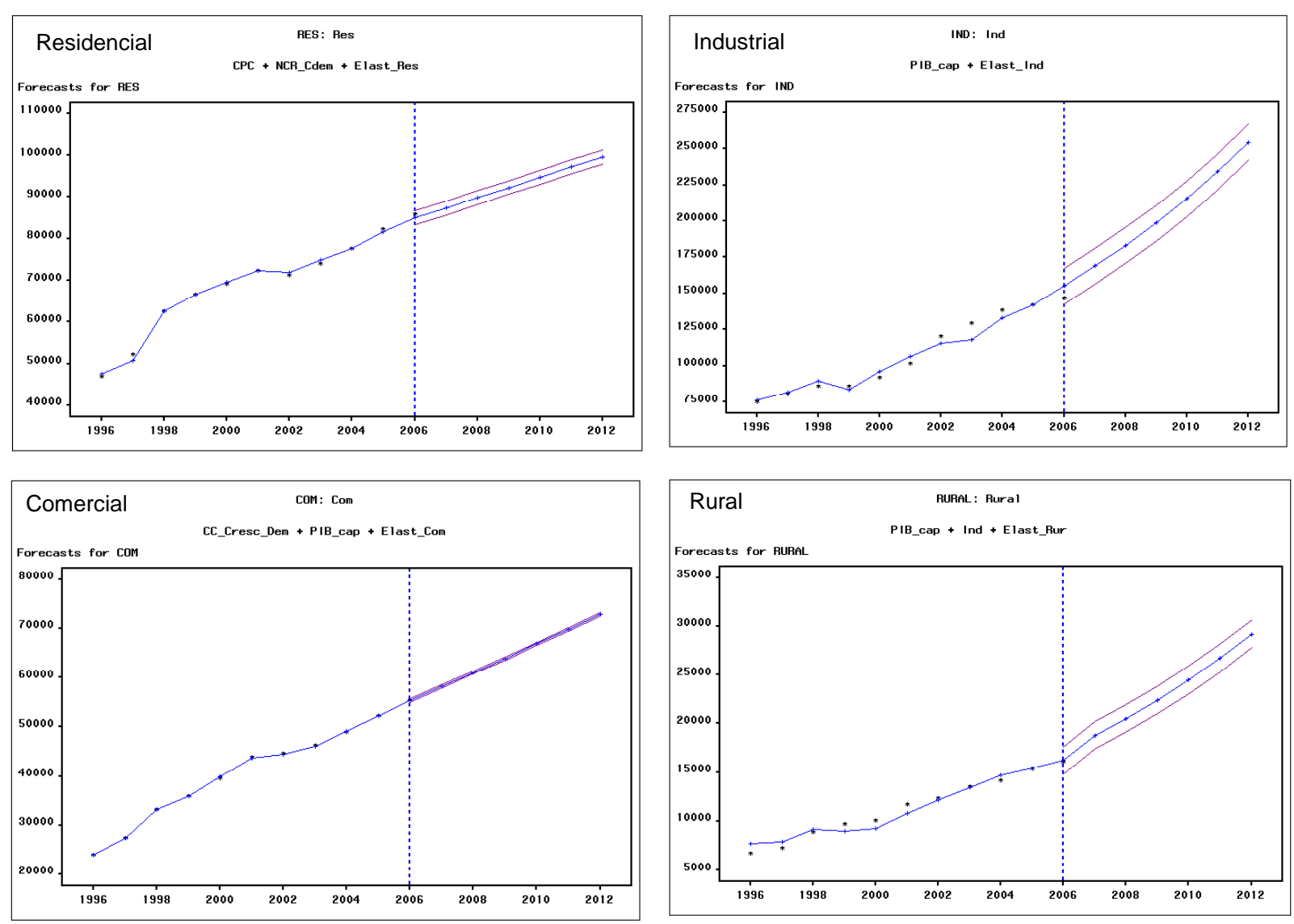

Figura 4.16 Resultados da previsão de energia utilizando a metodologia que representa ao Brasil considerando a elasticidade-renda (previsão em GWh)

Por outro lado, os valores do MAPE obtidos nas simulações mostraram-se também próximos a aqueles obtidos quando se tinha desconsiderado a elasticidade (Tabela 4.4), o que corrobora o fato que a elasticidade-renda, no modelo de previsão, não teria tanta incidência quanto às demais variáveis econométricas consideradas.

Tabela 4.4 Comparação de resultados com / sem considerar a elasticidade-renda

\begin{tabular}{|l|r|r|r|r|r|}
\hline \multirow{2}{*}{ Classe de } & \multicolumn{2}{|c|}{ Previsão em 2012 (GWh) } & \multirow{2}{*}{ Diferença } & \multicolumn{2}{|c|}{ MAPE (\%) } \\
\cline { 2 - 3 } \cline { 5 - 6 } Consumo & Sem Elastic & \multicolumn{1}{c|}{ Com Elastic } & Porcentual & Sem Elastic & Com Elastic \\
\hline RES & 99524 & 99675 & $0.15 \%$ & 0.9120 & 0.8258 \\
IND & 251306 & 254539 & $1.29 \%$ & 3.7987 & 4.5045 \\
COM & 73528 & 73209 & $-0.43 \%$ & 0.3673 & 0.2284 \\
RUR & 28322 & 29216 & $3.16 \%$ & 4.9737 & 5.0968 \\
\hline
\end{tabular}




\section{CAPÍTULO V}

\section{CONCLUSÕES}

Resultado da análise e comparações entre as metodologias tarifárias e de previsão de energia, foi possível estabelecer as seguintes conclusões:

- No trabalho fez-se uma revisão das principais metodologias de tarifação ao nível da transmissão propostas na literatura especializada mostrando as vantagens e desvantagens das mesmas.

- Constatou-se que em todos os países analisados existe livre acesso ao uso das instalações de transmissão, fato importante para criar as condições de concorrência no setor elétrico. A atividade da transmissão, em todos os países analisados, é desenvolvida por empresas que se dedicam unicamente a esse segmento da indústria.

- Quanto aos encargos pelo uso das redes de transmissão, aplicados aos demais agentes do sistema (geração e distribuição), existem várias abordagens, procurando modelar um problema tecnicamente complexo de forma aceitável para a adequada representação das particularidades do sistema elétrico de cada país, de modo que não existe consenso geral, a nível internacional, para estabelecer uma metodologia padrão.

- A forma de tarifação pelos serviços de transmissão tem influência no funcionamento e na expansão do setor elétrico como um todo, visto que estes preços afetam na tomada de decisões dos geradores, consumidores e proprietários dos sistemas de transmissão, em termos de investimento e operação. Para a remuneração da transmissão é usual a aplicação de uma receita tarifária resultante da diferença de preços nos extremos das linhas mais um encargo complementar, ou pedágio, que complementa as receitas requeridas pela empresa transmissora.

- De todas as alternativas de tarifação existentes até agora, apenas algumas foram aplicadas na prática, já que boa parte delas permanecem só como propostas teóricas. Entre os métodos de tarifação aplicados na prática destacam-se aqueles baseados no custo marginal de curto prazo (Argentina, Bolívia, Chile e Peru) e aquelas baseadas no custo marginal de longo prazo (aplicada no Brasil). A principal desvantagem do método de tarifação marginal é que esta, conforme mencionado no Capítulo II, não consegue recuperar a totalidade dos custos de investimento e operação da rede de transmissão, sendo necessária a cobrança da parcela complementar (pedágio).

- A partir do momento da implementação das novas regras no ambiente liberalizado e competitivo, o marco regulatório do segmento de transmissão sofreu algumas mudanças. Particularmente, um aspecto que demandou maior atenção foi a questão dos mecanismos para 
a expansão das redes. Foi assim que alguns países como a Argentina, Chile e Peru modificaram suas regulamentações ao perceberem que os sinais para a expansão da transmissão não eram os mais adequados. Pôde-se constatar que apesar dos contínuos esforços para melhorar os aspectos regulatórios da transmissão, o marco regulatório desse segmento ainda não está completamente consolidado. Assim, prevê-se que este ainda será um tema de discussão nos próximos anos.

- A partir da análise comparativa apresentada no capitulo III, no referente às transações internacionais, pôde-se constatar que o tratamento técnico mais freqüente tem sido considerar as exportações de energia de forma similar à adição de carga ao sistema, enquanto que as importações de energia são tratadas similarmente ao caso da conexão de geradores à rede. $\mathrm{O}$ procedimento aplicado em relação à expansão da rede de transmissão, na maioria dos casos analisados, baseia-se na aplicação de leilões ou concursos públicos.

- Já no relacionado ao estudo da previsão de mercado, foram apresentadas as principais variáveis econométricas utilizadas nas metodologias de previsão de longo prazo dos cinco países Sul-Americanos anteriormente considerados.

- Observou-se que a composição das metodologias de previsão da demanda de energia utilizada no Brasil e nos demais dos países analisados, possuem importantes semelhanças, principalmente no relacionado às variáveis econométricas consideradas. Porém, caso existam conjunturas econômicas não correlatas com o consumo de eletricidade, como aconteceu com a metodologia da Argentina, poder-se-ia dispensar a variável PIB, substituindo-a por outras mais relevantes, como as consideradas na própria metodologia Argentina e nos demais países.

- Os resultados de previsão, bem como as diferenças relativas porcentuais obtidas, deram uma idéia do grau de adesão e proximidade entre as metodologias dos países considerados em relação à do Brasil. Esta análise em particular pode ser encontrada no Capitulo IV do trabalho.

- A partir do teste de sensibilidade realizado com as metodologias consideradas, foi possível observar que algumas das metodologias estudadas poderiam oferecer resultados mais próximos dos reais, quando aplicados ao caso do Brasil, ou de outro país. Contudo, esta dedução está condicionada ao número de amostras presentes na série histórica, já que a própria metodologia Brasileira poderia gerar melhores resultados caso seja considerado um histórico maior no referido teste de sensibilidade.

- Quanto ao uso da elasticidade-renda, como uma outra variável econométrica na metodologia do Brasil, foi possível constatar que esta variável não teve impacto considerável na previsão quando comparada com os resultados nos quais foi desconsidera esta variável. 
- Finalmente, apesar das diferenças nos resultados obtidos a partir de cada metodologia, acredita-se que a aplicação destes métodos com dados de seus respectivos países produzem resultados coerentes e compatíveis com o crescimento de seus mercados elétricos.

\subsection{Investigações Futuras}

Apesar de ter-se abordado e estudado com certa profundidade as vertentes selecionadas para o desenvolvimento dessa Dissertação, seria interessante aprofundar questões como:

- Realizar um estudo minucioso buscando aferir qual seria a metodologia alternativa de tarifação da transmissão que melhor poderia ser aplicada no Brasil.

- Realizar simulações utilizando um sistema básico onde sejam utilizadas e comparadas as principais metodologias de tarifação na transmissão.

- Em relação à análise de previsão, seria interessante a confrontação entre os resultados obtidos utilizando a técnica das RNA's e outros softwares especializados nesta tarefa.

- Avaliar, uma vez aplicada nas principais classes de consumo, a elasticidade-preço e seu impacto nas previsões de energia. Particularmente, a inclusão da elasticidade na metodologia de previsão que considera as tarifas médias de consumo poderia ser analisada. De fato, a análise da elasticidade-preço sobre o histórico e sobre a previsão de energia pode ser motivo de um outro trabalho de pesquisa. 


\section{REFERÊNCIAS}

[1] PEREZ, A.I.J.; RUBIO, F. J.; PUERTA, G.J. F.; ARCELUZ, O. J.; PÉREZ, J. Marginal Pricing of Transmission Services: An Analysis of Cost Recovery. IEEE Transactions on Power Systems, v. 10, $\mathrm{n}$. 1, p. 546-553, Feb. 1995.

[2] LUCA, A.; OliveIRA, M. D. P.; LOURENÇO, R. Metodologias de Alocação de Custos. ELETROBRÁS - Nota Técnica - Projeto RESEB, Rio de Janeiro, Brasil, 1999.

[3] TABORS, R.D. Transmission System Management and pricing: New Paradigms and International Comparison, IEEE Transactions on Power Systems, v. 9, n. 1, p. 206-215, 1994.

[4] HAPP, H. Cost of Wheeling Methodologies, IEEE Transactions on Power Systems, v.9, n. 1, 1994.

[5] SHISRMOHAMMADI, D.; VIEIRA, X; GORENSTIN, B; PEREIRA, V.P. Some Fundamental Technical Concepts About Cost Based Transmission Pricing, IEEE Transactions on Power Systems, v. 11, n. 2, May 1996

[6] SHIRMOHAMMADI, D.; GRIBICK, PR.; LAW, E.T.K.; MALINOWSKI, J.H.; O'DONEKK, R.E. Evaluation of transmission network capacity use for wheeling transactions. IEEE Transactions on Power Systems, v. 4, n. 4, p. 1405-1413, Oct. 1989.

[7] PAN, J; TEKLU, Y; RAHMAN, S; JUN, K. Review of usage-based transmission cost Allocation Methods under Open Access, IEEE Transactions on Power Systems, v. 15, n. 4, Nov. 2000.

[8] CARAMANIS, M.C.; BOHN, R.E.; SCHWEPPE, F.C. Optimal Spot Pricing: Practice and Theory, IEEE Transactions on Power Apparatus and Systems, v. PAS-101, n. 9 Sep. 1982.

[9] GREEN, R. Electricity Transmission Pricing: An International Comparison, Utilities Policy Elsevier Science Ltd., v. 6, n. 3, p. 177-184, 1997.

[10] GREEN, R. Transmission Pricing in England and Wales, Utility Policy, v. 6, n. 3, p. 185 -193, 1997.

[11] BAKIRTZIS, A; BISKAS, P; MAISSIS, A; CORONIDES, A; KABOURIS, J; EFSTATHIOU, M. Comparison of Two Methods for Long-run Marginal Cost-Based Transmission Use-of-system Pricing, IEE Proceedings on Generation. Transmission. Distribution, v. 148, n. 4, July 2001.

[12] TSUKAMOTO, Y; IYODA. A. Allocation of Fixed Transmission Cost to Wheeling Transactions by Cooperative Game Theory, IEEE Transactions on Power Systems, v. 11, n. 2, 1996.

[13] FERRERO, R.W.; SHAHIDEHPOUR, S.M.; RAMESH, V.C. Transaction Analysis in Deregulated Power Systems Using Game Theory, IEEE Transactions on Power Systems, v.12, n. 3, Aug. 1997.

[14] FERRERO, R.W.; SHAHIDEHPOUR, S.M. Application of Games with Incomplete Information for Pricing Electricity in Deregulated Power Pools, IEEE Transactions on Power Systems, v.13, n. 1, Feb. 1998.

[15] PEREZ-ARRIAGA, I.J.; RUDNICK, H; STADLIN, W.O. International Power System Transmission Open Access Experience, IEEE Transactions on Power Systems, v. 10, n. 1, Feb. 1995.

[16] RUDNICK, H.; RAINERI, R. Transmission Pricing Practices in South America, Utilities Policy, v. 6, n. 3 p. 211-218, 1997.

[17] PRIDDLE R. Competition in Electricity Markets, Utilities Policy, OECD/IEA Publications, 2001. Disponível em: <http://www.iea.org/textbase/nppdf/free/2000/compet2001.pdf〉. Acesso em 12 de Abril de 2007.

[18] RAMOS, D.S.; DA SILVA, E. L.; PEREIRA, M. V. F. Fixação de Tarifas de Transporte de Energia em Ambiente de Competição no Setor Elétrico: Paradigmas a Serem Observados e Metodologia de Cálculo. In: REUNIÃO INTERNACIONAL DO SUBCOMITÊ DE PLANEJAMENTO E MEIO-AMBIENTE DA (SUPLAMA/CIER), Quito, 1998.

[19] ODÉRIZ, F.J. Metodologias de Asignacion de Costos de la Red de Transporte en un Contexto de Regulacion Abierta a la Competência. 1999. 323 p. Tese (Doutorado)- Universidad Pontifícia Comillas de Madrid, España. 
[20] RUDNICK H.; PALMA R.; FERNANDEZ J. Marginal Pricing and Supplement Cost Allocation in Transmission Open Access. IEEE Transactions on Power Systems, v.10 n.2, May 1995.

[21] DE LA CRUZ, R.; GARCÍA, R. La Problemática de la Actividad de Transmisión de Energía en el Perú, Economía y Sociedad, No. 54, CIES, Dic. 2004. Disponível em: 〈http://www.consorcio.org/bol.asp〉 Acesso em: 10 de abril, 2007.

[22] RUDNICK, H.; VARELA, R.; HOGAN, W. Evaluation of Alternatives for Power System Coordination and Pooling in a Competitive Environment. In: IEEE/PES WINTER MEETING, Baltimore. pp. 21-25, Jan. 1996.

[23] TSUKAMOTO Y.; IYODA. A. Allocation of Fixed Transmission Cost to Wheeling Transactions by Cooperative Game Theory, IEEE Transactions on Power Systems, v. 11, n. 2, 1996.

[24] FERRERO R.W.; SHAHIDEHPOUR S.M.; RAMESH V.C. Transaction Analysis in Deregulated Power Systems Using Game Theory, IEEE Transactions on Power Systems, v.12, n. 3, Aug. 1997.

[25] FERRERO R.W.; SHAHIDEHPOUR, S.M. Application of Games with Incomplete Information for Pricing Electricity in Deregulated Power Pools, IEEE Transactions on Power Systems, v.13, n. 1, Feb. 1998.

[26] ZOLEZZI, J.; RUDNICK, H. Transmission cost Allocation by Cooperative Games and Coalition Formation, IEEE Transactions on Power Systems, v. 17, p. 1008-1015, Nov. 2002.

[27] PISTONESI, H. Sistema Eléctrico Argentino: Los Principales Problemas Regulatorios y el Desempeño Posterior a la Reforma, Serie Recursos Naturales e Infraestructura no 10. Santiago de Chile, Jul. 2000. CEPAL/ECLARC, 2000,72p. Disponível em: <http://www.cepal.org/cgibin/getProd.asp?xml=/publicaciones/xml/9/4969/P4969.xml\&xsl=/drni/tpl/p9 f.x $>$. Acesso em: 2 de Maio de 2006.

[28] ROMERO, C. A. Regulación e inversiones en el sector eléctrico Argentino, Reformas Económicas, n.5, pp. 92. LC/L.1145-P/E, Sept. 1998. Disponível em: <www.eclac.cl/publicaciones/ xml/8/4268/lcl1145e.pdf> Acesso em 13 de dezembro, 2006.

[29] CAMMESA, Procedimientos para la Programación de la Operación, Despacho de Cargas y el Cálculo de Precios, Disponível em: <http://www.cammesa.com/ inicio.nsf/marconormativa> Acesso em 1 de Fevereiro, 2008.

[30] VARGAS, C.A.; ÁVILA, P.P. Una Reforma con Pocas Luces, Privatización del Sector Eléctrico Boliviano, CEDLA, La Paz, Jul. 2006, 121 pp. Disponível em: <http://www.cedla.org/pub/pubfree.php?id_pub=68\&PHPSESSID=678498133d411fdd44949d1517f0d 75e> Acesso em 28 de Novembro, 2006.

[31] RUDNICK, H.; MOCARQUER, S.; SORE, F. Distribución de Pagos de Sistemas de Transmisión entre Generación y Demanda: Experiencia Internacional, Derecho Administrativo, n. 12, pp. 135-153, 2004. Disponível em: 〈http://www2.ing.puc.cl/ power/paperspdf/Rudnick MocarquerSore.pdf > Acesso em: 7 de Maio de 2006.

[32] ANEEL - Agência Nacional de Energia Elétrica. Resumo Geral dos Novos Empreendimentos de Geração. Disponível em: 〈http://www.aneel.gov.br/arquivos/pdf/Resumo_Geral_jul_2008.pdf>Acesso em 5 de Março, 2007.

[33] DA SILVA, E.L.; MOROZOWSKI FILHO, M.; DE SOUZA, A.; FINARDI, E.C. Projeto ANEEL/UFSC, Regras do Mercado Atacadista de Energia Elétrica, 2000. Disponível em: <www.aneel.gov.br/aplicacoes/AudienciaPublica/audiencia_proton/2000/ap002/Parecer\%20UFSC.pdf> Acesso em 12 de Setembro, 2007.

[34] ANEEL, Tarifas de Uso do Sistema de Transmissão. Disponível em: <http://www.aneel.gov.br/area.cfm?idArea=97>Acesso em: 12 de Outubro, 2007.

[35] RUDNICK, H. Chile: Pioneer in Deregulation of the Electric Power Sector, IEEE Power Engineering Review; v. 14, n. 6, p. 28-30, 1994.

[36] HQI Transelec Chile S.A. Disponível em: 〈http://www.transelec.cl/transelec/index.php〉 Acesso 15 de Abril, 2006. 
[37] GUZMÁN, O.M.A.; GARCÍA, P.A.R.; MUÑOZ, C.M. Tarificación y Expansión del Sistema de Transmisión Bajo la Ley 19.940 (Ley Corta), AES Gener S.A, Santiago, 2004. Disponível em: <www2.ing.puc.cl/power/alumno04/Trabajo\%20de\%20Investiga cion-PUC.htm> Acesso em: $7 \mathrm{de}$ Abril, 2006.

[38] RONCAGLIOLO, F. Interconexiones Eléctricas Internacionales y sus Enseñanzas para el Caso Argentina-Chile, Relatório IEE3372 Mercados Eléctricos, Pontificia Universidad Católica de Chile, 2001. Disponível em: http://www2.ing.puc.cl/power/ alumno01/interc/interc.htm. Acesso em 7 de Julho, 2007.

[39] GUASCH, J.L.; SPILLER, P.T. Managing the Regulatory Process: Design, Concepts, Issues, and the Latin America and Caribbean Story. Book. Directions in Development Series. Washington, D.C.: World Bank and Johns Hopkins University Press, 1997.

[40] CAMPODÓNICO-SÁNCHEZ, H. Las Reformas Estructurales del Sector Eléctrico Peruano y las Características de la Inversión 1992-2000, Relatório para a CEPAL, May. 1999. Disponivel em: <www.cepal.org/cgibin/getProd.asp?xml=/publicaciones/xml/7/4547/P4547.

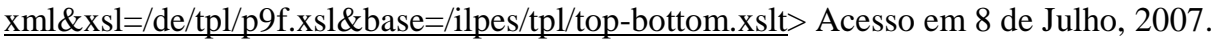

[41] ZOLEZZI, J.; RUDNICK, H. Planificación y Expansión de la Transmisión en Mercados Eléctricos Competitivos. In: VII SYMPOSIUM OF SPECIALISTS IN ELECTRIC OPERATIONAL AND EXPANSION PLANNING, VII SEPOPE, Curitiba, 2000.

[42] PARLOS, A.G.; OUFI, E.; MUTHUSAMI, J.; PATTON, A.D.; ATIYA, A.F. Development of an Intelligent Long-term Electric Load Forecasting System. In: PROCEEDINGS OF THE INTELLIGENT SYSTEMS APPLICATIONS TO POWER SYSTEMS ISAP 1996, p. 288-292, 28 Jan-2 Feb. 1996.

[43] JIA, N.X.; YOKOYAMA, R.; ZHOU, Y.C. A Novel Approach to Long-Term Load Forecasting Where Functional Relations and Impact Relations Coexist. In: INT. CONFERENCE ON ELECTRIC POWER ENGINEERING (PowerTech, 1999), Budapest, p. 38- 43, 1999.

[44] KANDIL, M.S.; EL-DEBEIKY, S.M.; HASANIEN, N.E. Long-term Load Forecasting for Fast Developing Utility Using a Knowledge-Based Expert System, IEEE Transactions on Power Systems, v. 17, n. 2, p. 491-496, May 2002.

[45] KHOA, T.Q.D.; PHUONG, L.M.; BINH, P.T.T.; LIEN, N.T.H. Application of Wavelet and Neural Network to Long-term Load Forecasting. In: Int. Conference on POWER SYSTEMS TECHNOLOGY (PowerCon 2004), v. 1, p. 840- 844, 21-24 Nov. 2004.

[46] FARAHAT, M.A. Long-term Industrial Load Forecasting and Planning Using Neural Networks Technique and Fuzzy Inference Method. In: $39^{\text {th }}$ INT. UNIVERSITIES POWER ENGINEERING CONFERENCE (UPEC 2004), v. 1, pp. 368- 372, 6-8 Sept. 2004.

[47] DING, Q. Long-Term Load Forecast Using Decision Tree Method. In: 2006 IEEE-PES POWER SYSTEMS CONFERENCE AND EXPOSITION (PSCE '06), p.1541-1543, Oct. 29-Nov. 1, 2006.

[48] HIGHLEY, D.D.; HILMES, T.J. Load Forecasting by ANN, IEEE Transactions on Computer Applications, v. 6, n. 3, pp. 10-15, Jul. 1993.

[49] HUANG, C.M.; YANG, H.T. Evolving Wavelet-Based Networks for Short-Term Load Forecasting, IEE Proceedings on Generation, Transmission and Distribution, v. 148, n. 3, May 2001, pp. 222 - 228.

[50] Statistical Analysis System Software $\left(\mathrm{SAS}^{\circledR}\right)$, v. 8.02, 1999.

[51] Associação Brasileira de Distribuidores de Energia Elétrica (ABRADEE). Disponível em: <www.aneel.gov.br/aplicacoes/tarifamedia/default.cfm> Acesso em: 4 de Julho, 2007.

[52] Empresa de Pesquisa Energética (EPE). Plano Decenal de Expansão de Energia 2007/2016, Vol. 1. Disponível em: 〈www.epe.gov.br/PDEE/Forms/EPEEstudo.aspx> Acesso em: 10 Junho, 2007.

[53] Instituto Brasileiro de Geografia e Estatística (IBG). Disponível em: 〈www.ibge.gov.br/> Acesso em: 15 de Junho, 2007.

[54] ANEEL, Nota Técnica 003/1999 SRT/ANEEL, Metodologia para Cálculo das Tarifas Nodais. Disponível em http://www.aneel.gov.br/aplicacoes/leituraarquivo/arquivos/Metodologia completa.pdf. Acesso em 17 de Junho de 2007. 
[55] Ministério de Minas e Energia da Republica do Peru. Disponível em: 〈www.minem.gob.pe > Acesso em: 11 de Agosto de 2007.

[56] Unidade de Planejamento Mineiro Energético (UPME). Disponível em: 〈www.upme. gov.co〉 Acesso em: 13 de Agosto de 2007.

[57] Secretaria de Energia da República Argentina. Disponível em: 〈energia3.mecon. gov.ar〉 Acesso em: 15 de Novembro, 2007.

[58] ZOLEZZI J.; RUDNICK H. Tarificación del Sistema de Transmisión Eléctrica: Aproximación Mediante Juegos Cooperativos. In: VII SYMPOSIUM OF SPECIALISTS IN ELECTRIC OPERATIONAL AND EXPANSION PLANNING (VII SEPOPE), Curitiba, 2000.

[59] Comitê Nacional de Despacho de Carga (CNDC), Memoria anual del Comité Nacional de Despacho de Carga y Resultados de Operación del Sistema Interconectado Nacional 2006. Disponível em: <www.cndc.bo/boletines/anual.php > Acesso em: 28 de Maio, 2007.

[60] Nota Técnica ANEEL, "Manual da Metodologia Nodal para Cálculo de Tarifas de Uso do Sistema Elétrico", Aprovado pela Resolução. ANEEL 281/99. Disponível em: 〈http://www.aneel.gov.br/aplicacoes/leitura_arquivo/arquivos/Metodologia_completa.pdf $>$ Acesso em 17 de Junho de 2007.

[61] MARANGON L.J.W; ZAMBRONI S.A.C; LIMA L.B.I. Principais Obstáculos à Intensificação do Sinal Locacional na Metodologia Nodal. CONGRESSO DE INOVAÇÃO TECNOLOGICA EM ENERGIA ELETRICA In Anais do II CITENEL 2003. Salvador, BA, 2003

[62] Canal Energia, Empresas do Setor de Energia Elétrica. Disponível em: <www.canalenergia.com.br/zpublisher/secoes/ EMPRESAS.asp> Acesso em: 8 de Março, 2007.

[63] GATELOVIC A., MUÑOZ M.C. The New Chilean Transmission charge Scheme as Compared With Current Allocation Methods, IEEE Transactions on Power Systems, Vol 21 No. 1 February 2006. pp. 99-107.

[64] Superintendencia de Electricidad da Republica da Bolívia: Disponível em: <www.superele.gov.bo/ index.php?option=com_wrapper\&Itemid=38> Acesso em: 28 de Maio, 2007.

[65] ZAMORA, F.H.P. Previsão Espacial de Carga em Sistemas de Distribuição Utilizando Técnicas de Inteligência Artificial e Plataforma GIS. 2003. 215p. Tese (Doutorado); Escola politécnica, Universidade de São Paulo.

[66] ARAÚJO, M.A.G. Previsão de Demanda de Energia Elétrica por Meio de Redes Neurais Artificiais. 2005. 112p. Dissertação (Mestrado); Universidade Federal do Rio Grande do Sul, Porto Alegre.

[67] Ministério de Minas e Energia, Empresa de Pesquisa Energética, "Balanço Energético Nacional 2007". Disponível em: 〈https://ben.epe.gov.br> Acesso em: 15 de Marzo, 2008.

[68] MACHADO, J.T.P.; AREIAS, L.E., MARZANO, L.G.B., RIBEIRO, P.M., CALDAS R.P. Generation Investments in the Brazilian New Electric Sector Model An Analysis of Transmission Tariffs. In: IEEE Power Tech Conference, September, Porto, Portugal, 2001.

[69] Fundação Getulio Vargas. Disponível em: 〈http://www.fgvdados.fgv.br/> Acesso em: 18 de Abril, 2008.

[70] Comisión Nacional de Energia de Chile. Disponível em: <www.cne.cl/electricidad/ doc fijacion/Estudios Empresas/Informe EEDD_AT6.pdf> Acesso em: 20 de Abril, 2008.

[71] The World Bank. Disponível em: 〈http://ppi.worldbank.org/resources/ppi_countryClassifica tion.aspx $>$ Acesso em: 21 de Abril de 2008.

[72] Agência de Noticias Reuters. Disponível em: <http://noticias.uol.com.br/ultnot/reuters/2007/ 10/22/ult1928u5000.htm> Acesso em: 21 de Abril, 2008.

[73] WILLIS, H.L. Spatial Electric Load Forecasting. Marcel Dekker, N.Y., 1996

[74] PINDICK R.S., RUBINFIELD D.L. Microeconomics, $5^{\text {th }}$ Edition, Prentice Hall, New Jersey, 1997. pp. 117-123.

[75] EARLE R.L., Demand Elasticity in the California Power Exchange Day-Ahead Market. The Electricity Journal, Elsevier Science Inc., v. 13. n. 8, Oct. 2000. pp. 59-65. 
[76] BOONEKAMP P.G.M. Price Elasticities, Policy Measures and Actual Developments in Household Energy Consumption - A Bottom Up Analysis for the Netherlands, Energy Economics, Science Direct, v. 29. n. 2, Nov. 2005. pp. 133-157.

[77] LIJESEN M.G. The Real-time Price Elasticity of Electricity, Energy Economics, Science Direct, v. 29. n. 2, March 2007. pp. 249-258.

[78] Empresa de Pesquisa Energética (EPE), Projeções da Demanda de Energia Elétrica para o Plano Decenal de Expansão de Energia 2008-2017, Nota Técnica DEN 01/08, Rio de Janeiro, Março de 2008. Disponível em: 〈http://www.epe.gov.br/PDEE/Forms/ EPEEstudo.aspx> Acesso em: 10 de Junho, 2008.

[79] TÁUtiva C. M.; CADENA A. M.; DURAN H. C.; CHAHÍN C. A. Esquemas de Expansión y de Remuneracion de Sistemas de Transmisión que Operan en Mercados Eléctricos Competitivos. In: III CONGRESO INTERNACIONAL DE LA REGIÓN ANDINA (IEEE ANDESCON 2006), Quito, 8 -10 Nov. 2006. pp. 1-10. Disponível em: <http://www.fieespe.edu.ec/ jlarco/Andescon06/ documentos/P148.pdf> Acesso em: 21 de Maio, 2008.

[80] FLETCHER K.; MARSHALL M. Forecasting Regional Industrial Energy Demand: The ENUSIM EndUse Model, Publisher Routledge Midlands, UK, 14 April 1995.

[81] HO S.L.; XIE M.; GOH T.N. A Comparative Study of Neural Network and Box-Jenkins ARIMA Modeling in Time Series Prediction, Computers \& Industrial Engineering, January, 2002.

[82] HIPPERT H.S.; PEDREIRA C.E.; SOUZA R.C. Neural Networks for Short-Term Load Forecasting: A Review and Evaluation, IEEE Transactions on Power Systems, Vol. 16, no. 1, 2001, pp. 44-55.

[83] DEL CARPIO HUAYLLAS T.E.; RAMOS D.S. Análise Comparativa de Modelos Tarifarios e de Previsão de Mercado de Energia de Alguns Paises Sul Americanos. In: VII CONGRESSO LATINOAMERICANO GENERACION Y TRANSPORTE DE ENERGIA ELECTRICA, Valparaiso (Chile), 22-25 Out. 2007.

[84] DEL CARPIO HUAYLLAS T.E.; RAMOS D.S. Metodologias de Previsão de Mercado de Energia Elétrica: Uma Análise Comparativa em Âmbito Sul Americano. Submetido para revisão à Revista do IEEE America Latina, Set. 2008.

[85] C A Authority, Economic Regulation and Incremental Costs, Consultation Paper, Civil Aviation Authority, CAA House, 45-59 Kingsway, London WC2B 6TE, Feb. 2001. Disponível em: www.caa.co.uk/docs/5/ergdocs/economicregincrecostsfeb01.pdf, Acesso em: 06 de Dezembro, 2008.

[86] Comunidad Andina, Secretaria General, Normativa Andina, Decisión 536 - Marco General para la Interconexión Subregional de Sistemas Eléctricos e Intercambio Intracomunitario de Electricidad, Disponível em: www.comunidadandina.org/normativa/dec/D536.htm. Acesso em: 06 de Dezembro, 2008. 


\section{ANEXO A: Outros Métodos de Previsão de Mercado de Energia Elétrica Comumente Utilizados}

i) Sistemas Especialistas (Expert Systems)

Esta técnica de previsão faz uso de regras, comumente de natureza heurística, nas suas previsões. Os sistemas especialistas incorporam regras e procedimentos usados por peritos humanos, dentro do campo de interesse, no software que depois será capaz de fazer previsões de forma automática sem assistência humana. O uso dos sistemas especialistas começou nos 1960 em aplicações como a prospecção geológica e desenho de computadores. Os sistemas especialistas funcionam melhor quando um perito humano estiver acompanhando o desenvolvimento do software de previsão, desta forma o perito passará o seu conhecimento ao software de sistema especialista. Esta técnica foi testada em vários locais nos Estados Unidos e mostrou erros pequenos na previsão.

\section{ii) Lógica fuzzy}

A lógica fuzzy é uma generalização da lógica Booleana utilizada no desenho de circuitos digitais. A entrada (input) na lógica Booleana adota um valor verdadeiro de "0" ou "1" No caso da lógica fuzzy a entrada vem associada a determinadas faixas (ranges) de valores qualitativos. Por exemplo, a carga de um transformador na lógica fuzzy poderia ser baixa, média ou pesada. Ou seja, a lógica fuzzy permite, de forma lógica, deduzir determinadas saídas a partir de entradas fuzzy (difusas). Assim, a lógica fuzzy pode ser considerada como uma das varias técnicas para mapear entradas e saídas, o que a torna aplicável ao ajuste de curvas na área de previsão. Uma das vantagens do uso da lógica fuzzy é que não precisa de modelos matemáticos para o processamento e nem dados de entrada muito precisos, isso faz que esta técnica mostre-se robusta, quando apropriadamente desenhada, em aplicações de previsão de carga. 


\section{ANEXO B: A Elasticidade e o Consumo de Eletricidade}

A partir da teoria econômica [74] sabe-se que: 'o conceito de elasticidade é usado para medir a reação das pessoas frente a mudanças nas variáveis econômicas'. No nosso caso, a elasticidade-preço da demanda pode ser definida como a resposta da demanda frente às variações no preço. Por exemplo, para alguns bens os consumidores reagem bastante quando o preço sobe ou desce (demanda elástica), enquanto que para outros, a demanda fica quase inalterada quando o preço sobe ou desce (demanda inelástica). Do mesmo modo os produtores também têm suas reações e a oferta pode ser elástica ou inelástica.

Em termos matemáticos, e de forma geral, a elasticidade pode ser expressa como [75]:

$$
E=\frac{d q / q}{d p / p}=\frac{\text { variação_percentual_na_quantidade }}{\text { mudança } a_{-} \text {percentual_no_preço }}
$$

onde,

$q:$ quantidade do produto

$p:$ preço do produto

Basicamente a elasticidade da demanda, em relação ao preço, pode ser classificada em três tipos:

i) Elásticos: Se a elasticidade-preço do bem for maior que 1,0 diz-se que a demanda por esse bem é elástica. Isto é, se o preço sobe em 1\%, a quantidade demandada decresce em mais de $1 \%$. Ou seja, os consumidores são bastante sensíveis a variações no preço (Figura B1a).

ii) Inelásticos: Se a elasticidade-preço do bem for menor que 1,0 diz-se que a demanda por esse bem é inelástica. Isto é, se o preço sobe em $1 \%$, a quantidade demandada decresce em menos de $1 \%$. Ou seja, os consumidores são relativamente insensíveis a variações no preço (Figura B.1b).

iii) Elasticidade Unitária: Se a elasticidade-preço do bem for igual a 1,0 diz-se que a demanda por esse bem é de elasticidade neutra. A variação percentual na quantidade é igual à variação percentual no preço (Figura B.1c).

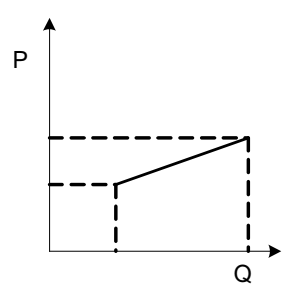

(a) E >1 (elástico)

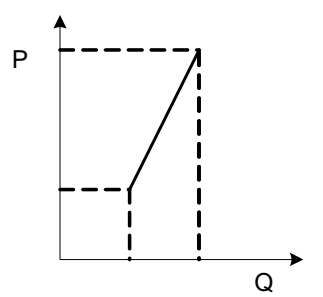

(b) $\mathrm{E}<1$ (inelástico)

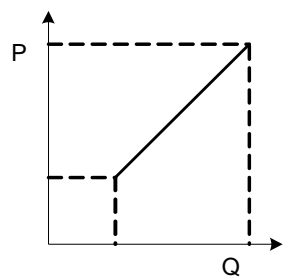

(c) $\mathrm{E}=1$ (unitário)

Figura B1. Tipos de elasticidade 
No caso da eletricidade, a elasticidade da demanda é geralmente inelástica enquanto que a demanda de outros produtos, por exemplo, a gasolina, é geralmente elástica. Isto se deve a que em certo grau a concessionária de distribuição de energia exerce um monopólio, regulado pelo governo. Assim, quando o preço da energia sobe, não é possível simplesmente se desligar da concessionária atual para se ligar a outra. Em termos simples, não existem substitutos imediatos para este produto. No caso dos combustíveis como a gasolina, se o preço subir em um determinado ponto de abastecimento, o consumidor pode tranqüilamente procurar e achar outro com menor preço. Uma análise mais especifica em relação ao tratamento da eletricidade e a elasticidade pode ser encontrada em [76] e [77]. 


\section{ANEXO C: Históricos de Dados Utilizados nas Simulações}

Tabela C1. Consumo Agregado das Classes Consideradas (GWh/ Ano)

\begin{tabular}{|c|r|r|r|r|}
\hline Ano & Residencial & \multicolumn{1}{c|}{ Industrial } & Comercial & \multicolumn{1}{c|}{ Rural } \\
\hline 1996 & 47042 & 75069 & 24024 & 6707 \\
\hline 1997 & 52336 & 80616 & 27463 & 7265 \\
\hline 1998 & 62628 & 85904 & 33140 & 8887 \\
\hline 1999 & 66545 & 85675 & 35941 & 9688 \\
\hline 2000 & 69230 & 91986 & 39635 & 10029 \\
\hline 2001 & 72347 & 101748 & 43837 & 11722 \\
\hline 2002 & 71268 & 120173 & 44627 & 12361 \\
\hline 2003 & 74074 & 129350 & 46235 & 13508 \\
\hline 2004 & 77570 & 138697 & 48953 & 14151 \\
\hline 2005 & 82175 & 141754 & 52203 & 15333 \\
\hline 2006 & 85848 & 146610 & 55311 & 16034 \\
\hline
\end{tabular}

Tabela C2. Crescimento Demográfico e PIB Nacional

\begin{tabular}{|c|r|r|}
\hline Ano & $\begin{array}{c}\text { Crescimento } \\
\text { Demográfico (hab) }\end{array}$ & $\begin{array}{c}\text { PIB } \\
\text { (milhões de } \mathrm{R} \$ \text { ) }\end{array}$ \\
\hline 1996 & 157070163 & 720816 \\
\hline 1997 & 163470521 & 872452 \\
\hline 1998 & 165687517 & 939479 \\
\hline 1999 & 167909738 & 981764 \\
\hline 2000 & 170143121 & 1.110861 \\
\hline 2001 & 173500000 & 1.194970 \\
\hline 2002 & 176250000 & 1.336748 \\
\hline 2003 & 178750000 & 1.494767 \\
\hline 2004 & 181500000 & 1.797054 \\
\hline 2005 & 184100000 & 1.998646 \\
\hline 2006 & 186550000 & 2.227446 \\
\hline Fonte: IBGE & & \\
\hline
\end{tabular}

Tabela C3. Evolução das Tarifas Médias de Consumo (R\$/MWh)

\begin{tabular}{|c|r|r|r|r|}
\hline Ano & Residencial & Industrial & Comercial & \multicolumn{1}{c|}{ Rural } \\
\hline 1996 & 107 & 50 & 100 & 62 \\
\hline 1997 & 120 & 55 & 108 & 67 \\
\hline 1998 & 126 & 57 & 112 & 69 \\
\hline 1999 & 139 & 63 & 122 & 75 \\
\hline 2000 & 159 & 71 & 137 & 85 \\
\hline 2001 & 180 & 82 & 156 & 97 \\
\hline 2002 & 210 & 96 & 186 & 175 \\
\hline 2003 & 239 & 112 & 210 & 136 \\
\hline 2004 & 270 & 137 & 239 & 154 \\
\hline 2005 & 291 & 185 & 263 & 167 \\
\hline 2006 & 295 & 208 & 274 & 176 \\
\hline
\end{tabular}


Tabela C4. Variáveis Utilizadas no Modelo Argentino

\begin{tabular}{|c|c|r|r|r|}
\hline Ano & $\begin{array}{c}\text { Produção Ind. } \\
\text { Automotriz } \\
\text { (unidades) }\end{array}$ & $\begin{array}{c}\text { Consumo de } \\
\text { Cimento } \\
\text { (milhões de } \\
\text { toneladas) }\end{array}$ & $\begin{array}{c}\text { Taxa de } \\
\text { Emprego }\end{array}$ & $\begin{array}{c}\text { Taxa de } \\
\text { Desemprego }\end{array}$ \\
\hline 1996 & 1804328 & 34246 & 0,4514 & 0,0698 \\
\hline 1997 & 2069703 & 38373 & 0,4435 & 0,0787 \\
\hline 1998 & 1586291 & 40280 & 0,4426 & 0,0901 \\
\hline 1999 & 1356714 & 40515 & 0,4479 & 0,0968 \\
\hline 2000 & 1691240 & 39628 & 0,4479 & 0,0958 \\
\hline 2001 & 1817116 & 38167 & 0,4452 & 0,0936 \\
\hline 2002 & 1791530 & 36682 & 0,4547 & 0,0917 \\
\hline 2003 & 1827791 & 35722 & 0,4552 & 0,0974 \\
\hline 2004 & 2317227 & 35837 & 0,4649 & 0,0890 \\
\hline 2005 & 2530840 & 37575 & 0,4725 & 0,0931 \\
\hline 2006 & 2611034 & 41486 & 0,4768 & 0,0968 \\
\hline \multicolumn{2}{|r|}{} \\
Fonte: \\
Consumo de cimento: http://www.cbicdados.com.br/files/textos/032.pdf; http://www.cimento.org/ \\
Taxa de Emprego e Taxa de Desemprego: http://www.mct.gov.br/index.php//content/view/5871.html \\
Produção Ind. Automotriz: http://www.anfavea.com.br/anuario2007/Cap2 1 2007.pdf \\
\hline
\end{tabular}

Tabela C5. Dados do Brasil utilizados no Modelo Chileno

\begin{tabular}{|c|r|r|r|}
\hline Ano & Construção Civil & $\begin{array}{c}\text { Índice de } \\
\text { preços por } \\
\text { Atacado }\end{array}$ & $\begin{array}{c}\text { Índice } \\
\text { Nacional de } \\
\text { Preços ao } \\
\text { Consumidor }\end{array}$ \\
\hline 1996 & 39745768 & 122,4 & 148,1 \\
\hline 1997 & 40644623 & 132,2 & 159,6 \\
\hline 1998 & 41839703 & 137,6 & 166,1 \\
\hline 1999 & 42851326 & 158,0 & 174,2 \\
\hline 2000 & 45021478 & 188,5 & 187,3 \\
\hline 2001 & 46424281 & 212,6 & 200,2 \\
\hline 2002 & 48154781 & 245,5 & 216,8 \\
\hline 2003 & 49891525 & 318,9 & 247,9 \\
\hline 2004 & 51578980 & 351,9 & 263,0 \\
\hline 2005 & 53114000 & 375,2 & 278,1 \\
\hline 2006 & 54610000 & 388,4 & 285,7 \\
\hline
\end{tabular}

Fonte: http://www.ibge.gov.br/home/ 


\section{ANEXO D: Diferenças Relativas Individuas entre a Metodologia do Brasil e os Outros Países}

\section{D1. Diferenças Relativas entre as Metodologias do Brasil e Peru}

Neste, bem como nos resultados subseqüentes, a curva A representará a metodologia adotada no Brasil enquanto que a curva B representará a metodologia adotada pelo país em questão.
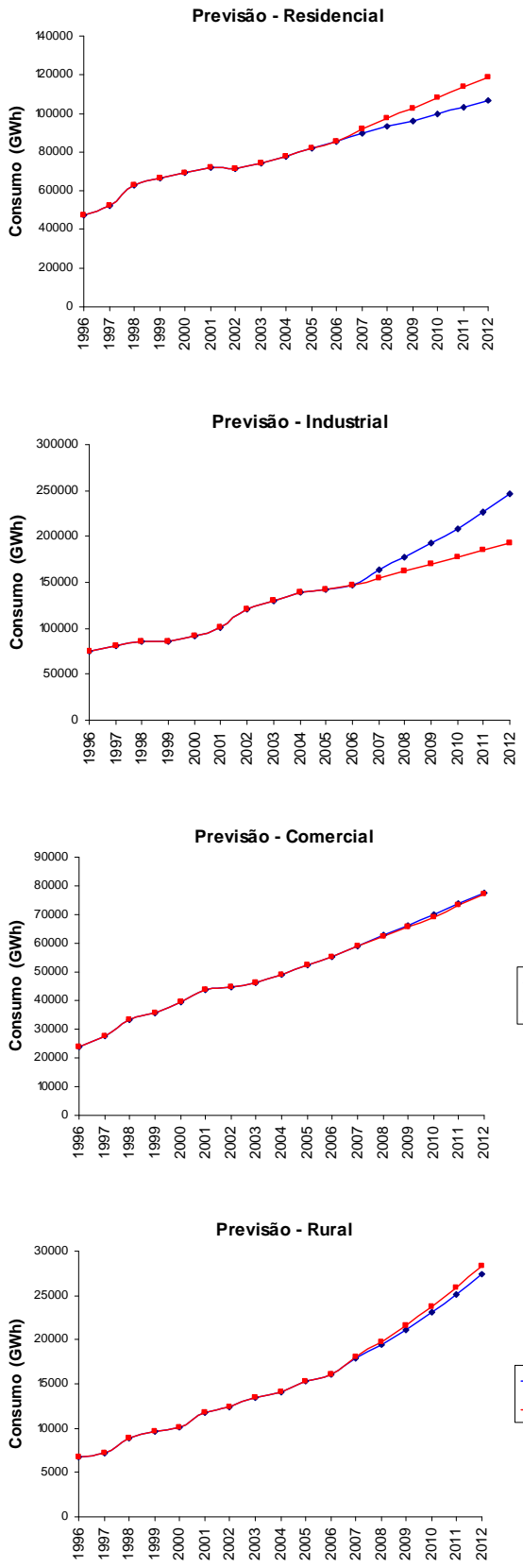

(a)

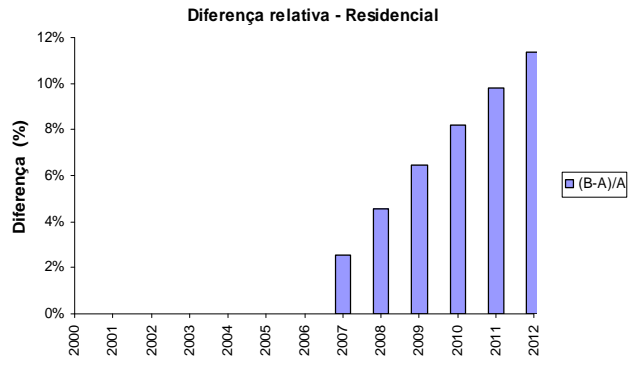

Diferença relativa - Industrial
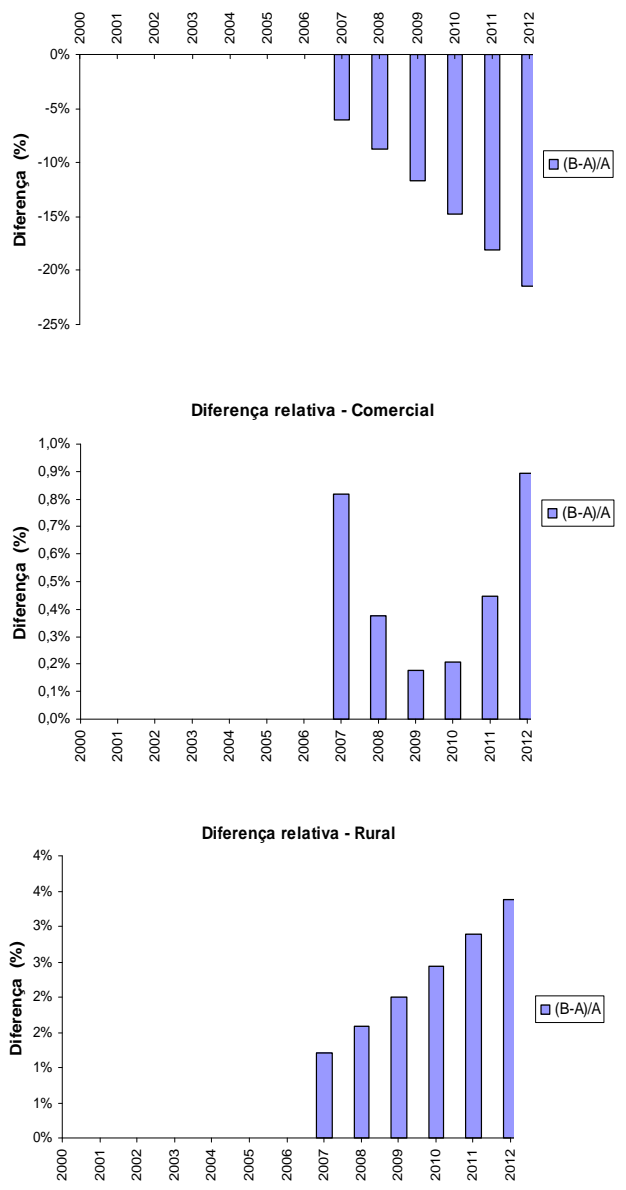

(b)

Figura D1 (a) Diferença entre as metodologias do Brasil e Peru

(b) Diferenças relativas porcentuais

Em relação a estes resultados (Figura D1), podem ser feitos os seguintes comentários:

- No caso Residencial observa-se uma diferença relativa na previsão de $11 \%$ em 2012, e na qual a 
curva A mostra-se mais conservativa em relação à curva B. Neste caso foi feito um teste com e sem tarifa média, a inclinação da curva da tarifa média é maior do que a inclinação da curva do PIB per capita, daí que a previsão da classe Residencial considerando a tarifa média seja mais pronunciada do que quando era apenas considerado o PIB.

- No caso da curva Industrial, pode-se ver também que conforme evolui a previsão a diferença relativa entre as curvas A e B é maior, sendo a máxima de $21 \%$ em 2012. Contrariamente ao caso anterior (classe Residencial) a curva A mostra ser mais otimista.

- No caso Comercial, ambas as metodologias demonstraram resultados próximos com uma diferença relativa porcentual muito pequena de aproximadamente 0,9\% em 2009.

- A previsão correspondente ao caso Rural apresenta uma diferença relativa de aproximadamente $3.4 \%$ em 2012, com a curva A mostrando-se um pouco mais conservativa em relação à curva B

Percebe-se, na maioria dos casos, que para anos mais futuros a diferença porcentual relativa é maior o que é inerente às técnicas de previsão de longo prazo.

\section{D2. Diferenças Relativas entre as Metodologias de Previsão do Brasil e da Argentina}

De forma similar ao item anterior, foram comparados os resultados de previsão por classe de consumo das metodologias do Brasil e da Argentina (Figura D2).

- No caso Residencial a curva A (Brasil) mostra-se um pouco conservativa em relação a B (Argentina), apresentando uma diferença relativa máxima de 9\% em 2012.

- Contrariamente no caso Industrial, a curva A mostra-se mais otimista em relação à curva $\mathrm{B}$, apresentando uma diferença de $24 \%$ em 2012.

- Os resultados no caso Comercial ofereceram resultados muito próximos com uma diferença relativa porcentual pequena igual a aproximadamente $2.54 \% \mathrm{em} 2009$.

- No caso Rural, a curva A mostrou uma tendência mais otimista em relação à curva $\mathrm{B}$, com uma diferença relativa porcentual de $19 \%$ em 2012. 

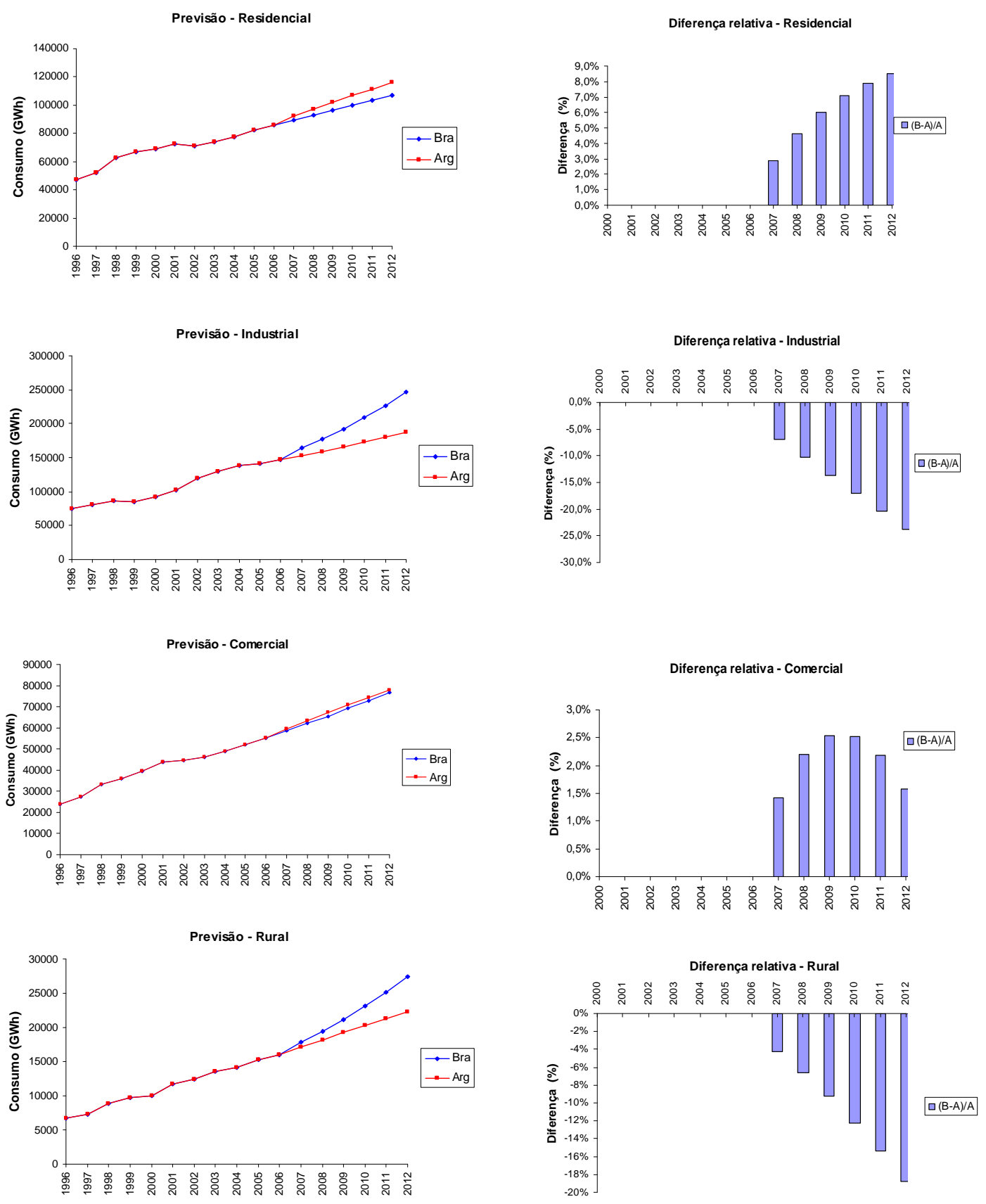

(a)

(b)

Figura D2 (a) Diferença entre as metodologias do Brasil e da Argentina (b) Diferenças relativas porcentuais

\section{D3. Diferenças Relativas entre as Metodologias do Brasil e da Bolívia}

Neste item serão comparadas respostas obtidas através das metodologias comumente usadas no Brasil e na Bolívia. Deve-se ressaltar que o fato de uma determinada metodologia ter produzido resultados com cenários mais otimistas ou conservadores não implica que este seja a melhor ou a pior metodologia. Isso vai depender das características operativas e principalmente econômicas (PIB), bem como da evolução histórica de cada um dos países analisados. 

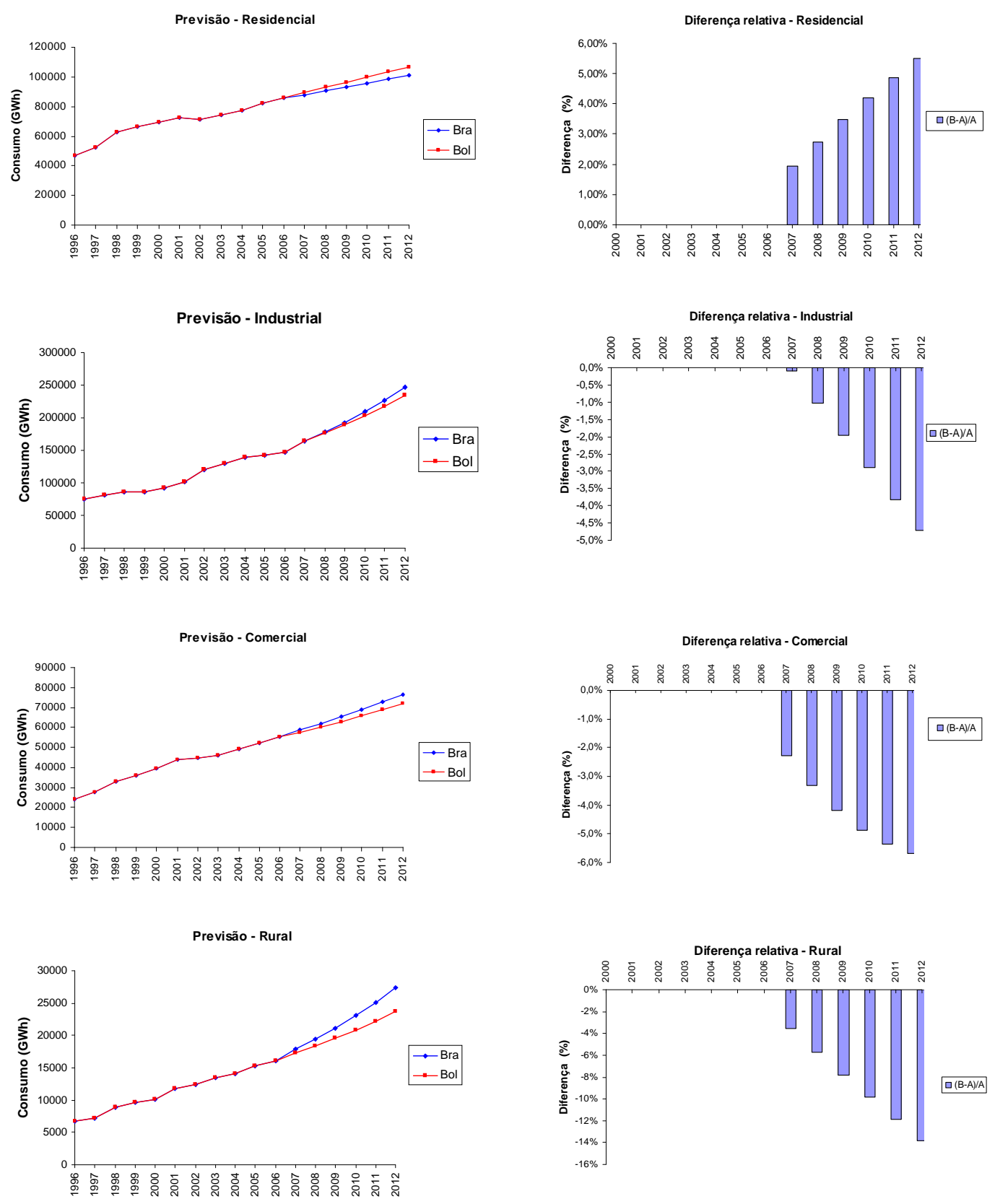

(a)

(b)

Figura D3 (a) Diferença entre as metodologias do Brasil e da Bolívia

(b) Diferenças relativas porcentuais

- No caso Residencial (Figura D.3) a curva A mostra-se um pouco mais conservativa em relação à curva B (Bolívia), apresentando uma diferença porcentual relativa máxima de 6\% em 2012.

- No caso Industrial, a curva A mostra-se um pouco mais otimista em relação à curva $\mathrm{B}$, apresentando uma diferença de 5\% em 2012.

- De forma similar ao caso anterior, a curva A de previsão no caso Comercial, é levemente maior a curva B. A máxima diferença relativa porcentual sendo de 5,7\% em 2012.

- Já no caso Rural, a curva A apresenta um cenário mais otimista em relação à curva $\mathrm{B}$, com uma diferença relativa porcentual de aproximadamente 14\% em 2012. 


\section{D4. Diferenças Relativas entre as Metodologias de Previsão do Brasil e do Chile}

De forma similar às anteriores metodologias, neste item serão comparados os resultados de previsão obtidos (Figura D4).
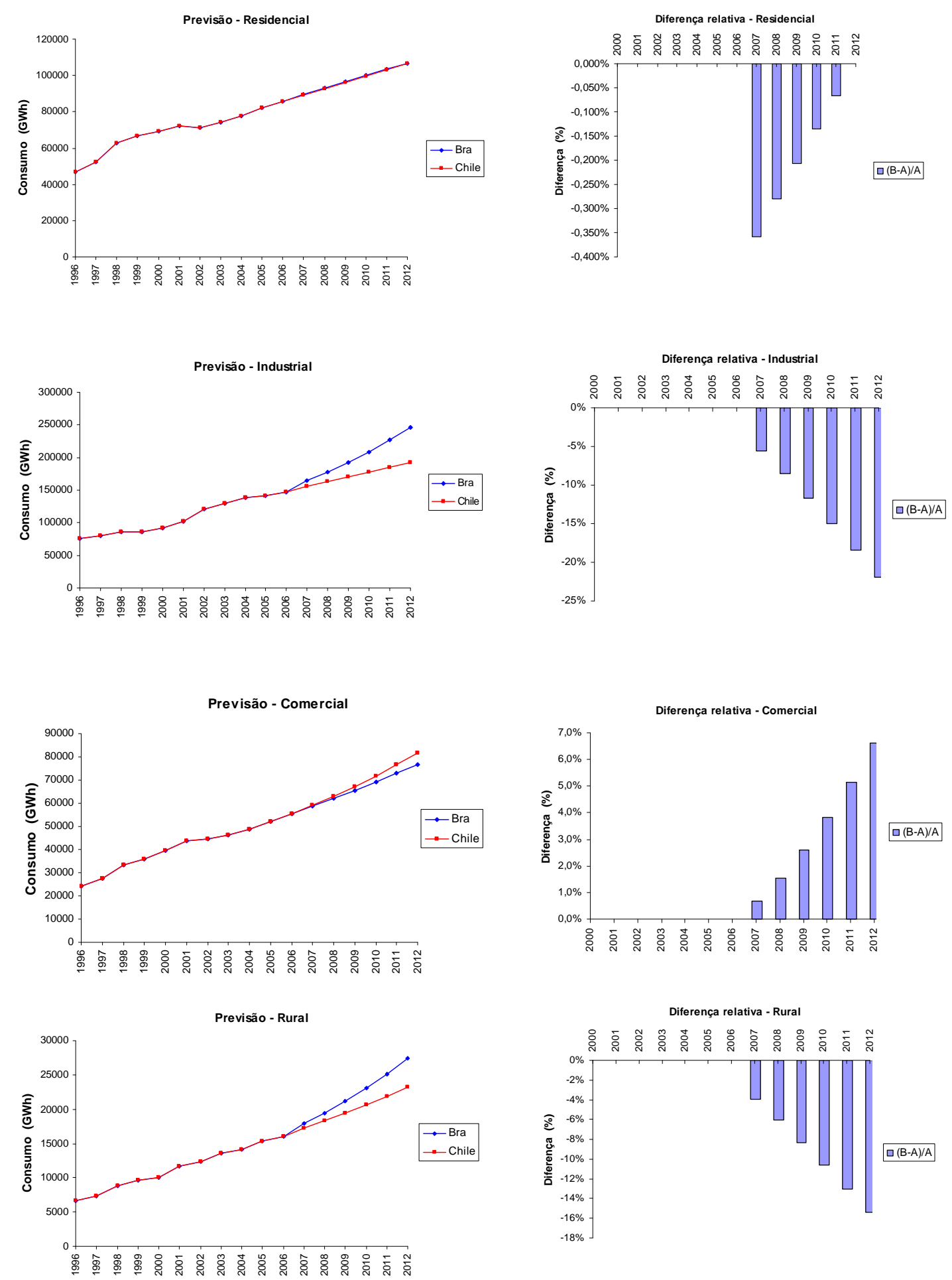

(a)

(b)

Figura D4 (a) Diferença entre as metodologias do Brasil e Chile (b) Diferenças relativas porcentuais 
- Pode-se ver que no caso Residencial a diferença relativa porcentual entre ambas as metodologias é muito pequena, aproximadamente $0,01 \%$ em 2012.

- Contrariamente no caso Industrial, a curva A mostra-se mais otimista em relação à curva B, apresentando uma diferença relativa de 22\% em 2012.

- No caso Comercial, a curva B mostrou uma tendência mais otimista em relação á curva A, com uma diferença relativa porcentual de 6,2\% em 2012. Diferentemente do caso Industrial, as variáveis explicativas utilizadas nesta classe produzem resultados próximos.

- No caso Rural, a metodologia chilena (curva B) mostrou-se mais conservadora em relação à curva A. A diferença relativa porcentual obtida foi de $15,4 \%$ em 2012. 


\title{
ANEXO E: Decisión 536 para la Interconexión Subregional de Sistemas Eléctricos
}

\author{
Marco General para la Interconexión Subregional de Sistemas Eléctricos e Intercambio Intracomunitario de \\ Electricidad [86].
}

\section{LA COMISION DE LA COMUNIDAD ANDINA, EN REUNION AMPLIADA CON LOS MINISTROS DE ENERGIA,}

VISTOS: Los artículos 3, 22, 50, 51 y 54 del Acuerdo de Cartagena, los artículos 1 y 38 del Tratado de Creación del Tribunal de Justicia de la Comunidad Andina, el Reglamento de la Comisión de la Comunidad Andina contenido en la Decisión 471 y la Propuesta 78/Rev. 3 de la Secretaría General de la Comunidad Andina,

CONSIDERANDO: Que el Acuerdo de Cartagena dispone que la integración física será uno de los mecanismos para alcanzar los objetivos de la Comunidad Andina;

Que la interconexión de los sistemas eléctricos de los Países Miembros y los intercambios comerciales intracomunitarios de electricidad pueden brindar importantes beneficios a los Países Miembros en términos económicos, sociales y ambientales y pueden conducir a la utilización óptima de sus recursos energéticos y a la seguridad y confiabilidad en el suministro eléctrico;

Que, para la operación de interconexiones intracomunitarias y el desarrollo de transacciones comerciales de electricidad entre los Países Miembros, se han identificado aspectos legales y regulatorios que deben ser armonizados;

Que es deseable que la operación de interconexiones intracomunitarias y el desarrollo de transacciones comerciales de electricidad entre los Países Miembros, conduzca al desarrollo de sistemas regionales interconectados y al futuro funcionamiento de un mercado integrado de energía entre los Países Miembros de la Comunidad Andina;

Que las reglas y condiciones operativas y comerciales para los intercambios de electricidad entre los Países Miembros y para el funcionamiento de un mercado integrado de energía deben basarse en criterios de no discriminación en el tratamiento entre los respectivos Países, sin perjuicio de la autonomía en el establecimiento de políticas internas de regulación y operación de los sistemas eléctricos nacionales;

Que resulta conveniente disponer de un marco jurídico comunitario para la armonización de los aspectos legales y los marcos regulatorios de los Países Miembros, que facilite las interconexiones y los intercambios de electricidad;

Que luego de varias reuniones previas, el 22 de septiembre de 2001 en Cartagena de Indias, Colombia, los Ministros de Energía y Minas de Colombia, Ecuador y Perú, en presencia del Director de Electricidad del Ministerio de Energía y Minas de Venezuela, suscribieron un Acuerdo para la Interconexión Regional de los Sistemas Eléctricos y el Intercambio Internacional de Energía Eléctrica, encargándose a los Organismos Reguladores de esos Países, la preparación de los principios para la armonización de marcos normativos;

Que en cumplimiento del mandato establecido en el Acuerdo Interministerial de Cartagena, los especialistas de los Organismos Reguladores de Colombia, Ecuador, Perú y Venezuela prepararon el documento titulado "Propuesta de Armonización de Marcos Normativos - noviembre de 2001", en el que se identificaron principios para armonizar los marcos normativos de los países suscriptores del Acuerdo;

Que las autoridades y delegados de los Organismos Reguladores de Colombia, Ecuador, Perú y Venezuela, se reunieron en Quito, Ecuador, el 13 y 14 de diciembre de 2001, y posteriormente en Caracas, Venezuela, el 17 y 18 de enero de 2002 , acordando principios normativos necesarios para armonizar los marcos legales y regulatorios;

Que los Ministros de Energía y Minas de Colombia, Ecuador y Perú, el día 19 de abril de 2002, en la ciudad de Quito, suscribieron el Acuerdo Complementario al de Interconexión Regional de los Sistemas Eléctricos y el Intercambio Internacional de Energía Eléctrica, donde se acordaron principios generales para la integración eléctrica entre los países suscriptores; y

Que en el Acta de Santa Cruz de la Sierra, Bolivia, adoptada el día 30 de enero de 2002, el Consejo Presidencial Andino destacó la creciente importancia estratégica de la temática energética en el Hemisferio y de su interés para vigorizar la integración subregional andina, latinoamericana y hemisférica;

\section{DECIDE:}

Adoptar el siguiente Marco General para la interconexión subregional de sistemas eléctricos e intercambio intracomunitario de electricidad

\section{Capítulo I}

Reglas fundamentales:

Artículo 1.- La interconexión subregional de los sistemas eléctricos y el intercambio intracomunitario de electricidad entre los Países Miembros de la Comunidad Andina se hará conforme a las siguientes reglas:

1. Los Países Miembros no mantendrán discriminaciones de precios entre sus mercados nacionales y los mercados externos, ni discriminarán de cualquier otra manera en el tratamiento que concedan a los agentes internos y externos en cada País, tanto para la demanda como para la oferta de electricidad.

2. Los Países Miembros garantizarán el libre acceso a las líneas de interconexión internacional. 
3. El uso físico de las interconexiones será consecuencia del despacho económico coordinado de los mercados, el cual será independiente de los contratos comerciales de compraventa de electricidad.

4. Los contratos que se celebren para la compraventa intracomunitaria de electricidad serán únicamente de carácter comercial. Ningún contrato de compraventa podrá influir en el despacho económico de los sistemas.

5. La remuneración de la actividad del transporte de electricidad en los enlaces internacionales tendrá en cuenta que la aplicación del principio de libre acceso a los enlaces elimina la vinculación entre el flujo físico y los contratos de compraventa internacional de electricidad.

6. Los Países Miembros asegurarán condiciones competitivas en el mercado de electricidad, con precios y tarifas que reflejen costos económicos eficientes, evitando prácticas discriminatorias y abusos de posición dominante.

7. Los Países Miembros permitirán la libre contratación entre los agentes del mercado de electricidad de los Países, respetando los contratos suscritos de conformidad con la legislación y marcos regulatorios vigentes en cada País, sin establecer restricciones al cumplimiento de los mismos, adicionales a las estipuladas en los contratos para los mercados nacionales.

8. Los Países Miembros permitirán las transacciones internacionales de electricidad, de corto plazo.

9. Los Países Miembros promoverán la participación de la inversión privada en el desarrollo de la infraestructura de transporte de electricidad para las interconexiones internacionales.

10. Las rentas que se originen como resultado de la congestión de un enlace internacional no serán asignadas a los propietarios del mismo.

11. Los Países Miembros no concederán ningún tipo de subsidio a las exportaciones ni importaciones de electricidad; tampoco impondrán aranceles ni restricciones específicas a las importaciones o exportaciones intracomunitarias de electricidad.

12. Los precios de la electricidad en ambos extremos de los enlaces intracomunitarios deberán servir para valorar las transacciones internacionales de electricidad, de corto plazo, producto de los flujos físicos determinados por los despachos económicos coordinados.

\section{Capítulo II}

Agentes participantes en las transacciones internacionales

Artículo 2.- Las autorizaciones, licencias, permisos o concesiones para la actuación en el mercado de electricidad o para la realización de transacciones comerciales internacionales no podrán ser negados cuando el interesado haya cumplido los requisitos señalados en la normativa de cada País para sus propios agentes.

Artículo 3.- Un agente debidamente autorizado y habilitado para comercializar internacionalmente electricidad en un País Miembro podrá realizar este tipo de actividades en cualquiera de los demás Países Miembros.

Artículo 4.- Los entes normativos y entes reguladores de los Países Miembros intercambiarán periódicamente información sobre la propiedad y la participación accionaria de los agentes en sus respectivos mercados.

Capítulo III

\section{Tratamiento de restricciones e inflexibilidades}

Artículo 5.- Las restricciones e inflexibilidades operativas asociadas con las transacciones de importación y exportación serán tratadas en las mismas condiciones para agentes internos y externos.

\section{Capítulo IV}

Cargos adicionales en las transacciones

Artículo 6.- La importación y la exportación de electricidad estarán sujetas a los mismos cargos propios del sector eléctrico, que se aplican a la generación y demandas locales.

\section{Capítulo V}

Desarrollo de los enlaces internacionales

Artículo 7.- Los Países Miembros establecerán mecanismos para la remuneración de la actividad del transporte de electricidad en los enlaces internacionales.

Artículo 8.- Los Países Miembros garantizarán un acceso libre, oportuno y transparente a la información que los organismos y los agentes del mercado requieran para la planificación de construcción de enlaces internacionales, incluyendo datos acerca de los recursos, oferta y demanda.

Artículo 9.- En los procesos de planificación de la expansión de los sistemas nacionales de transmisión y los enlaces internacionales, cada País Miembro tomará en cuenta la información de los demás Países, buscando coordinar la planificación con una visión de integración regional.

Artículo 10.- Los Países Miembros coordinarán los procesos dirigidos a la construcción de enlaces. En el caso de que dichos enlaces sean considerados como activos de uso común, la coordinación será efectuada por los organismos encargados de la licitación para su realización. 


\section{Capítulo VI}

Remuneración de potencia en las transacciones internacionales

Artículo 11.- Los reguladores de los Países Miembros propondrán una metodología para el cálculo del cargo de capacidad. Los contratos de compraventa no serán incluidos en los mecanismos de cálculo para la asignación y pago del cargo de capacidad.

\section{Capítulo VII}

Transacciones internacionales de electricidad de corto plazo

Artículo 12.- El despacho económico de cada País considerará la oferta y la demanda de los Países de la Subregión equivalentes en los nodos de frontera. Los flujos en los enlaces internacionales y, en consecuencia, las transacciones internacionales de electricidad de corto plazo, se originarán en el despacho coordinado entre Países, de conformidad con las respectivas regulaciones.

Artículo 13.- Las transacciones internacionales de electricidad de corto plazo no estarán condicionadas a la existencia de excedentes y únicamente estarán limitadas por la capacidad de los enlaces internacionales.

Artículo 14.- Los administradores de los mercados nacionales de los Países Miembros serán los entes encargados de liquidar de manera coordinada las transacciones internacionales de electricidad. Para este fin, de conformidad con las respectivas regulaciones, los administradores de los mercados nacionales de los Países Miembros liquidarán de manera coordinada los intercambios internacionales de energía, a través de la suscripción de acuerdos de administración de los mercados, liquidación de las transacciones e intercambio de información.

Artículo 15.- Los operadores de los sistemas eléctricos de los Países Miembros celebrarán acuerdos para la coordinación de la operación de los enlaces internacionales.

Artículo 16.- Los administradores de los mercados de los Países Miembros constituirán garantías que cubran el monto esperado de las transacciones internacionales de electricidad de corto plazo. La metodología para el cálculo de dichas garantías será desarrollada en conjunto por los reguladores. Sólo podrán efectuarse transacciones internacionales de electricidad de corto plazo si existen tales garantías.

Artículo 17.- Las transacciones internacionales de electricidad de corto plazo serán consideradas en la asignación y pago del cargo por capacidad en condiciones similares a los agentes internos de cada País. En tal sentido, la importación o exportación recibirá o pagará, respectivamente, el cargo por capacidad.

Artículo 18.- La definición de los precios de la electricidad en cada lado de la frontera deberá considerar todos los cargos propios del sector eléctrico existentes en cada sistema y expresarse en dólares de los Estados Unidos de América.

\section{Capítulo VIII}

\section{Armonización de normativas nacionales}

Artículo 19.- Los Países Miembros impulsarán los cambios en sus respectivas normativas nacionales que promuevan la armonización de sus marcos normativos en materia de operación de interconexiones eléctricas y de transacciones comerciales de electricidad.

\section{Capítulo IX}

\section{Mecanismo de Seguimiento}

Artículo 20.- Se crea el Comité Andino de Organismos Normativos y Organismos Reguladores de Servicios de Electricidad. El Comité estará encargado de promover las normas que sean necesarias para alcanzar los objetivos previstos en el presente Marco General, incluyendo Resoluciones de la Secretaría General o Convenios.

El Comité también hará seguimiento a los compromisos en materia de armonización de normativas nacionales.

El Comité estará conformado por los titulares de los organismos normativos y de los organismos reguladores nacionales de los servicios de electricidad en cada uno de los Países Miembros, o por sus respectivos representantes.

El Comité adoptará su Reglamento Interno, el mismo que establecerá los mecanismos para su organización y funcionamiento y regulará las modalidades de participación y consulta a otros actores, tales como los operadores de los sistemas, los administradores de los mercados de electricidad y los agentes en los mercados.

\section{Capítulo X}

\section{Disposiciones Finales}

Artículo 21.- Las empresas que participen en contratos internacionales para la compraventa intracomunitaria de electricidad podrán utilizar el sistema arbitral previsto en el Tratado de Creación del Tribunal de Justicia de la Comunidad Andina, con el fin de que la Secretaría General o el Tribunal de Justicia diriman las controversias que se puedan suscitar respecto de la aplicación o interpretación de aspectos contenidos en los contratos que suscriban a tal efecto.

Artículo 22.- Los Países Miembros dictarán las normas que sean necesarias para alcanzar los objetivos previstos en el presente Marco General, incluso a través de Convenios, los mismos que formarán parte del ordenamiento jurídico de la Comunidad Andina.

Conforme a lo previsto en el ordenamiento comunitario andino, la Secretaría General publicará los textos de los Convenios en la Gaceta Oficial del Acuerdo de Cartagena. 
Mediante Resolución de la Secretaría General, y a propuesta del Comité Andino de Organismos Normativos y Organismos Reguladores de Servicios de Electricidad, se desarrollará la terminología y las definiciones comunes a ser aplicadas para la correcta interpretación de las normas contenidas en el presente Marco General y de las que de él se deriven.

Artículo 23.- Nada de lo previsto en la presente Decisión impedirá que los Países Miembros suscriban acuerdos con otros países de la región para promover la interconexión de sistemas eléctricos y el intercambio internacional de energía.

\section{Capítulo XI}

\section{Disposición Transitoria}

Artículo 24.- La presente Decisión no será aplicable a Bolivia, hasta que este País solicite su incorporación a la misma. Para la incorporación de Bolivia no se requerirá modificar la Decisión, sino que bastará con que ese País notifique formalmente su intención a la Comisión de la Comunidad Andina. La incorporación será publicada en la Gaceta Oficial del Acuerdo de Cartagena. Entre tanto, las obligaciones y beneficios que se derivan del presente Marco General no serán aplicables a Bolivia.

Lo previsto en el párrafo anterior no impedirá que las autoridades de Bolivia puedan participar en las reuniones del Comité Andino de Organismos Normativos y Organismos Reguladores de Servicios de Electricidad.

Dada en la ciudad de Lima, Perú, a los diecinueve días del mes de diciembre del año dos mil dos. 